\title{
Mechanistic Studies on the Nickel- Catalyzed Cyclopropanation with Lithiomethyltrimethylammonium Triflate
}

\author{
Journal Article \\ Author(s): \\ Künzi, Stefan A.; Gershoni-Poranne, Renana; Chen, Peter (1) \\ Publication date: \\ 2019-05-02 \\ Permanent link: \\ https://doi.org/10.3929/ethz-b-000340481
}

Rights / license:

In Copyright - Non-Commercial Use Permitted

Originally published in:

Organometallics 38(9), https://doi.org/10.1021/acs.organomet.9b00027 


\title{
Mechanistic Studies on the Nickel-Catalyzed Cyclopropanation with Lithiomethyltrimethylammonium Triflate.
}

\author{
Stefan A. Künzi, Renana Gershoni-Poranne, Peter Chen* \\ Laboratorium für Organische Chemie, ETH Zürich, Zürich, Switzerland \\ KEYWORDS. Cyclopropanation, mechanism, nickel, ylide
}

\begin{abstract}
We report here our mechanistic study of the previously published nickel-catalyzed cyclopropanation reaction using lithiomethyltrimethylammonium triflate as methylene donor. The cyclopropane yield is highly dependent on the olefin substrate and correlates well with the binding affinity of the olefin to $\mathrm{Ni}(\mathrm{o})$ as established elsewhere. Based on this observation we developed a simplified mechanistic model that can explain several odd observation we found in our initial report. Most importantly, a binding equilibrium between olefin substrate and phosphine ligand appears to govern the ratio between product formation and unproductive ylide decomposition in a side-reaction.
\end{abstract}

\section{Introduction}

Only a few methods are known for transferring methylene to electron-rich alkenes to form cyclopropanes. For large scale production, the Simmons-Smith and related metal carbenoid-based reactions are preferred, though they often suffer from the generation of large amounts of waste. ${ }^{1}$ Transition metal-catalyzed cyclopropanation using diazomethane is a well-studied and very versatile method, but, due to the inherent instability and toxicity of the reagent itself, or its precursors, the reaction is limited to smallscale reactions. ${ }^{2}$

To circumvent these drawbacks, extensive research had focused on the in situ generation of diazomethane from more stable precursors, in order to circumvent the need for isolation or the design of new reagents as methylene donors. ${ }^{3}$

Recently, we took the alternative approach of non-diazo methylene donors and reported on the nickel-catalyzed cyclopropanation of several electron-rich, alkyl substituted alkenes using lithiomethyltrimethylammonium triflate as methylene donor, generated in situ from tetramethylammonium triflate and BuLi (Scheme 1). ${ }^{4}$

In that report, we also noted a peculiar behavior with respect to the catalyst loading. The highest yield of cyclopropanation of cyclooctene (COE) was obtained with a catalyst loading in the range of 0.5 to $1.0 \mathrm{~mol} \%$. At lower or higher loadings, a decreased yield was obtained, resulting in a bell-shaped curve for catalyst loading versus yield. We observed polyethylene and small amounts of cyclopropane $\left(\mathrm{C}_{3} \mathrm{H}_{6}\right)$ as side-products, presumably stemming from initial formation of ethene via homocoupling of two nickel carbenes.

We proposed an explanation based on two competing processes with the same intermediate species, i.e., a nickel carbene that can undergo either cyclopropanation with an alkene to afford the cyclopropane product or homocoupling with another nickel carbene molecule to afford ethene. The initially formed ethene could then react further, to afford the observed side products. Overall, this would lead to an unproductive decomposition of the reagent. We predicted the product formation to be kinetically $1^{\text {st }}$ order in catalyst and the homocoupling to be $2^{\text {nd }}$ order (assuming the homocoupling step to be rate-limiting, rather than nickel carbene formation) or at least bimolecular with respect to the proposed nickel carbene. Overlaying these two competing reactions could then explain the observed behavior, where the homocoupling kinetically outcompetes product formation at high catalyst loadings, at least for the reported case of catalyst loadings above the optimum 0.5 to $1 \mathrm{~mol} \%$ with $\left(\mathrm{Ph}_{3} \mathrm{P}\right)_{2} \mathrm{NiBr}_{2}$ as precatalyst and $\mathrm{COE}$ as substrate.

Additionally, we observed that the yield was influenced by whether the flask was open or closed to an argon Schlenk line, when using COE as substrate. ${ }^{5}$ Based on these and other experimental observations, and in analogy to literature precedent of isolated nickel species, we postulated a possible catalytic cycle with a nickel carbene as an important intermediate. ${ }^{6}$

Herein, we report mechanistic studies, including extensive kinetic and computational investigations, which support the involvement of a reactive nickel carbene intermediate, and reveal the intricate balance between ligand and alkene binding that explains the observed substrate-dependence of the cyclopropanation yield.

The rationale for this work is formulated as the following series of questions, which we seek to address herein.

Firstly, what is the possible resting state of the catalyst? What are the ligands bound to the nickel?

Secondly, what is the cause of the substrate dependence that we noticed earlier? How does the substrate dependence relate to the catalyst resting state? 
Thirdly, what causes the effect of the catalyst loading on the cyclopropanation yield?

Fourthly, why is there a difference between running the reaction open or closed to the argon Schlenk line?

The findings we report here help us to formulate an answer as to what might be the catalyst resting state and how this relates to the $\pi$-acidity and formation constant of the $\pi$ complex of the substrate with the catalyst. The resultant model we propose, albeit rather simple, offers an explanation to the aforementioned effect on catalyst loading. Alkene competition experiments within this model framework offer insights regarding the reactivity and stability of the resting state.

Scheme 1. Previously Reported Cyclopropanation using Tetramethylammonium Triflate as Methylene Donor and a Proposed Simplified Catalytic Cycle. ${ }^{4}$

a) General reaction scheme

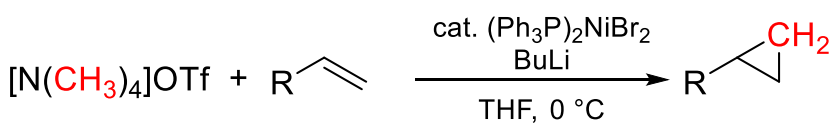

b) Simplified catalytic cycle

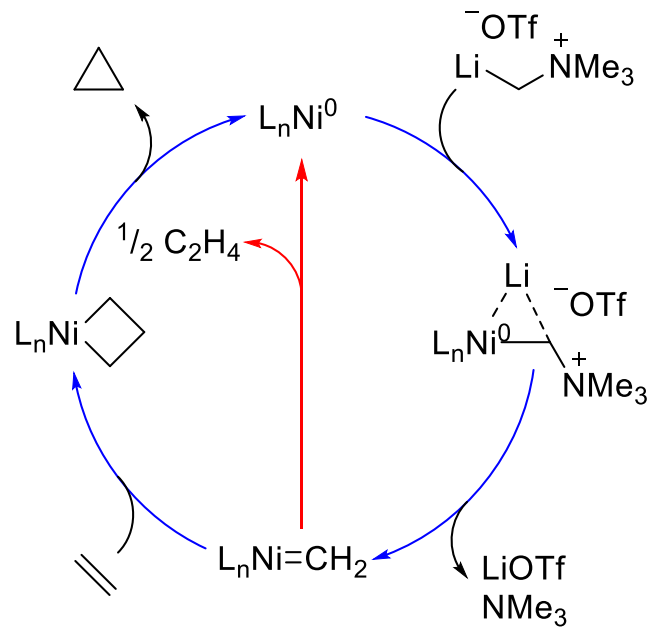

\section{Experimental Methods}

Kinetic measurements were conducted by quenching aliquots under protic conditions. Product formation was measured by GC-FID using a previously added internal standard and $\mathrm{k}_{\mathrm{obs}}$ was determined using initial rates.

The consumption of ylide was measured indirectly by determining the relative amount of remaining $\left[\mathrm{NMe}_{4}\right]^{+}$by ${ }^{1} \mathrm{H}$ NMR against a previously added internal standard. An exponential fit over the entire reaction profile was used to determine $\mathrm{k}_{\mathrm{obs}}$.

We used two different Methods, A and B, that differ in the generation of the ammonium ylide reagent, either in situ (A) or preformed (B) (see Scheme 2).

For method A, [ $\left.\mathrm{NMe}_{4}\right]$ OTf (1.1 equiv), alkene and catalyst were mixed together, cooled to o ${ }^{\circ} \mathrm{C}$, then BuLi (1 equiv) was added to form the ylide in situ.

For method B, the ammonium salt was deprotonated first (in the presence or absence of alkene) before the catalyst was added to the preformed ylide to initiate the cyclopropanation/ylide decomposition.

Scheme 2. Two Different Methods Employed to Generate the Active Reagent $\left[\mathrm{LiCH}_{2} \mathrm{NMe}_{3}\right] \mathrm{OTf}$, either after (A) or before (B) Addition of Catalyst.

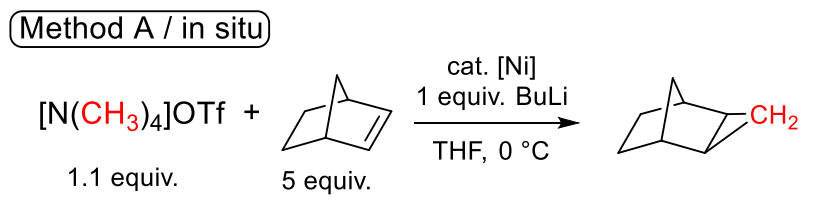

Method B / preformed

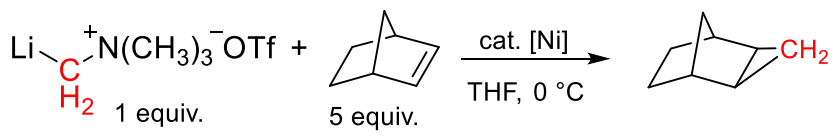

\section{Computations.}

All calculations were performed using Gaussian og Revision D. ${ }^{7}$ All geometries were optimized and frequencies calculations were performed to ensure real minima for the intermediates (i.e., $\mathrm{N}_{\mathrm{imag}}=0$ ) and $1^{\text {st }}$ order saddle points for the transition states (i.e., $\mathrm{N}_{\mathrm{imag}}=1$ ). The energies reported are zero-point corrected energies. We first performed a benchmarking procedure, in which we compared crystal structures of literature-reported compounds that are analogous to the intermediates in our system to computationally optimized structures (19 different combinations of density functionals and basis sets were tested, Table S2O summarizing the results is provided in the Supporting Information). Following this procedure, we settled on the functional/basis-set combination Mo6L/def2-SVP, and these results are presented in the text. In addition, we performed calculations at the same level with an implicit solvent model, which yielded similar results.

For the Kinetic Isotope Effect calculations, we employed the ISOEFF software, which calculates isotope effects based on the Bigeleisen equation, using input from a quantum mechanical calculation (i.e., the Hessian matrix obtained from Gaussian). ${ }^{8}$

\section{Results}

Our earlier published work reported yields for cyclopropanation over a limited range of conditions and substrates. In the present report, we extend the experimental data with measurements of rates for cyclopropanation or homocoupling.

\subsection{Kinetic Orders}

The limited scope and most of the unusual features observed for the reaction, had been explained by means of the catalytic cycle depicted in Scheme 1, in particular via the competition between a productive cyclopropanation that would be kinetically $1^{\text {st }}$-order in nickel carbene and an unproductive homocoupling that would be $2^{\text {nd }}-$ order in the same carbene. Addition of $\mathrm{NMe}_{3}$ (up to 1 equiv with respect to ylide) as reported earlier (to test for reversible nickel 
carbene formation), ${ }_{4}^{4}$ as well as $\mathrm{NMe}_{2} \mathrm{Bn}$ (10 equiv, this report) paradoxically did not improve the cyclopropanation yield or produce a rearrangement product from a putative $\mathrm{NMe}_{2} \mathrm{Bn}$ derived ylide (Schemes $\mathrm{S}_{17}$ and $\mathrm{S} 18$ ). ${ }^{9}$ This motivated us to execute kinetic experiments-measuring rates as opposed to yields-to confirm or call into question the putative catalytic cycle in Scheme 1.

We used three different methods for preparation of the active $\mathrm{Ni}(\mathrm{o})$ species: a) reduction of $\mathrm{Ni}$ (II) in situ prior to ylide formation , b) reduction of $\mathrm{Ni}(\mathrm{II})$ in situ with the ylide, and c) initiation with a $\mathrm{Ni}(\mathrm{o})$ catalyst. The plot of $\mathrm{k}_{\mathrm{obs}}$ for cyclopropanation of norbornene (the best substrate) versus catalyst loading between 0.25 and $1.0 \mathrm{~mol} \%$ shows kinetic orders between $0.80 \pm 0.02$ and $1.17 \pm 0.08$, as depicted in Figure 1.

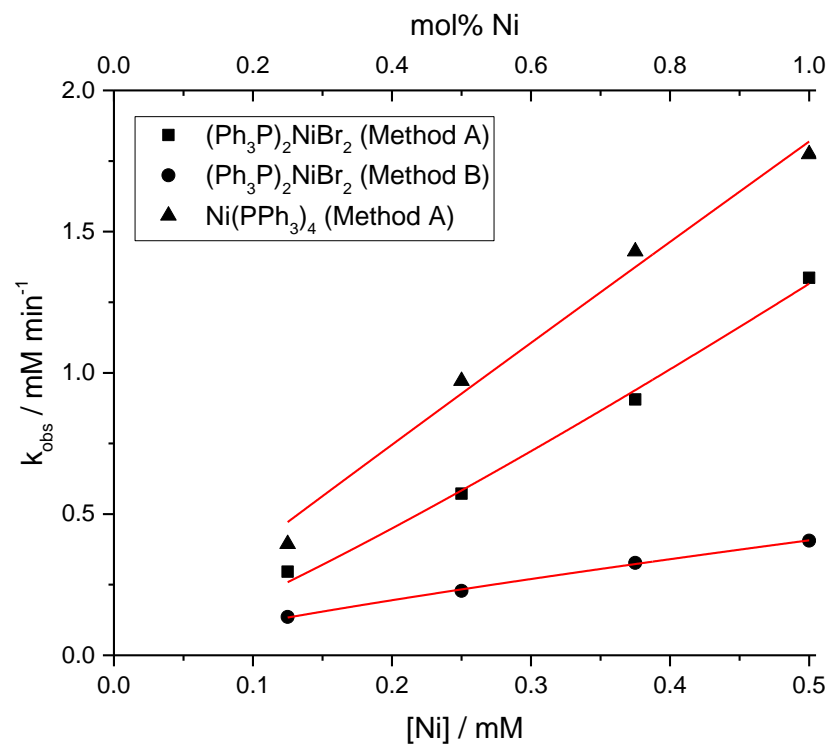

Figure 1. Plot of $\mathrm{k}_{\mathrm{obs}}$ versus [catalyst] using $\left(\mathrm{Ph}_{3} \mathrm{P}\right)_{2} \mathrm{NiBr}_{2}$ and Method A (squares) or Method B (circles) as precatalyst or $\mathrm{Ni}\left(\mathrm{PPh}_{3}\right)_{4}$ (Method A, triangles) with NBE. The red curves depict $\mathrm{a}$ fit to the function $\mathrm{y}=\mathrm{ax}^{\mathrm{b}}$ to establish the order in [Ni] as follows: $\mathrm{b}=1.17 \pm 0.08$ (squares), $\mathrm{b}=0.80 \pm$ 0.02 (circles), $\mathrm{b}=1.0 \pm 0.1$ (triangles).

We attribute the non-overlapping lines for the three initiation methods to slightly different initiation efficiencies, but we note that all methods deliver close to $1^{\text {st-order de- }}$ pendence of cyclopropanation rate on $\mathrm{Ni}$ concentration. The initiation method with $\mathrm{Ni}\left(\mathrm{PPh}_{3}\right)_{4}$, the $\mathrm{Ni}(\mathrm{o})$ source, gave the cleanest ${ }^{\text {st }}$-order kinetics, as well as the highest absolute rates, implying the most efficient activation. Thus, we used the $\mathrm{Ni}\left(\mathrm{PPh}_{3}\right)_{4}$ catalyst for the determination of the kinetic order of homocoupling with respect to $\mathrm{Ni}$ concentration. For this latter experiment, the consumption of ylide, determined by quenching of aliquots taken of a reaction set up substrate-free, but otherwise identical to the cyclopropanation runs with preformed ylide (method B), was performed by tracking tetramethylammonium disappearance by ${ }^{1} \mathrm{H}$ NMR, as described in the SI. The plot of $\mathrm{k}_{\mathrm{obs}}$, shown in Figure 2 , covering the range of catalyst concentration from 0.5 to $2.0 \mathrm{~mol} \%$, gave an order of $1.34 \pm .001$ in catalyst, which is closer to $1^{\text {st }}$ than it is to the $2^{\text {nd }}-$ order behavior that we had expected.

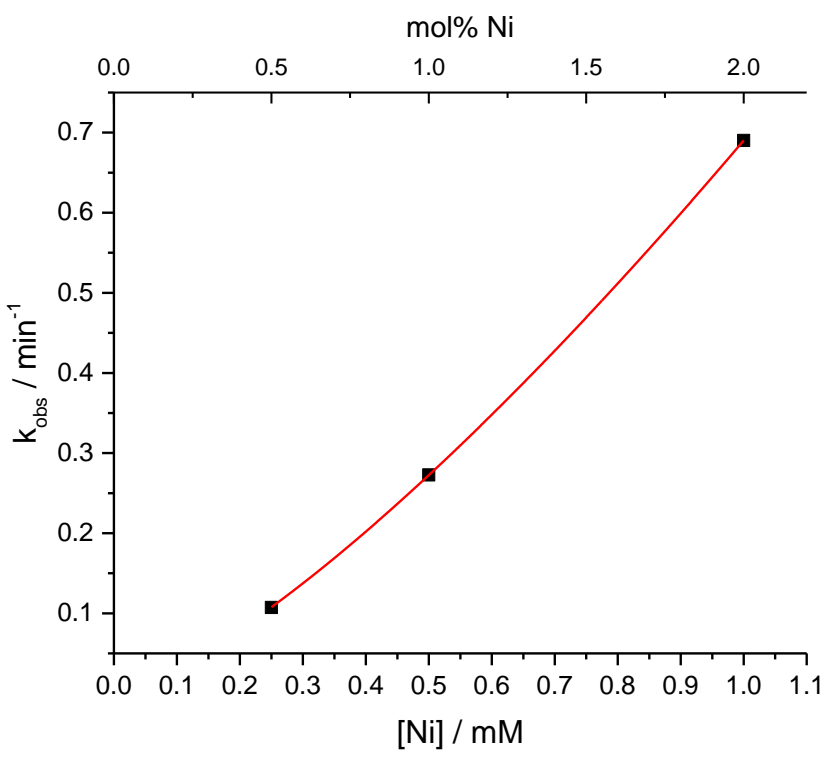

Figure 2. Plot of $\left[\mathrm{Ni}\left(\mathrm{PPh}_{3}\right)_{4}\right]$ versus $\mathrm{k}_{\text {obs }}$ for the consumption of ylide in the absence of alkene. The red curve depicts $\mathrm{a}$ fit to the function $\mathrm{y}=\mathrm{ax} \mathrm{x}^{\mathrm{b}}$ to establish the order in $[\mathrm{Ni}], \mathrm{b}$ $=1.341 \pm 0.001$.

The unexpected results with excess trimethylamine ${ }^{4}$ and, particularly, the unexpected kinetic order for homocoupling in the absence of substrate, motivated us to determine the kinetic order of the reaction with respect to substrate and phosphine, namely, norbornene and triphenylphosphine. The plots of $\mathrm{k}_{\mathrm{obs}}$ for cyclopropanation of norbornene versus concentration of either norbornene or triphenylphosphine, shown in Figures 3 and 4, show orders of $0.18 \pm 0.02$ and $0.17 \pm 0.05$, respectively, over an approximately one order-of-magnitude range of concentrations. While the proposed catalytic cycle in Scheme 1 could afford a variety of kinetic orders, depending on which step is ratelimiting, the close to zero-order kinetics with respect to both substrate and phosphine were nevertheless surprising.

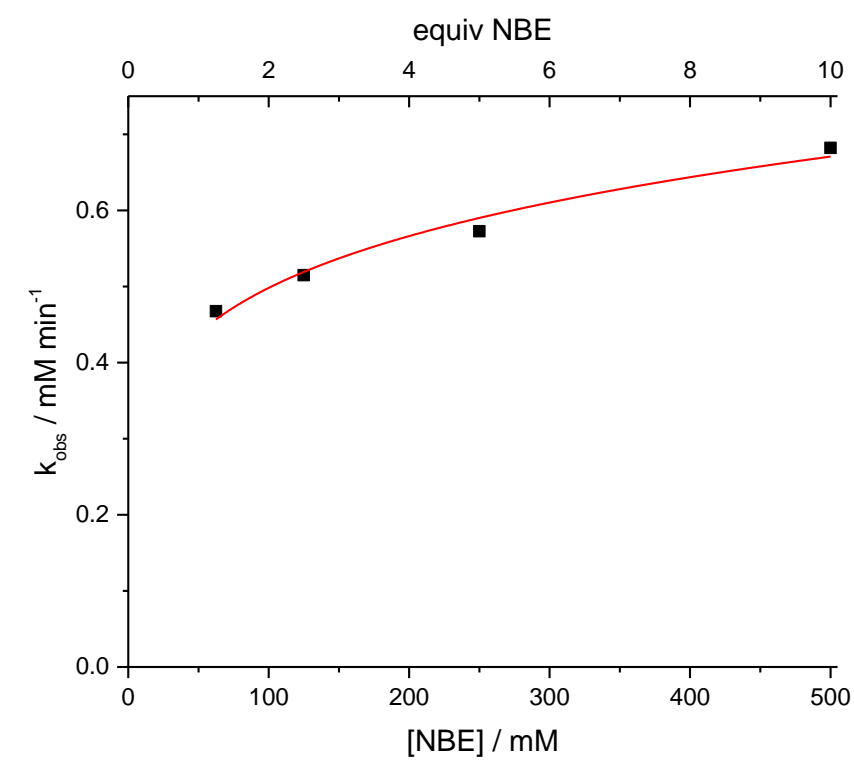

Figure 3. Plot of $\mathrm{k}_{\mathrm{obs}}$ versus [NBE] using $0.5 \mathrm{~mol} \%$ $\left(\mathrm{Ph}_{3} \mathrm{P}\right)_{2} \mathrm{NiBr}_{2}$ (Method A). The red curve depicts a fit to the 
function $\mathrm{y}=\mathrm{ax}^{\mathrm{b}}$ to establish the order in norbornene, $\mathrm{b}=0.18$ \pm 0.02 .

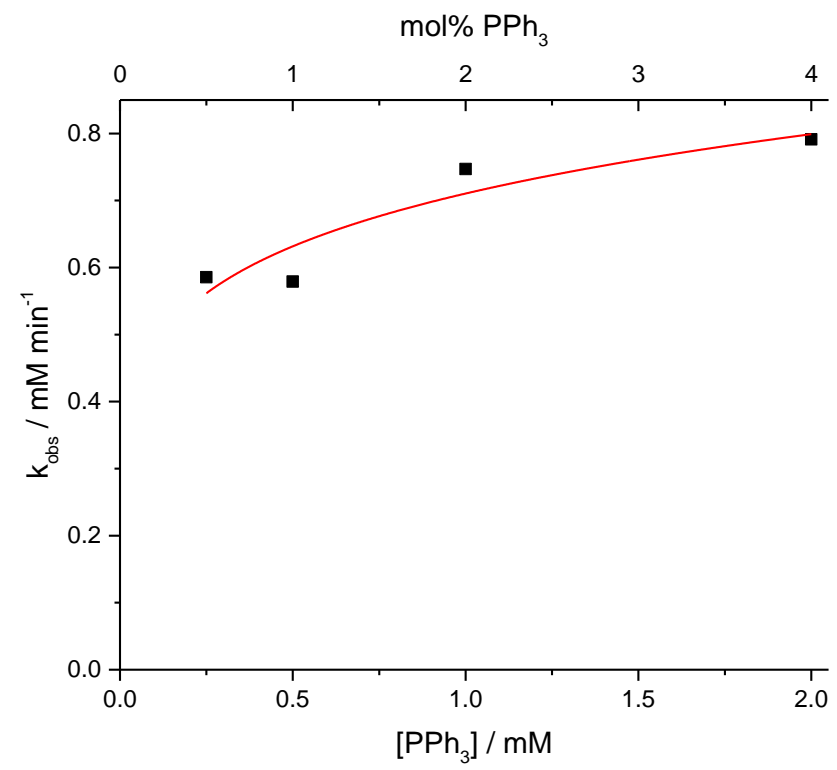

Figure 4. Plot of $\mathrm{k}_{\mathrm{obs}}$ versus $\left[\mathrm{PPh}_{3}\right]$ using $0.5 \mathrm{~mol} \%$ $\mathrm{Ni}(\text { acac })_{2}$ (Method A). The red curve depicts a fit to the function $\mathrm{y}=\mathrm{ax}$ b to establish the order in $\mathrm{PPh}_{3}, \mathrm{~b}=0.17 \pm$ 0.05 .

The order in ylide shows a more complex behavior and appears to be o or 1 depending on the exact reaction conditions and conversion. An additional discussion about the order in ylide can be found in the Supporting Information (Figure S11).

\subsection{Kinetic Isotope Effect}

While not entirely foolproof, kinetic isotope effects generally deliver information on the rate-limiting transition state, which makes them appropriate for the present situation. Switching to the perdeuterated ammonium salt $\left[\mathrm{N}\left(\mathrm{CD}_{3}\right)_{4}\right] \mathrm{OTf}$ under otherwise identical conditions (using method A) yielded a large secondary kinetic isotope effect of 2.1 (Scheme 3). This is consistent with $\mathrm{sp}^{3-}$ to $\mathrm{sp}^{2}$-rehybridization in the rate-limiting transition state, which suggests that the transition state from the $\mathrm{Ni}$-coordinated ylide to the $\mathrm{Ni}$ carbene is rate-limiting.

Scheme 3. Determination of a Secondary KIE using Perdeuterated Tetramethylammonium Triflate.

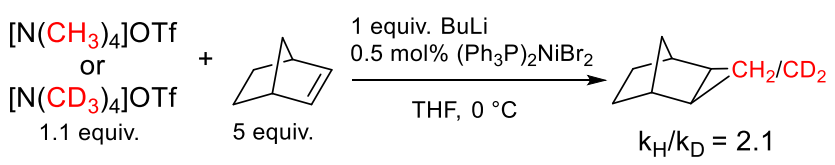

Having the measured $\mathrm{k}_{\mathrm{H}} / \mathrm{k}_{\mathrm{D}}$ of 2.1, we computationally investigated a number of catalytic cycles to see whether other elementary steps, other than the carbene formation, could plausibly be consistent with the KIE. For each step in a composite catalytic cycle, shown in the SI (Figure $\mathrm{S}_{78}$ ), we employed the ISOEFF software, which calculates isotope effects based on the Bigeleisen equation, using input from a quantum mechanical calculation (i.e., the Hessian matrix obtained from Gaussian), and found a predicted kinetic isotope effect of $\mathrm{k}_{\mathrm{H}} / \mathrm{k}_{\mathrm{D}}=\mathbf{2 . 5 0}$ for the carbene formation step. No other elementary step gives a KIE even close to compatible with that which we observed experimentally (Table S24).

\subsection{Relative Rates of Cyclopropanation for Different Substrates}

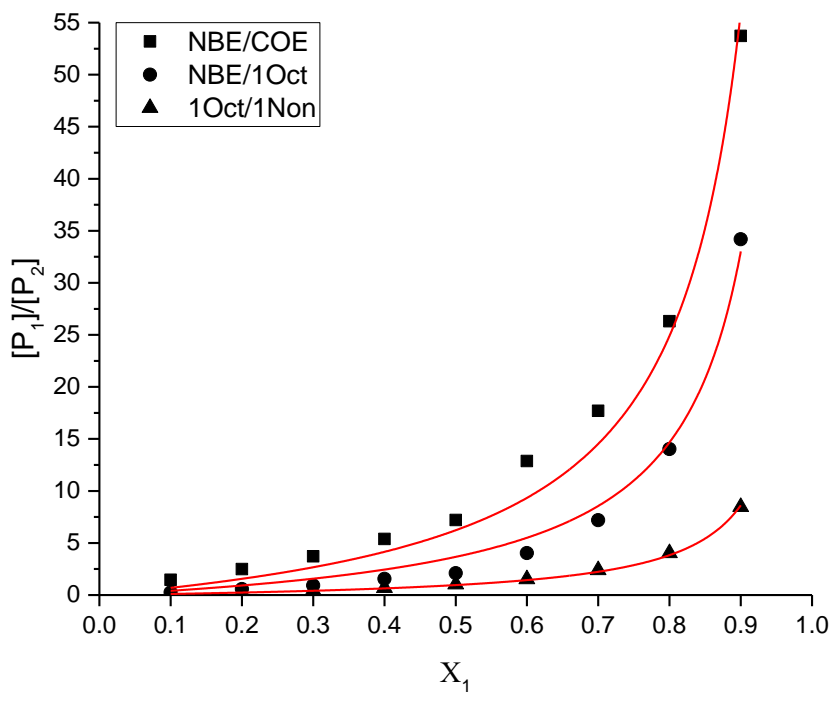

Figure 5. Plot of mole fraction of alkene $1, \mathrm{X}_{1}$, versus product ratio, $\left[\mathrm{P}_{1}\right] /\left[\mathrm{P}_{2}\right]$, derived from alkene 1 and alkene 2 , respectively, with the following pairs of alkenes. 1: norbornene, 2 : cyclooctene (squares); 1: norbornene, 2: 1-octene (circles); 1: 1octene, 2: 1-nonene (triangles). $0.5 \mathrm{~mol} \%\left(\mathrm{Ph}_{3} \mathrm{P}\right)_{2} \mathrm{NiBr}_{2}$ was used as precatalyst. The red curves depict a fit to the function $\mathrm{y}=\mathrm{aX}_{1} /\left(1-\mathrm{X}_{1}\right.$ ) (see eq (1) and Discussion). $\mathrm{a}=6.2 \pm 0.2$ (squares), $\mathrm{a}=3.7 \pm 0.1$ (circles), $\mathrm{a}=0.96 \pm 0.01$ (triangles).

Given that norbornene provides significantly higher yields, and, accordingly, better mass balances, than the other olefinic substrates tested, we opted, for the determination of rate constants for the cyclopropanation of cyclooctene and 1-octene, for example, for a competition experiment. Binary mixtures of norbornene with the other olefins were cyclopropanated, and the ratio of product cyclopropanes determined by GC-FID of quenched aliquots, giving the results shown in Figure 5. Adjusting the product ratios for the ratio of the substrates, we obtained the relative rate constants for cyclopropanation of the cyclooctene and 1octene, relative to that for norbornene, shown in Table 1 (see Discussion).

\subsection{Further Yields and Job Plots}

We extended the range of yield measurements considerably, as compared to those in our previous report, concentrating on variations in the catalyst loading, variation of the catalyst itself, the Ni:phosphine ratio, and addition of an excess of $\mathrm{PPh}_{3}$. These results are given in tabular form in 
the SI, and appear in Figures 9-10 in the Discussion, where they will be used as the test set (see below) to assess the adequacy of the our newly proposed catalytic cycle and the minimal kinetic model derived from that catalytic cycle.

\section{Discussion}

In the following, we discuss the results of our mechanistic studies and how they change and strengthen our understanding of the reaction mechanism at hand.

Mirroring the general structure of the Results section, we look first at the kinetic orders to establish the resting state of the catalyst and discuss the KIE, in order to infer the rate-limiting step. Based on this data we then propose a catalytic cycle. At its heart is a pre-equilibrium between the phosphine ligand(s) and the alkene substrate coordinated to nickel(o) that leads us to propose a Curtin-Hammettlike scenario.

Depending on which side the pre-equilibrium lies, one branch leads to cyclopropanation and the other consumes the ylide in an unproductive side-reaction. We develop this scenario into a very simple mathematical model. In order to do so, we first look at the special case of the alkene competition experiments (Figure 5), ignoring the side-reaction. Then, we generalize the mathematical formalisms to a single alkene in competition with homocoupling using only one fit parameter.

Finally, we apply this model to our data to shed light on the anomalous observations we made initially.

\subsection{Resting State of Catalyst}

In our originally proposed catalytic cycle, we assumed that a competition exists between product formation, which is $1^{\text {st }}$ order in catalyst, and a background reaction that decomposes the ylide unproductively in a bimolecular homocoupling reaction. This bimolecular homocoupling would be $2^{\text {nd }}$ order in catalyst, assuming the homocoupling step, whatever its exact nature, to be the rate-limiting step (see below, discussion about KIE).

Contrary to these initial assumptions, we observed the reaction to be approximately $1^{\text {st }}$ order in catalyst for the reaction with norbornene, as well as in the absence of any added alkene at all, i.e., when we look at the homocoupling reaction in isolation. Using norbornene as substrate, we observed approximately $\mathrm{o}^{\text {th }}$ order in olefinic substrate, indicative of saturation behavior in alkene. We also observed $\mathrm{a} \mathrm{o}^{\text {th }}$ order in $\mathrm{PPh}_{3}$ when tracking product formation. Considering these three kinetic orders together, we propose that the resting state is a nickel(o) species with the alkene and/or $\mathrm{PPh}_{3}$ already coordinated, meaning that substrate coordination has already taken place before the rate-limiting step. Additionally, we argue that the homocoupling reaction has the same resting state manifold and the actual homocoupling step itself is not rate-limiting. Thus, product formation and homocoupling intersect via the same resting state manifold of $\mathrm{Ni}(\mathrm{o})$ species.

\subsection{Rate-Limiting Step}

The normal secondary KIE of 2.1 suggests a sp3- to $\mathrm{sp}^{2}$-rehybridization in the rate-limiting transition state. This result is most consistent with nickel carbene formation being rate-limiting. Going from the tetrahedral sp3-hybridized nickel ylide adduct to the planar $\mathrm{sp}^{2}$-hybridized carbon in the nickel carbene is the only such step in our proposed mechanism..$^{10}$ In order to corroborate this finding, we performed DFT calculations on a model system and obtained the KIEs for all relevant steps in our proposed catalytic cycle (Table S24). Indeed, not only is the calculated KIE for the carbene formation in satisfactory agreement with our experimental value, all other KIEs are close to one or inverse. This corroboration strongly indicates that we correctly identified the turnover-limiting transition state. Additionally, this makes an alternative mechanism, a nucleophilic attack on the nickel-bound alkene by the ylide, followed by ring-closure, unlikely. ${ }^{11}$ None of the steps in the alternative mechanism involves a change in hybridization of the appropriate carbon and thus no (large) KIE would be expected.

Furthermore, the carbene formation by extrusion of $\mathrm{NMe}_{3}$ can be seen (formally) as an oxidative process, where the niccolate(o) is oxidized to a nickel(II) carbene. ${ }^{12}$ This is in agreement with the description of Hillhouse's isolated carbene complexes and selectivities for polar olefins with diazomethane as observed by Ibers. ${ }^{2 c}$ This picture is corroborated by our calculations, which show that the barrier for $\mathrm{NMe}_{3}$ extrusion is lowered in a system with more strongly $\sigma$-donating ligands, e.g. two $\mathrm{PH}_{3}$ ligands, than in a system with a less electron-rich nickel center ligated by one phosphine and one ethene (9 versus $15 \mathrm{kcal} \mathrm{mol}^{-1}$, Tables S21 and S25).

\subsection{Proposed Catalytic Cycle}

Combining the insights presented above regarding the resting state and the rate-limiting step we propose the catalytic cycle presented in Figure 6 . The aforementioned preequilibrium in which $\mathrm{PPh}_{3}$ and alkene compete for nickel(o) is denoted with the equilibrium constant $\mathrm{K}$ in Figure 6 in the colored block in the center of the diagram. This mechanistic conclusion led us to Tolman's work on the binding affinity of alkenes to nickel(o), specifically nickel(o)-tri-o-tolyl phosphite complexes, in which norbornene $(K=4.4)$ was shown to bind significantly more strongly to nickel(o) than, e.g., cyclooctene $(\mathrm{K}=0.062)$ (Scheme 4). ${ }^{13}$ We had observed that more strongly bound alkenes (based on Tolman's equilibrium constants) resulted in higher yields for the cyclopropanation, which is consistent with the proposed mechanism. ${ }^{14,15}$

\section{Scheme 4. Tolman's Alkene Equilibrium Con-} stants. ${ }^{13 a}$

$$
\begin{aligned}
\mathrm{A}+\mathrm{NiL}_{3} \rightleftharpoons \mathrm{K} & (\mathrm{A}) \mathrm{NiL}_{2}+\mathrm{L} \quad \begin{array}{l}
\mathrm{A}=\text { Alkene } \\
\mathrm{L}=\left[\mathrm{P}(\mathrm{O} \text {-o-tolyl })_{3}\right]
\end{array} \\
\mathrm{K}=\frac{\left[(\mathrm{A}) \mathrm{NiL}_{2}\right][\mathrm{L}]}{\left[\mathrm{NiL}_{3}\right][\mathrm{A}]} &
\end{aligned}
$$

\begin{tabular}{ll}
\hline Alkene & $\mathbf{K}^{a}$ \\
\hline Norbornene & 4.4
\end{tabular}


$\begin{array}{ll}\text { 1-Hexene }^{b} & 5.0 \times 10^{-1} \\ \text { Cyclooctene } & 6.2 \times 10^{-2} \\ \text { Cyclohexene } & 3.5 \times 10^{-4}\end{array}$

${ }^{a}$ Taken from ref. $13 \mathrm{a} .{ }^{b}$ Also used for other 1 -alkenes.

The analogous mechanistic scenario was proposed for the (ligandless) Pd-catalyzed cyclopropanation with diazomethane. In a DFT study by Straub, the extrusion of $\mathrm{N}_{2}$ from diazomethane by an alkene-ligated $\mathrm{Pd}(\mathrm{o})$ complex to form a Pd carbene was identified as the most likely rate-determining step, followed by facile intramolecular cyclopropanation of the $\eta^{2}$-bound alkene. ${ }^{16}$ Indeed, the improved yields with diazo compounds or $\alpha$-lithiated sulfones for more $\pi$-acidic alkenes were noted previously. ${ }^{2 c, 11 b, 17}$ After adduct formation of the ammonium ylide with the active catalyst, extrusion of $\mathrm{NMe}_{3}$ in the rate-limiting step leads to a nickel carbene species. Once the nickel carbene is formed, the bound alkene can undergo intramolecular $[2+2]$-addition to the nickelacyclobutane. This is followed by rapid reductive elimination to give the product. The viability of these kinetically invisible steps has been confirmed by our calculations and has been observed for analogous systems as pointed out earlier. ${ }^{4}$

If on the other hand no alkene is coordinated at the time the nickel carbene is formed, it can undergo unproductive homocoupling.

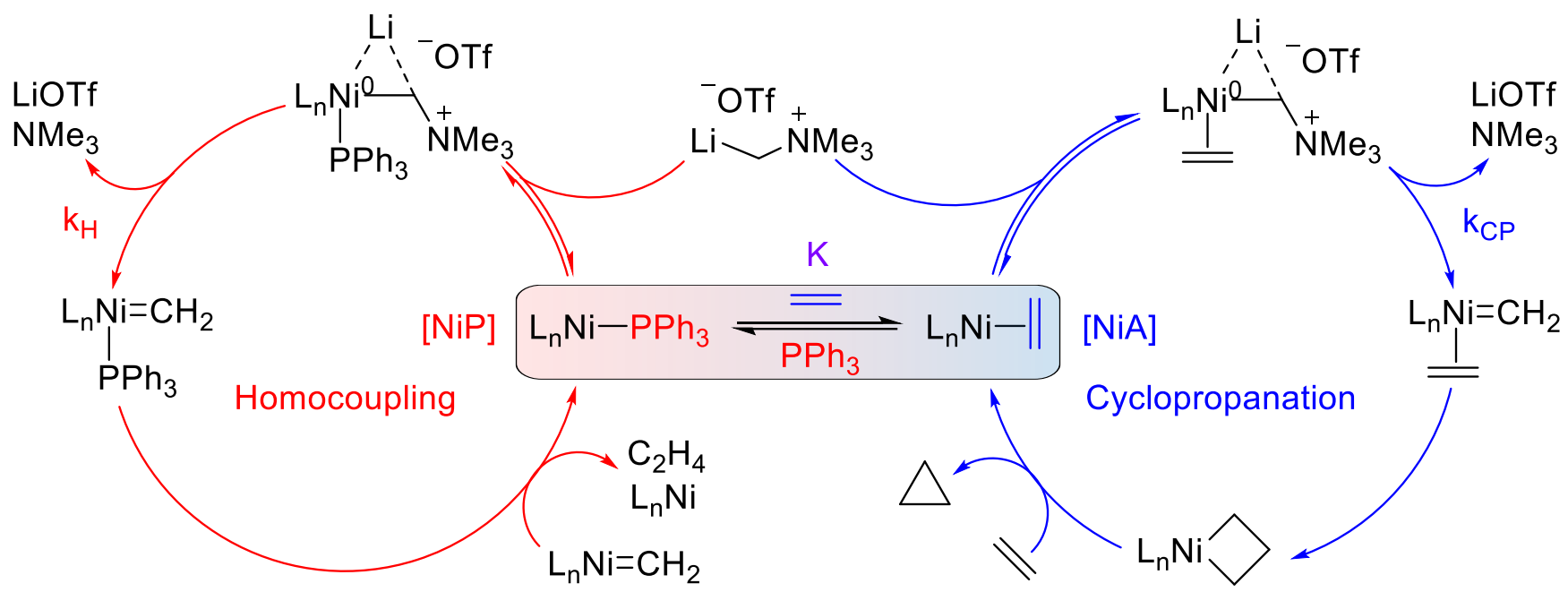

Figure 6. Proposed catalytic cycle. Central to the reaction is the highlighted equilibrium between ligand and alkene binding.

\subsection{Derivation of a Minimal Model}

As discussed above, we derive our model first for the specific case of two competing alkenes (Scheme 5 and Figure 5).

Scheme 5. Simplified Mechanistic Scenario with an Alkene Exchange Equilibrium before Cyclopropanation.
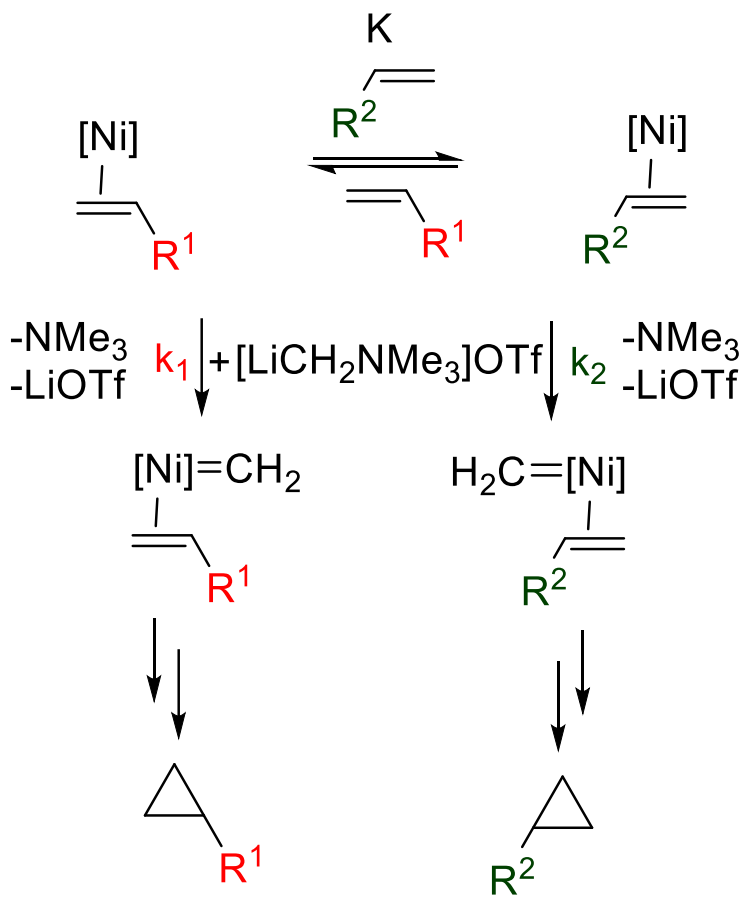
Assuming a Curtin-Hammett scenario, the two alkenes exchange rapidly in a pre-equilibrium $(\mathrm{K})$ before the rate-limiting nickel carbene formation $\left(\mathrm{k}_{1}, \mathrm{k}_{2}\right){ }^{18}$ This is followed by a fast, irreversible $[2+2]$-cycloaddition once the nickel carbene is formed (i.e., bimolecular alkene exchange is expected to be much slower for the nickel carbene complex compared to unimolecular nickelacyclobutane formation). This simplified mechanistic scenario leads to the following equation for the product ratio derived from alkene 1 and 2 , respectively,

$$
\frac{\left[\mathrm{P}_{1}\right]}{\left[\mathrm{P}_{2}\right]}=\frac{\mathrm{k}_{1} \mathrm{~K}_{1}}{\mathrm{k}_{2} \mathrm{~K}_{2}} \frac{\mathrm{X}_{1}}{\left(1-\mathrm{X}_{1}\right)}
$$

where $k_{i}$ is the rate constant for the cyclopropane formation from the respective nickel alkene complex, $K_{i}$ is corresponding to Tolman's equilibrium constant for alkene $\mathrm{i}$, and $\mathrm{X}_{1}$ is the mole fraction of alkene 1 (see Supporting Information for full derivation). ${ }^{19}$

Comparing the fit function from Figure 5, $y=a X_{1} /\left(1-X_{1}\right)$, with eq (1) gives $a=k_{1} K_{1} /\left(k_{2} K_{2}\right)$. We then arrive at a relative order of rate constants $k_{\text {rel }}$ as seen in Table 1 . The competition experiment between 1-octene and 1-nonene serves as an internal validation. The obtained value of $\mathrm{a}=0.96$ is very close to the expected value of 1 , indicating that both alkenes behave identically, or at least very similarly (Figure 5). ${ }^{13 a}$

Table 1. Determination of Relative Rate Constants from Competition Experiments.

\begin{tabular}{lll}
\hline Alkene & $\mathbf{K}^{a}$ & $\mathbf{k}_{\text {rel }}$ \\
\hline Norbornene & 4.4 & $1^{c}$ \\
1-Octene & $5.0 \times 10^{-1} b$ & 2.4 \\
Cyclooctene & $6.2 \times 10^{-2}$ & 11.4
\end{tabular}

${ }^{a}$ Values for $\mathrm{K}$ are taken from ref. 13a. See also discussion in ref. $14 .{ }^{b}$ Value for 1 -hexene in ref. 13 a. ${ }^{c} k_{\text {rel }}$ for NBE set to 1.

This model reveals that weakly binding/weaker $\pi$-acidic substrates react faster (i.e., $k_{i} / k_{\text {rel }}$ is larger, less ground state stabilization), but less of the corresponding nickel(o) alkene species is present in solution ( $\mathrm{K}_{\mathrm{i}}$ is smaller) because they stabilize nickel(o) less. ${ }^{20}$ This is logically consistent with an oxidative process (nickel carbene formation) being slower at a less electron-rich metal.

We can now proceed to the more general case in which a single alkene is in a pre-equilibrium with $\mathrm{PPh}_{3}$. The observed $1^{\text {st }}$ order kinetics in catalyst for the ylide consumption in the absence of added alkene indicates that the nickel carbene formation is also the rate-determining step in the substrate-free case, with an analogous resting state being before that transition state. With this idea in mind, we extend the aforementioned mechanistic model with rapid alkene/alkene exchange before the rate-determining nickel carbene formation, to the general case for the cyclopropanation reaction. This leads to the following mechanistic sketch shown in Scheme 6.

Both pathways, cyclopropanation and unproductive ylide decomposition/homocoupling, share the same resting state manifold, i.e., a nickel(o) species with alkene (NiA) and phosphine ligands $(\mathrm{NiP})$ in equilibrium. If a nickel(o) species with an alkene ligand reacts with an ylide to form the nickel carbene, it will follow the pathway of cyclopropanation $\left(\mathrm{k}_{\mathrm{CP}}\right)$. If, on the other hand, there is no bound alkene but only phosphine ligands on the nickel, it will react unproductively once the nickel carbene is formed $\left(\mathrm{k}_{\mathrm{H}}\right)$. Both pathways have the same dependence on ylide concentration, (approximately) $1^{\text {st }}$ order, as evidenced by the reaction profile of ylide consumption (Figure $\mathrm{S}_{12}$ ).

This regime leads again to a Curtin-Hammett scenario, where the yield is determined by the competition between the two rates, $\mathrm{k}_{\mathrm{CP}}$ [ylide][NiA] and $\mathrm{k}_{\mathrm{H}}$ [ylide][NiP], with the pre-equilibrium between $\mathrm{NiA}$ and $\mathrm{NiP}$ controlled by relative concentrations and binding affinities of alkene versus phosphine.

Scheme 6. Simplified Mechanistic Scenario with an Alkene Exchange Equilibrium before Cyclopropanation.
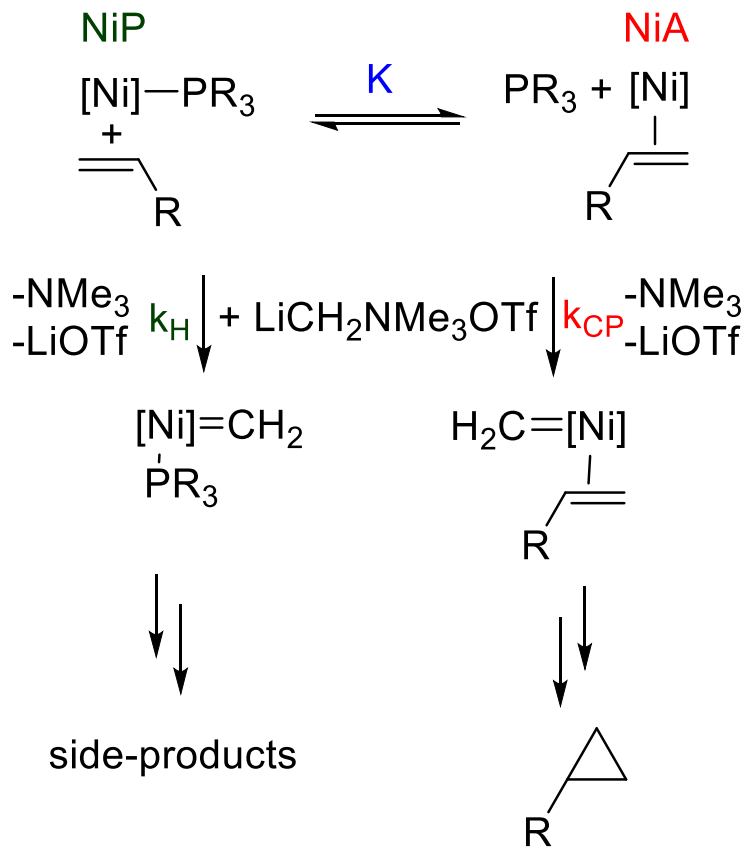

Standard mathematical treatment of this scenario yields the following equation (see Supporting Information for full derivation).

$$
\% \text { yield }=100 \cdot \frac{\frac{k_{C P}}{k_{H}}\left([N i]_{t o t}-[N i P]\right)}{\frac{k_{C P}}{k_{H}}[N i]_{t o t}+\left(1-\frac{k_{C P}}{k_{H}}\right)[N i P]}
$$

where $[\mathrm{NiP}]$ is a function of the total concentrations of $\mathrm{Ni}$, phosphine, and alkene, $[\mathrm{Ni}]_{\text {tot }},[\mathrm{P}]_{\text {tot }}$, and $[\mathrm{A}]_{\text {tot }}$, respectively, as well as the equilibrium constant $\mathrm{K}$. The yield is 
thus dependent on these three concentrations, as well as on the alkene binding constant $\mathrm{K}$ and on the ratio of the rate constants $\mathrm{k}_{\mathrm{CP}} / \mathrm{k}_{\mathrm{H}}$ (Scheme 6).

This model can also be applied to the rate of cyclopropanation to give eq. (3). In this case, $\mathrm{k}_{\mathrm{obs} \text {,rel }}$ is normalized against an arbitrarily chosen reference $k_{o b s}$ of a given series of experimental data (usually the lowest concentration of $\left.[\mathrm{Ni}]_{\text {tot }}\right)$.

$$
\begin{gathered}
k_{o b s}=k_{C P}[N i A]=k_{C P}\left([N i]_{t o t}-[N i P]\right) \\
k_{o b s, r e l, n}=\frac{k_{C P}\left([N i]_{t o t, n}-[N i P]_{n}\right)}{k_{C P}\left([N i]_{t o t, 1}-[N i P]_{1}\right)}=\frac{[N i A]_{n}}{[N i A]_{1}}
\end{gathered}
$$

At this point we refrain from making any assumptions about what the possible species NiP and NiA might look like, except that $\mathrm{NiA}$ is a species with at least one alkene coordinated, whereas NiP is a species in which one alkene has been replaced by a phosphine ligand $\left(\mathrm{PPh}_{3}\right.$ in this case), most likely however an alkene-free tris-phosphine nickel complex.

\subsection{Fit of Model to Data}

Next, we apply this mechanistic model to our data to see if it agrees with our observations, at least qualitatively.

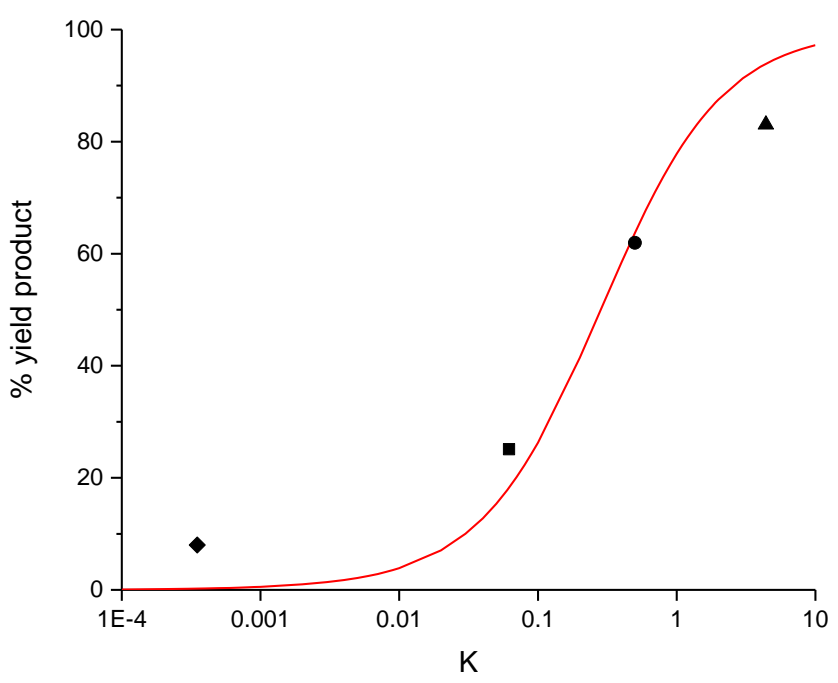

Figure 7. Plot of K (from Tolman, ${ }^{13} \log$ scale) versus the experimental yield (black symbols, $\left.1.0 \mathrm{~mol} \%\left(\mathrm{Ph}_{3} \mathrm{P}\right)_{2} \mathrm{NiBr}_{2}\right)$ and the predicted yield (red line) based on our mechanistic model for the cyclopropanation of cyclohexene (diamond, data from ref. 4), COE (square), 1-octene (circle), and NBE (triangle). The ratio $\mathrm{k}_{\mathrm{CP}} / \mathrm{k}_{\mathrm{H}}$ was used as a parameter to fit the experimental data according to eq (2) to give $\mathrm{k}_{\mathrm{CP}} / \mathrm{k}_{\mathrm{H}}=0.014$. $[\mathrm{Ni}]_{\text {tot }}=0.5 \mathrm{mM}$, $[\mathrm{P}]_{\text {tot }}=1 \mathrm{mM},[\mathrm{A}]_{\text {tot }}=250$.

Using the model described above, we used the ratio $\mathrm{k}_{\mathrm{CP}} / \mathrm{k}_{\mathrm{H}}$ as the sole parameter to fit eq (2) to the cyclopropanation yields with different alkenes (Figure 7) at one representative set of concentrations (see Figure S2o for other catalyst concentrations). This gives a ratio of rate constants $\mathrm{k}_{\mathrm{CP}} / \mathrm{k}_{\mathrm{H}}$ of o.014. That is, the rate constant of homocoupling $\left(\mathrm{k}_{\mathrm{H}}\right)$ is larger than that for cyclopropanation $\left(\mathrm{k}_{\mathrm{CP}}\right)$. Note that $\mathrm{k}_{\mathrm{CP}}$ is therefore an average value over all alkenes. Because the al- kene is necessarily involved in the rate-limiting step (according to our model), $\mathrm{k}_{\mathrm{CP}}$ should vary with the nature of the alkene and thus $\mathrm{k}_{\mathrm{CP}}$ is not independent of $\mathrm{K}$.

We already gleaned this interdependence of $\mathrm{k}_{\mathrm{CP}}$ and $\mathrm{K}$ in the alkene competition experiments (as $\mathrm{k}_{\mathrm{rel}}$ in Table 1 ), but we chose to use the admittedly extreme simplification of a single $\mathrm{k}_{\mathrm{CP}} / \mathrm{k}_{\mathrm{H}}$ ratio, and compare the numerical results to experiment.

\subsection{Comparison of Model to Data}

The extracted parameter $\mathrm{k}_{\mathrm{CP}} / \mathrm{k}_{\mathrm{H}}$ (Figure 7 ) is the sole fit to our mechanistic data; accordingly, all further predictions are based thereupon.

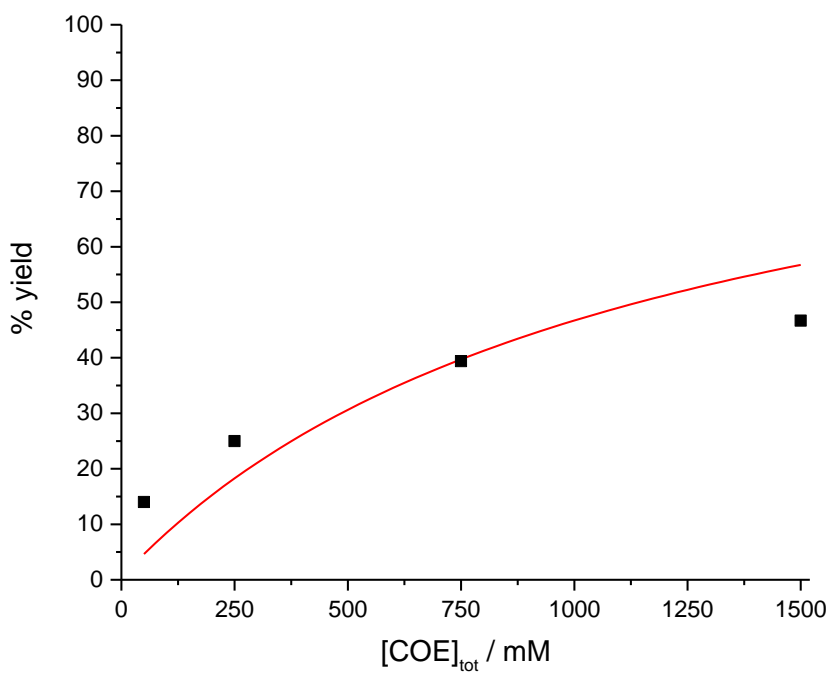

Figure 8. Plot of COE concentration versus the measured yield (squares) and predicted yield (red curve) based on our model (eq (2)) for cyclopropanation of COE using $1.0 \mathrm{~mol} \%$ $\left(\mathrm{Ph}_{3} \mathrm{P}\right)_{2} \mathrm{NiBr}_{2} . \mathrm{k}_{\mathrm{CP}} / \mathrm{k}_{\mathrm{H}}=0.014,[\mathrm{Ni}]_{\text {tot }}=0.5 \mathrm{mM},[\mathrm{P}]_{\text {tot }}=1 \mathrm{mM}$ with no further adjustment of parameters. Data from ref. 4 .

Figure 8 , in which the computed yield for cyclopropanation of cyclooctene over a broad range of substrate concentrations matches the experiment well, despite the fit of $\mathrm{k}_{\mathrm{CP}} / \mathrm{k}_{\mathrm{H}}$ at a single concentration, gives a first indication that this rather bold approximation provides a better-thanqualitative description of the reaction.

In agreement with our rate data above, the model reasonably reproduces the orders in $\mathrm{NBE}, \mathrm{PPh}_{3}$ and catalyst (Figures $\mathrm{S}_{24}, \mathrm{~S}_{25}$, and $\mathrm{S}_{26}$ ), as would be expected. 


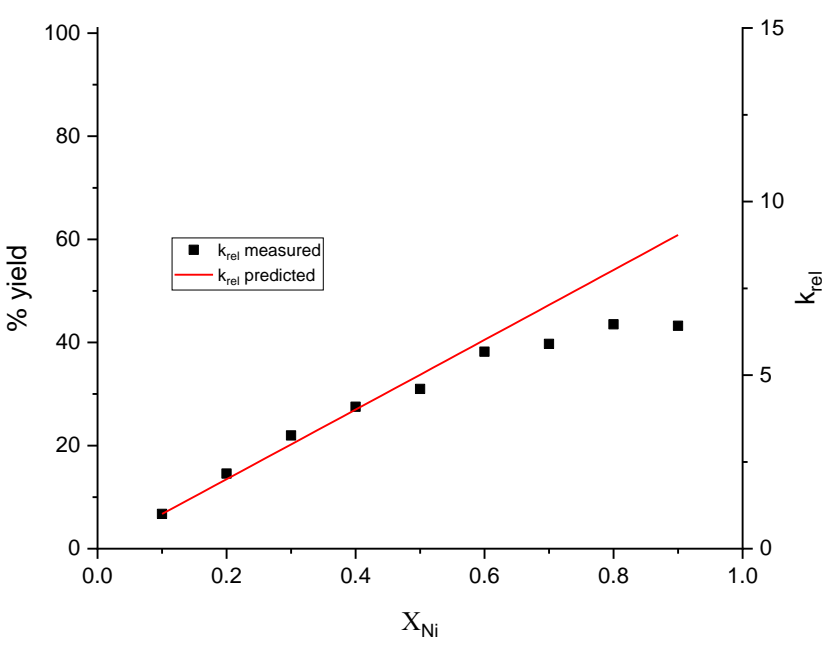

Figure 9. Plot of mole fraction of nickel $\mathrm{X}_{\mathrm{Ni}}$ (using $\mathrm{Ni}(\text { acac })_{2}$ ) versus the measured rate (squares) and predicted rate (red solid curve) (approximated as initial yield after $30 \mathrm{~min}$ ) based on our model (eq (4)) for the cyclopropanation of NBE, all with no further adjustment of parameters. $\mathrm{k}_{\mathrm{CP}} / \mathrm{k}_{\mathrm{H}}=0.014$, $[\mathrm{Ni}]_{\mathrm{tot}}+[\mathrm{P}]_{\mathrm{tot}}=0.5 \mathrm{mM},[\mathrm{A}]_{\mathrm{tot}}=250 \mathrm{mM}$.

The model also predicts that for NBE as substrate, the rate of cyclopropanation might change significantly but the yield does not vary noticeably, despite there being an exchange of phosphine and olefin in the resting state, as seen in Figure 9.

At higher $\mathrm{X}_{\mathrm{Ni}}$, the experimental yields and rates deviate downwards from those predicted by our model. A reasonable explanation for this behavior is a less stable catalyst under the very low concentration of phosphine ligand (Figure 9).

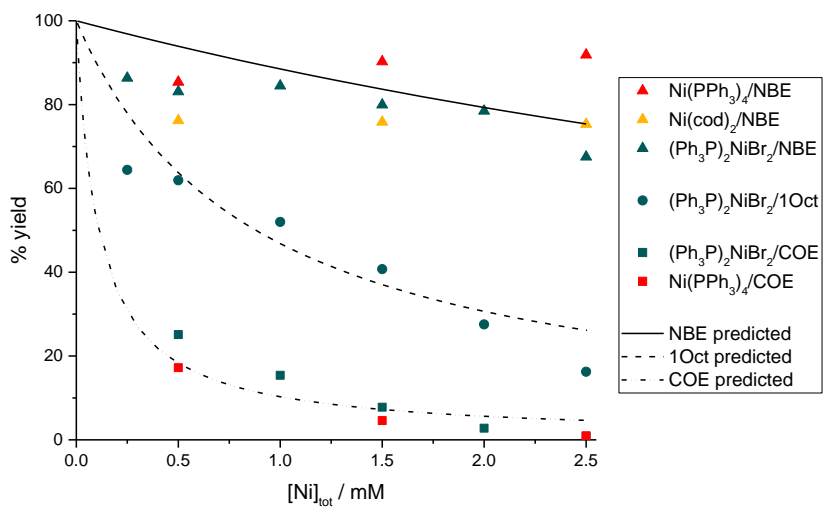

Figure 10. Plot of catalyst concentration versus yield for $\mathrm{COE}$ (squares), 1-octene (circles) and norbornene (triangles). The black curves depict the predicted yield based on our model (eq (2)), with no further adjustment of parameters. $\mathrm{k}_{\mathrm{CP}} / \mathrm{k}_{\mathrm{H}}=0.014$, $[\mathrm{P}]_{\text {tot }}=2[\mathrm{Ni}]_{\text {tot }},[\mathrm{A}]_{\text {tot }}=250 \mathrm{mM}$.

One key initial finding, as mentioned in the Introduction and for which we sought an explanation, was that at higher catalyst loading the yield of cyclopropanation is suppressed using COE as substrate. This has been shown here also for norbornene (and 1-octene) as substrate, but only if a $\mathrm{Ni}(\mathrm{II})$ precatalyst is used, and only to a small extent in the NBE case. When an already reduced precatalyst, $\mathrm{Ni}\left(\mathrm{PPh}_{3}\right)_{4}$, was used the same effect was observed for cyclooctene but not for norbornene (Figure 10). This shows, on the one hand, that the reduction of $\mathrm{Ni}(\mathrm{II})$ to $\mathrm{Ni}(\mathrm{o})$, as we propose, is an issue and does lead to partial catalyst deactivation. This can also be gleaned from the data in Figure 1.

On the other hand, with the model in hand, this catalyst loading effect can be explained by the specific interplay between $\mathrm{K}$ for the alkene and the catalyst concentration employed. With increasing precatalyst loading, there is a simultaneous increased concentration of phosphine ligand $\left(\mathrm{P}_{\text {tot }}\right)$ in the system, while the concentration of alkene $\left(\mathrm{A}_{\text {tot }}\right)$ is kept constant. Based on the value of $K$, it is possible for the phosphine ligand to replace the alkene binding to the catalyst, i.e. [NiP] increases and more ylide decomposes unproductively in a parasitic side reaction. Thus, the observed decrease in yield is not present for a strongly binding alkene (NBE) but is observable for a weakly binding alkene (COE) (Figure 10). In accordance with this model, addition of an excess of $\mathrm{PPh}_{3}$ under otherwise standard conditions for COE led to a strongly suppressed or even completely inhibited cyclopropanation reaction (see Supporting Information). This also explains why chelating bisphosphine or strongly binding monophosphine ligands have proven to be worse ligands than $\mathrm{PPh}_{3}$ in terms of yield. The alkene cannot compete for a coordination site on the metal, leaving the the ylide to decompose unproductively. The binding of phosphines to $\mathrm{Ni}(\mathrm{o})$ has been shown to be dominated by steric effects. ${ }^{21}$ The initial rise in cyclopropanation yield as the $\mathrm{Ni}$ concentration is increased is likely explained by outcompeting catalyst decomposition and uncatalyzed ylide decomposition relative to the slow rate of cyclopropanation at low catalyst loadings.

\subsection{Implication for Ligand Design}

Thus far, we have only looked at the influence of the alkene substrate on the proposed pre-equilibrium. To make the reaction catalyst-controlled, guided by our mechanistic insight, a catalyst/ligand system is needed that does not inhibit, or even promotes, binding of the substrate, yet still has an ancillary ligand to stabilize $\mathrm{Ni}(\mathrm{o})$. We took inspiration from a recent report by $\mathrm{Wu}$ and Doyle regarding the influence of remote steric effects. ${ }^{22}$ A small buried volume $\% \mathrm{~V}_{\mathrm{Bur}}$ of a phosphine ligand would allow for substrate coordination. A large cone angle with substituents pointing away from the immediate coordination sphere of $\mathrm{Ni}$ would nevertheless result in a large steric profile with respect to coordination of more than one phosphine.

With this rationale in mind, we synthesized two new triaryl phosphine ligands with differing numbers of 3,5-di-tertbutylphenyl groups on phosphorous, either one or two. Indeed, both ligands gave improved yields over the standard ligand $\mathrm{PPh}_{3}$ for the cyclopropanation of COE, $32 \%$ and 48 $\%$, respectively (Figure 11 and Table $\mathrm{S} 18$ ).

To test our hypothesis of the remote steric effect, we generated a steric-only regression model using five different phosphines ranging from the sterically small $\mathrm{PPhMe}_{2}$ to our new, larger ligands (as well as spanning the largest 
range of yields presently possible for the substrate COE). ${ }^{23}$ We generated for the ligand set two steric parameters, buried volume $\% \mathrm{~V}_{\mathrm{Bur}}$ and exact ligand solid cone angle $\Theta^{\circ} .{ }^{24}$

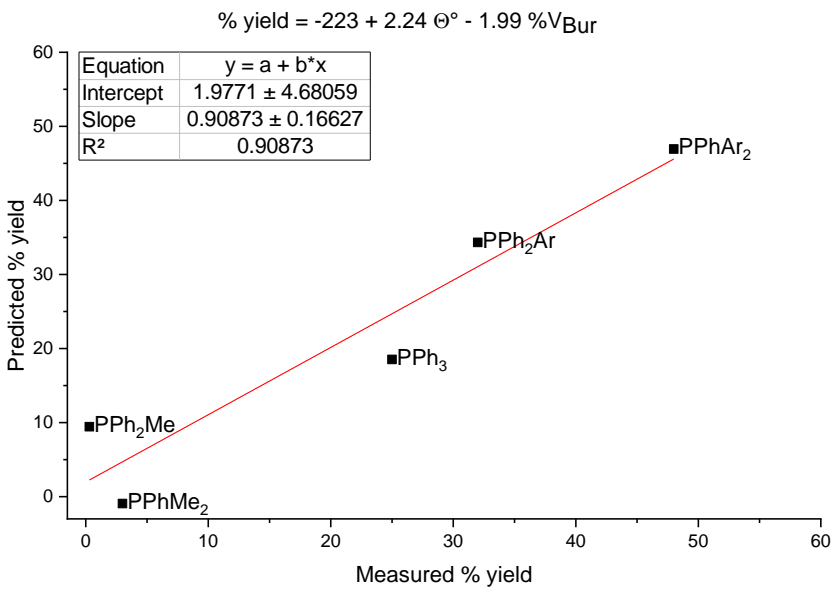

Figure 11. Plot of measured yield versus predicted yield using a steric-only regression model with buried volume $\% \mathrm{~V}_{\text {Bur }}$ and

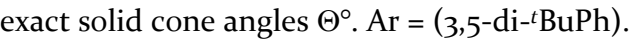

Already a good correlation between predicted and measured yields for our small ligand set can be achieved using only these two steric parameters, displaying the merit of harnessing remote steric effects on the ligand design. Additionally, the applicability of our rationale is reflected in the coefficients extracted from the regression model (Figure 11), i.e., the larger the cone angle with concomitantly small buried volume, the higher the predicted yield.

To further assess the veracity of the implicated pre-equilibrium binding, we measured the binding constants $\mathrm{K}$ for cyclooctene in the presence of the ligands in Figure 11 (see Supporting Information). Indeed, the $\mathrm{K}$ correlates well with the cyclopropanation yield. Figure 7 has been reproduced in the Supporting Information with the additional data (Figure $\mathrm{S}_{76}$ )

\section{Conclusion}

In summary, our mechanistic studies lead us to propose a kinetic model that explains (most) experimental observations, at least qualitatively, and gave us initial guidelines for an improved, and partially verified, rational ligand design.

1) The active nickel catalyst with at least one alkene bound, $\mathrm{NiA}$, is the resting state of the catalytic (cyclopropanation) cycle. The concentration of $\mathrm{NiA}$, in turn, depends on the equilibrium constant $\mathrm{K}$; for NBE the concentration of NiA is higher than for COE. This species can undergo nickel carbene formation with the ammonium ylide present in solution, followed by rapid product formation, most likely via a nickelacyclobutane.

2) Depending on the binding constant $\mathrm{K}$ of the alkene substrate, a significant amount of the nickel catalyst can exist as an alkene-free nickel species (NiP) that can also undergo nickel carbene formation in the rate-determining step to engage in rapid homocoupling (and, potentially, further side reactions)(highlighted equilibrium in Figure 6). We propose NiP to be the resting state of this side-reaction cycle.

3) Carbene formation is faster for $\mathrm{NiP}$ than $\mathrm{NiA}\left(\mathrm{k}_{\mathrm{H}}\right.$ $>\mathrm{k}_{\mathrm{CP}}$, Figure 7 ). Thus, NiP competes for the ylide in a parasitic cycle. This explains the pronounced substrate-dependence of the yield that we noted earlier. Unless the substrate binds well enough to drive the equilibrium to the alkene-ligated nickel species, and, therefore, cyclopropanation, the phosphine-ligated species will dominate and engage in the faster and unproductive background reaction, i.e. homocoupling (Figure 6).

4) Additionally, competition experiments indicate that there is an inverse relationship between the equilibrium constant $\mathrm{K}$ and the rate constant $\mathrm{k}_{\mathrm{CP}}$ for cyclopropanation (i.e. $k_{\text {rel }}$ in Table 1 ). Together with the larger rate constant for homocoupling $\mathrm{k}_{\mathrm{H}}$ over the (average) rate constant for cyclopropanation $\mathrm{k}_{\mathrm{CP}}$ (Figure 7 ) one can see that the higher the $\pi$-acidity of the ligand is ( $\left.\mathrm{NBE}>\mathrm{PPh}_{3}\right)$, the smaller the rate constant becomes.

5) The product of the homocoupling, ethene, is also itself an outstanding ligand. ${ }^{13}$ A headspace analysis of the reaction showed that cyclopropane is a side-product of the reaction. Leaving the flask open to the Schlenk line likely allows the ethene to escape and thus might be the reason for the effect of an open versus a closed reaction flask.

6) Our mechanistic studies have afforded us with a blueprint for an improved ligand design. The preequilibrium binding can be influenced by employing ligands with remote steric hindrance, expressed as a small buried volume and a large cone angle, thus discouraging saturation of the catalyst with phosphine ligands, i.e., resulting in a larger K. Our measured binding constants for several phosphines give credence to this hypothesis.

The above-outlined mechanism and the resulting blueprint for an improved ligand design will serve as a highly valuable basis for the rational design of new ligands with above-mentioned features. Our initial results showcase a promising way forward. These mechanism-driven efforts, including an enlarged and more detailed ligand parametrization set, are currently ongoing and will be reported in due course.

\section{ASSOCIATED CONTENT}

This material is available free of charge via the Internet at http://pubs.acs.org.

Experimental details, characterizations, and geometries for all computed structures.

\section{AUTHOR INFORMATION}

\section{Corresponding Author}

*peter.chen@org.chem.ethz.ch. 
ORCID

Peter Chen: oooo-0oo2-9280-4369

\section{Funding Sources}

This work was supported by the Schweizerischen Nationalfonds and the ETH Zürich.

Notes

The authors declare no competing financial interest.

\section{ACKNOWLEDGMENT}

Augustin A. S. W. Tchawou (Chen group) is thanked for the preparation of authentic heptylcyclopropane and its GC calibration curve.

\section{REFERENCES}




\section{TOC Graphic}

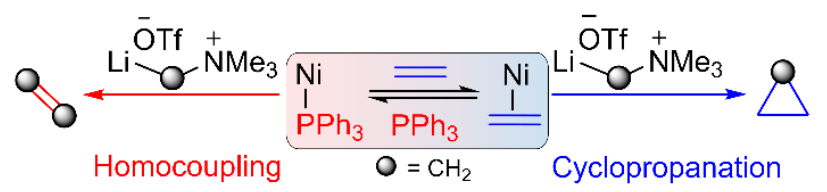

(1) (a) Pasco, M.; Gilboa, N.; Mejuch, T.; Marek, I. The Renaissance of Zinc Carbenoid in Stereoselective Synthesis in Acyclic Systems. Organometallics 2013, 32, 942-950. (b) Charette, A. B. Cyclopropanation mediated by zinc organometallics. In The Chemistry of Organozinc Compounds; Rappoport, Z., Marek, I., Eds.; Wiley: Chichester, 2006; Vol. 1, pp 237 - 286. For a recent Ni-catalyzed Simmons-Smith-type method, see: (c) Zhou, Y.-Y.; Uyeda, C. Reductive Cyclopropanations Catalyzed by Dinuclear Nickel Complexes. Angew. Chem. Int. Ed. 2016, 55, 3171-3175.

(2) (a) Tomilov, Y. V.; Bordakov, V. G.; Dolgii, I. E.; Nefedov, O. M. Reaction of diazoalkanes with unsaturated compounds. Communication 2. Cyclopropanation of olefins by diazomethane in the presence of palladium compounds. Russ. Chem. Bull. 1984, 33, 533-538. (b) Denmark, S. E.; Stavenger, R. A.; Faucher, A.-M.; Edwards, J. P. Cyclopropanation with Diazomethane and Bis(oxazoline)palladium(II) Complexes. J. Org. Chem. 1997, 62, 3375-3389. (c) Nakamura, A.; Yoshida, T.; Cowie, M.; Otsuka, S.; Ibers, J. A. Cyclopropanation Reactions of Diazoalkanes with Substituted Olefins in the Presence and Absence of Nickel(o) and Palladium(o) Catalysts. The Structure of (Diazofluorene)bis(tert-butyl isocyanide)nickel(o); a Complex Containing a $\pi$-Bonded Diazofluorene Molecule. J. Am. Chem. Soc. 1977, 99, 21082117.

(3) (a) Tchawou, A. S. W.; Raducan, M.; Chen, P. Mechanism-Based Design and Optimization of a Catalytic Electrophilic Cyclopropanation without Diazomethane. Organometallics 2017, 36, 180-191. (b) den Hartog, T.; Sarria Toro, J. M.; Chen, P. A Palladium-Catalyzed Methylenation of Olefins Using Halomethylboronate Reagents. Org. Lett. 2014, 16, 1100-1103. (c) Morandi, B.; Carreira, E. M. Iron-Catalyzed Cyclopropanation in $6 \mathrm{M} \mathrm{KOH}$ with in Situ Generation of Diazomethane. Science 2012, 335, 1471-1474. (d) Gai, Y.; Julia, M.; Verpeaux, J.N. Nickel-Catalyzed Cyclopropanation of Alkenes via Methylene Transfer from Lithiated tert-Butyl Methyl Sulfone. Synlett 1991, 56-57.

(4) Künzi, S. A.; Sarria Toro, J. M.; den Hartog, T.; Chen, P. Nickel-Catalyzed Cyclopropanation with NMe ${ }_{4} \mathrm{OTf}$ and $n$ BuLi. Angew. Chem. Int. Ed. 2015, 54, 10670-10674.

(5) We have made this observation both for the Ni-catalyzed reaction in ref. 4 as well as the uncatalyzed reaction in refs. $10 b$ and 15 .

(6) All attempts to isolate a nickel carbene in analogy to Hillhouse's complexes derived from an ammonium ylide have failed so far. See, a) Mindiola, D. J.; Hillhouse, G. L. Synthesis, Structure, and Reactions of a Three-Coordinate Nickel-Carbene Complex, \{1,2-Bis(di-tertbutylphosphino)ethane\} $\mathrm{Ni}=\mathrm{CPh}_{2}$. J. Am. Chem. Soc. 2002, 124, 9976-9977. b) Iluc, V. M.; Hillhouse, G. L. Three-Coordinate Nickel Carbene Complexes and Their One-Electron Oxidation Products. J. Am. Chem. Soc. 2014, 136, 6479-6488.

(7) Frisch, M. J.; Trucks, G. W.; Schlegel, H. B.; Scuseria, G. E.; Robb, M. A. ; Cheeseman, J. R.; Scalmani, G.; Barone, V.; Petersson, G. A.; Nakatsuji, H.; Li, X.; Caricato, M.; Marenich, A.; Bloino, J.; Janesko, B. G.; Gomperts, R.; Mennucci, B.; Hratchian, H. P.; Ortiz, J. V.; Izmaylov, A. F.; Sonnenberg, J. L.; Williams-Young, D.; Ding, F.; Lipparini, F.; Egidi, F.; Goings, J.; Peng, B.; Petrone, A.; Henderson, T.; Ranasinghe, D.; Zakrzewski, V. G.; Gao, J.; Rega, N.; Zheng, G.; Liang, W.; Hada, M.; Ehara, M.; Toyota, K.; Fukuda, R.; Hasegawa, J.; Ishida, M.; Nakajima, T.; Honda, Y.; Kitao, O.; Nakai, H.; Vreven, T.; Throssell, K.; Montgomery, Jr., J. A.; Peralta, J. E.; Ogliaro, F.; Bearpark, M.; Heyd, J. J.; Brothers, E.; Kudin, K. N.; Staroverov, V. N.; Keith, T.; Kobayashi, R.; Normand, J.; Raghavachari, K.; Rendell, A.; Burant, J. C.; Iyengar, S. S.; Tomasi, J.; Cossi, M.; Millam, J. M.; Klene, M.; Adamo, C.; Cammi, R.; Ochterski, J. W.; Martin, R. L.; Morokuma, K.; Farkas, O.; Foresman, J. B; Fox, D. J. Gaussian o9, Revision D.o1; Gaussian, Inc.: Wallingford, CT, 2016.

(8) Anisimov, V.; Paneth, P. ISOEFF98. A program for studies of isotope effects using Hessian modifications. J. Mathem. Chem. 1999, $26,75-86$.

(9) The ammonium ylide derived from deprotonating $\left[\mathrm{BnNMe}_{3}\right] \mathrm{X}$ is known to undergo facile Stevens and Sommelet-Hauser rearrangements and did so under our conditions (BuLi, THF, o ${ }^{\circ} \mathrm{C}$, no [Ni] or alkene present). (a) Stevens, T. S.; Creighton, E. M.; Gordon, A. B.; MacNicol, M. CCCCXXIII.-Degradation of Quaternary Ammonium Salts. Part I. J. Chem. Soc. 1928, 3193-3197. (b) Puterbaugh, W. H.; Hauser, C. R. Isolation of Intermediate Alkali Salt in ortho-Substitution Rearrangement of Benzyltrimethylammonium Ion as Benzophenone Adduct. J. Am. Chem. Soc. 1964, 86, 1105-1107. (c) Lepley, A. R.; Becker, R. H. Quaternary benzylammonium ion rearrangements with organolithium compounds-I: Simple tertiary amines from the attack of N-butyl-lithium on benzyltrimethylammonium iodide. Tetrahedron 1965, 21, 2365-2373.

(10) (a) Based on x-ray crytal structure of the complex $\left[\left(\mathrm{Cy}_{3} \mathrm{PCH}\left(\mathrm{CH}_{3}\right) \mathrm{Ni}(\mathrm{CO})_{3}\right]\right.$ it has been noted that the phosphonium ylide carbon is sp $_{3}$-hybridized: Heydenreich, F.; Mollbach, A.; Wilke, G.; Dreeskamp, H.; Hoffmann, E. G.; Schroth, G.; Seevogel, K.; Stempfle, W. Stevensanaloge, Durch Nickelkomplexe Katalysierte Umlagerung Von Triarylphosphoryliden Und Darstellung Sowie Strukturbestimmung Von Phosphorylid-Nickeltricarbonylkomplexen. Isr. J. Chem. 1972, 10, 293-319. (b) Additionally, computational studies by our group have shown that the anionic carbon of the $\mathrm{N}$-ylide is tetrahedral with or without coordination to Li: den Hartog, T.; Sarria Toro, J. M.; Couzijn, E. P. A.; Chen P. A lithiomethyl trimethylammonium reagent as a methylene donor. Chem. Commun. 2014, 50, 10604-10607. 
(11) This mechanistic possibility has been proposed with diazomethane via an outer sphere attack or with an $\alpha$-lithiated sulfone via coordination/insertion, respectively: (a) Harrold, N. D.; Corcos, A. R.; Hillhouse, G. L. Synthesis, structures, and catalytic reactivity of bis(N-heterocyclic carbene) supported diphenyldiazomethane and 1-azidoadamantane complexes of nickel. J. Organomet. Chem. 2o16, 813, 46-54. (b) Gai, Y.; Julia, M.; Verpeaux, J.-N. Conversion of non-activated alkenes into cyclopropanes with lithiated sulfones under nickel catalysis. Bull. Soc. Chim. Fr. 1996, 133, 817-829.

(12) Concomitantly, the oxidation state of the transferred carbon atom changes from -2 to -4 going from the ylidic carbon to the carbenic carbon. Formally, this process can be regarded a reductive cleavage of the $\mathrm{C}-\mathrm{N}$ bond.

(13) (a) Tolman, C. A. Olefin Complexes of Nickel(o). III. Formation Constants of (Olefin)bis(tri-o-tolyl phosphite)nickel Complexes. J. Am. Chem. Soc. 1974, 96, 2780-2789. (b) The analogous equilibrium constant for $\mathrm{Ni}\left(\mathrm{PPh}_{3}\right)_{3}$ and ethene has also been measured and is comparable to the value with $\mathrm{P}(\mathrm{O}-\mathrm{o}-\mathrm{tolyl})_{3}$ ) from ref. 13a, $\mathrm{K}=250$ (ref. 13a) vs. 300 (ref. 13c): (c) Tolman, C. A.; Seidel, W. C.; Gerlach, D. H. Triarylphosphine and Ethylene Complexes of Zerovalent Nickel, Palladium, and Platinum. J. Am. Chem. Soc. 1972, 94, 2669-2676.

(14) While the equilibrium constants measured in ref. 13a where determined under different conditions (benzene at room temperature with $\left.\mathrm{P}(\mathrm{O}-\mathrm{o} \text {-tolyl })_{3}\right)$ than our reaction conditions (THF at o ${ }^{\circ} \mathrm{C}$ with $\left.\mathrm{PPh}_{3}\right)$, the qualitative trend should be the same. We opted for these experimental values to already have a large library of alkenes at hand. Additionally, we measured the binding constants for cyclooctene, 1-octene, and norbornene with $\mathrm{PPh}_{3}$ (THF, room temperature) and cyclooctene with $\mathrm{P}(\mathrm{O}-\mathrm{o} \text {-tolyl })_{3}$ with a good agreement to Tolman's values (see Supporting Information, Table S8).

(15) Other (activated) alkenes with equilibrium constants $\mathrm{K}$ greater than that of norbornene (see ref. 13a) can already react with $\left[\mathrm{LiCH}_{2} \mathrm{~N}\left(\mathrm{CH}_{3}\right)_{3}\right] \mathrm{OTf}$ in an uncatalyzed addition-ring-closure sequence to give cyclopropanes (e.g. styrene (K=10, ref. 13a), see: Sarria Toro, J. M.; den Hartog, T.; Chen P. Cyclopropanation of styrenes and stilbenes using lithiomethyl trimethylammonium triflate as methylene donor. Chem. Commun. 2014, 50, 10608-10610.

(16) (a) Straub, B. Pd(o) Mechanism of Palladium-Catalyzed Cyclopropanation of Alkenes by $\mathrm{CH}_{2} \mathrm{~N}_{2}$ : A DFT Study. J. Am. Chem. Soc. 2002, 124, 14195-14201. (b) For a computational study for cyclopropanation with a Ni carbene, see: Zhang, X.; Geng, Z.-Y.; Wang, Y.-C.; Li, W.-Q.; Wang, Z.; Liu, F.-X. A theoretical study nickel-catalyzed cyclopropanation reactions. Nickel(o) versus nickel(II). J. Mol. Struct.: THEOCHEM 2009, 893, 56-66.

(17) (a) Anciaux, A. J.; Hubert, A J.; Noels, A. F.; Petiniot, N.; Teyssié, P. Transition-Metal-Catalyzed Reactions of Diazo Compounds. 1. Cyclopropanation of Double Bonds. J. Org. Chem. 1980, 45, 695-702. (b) Berthon-Gelloz, G.; Marchant, M.; Straub, B.; Marko, I. E. Palladium-Catalyzed Cyclopropanation of Alkenyl Silanes by Diazoalkanes: Evidence for a Pd ${ }^{\circ}$ Mechanism. Chem. Eur. J. 2009, 15, $2923-2931$.

(18) This sccenario is not unsimilar to the hydrogenation (under low $\mathrm{H}_{2}$ pressure) of acetamidocinnamate with a cationic Rh(I)-catalyst, where the product ratio (enantiomeric excess) depends both on the binding pre-equilibrium of the substrate and the subsequent turnoverlimiting step: Landis, C. R.; Halpern, J. Asymmetric Hydrogenation of Methyl-(Z)- $\alpha$-acetamidocinnamate Catalyzed by $\{1,2-B i s(($ phenylo-anisoyl)phosphino)ethane\}rhodium(I): Kinetics, Mechanism, and Origin of Enantioselection. J. Am. Chem. Soc. 1987, 109, 1746-1754.

(19) Using the equilibrium constants from ref. 13a we simplify our analysis by comparing the relative stabilities of the nickel alkene complexes with respect to the (hypothetical) reference compound of $\mathrm{Ni}\left(\mathrm{P}(\mathrm{O}-\mathrm{o} \text {-tolyl })_{3}\right)_{3}$.

(20) ESCA Ni ${ }^{2} \mathrm{P}_{3 / 2}$ binding energies for (alkene $) \mathrm{Ni}\left(\mathrm{P}(\mathrm{O}-\mathrm{o} \text {-tolyl })_{3}\right)_{2}$ correlate with their formation constants $\mathrm{K}$ from ref. 13a. Also, homoleptic phosphine/phosphite complexes of nickel(o) have lower $\mathrm{Ni}^{2} \mathrm{P}_{3 / 2}$ binding energies than their monoalkene counterparts. For ESCA data, see: Tolman, C. A.; Riggs, W. M.; Linn, W. J.; King, C. M.; Wendt, R. C. Electron Spectroscopy for Chemical Analysis of Nickel Compounds. Inorg. Chem. 1973, 12, 2770-2778.

(21) All bisphosphine ligands employed gave $\leq 12 \%$ yield for the cyclopropanation of COE $\left(23 \%\right.$ with $\left.\left(\mathrm{Ph}_{3} \mathrm{P}\right)_{2} \mathrm{NiBr}_{2}\right)$, see ref. 4 . Tolman has shown that coordination of (mono)phosphines to $\mathrm{Ni}(\mathrm{o})$ is largely dominated by sterics and smaller cone angles result in more stable

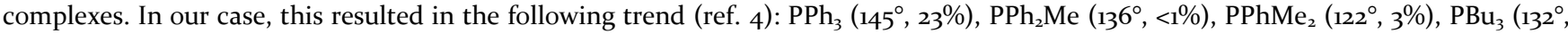
11\%). (a) Tolman, C. A. Phosphorus Ligand Exchange Equilibria on Zerovalent Nickel. A Dominant Role for Steric Effects. J. Am. Chem. Soc. 1970, 92, 2956-2965. (b) Tolman, C. A.; Reutter, D. W.; Seidel, W. C. A Calorimetric study of steric effects in the reactions of phosphorus ligands with $\mathrm{Ni}(\mathrm{COD})_{2}$. J. Organomet. Chem. 1976, 117, $\mathrm{C}_{30}-\mathrm{C}_{33}$.

(22) Wu, K.; Doyle, A. G. Parametrization of phosphine ligands demonstrates enhancement of nickel catalysis via remote steric effects. Nat. Chem. 2017, 9, 779-784.

(23) For two recent example for the parametrization of phosphine ligands in catalysis, see (a) ref. 22. (b) Zhao, S.; Gensch, T.; Murray, B.; Niemeyer, Z. L.; Sigman, M. S.; Biscoe, M. R. Enantiodivergent Pd-catalyzed C-C bond formation enabled through ligand parametrization. Science 2018, 362, 670-674.

(24) (a) Falivene, L.; Credendino, R.; Poater, A.; Petta, A.; Serra, L.; Oliva, R.; Scarano, V.; Cavallo, L. SambVca 2. A Web Tool for Analyzing Catalytic Pockets with Topographic Steric Maps. Organometallics 2016, 35, 2286-2293. (b) Bilbrey, J. A.; Kazez, A. H.; Locklin, J.; Allen, W. D. Exact Ligand Solid Angles. J. Comput. Chem. 2013, 34, 1189-1197. 


\title{
Supporting Information:
}

\section{Mechanistic Studies on the Nickel-Catalyzed Cyclopropanation with Lithiomethyltrimethylammonium Triflate}

\author{
Stefan A. Künzi, Renana Gershoni-Poranne, Peter Chen* \\ Laboratorium für Organische Chemie, ETH Zürich, Zürich, Switzerland \\ peter.chen@org.chem.ethz.ch
}

1. General methods 3

2. In Situ and Preformation of Lithiomethyltrimethylammonium Triflate for Kinetic Measurements ........ 3

3. Kinetic Measurements of Norbornene Cyclopropanation with $\left(\mathrm{Ph}_{3} \mathrm{P}\right)_{2} \mathrm{NiBr}_{2}-$ Method A (Direct Deprotonation)

4. Kinetic Measurements of Norbornene Cyclopropanation with $\left(\mathrm{Ph}_{3} \mathrm{P}\right)_{2} \mathrm{NiBr}_{2}-$ Method $\mathrm{B}$ (Preformed Ylide) 5

5. Determination of Secondary KIE with $\left[\mathrm{N}\left(\mathrm{CD}_{3}\right)_{4}\right] \mathrm{OTf}$ - Method A ..................................................... 7

6. Kinetic Measurements of Norbornene Cyclopropanation with $\left(\mathrm{Ph}_{3} \mathrm{P}\right)_{2} \mathrm{NiBr}_{2}-$ Order in NBE ................ 8

7. Kinetic Measurements of Norbornene Cyclopropanation with $\mathrm{Ni}(\mathrm{acac})_{2} / \mathrm{PPh}_{3}-$ Order in $\mathrm{PPh}_{3} \ldots \ldots \ldots \ldots . . .9$

8. Kinetic Measurements of Norbornene Cyclopropanation with $\left(\mathrm{Ph}_{3} \mathrm{P}\right)_{2} \mathrm{NiBr}_{2}-$ Method $\mathrm{B}$ (Preformed Ylide) - Order in Ylide

9. Kinetic Measurements of Ylide decomposition / Homocoupling with $\mathrm{Ni}\left(\mathrm{PPh}_{3}\right)_{4}$ in the Absence of Alkene

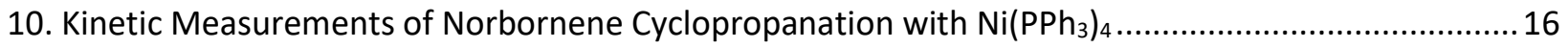

11. Influence of Catalyst Loading on the Cyclopropanation of Different Alkenes....................................17

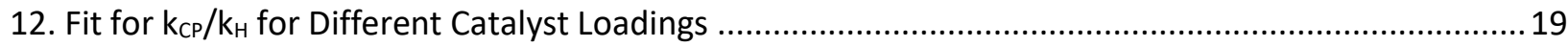

13. Method of Continuous Variation - Alkene Competition .............................................................. 19

14. Kinetic Measurements of Cyclopropanation with Norbornene and Cyclooctene - Competition Experiment.

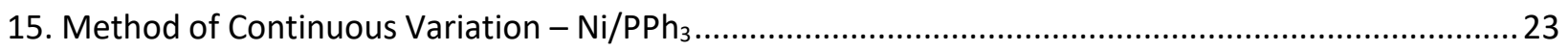

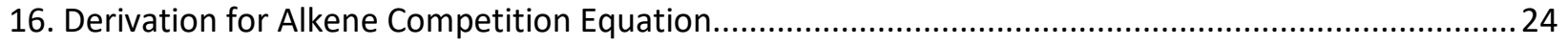

17. Derivation for Alkene-Ligand Competition Equation ...................................................................... 25

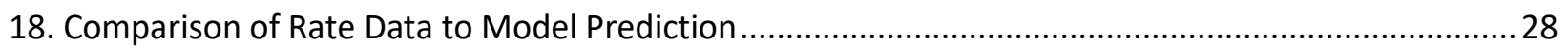




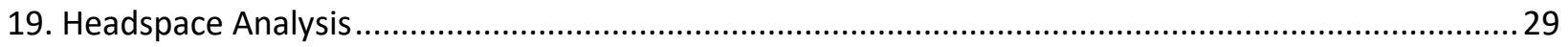

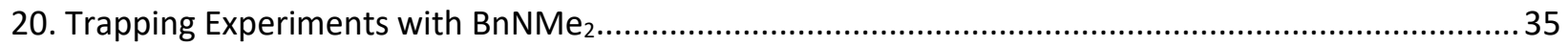

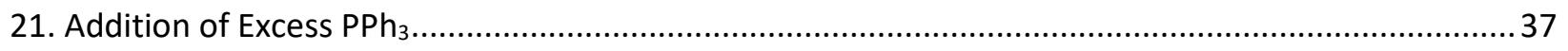

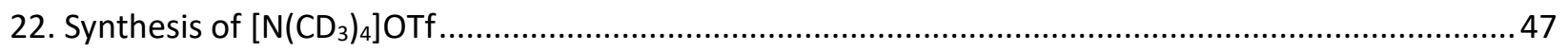

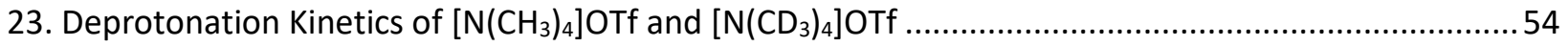

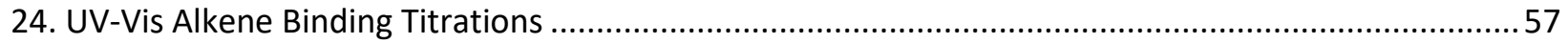

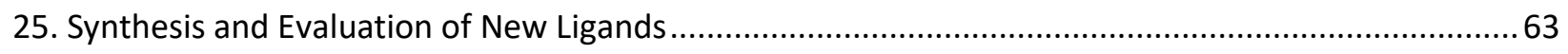

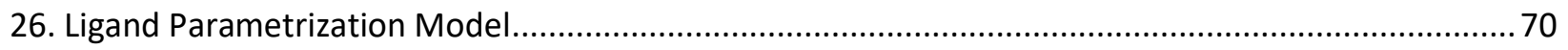

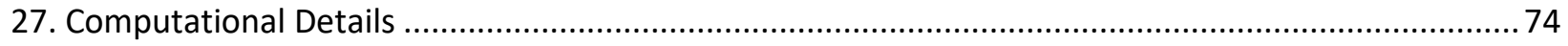

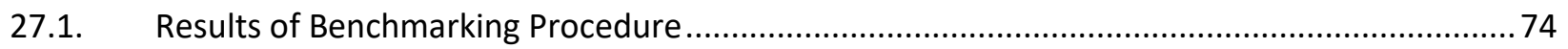

27.2. Energies of Structures for Ni-Phosphine-Alkene Cycle (NiPA) and KIEs .................................75

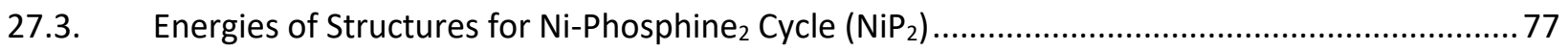

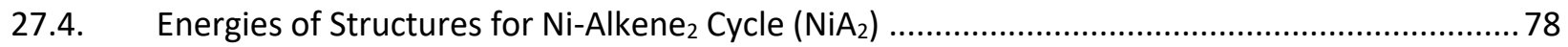

27.5. Observations regarding the Reductive Elimination Transition State........................................ 79

27.6. Optimization of Model Compounds and Parameter Calculation for Ligands ........................... 80

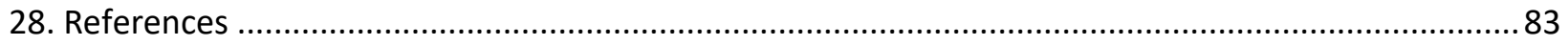




\section{General methods}

Note: All flasks and glass-coated stir bars (self-made or commercially available) used for cyclopropanation reactions were cleaned consecutively in a $\mathrm{KOH} / \mathrm{PrOH}$ base bath, aqua regia and dried overnight in an oven at $150^{\circ} \mathrm{C}$. As noted previously, the lithiomethyl trimethylammonium reagent is prone to decomposition even when low concentrations of undesired trace metals are present in the reaction mixture. ${ }^{1,2}$ Additionally, all cyclopropanation reactions were conducted in a closed Schlenk flask to allow no gas exchange, unless noted otherwise.

All reactions were conducted in a glove box with $\mathrm{N}_{2}$-atmosphere or using standard Schlenk techniques under Ar if not noted otherwise.

Concentration of solutions was conducted using a rotary evaporator at $40{ }^{\circ} \mathrm{C} .{ }^{1} \mathrm{H},{ }^{13} \mathrm{C},{ }^{31} \mathrm{P}$ and ${ }^{19} \mathrm{~F}$ NMR spectra were recorded at 300 or $400 \mathrm{MHz}$ (Bruker AV300 or AVIII400 spectrometers).

Chemical shifts were determined relative to the residual solvent peaks. The following abbreviations are used to indicate signal multiplicity: s, singlet; d, doublet; t, triplet; q, quartet; m, multiplet. GC-FID analysis was performed on a Finnigan Focus CG with a Zebron ZB-5MS, 30m*0.25 mm column. Headspace analysis was performed on a Thermo Scientific Trace1300 GC/ISQ Single Quad MS with a Phenomenex Zebron ZB-1MS $(60 \mathrm{~m})$ column using a isothermal temperature program at $40{ }^{\circ} \mathrm{C}$ by Daniel Zindel (LPC, ETH Zürich). UV-Vis measurements were performed on a Hitachi U-2010 spectrophotometer. Elemental analyses and high resolution mass spectrometry were performed by the Molecular and Biomolecular Analysis Service MoBiAS, ETH Zürich.

Anhydrous THF was distilled from $\mathrm{Na} /$ benzophenone under $\mathrm{N}_{2}$ prior to use.

Dibromobis(triphenylphosphine)nickel(II) (99\%) was purchased from Sigma-Aldrich, stored in the glove box and used as received. $n$-BuLi (2.0 M in cyclohexane) was purchased from Sigma-Aldrich and used as received. Cyclooctene was purchased from Sigma-Aldrich (95\%) or TCI (>95\%), distilled from Na under Ar and degassed by freeze-pump-thaw cycles prior to use. Cyclohexene was purchased from Sigma-Aldrich ( $\geq 99 \%)$, distilled from Na under Ar and degassed by freezepump-thaw cycles prior to use. Norbornene (99\%) was purchased from Sigma-Aldrich, stored in the glove box and used as received. Cyclooctane was purchased from $\mathrm{TCl}$ and used as received. $n$-Undecane $(\geq 99.8 \%$, analytical standard) was purchased from Fluka and used as received. Tetramethylammonium chloride $(\geq 98 \%)$ was purchased from Sigma-Aldrich, dried under vacuum and stored in the glove box. Tetramethyl- $d_{12}$-ammonium chloride was purchased from Cambridge Isotope Laboratories (98\%) or Sigma-Aldrich (98 atom \% D), dried under vacuum, and used immediately or stored in the glove box. Silver(I) trifluoromethanesulphonate was purchased from ABCR $(99 \%)$ or $\mathrm{TCl}(>98.0 \%)$ and used as received. $\mathrm{PBnPh}_{2}(99 \%)$ was purchased from Strem, stored in the glove box and used as received.

All other chemicals were purchased from commercial suppliers and used as received.

Authentic products, exo-tricyclo[3.2.1.0 2,4]octane, bicyclo[6.1.0]nonane, bicyclo[4.1.0]heptane, and hexylcyclopropane, were prepared following reported procedures and matched reported data. ${ }^{2,3,4}$

Augustin A. S. W. Tchawou (Chen group) is thanked for the preparation of authentic heptylcyclopropane and its GC calibration curve. ${ }^{5}$

Tetramethylammonium triflate was prepared as reported previously, dried under vacuum and stored in the glove box. ${ }^{1,2}$

All data was analyzed with Microsoft Excel 2016 and/or OriginLab OriginPro 2016 or 2019.

\section{In Situ and Preformation of Lithiomethyltrimethylammonium Triflate for Kinetic Measurements}

Scheme S1. Two Different Methods Employed to Generate the Active Reagent [ $\left.\mathrm{LiCH}_{2} \mathrm{NMe}_{3}\right] \mathrm{OTf}$, either after (A) or before (B) Addition of Catalyst.

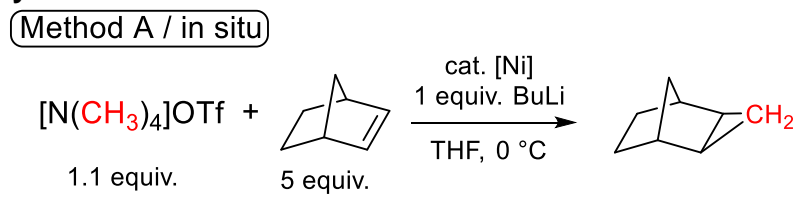

Method B / preformed

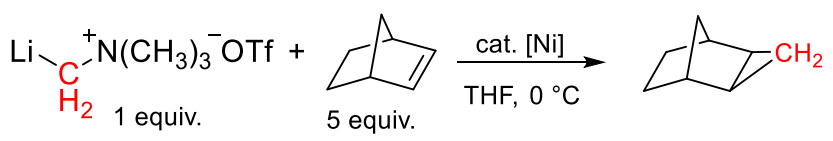


We used two different Methods, $A$ and $B$, that differ in the generation of the ammonium ylide reagent, either in situ (A) or preformed (B).

For method $\mathrm{A}$, [ $\left.\mathrm{NMe}_{4}\right] \mathrm{OTf}$ (1.1 equiv), alkene and catalyst were mixed together, cooled to $0{ }^{\circ} \mathrm{C}$, then BuLi ( 1 equiv) was added to form the ylide in situ. Under these conditions, a small induction phase was observed, most likely due to a non-instantaneous deprotonation of the not fully soluble ammonium salt in THF.

For method B, the ammonium salt was deprotonated first (in the presence or absence of alkene) before the catalyst was added to the preformed ylide to initiate the cyclopropanation/ylide decomposition. In this case, no induction phase was observed.

In general, we had opted to use method $A$ due to the more convenient reaction set up. In cases where we studied the consumption of ylide, method B was used to simplify the kinetics by having the maximum concentration of ylide present upon addition of catalyst.

We have only observed two significant differences between method A and B. For method A, we observe a small induction phase due to the deprotonation as mentioned above. Method B appears to form a smaller amount of active catalyst, likely due to the reduction with the ylide itself instead of BuLi. A more detailed discussion of the tetramethylammonium deprotonation can be found in Section 23.

\section{Kinetic Measurements of Norbornene Cyclopropanation with $\left(\mathrm{Ph}_{3} \mathrm{P}\right)_{2} \mathrm{NiBr}_{2}-\mathrm{Method} \mathrm{A}$ (Direct Deprotonation)}

\section{Scheme S2. Reaction Scheme for the Determination of the Order in Catalyst using Method A.}

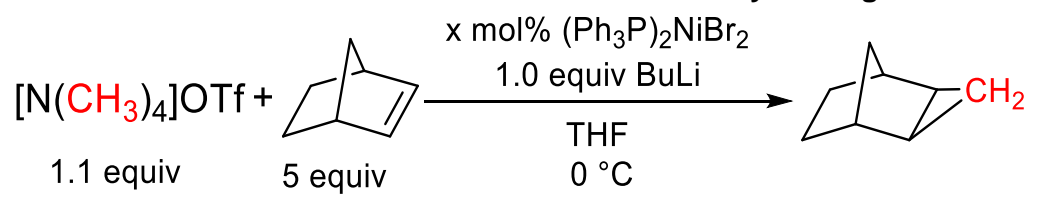

Inside the glove box, an oven-dried $50 \mathrm{~mL}$ Schlenk flask equipped with a J. Young inlet valve, glass stopper, screw cap with septum and a glass-coated stir bar was charged with [NMe ${ }_{4}$ OTf $\left(245.5 \mathrm{mg}, 1.1 \mathrm{mmol}, 1.1\right.$ equiv), $\left(\mathrm{Ph}_{3} \mathrm{P}\right)_{2} \mathrm{NiBr}_{2}$ in $\mathrm{THF}$ (prepared as stock solution, added dropwise by difference with a $2.5 \mathrm{~mL}$ gastight Hamilton syringe (previously dried at $50{ }^{\circ} \mathrm{C}$ in a vacuum oven)) and norbornene (471 $\mathrm{mg}, 5.0 \mathrm{mmol}, 5$ equiv). The flask was removed from the glove box and attached to a Schlenk line. Dry THF ( $x \mathrm{~mL}+$ (catalyst in THF) $\mathrm{mL}=19.5 \mathrm{~mL}$ THF) was added via syringe. Undecane $(50 \mu \mathrm{L})$ was added via a $50 \mu \mathrm{L}$ micro syringe as internal standard. The flask was immersed in an ice bath and the reaction allowed to equilibrate (over ca. $20 \mathrm{~min}$ ).

Then, an aliquot (ca. $0.2 \mathrm{~mL}$ ) was taken with a disposable $1 \mathrm{~mL}$ plastic syringe (flushed several times with Ar) and immediately quenched by injection into $2 \mathrm{~mL} \mathrm{H} \mathrm{H}_{2} / 2 \mathrm{~mL}$ pentane ( $\left.\mathrm{t}=0 \mathrm{~min}\right)$.

BuLi (500 $\mu \mathrm{L}, 1 \mathrm{mmol}, 1$ equiv; $2 \mathrm{M}$ in cyclohexane) was added dropwise over ca. $30 \mathrm{~s}$ via a $1 \mathrm{~mL}$ gastight Hamilton syringe (by difference; previously dried at $50^{\circ} \mathrm{C}$ in a vacuum oven) ( $\mathrm{t}=0$ min with first drop).

After the addition was completed, the flask was sealed/closed to the Schlenk line again and only opened when an aliquot was taken.

After vigorous mixing of the aliquot with a vortex mixer, the organic phase was filtered through a plug of $\mathrm{MgSO}_{4}$ and analyzed by GC-FID. The yield was determined by the integral ratio of the product versus undecane as internal standard using a previously determined calibration curve. 


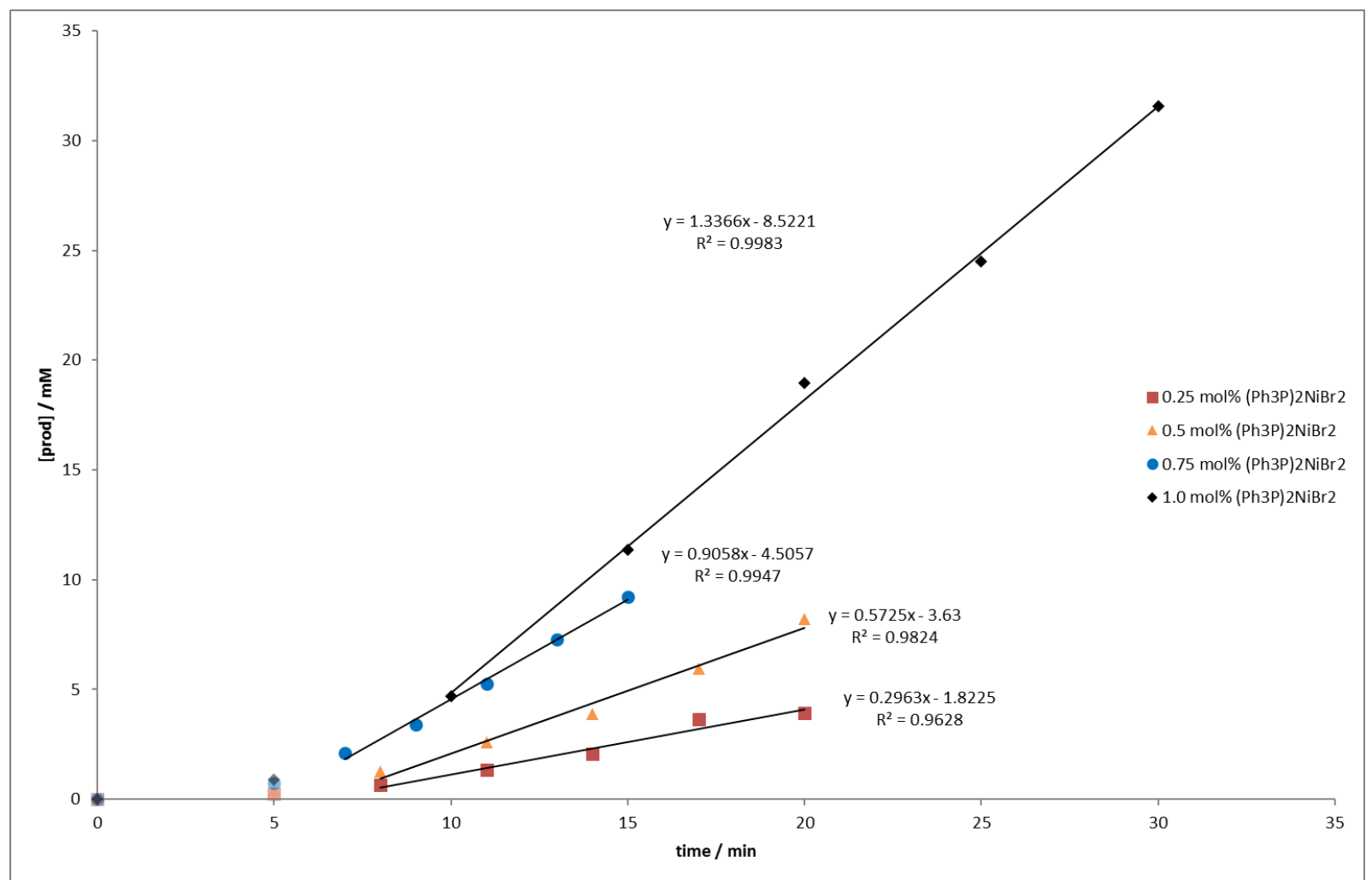

Figure S1. Plot of time versus product concentration for four different catalyst concentrations of $\left(\mathrm{Ph}_{3} \mathrm{P}\right)_{2} \mathrm{NiBr}_{2}$. The black lines depict an initial rate fit with omission of the first few data points of the induction phase (lightly shaded) to obtain $\mathrm{k}_{\mathrm{obs}}$.

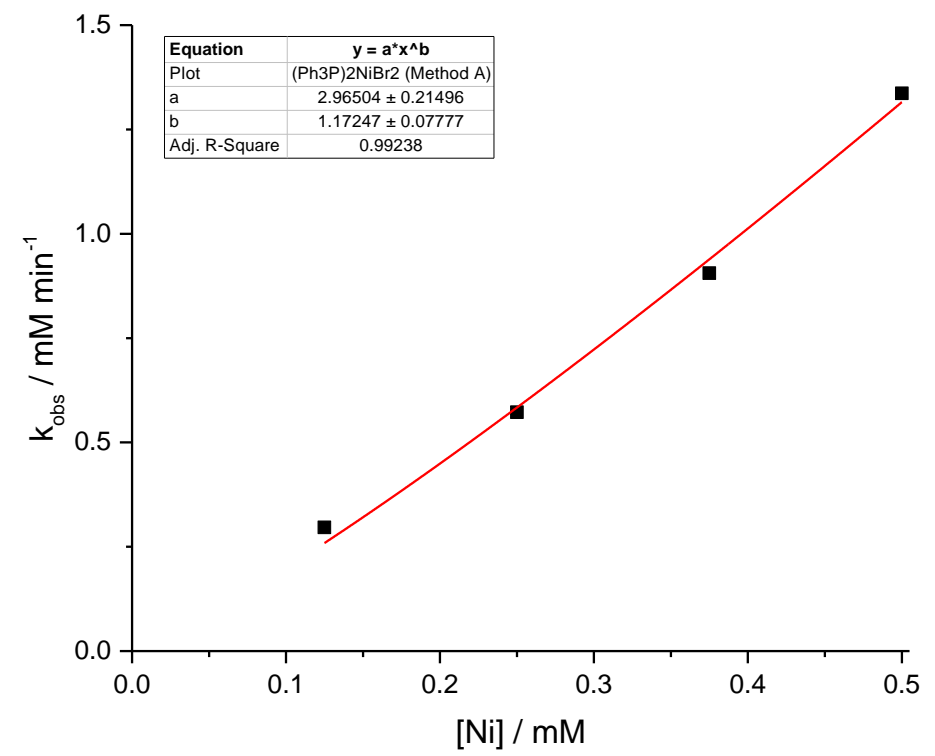

Figure S2. Plot of the catalyst concentration [Ni] of $\left(\mathrm{Ph}_{3} \mathrm{P}\right)_{2} \mathrm{NiBr}_{2}$ versus $\mathrm{k}_{\mathrm{obs}}$ for product formation with in situ deprotonation (Method A). The red curve depicts a fit to the function $y=a x^{b}$ to establish the order in $[\mathrm{Ni}], b=1.17 \pm 0.08$.

\section{Kinetic Measurements of Norbornene Cyclopropanation with $\left(\mathrm{Ph}_{3} \mathrm{P}\right)_{2} \mathrm{NiBr}_{2}-$ Method B (Preformed Ylide)}

Scheme S3. Reaction Scheme for the Determination of the Order in Catalyst using Method B. 


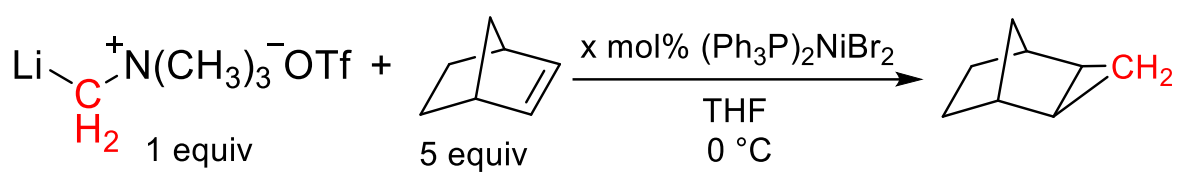

Inside the glove box, an oven-dried $50 \mathrm{~mL}$ Schlenk flask equipped with a J. Young inlet valve, glass stopper, screw cap with septum and a glass-coated stir bar was charged with [NMe ${ }_{4}$ OTf $(245.5 \mathrm{mg}, 1.1 \mathrm{mmol}, 1.1$ equiv) and norbornene (471 mg, $5.0 \mathrm{mmol}, 5$ equiv). The flask was removed from the glove box and attached to a Schlenk line. Dry THF (x mL + (catalyst in THF) $\mathrm{mL}=19.5 \mathrm{~mL}$ THF) was added via syringe. Undecane $(50 \mu \mathrm{L})$ was added via a $50 \mu \mathrm{L}$ micro syringe as internal standard. The flask was immersed in an ice bath and the reaction allowed to equilibrate (over ca. $20 \mathrm{~min}$ ).

BuLi (500 $\mu \mathrm{L}, 1 \mathrm{mmol}, 1$ equiv; $2 \mathrm{M}$ in cyclohexane) was added dropwise over ca. $30 \mathrm{~s}$ via a $1 \mathrm{~mL}$ gastight Hamilton syringe (by difference; previously dried at $50^{\circ} \mathrm{C}$ in a vacuum oven). The flask was sealed/closed to the Schlenk line unless reagents were added or aliquots collected.

After $15 \mathrm{~min}$, an aliquot (ca. $0.2 \mathrm{~mL}$ ) was taken with a disposable $1 \mathrm{~mL}$ plastic syringe (flushed several times with Ar) and immediately quenched by injection into $2 \mathrm{~mL} \mathrm{H} \mathrm{H}_{2} / 2 \mathrm{~mL}$ pentane ( $\left.\mathrm{t}=0 \mathrm{~min}\right)$.

Then, $\left(\mathrm{Ph}_{3} \mathrm{P}\right)_{2} \mathrm{NiBr}_{2}(\mathrm{x}$ mol\%) in THF (prepared as stock solution inside the glove box) was added dropwise by difference with a $2.5 \mathrm{~mL}$ gastight Hamilton syringe (previously dried at $50^{\circ} \mathrm{C}$ in a vacuum oven) over ca. $30 \mathrm{~s} \mathrm{(} \mathrm{t}=0$ min with first drop). After the addition was completed, the flask was sealed/closed to the Schlenk line again and only opened when an aliquot was taken.

After vigorous mixing of the aliquot with a vortex mixer, the organic phase was filtered through a plug of $\mathrm{MgSO}_{4}$ and analyzed by GC-FID. The yield was determined by the integral ratio of the product versus undecane as internal standard using a previously determined calibration curve.

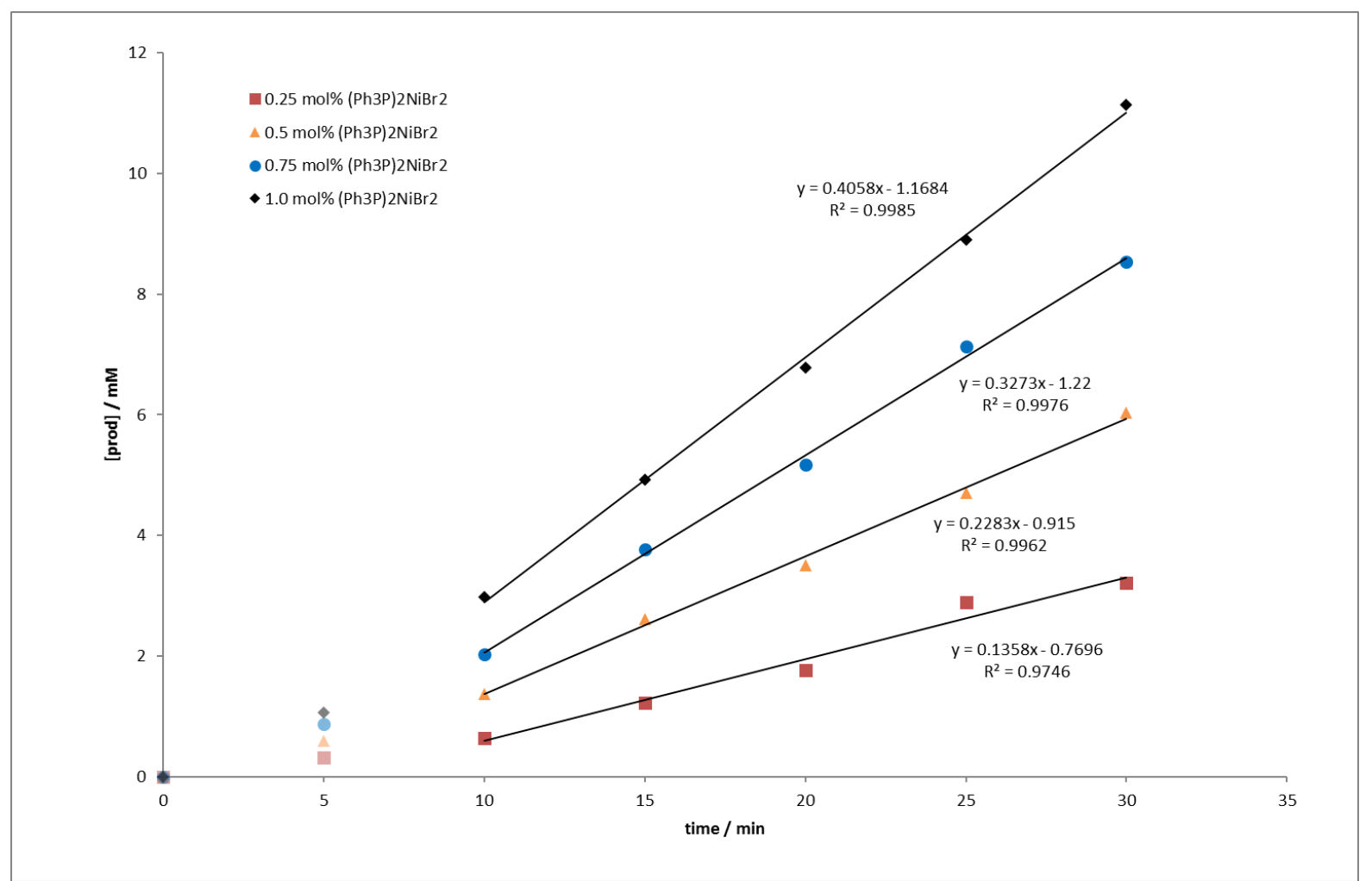

Figure S3. Plot of time versus product concentration for four different catalyst concentrations of $\left(\mathrm{Ph}_{3} \mathrm{P}\right)_{2} \mathrm{NiBr}_{2}$. The black lines depict an initial rate fit with omission of the first few data points of the induction phase (lightly shaded) to obtain $\mathrm{k}_{\mathrm{obs}}$. 


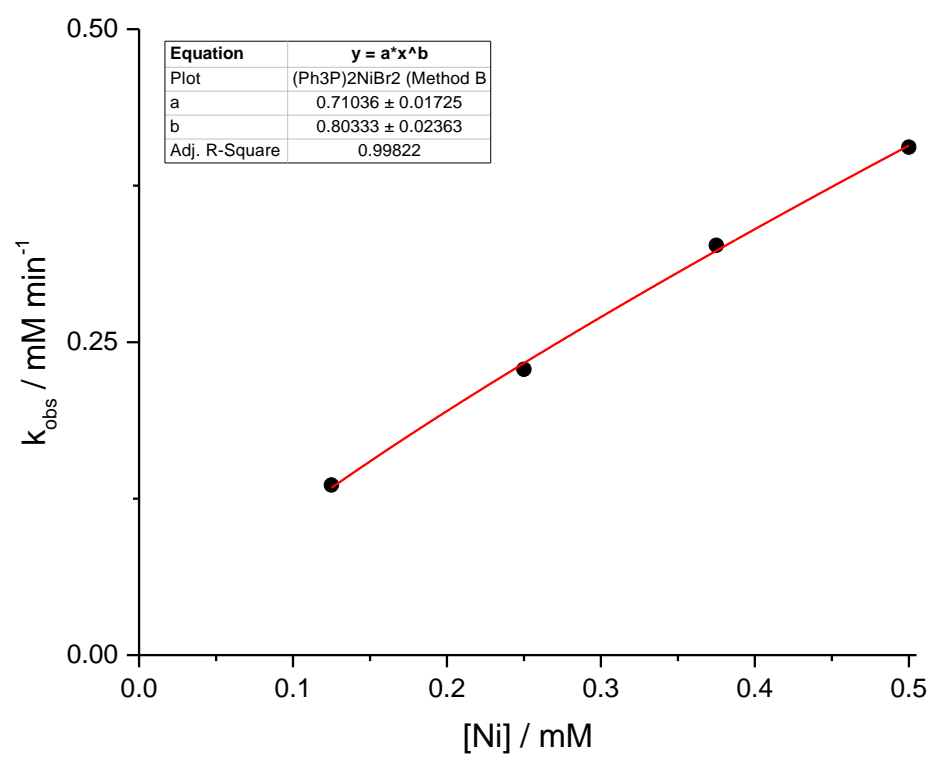

Figure S4. Plot of the catalyst concentration [Ni] of $\left(\mathrm{Ph}_{3} \mathrm{P}\right)_{2} \mathrm{NiBr}_{2}$ versus $\mathrm{k}_{\text {obs }}$ for product formation using the preformed ylide (Method B). The red curve depicts a fit to the function $y=a x^{b}$ to establish the order in $[\mathrm{Ni}], b=0.80 \pm 0.02$.

\section{Determination of Secondary KIE with $\left[\mathrm{N}\left(\mathrm{CD}_{3}\right)_{4}\right] \mathrm{OTf}$ - Method A}

Scheme S4. Reaction Scheme for the Determination of a Secondary KIE Using $\left[\mathrm{N}\left(\mathrm{CD}_{3}\right)_{4}\right] \mathrm{OTf}$.

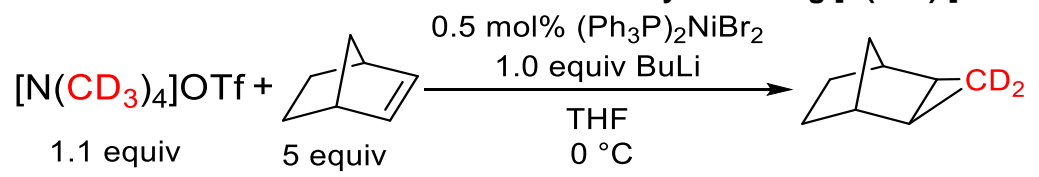

Inside the glove box, an oven-dried $50 \mathrm{~mL}$ Schlenk flask equipped with a J. Young inlet valve, glass stopper, screw cap with septum and a glass-coated stir bar was charged with [N(CD $\left.)_{4}\right] \mathrm{OTf}\left(258.8 \mathrm{mg}, 1.1 \mathrm{mmol}, 1.1\right.$ equiv), $\left(\mathrm{Ph}_{3} \mathrm{P}\right)_{2} \mathrm{NiBr}_{2}$ in $\mathrm{THF}_{(0.5}$ mol\%, prepared as stock solution, added dropwise by difference with a $2.5 \mathrm{~mL}$ gastight Hamilton syringe (previously dried at $50{ }^{\circ} \mathrm{C}$ in a vacuum oven)) and norbornene (471 mg, $5.0 \mathrm{mmol}, 5$ equiv). The flask was removed from the glove box and attached to a Schlenk line. Dry THF (x mL + (catalyst in THF) $\mathrm{mL}=19.5 \mathrm{~mL}$ THF) was added via syringe. Undecane $(50 \mu \mathrm{L})$ was added via a $50 \mu \mathrm{L}$ micro syringe as internal standard. The flask was immersed in an ice bath and the reaction allowed to equilibrate (over ca. $20 \mathrm{~min}$ ).

Then, an aliquot (ca. $0.2 \mathrm{~mL}$ ) was taken with a disposable $1 \mathrm{~mL}$ plastic syringe (flushed several times with Ar) and immediately quenched by injection into $2 \mathrm{~mL} \mathrm{H}_{2} \mathrm{O} / 2 \mathrm{~mL}$ pentane $(\mathrm{t}=0 \mathrm{~min})$.

BuLi (500 $\mu \mathrm{L}, 1 \mathrm{mmol}, 1$ equiv; $2 \mathrm{M}$ in cyclohexane) was added dropwise over ca. $30 \mathrm{~s}$ via a $1 \mathrm{~mL}$ gastight Hamilton syringe (by difference; previously dried at $50^{\circ} \mathrm{C}$ in a vacuum oven) ( $\mathrm{t}=0$ min with first drop).

After the addition was completed, the flask was sealed/closed to the Schlenk line again and only opened when an aliquot was taken.

After vigorous mixing of the aliquot with a vortex mixer, the organic phase was filtered through a plug of $\mathrm{MgSO}_{4}$ and analyzed by GC-FID. The yield was determined by the integral ratio of the product versus undecane as internal standard using a previously determined calibration curve. The same response factor for the product- $d_{2}$ was assumed. 


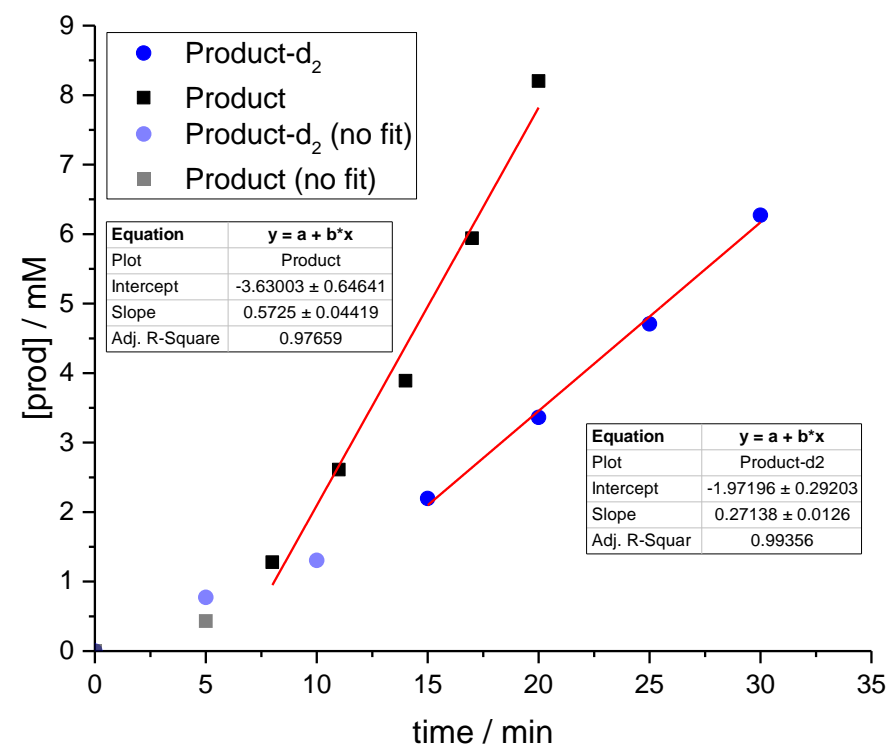

Figure S5. Plot of time versus product concentration using tetramethylammonium triflate or tetramethylammonium- $d_{12}$ triflate to probe a possible secondary KIE. The red lines depict an initial rate fit with omission of the first few data points of the induction phase (lightly shaded) to obtain $\mathrm{k}_{\mathrm{obs}}$, i. e. $\mathrm{k}_{\mathrm{H}}$ and $\mathrm{k}_{\mathrm{D}}$, for the protiated and deuterated tetramethylammonium reagent, respectively.

Table S1. Determination of the Secondary KIE using Tetramethylammonium-d12 Triflate.

\begin{tabular}{ccc}
$\mathbf{k}_{\mathbf{H}} / \mathbf{m M} \mathbf{m i n}^{-1}$ & $\mathbf{k}_{\mathbf{D}} / \mathbf{~ m M ~ m i n}^{-1}$ & $\mathbf{k}_{\mathbf{H}} / \mathbf{k}_{\mathbf{D}}$ \\
\hline$(0.57 \pm 0.04)$ & $(0.27 \pm 0.01)$ & $(2.1 \pm 0.3)$ \\
\hline
\end{tabular}

\section{Kinetic Measurements of Norbornene Cyclopropanation with $\left(\mathrm{Ph}_{3} \mathrm{P}\right)_{2} \mathrm{NiBr}_{2}-$ Order in $\mathrm{NBE}$}

Scheme S5. Reaction Scheme for the Determination of the Order in Norbornene.

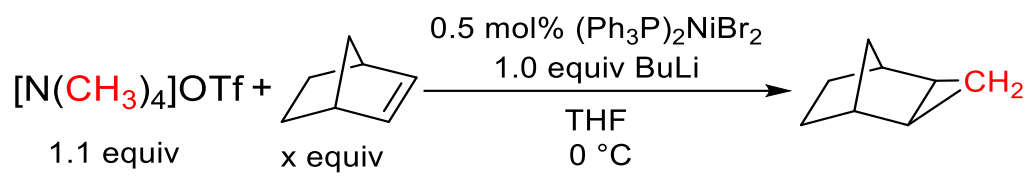

Inside the glove box, an oven-dried $50 \mathrm{~mL}$ Schlenk flask equipped with a J. Young inlet valve, glass stopper, screw cap with septum and a glass-coated stir bar was charged with [NMe ${ }_{4}$ ] Tff (245.5 mg, 1.1 mmol, 1.1 equiv), $\left(\mathrm{Ph}_{3} \mathrm{P}\right)_{2} \mathrm{NiBr}_{2}$ in THF $(0.5$ mol\%, prepared as stock solution, added by difference with a $2.5 \mathrm{~mL}$ gastight Hamilton syringe (previously dried at $50{ }^{\circ} \mathrm{C}$ in a vacuum oven)) and norbornene (x equiv). The flask was removed from the glove box and attached to a Schlenk line. Dry THF $(x \mathrm{~mL}+$ (catalyst in THF) $\mathrm{mL}=19.5 \mathrm{~mL}$ THF) was added via syringe. Undecane $(50 \mu \mathrm{L})$ was added via a $50 \mu \mathrm{L}$ micro syringe as internal standard. The flask was immersed in an ice bath and the reaction allowed to equilibrate (over ca. $20 \mathrm{~min}$ ).

Then, an aliquot (ca. $0.2 \mathrm{~mL}$ ) was taken with a disposable $1 \mathrm{~mL}$ plastic syringe (flushed several times with Ar) and immediately quenched by injection into $2 \mathrm{~mL} \mathrm{H} \mathrm{H}_{2} \mathrm{O} 2 \mathrm{~mL}$ pentane ( $\mathrm{t}=0 \mathrm{~min}$ ).

BuLi (500 $\mu \mathrm{L}, 1 \mathrm{mmol}, 1$ equiv; $2 \mathrm{M}$ in cyclohexane) was added dropwise over ca. $30 \mathrm{~s}$ via a $1 \mathrm{~mL}$ gastight Hamilton syringe (by difference; previously dried at $50^{\circ} \mathrm{C}$ in a vacuum oven) ( $\mathrm{t}=0$ min with first drop).

After the addition was completed, the flask was sealed/closed to the Schlenk line again and only opened when an aliquot was taken.

After vigorous mixing of the aliquot with a vortex mixer, the organic phase was filtered through a plug of $\mathrm{MgSO}_{4}$ and analyzed by GC-FID. The yield was determined by the integral ratio of the product versus undecane as internal standard using a previously determined calibration curve. 


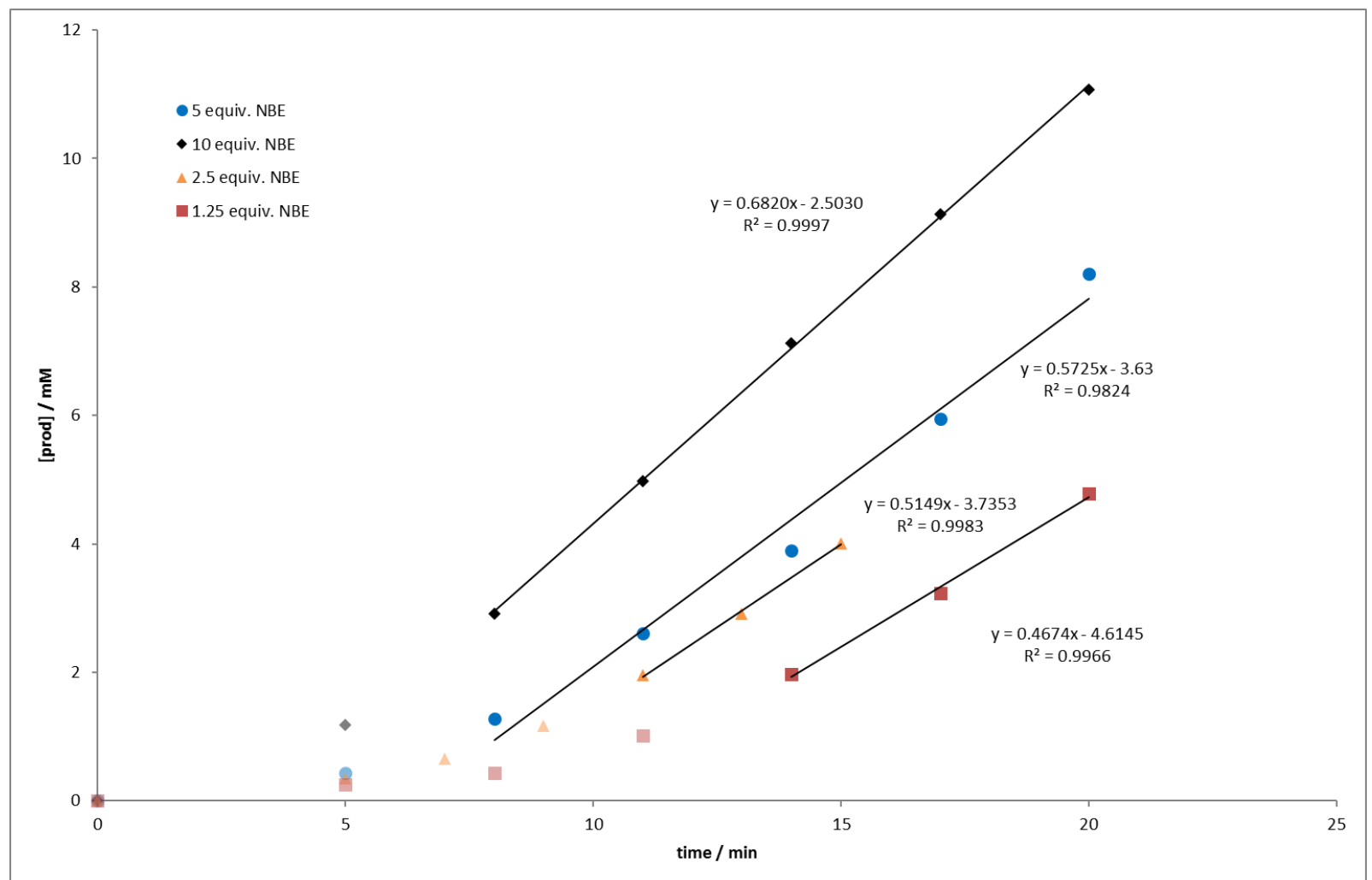

Figure S6. Plot of time versus product concentration for four different norbornene (NBE) concentrations. The black lines depict an initial rate fit with omission of the first few data points of the induction phase (lightly shaded) to obtain $\mathrm{k}_{\mathrm{obs}}$.

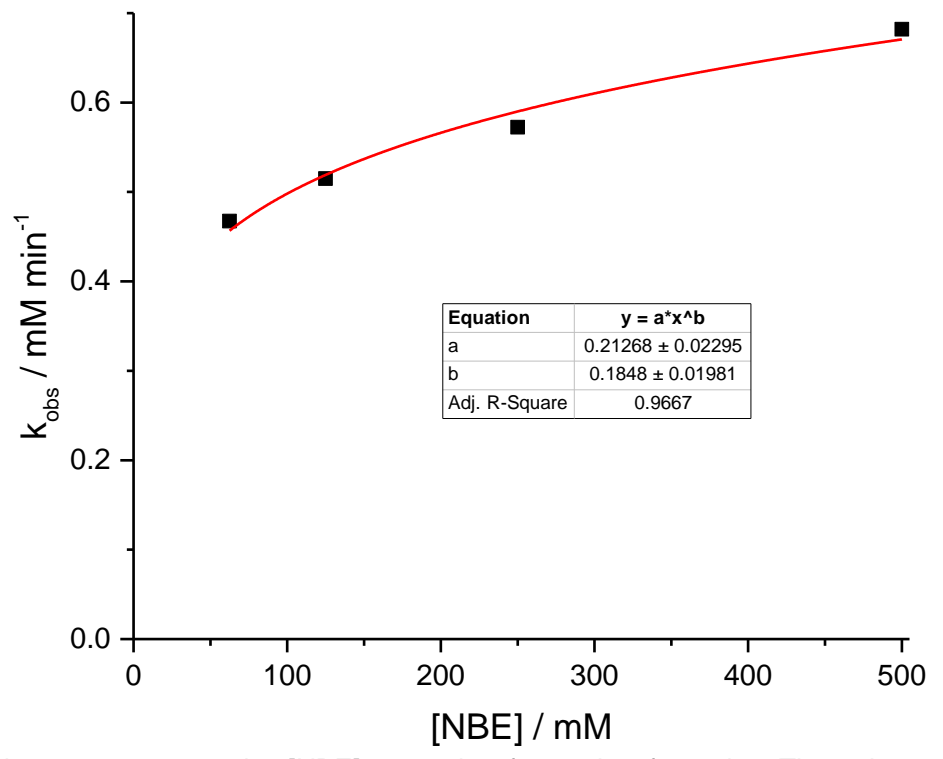

Figure S7. Plot of the norbornene concentration [NBE] versus $\mathrm{k}_{\mathrm{obs}}$ for product formation. The red curve depicts a fit to the function $y=a x^{b}$ to establish the order in [NBE], $b=0.18 \pm 0.02$.

\section{Kinetic Measurements of Norbornene Cyclopropanation with $\mathrm{Ni}(\mathrm{acac})_{2} / \mathrm{PPh}_{3}-$ Order in $\mathrm{PPh}_{3}$}

Scheme S6. Reaction Scheme for the Determination of the Order in $\mathrm{PPh}_{3}$. 


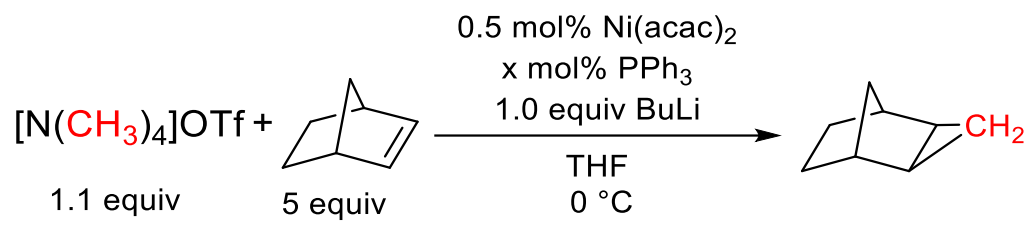

Inside the glove box, an oven-dried $50 \mathrm{~mL}$ Schlenk flask equipped with a J. Young inlet valve, glass stopper, screw cap with septum and a glass-coated stir bar was charged with [NMe $\left.{ }_{4}\right] \mathrm{OTf}(245.5 \mathrm{mg}, 1.1 \mathrm{mmol}, 1.1 \mathrm{equiv}), \mathrm{Ni}(\mathrm{acac})_{2}$ in THF $(0.5 \mathrm{~mol} \%$, prepared as stock solution, added by difference with a $2.5 \mathrm{~mL}$ gastight Hamilton syringe (previously dried at $50^{\circ} \mathrm{C}$ in a vacuum oven)), $\mathrm{PPh}_{3}$ in THF (prepared as stock solution, added by difference with a $2.5 \mathrm{~mL}$ gastight Hamilton syringe (previously dried at $50{ }^{\circ} \mathrm{C}$ in a vacuum oven)), and norbornene (471 mg, $5.0 \mathrm{mmol}, 5$ equiv). The flask was removed from the glove box and attached to a Schlenk line. Dry THF (x mL + (catalyst in THF) $\mathrm{mL}=19.5 \mathrm{~mL}$ THF) was added via syringe. Undecane $(50 \mu \mathrm{L})$ was added via a $50 \mu \mathrm{L}$ micro syringe as internal standard. The flask was immersed in an ice bath and the reaction allowed to equilibrate (over ca. $20 \mathrm{~min}$ ).

Then, an aliquot (ca. $0.2 \mathrm{~mL}$ ) was taken with a disposable $1 \mathrm{~mL}$ plastic syringe (flushed several times with Ar) and immediately quenched by injection into $2 \mathrm{~mL} \mathrm{H} \mathrm{H}_{2} \mathrm{O} / 2 \mathrm{~mL}$ pentane ( $\mathrm{t}=0 \mathrm{~min}$ ).

BuLi (500 $\mu \mathrm{L}, 1 \mathrm{mmol}, 1$ equiv; $2 \mathrm{M}$ in cyclohexane) was added dropwise over ca. $30 \mathrm{~s}$ via a $1 \mathrm{~mL}$ gastight Hamilton syringe (by difference; previously dried at $50^{\circ} \mathrm{C}$ in a vacuum oven) ( $\mathrm{t}=0 \mathrm{~min}$ with first drop).

After the addition was completed, the flask was sealed/closed to the Schlenk line again and only opened when an aliquot was taken.

After vigorous mixing of the aliquot with a vortex mixer, the organic phase was filtered through a plug of $\mathrm{MgSO}_{4}$ and analyzed by GC-FID. The yield was determined by the integral ratio of the product versus undecane as internal standard using a previously determined calibration curve.

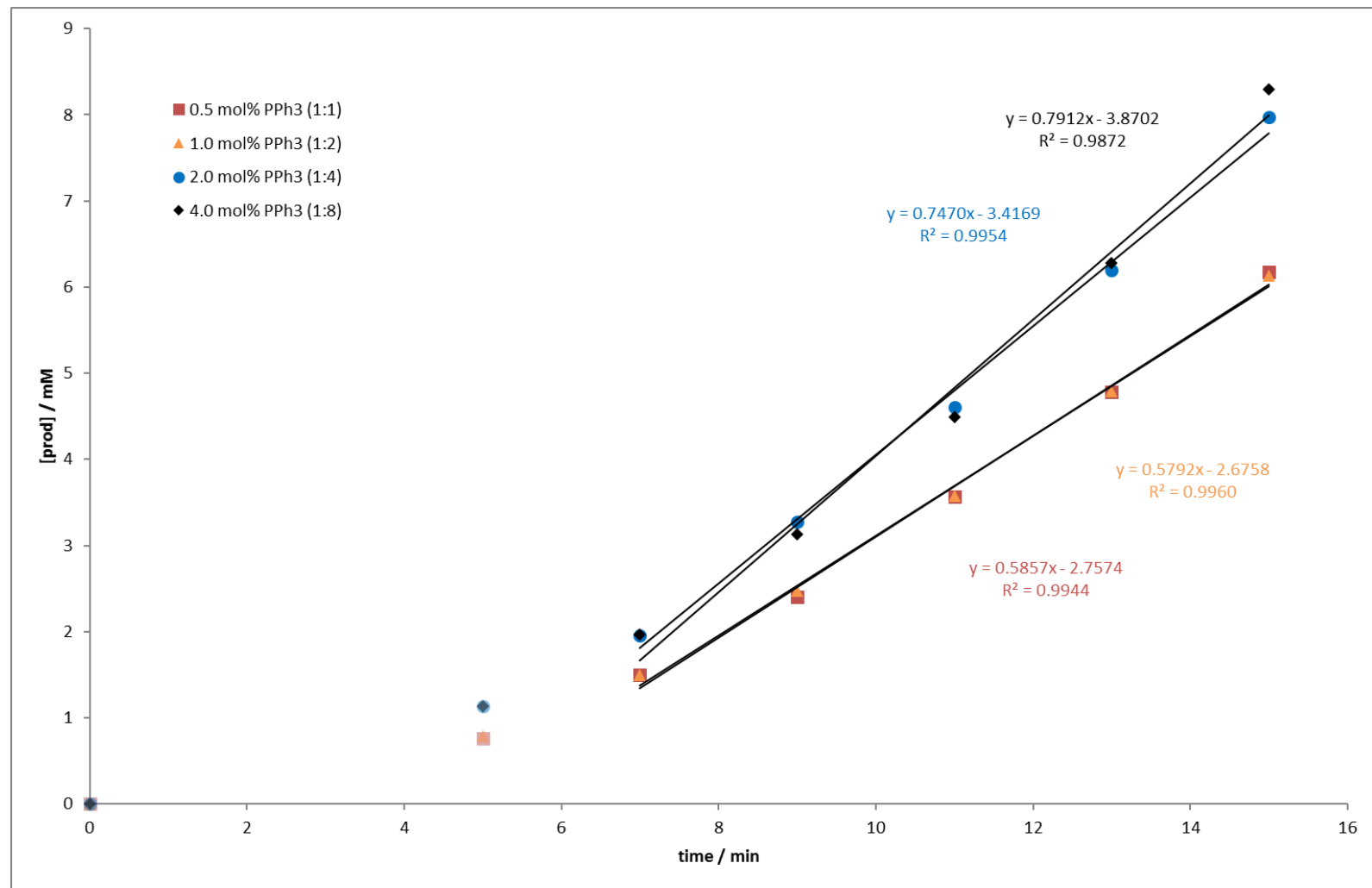

Figure S8. Plot of time versus product concentration for four different triphenylphosphine concentrations with constant nickel concentration. The black lines depict an initial rate fit with omission of the first few data points of the induction phase (lightly shaded) to obtain $\mathrm{k}_{\mathrm{obs}}$. 


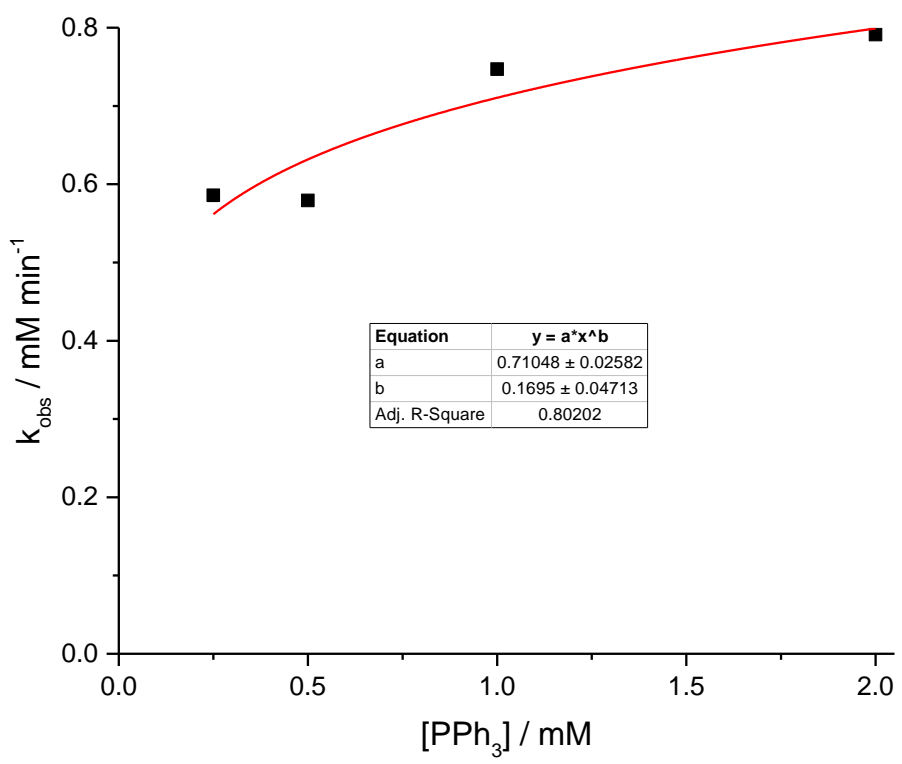

Figure S9. Plot of the triphenylphosphine concentration $\left[\mathrm{PPh}_{3}\right]$ versus $\mathrm{k}_{\mathrm{obs}}$ for product formation. The red curve depicts a fit to the function $y=a x^{b}$ to establish the order in $\left[\mathrm{PPh}_{3}\right], \mathrm{b}=0.17 \pm 0.05$.

\section{Kinetic Measurements of Norbornene Cyclopropanation with $\left(\mathrm{Ph}_{3} \mathrm{P}\right)_{2} \mathrm{NiBr}_{2}$ - Method B (Preformed Ylide) - Order in Ylide}

Scheme S7. Reaction Scheme for the Determination of the Order in Ylide using Method B.

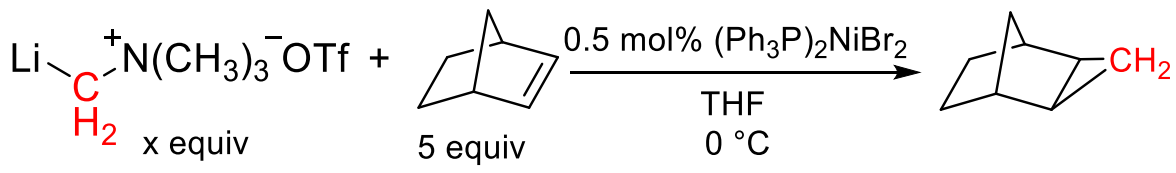

Inside the glove box, an oven-dried $50 \mathrm{~mL}$ Schlenk flask equipped with a J. Young inlet valve, glass stopper, screw cap with septum and a glass-coated stir bar was charged with [NMe 4 OTf $((x+0.1) \mathrm{mmol},(x+0.1)$ equiv) and norbornene $(471 \mathrm{mg}, 5.0$ $\mathrm{mmol}, 5$ equiv). The flask was removed from the glove box and attached to a Schlenk line. Dry THF (x mL + (catalyst in THF) $\mathrm{mL}=19.5 \mathrm{~mL}$ THF) was added via syringe. Undecane $(50 \mu \mathrm{L})$ was added via a $50 \mu \mathrm{L}$ micro syringe as internal standard. The flask was immersed in an ice bath and the reaction allowed to equilibrate (over ca. $20 \mathrm{~min}$ ).

BuLi (x mmol, $x$ equiv; $2 \mathrm{M}$ in cyclohexane) was added dropwise over ca. $30 \mathrm{~s}$ via a $1 \mathrm{~mL}$ gastight Hamilton syringe (by difference; previously dried at $50^{\circ} \mathrm{C}$ in a vacuum oven). The flask was sealed/closed to the Schlenk line unless reagents were added or aliquots collected.

After $15 \mathrm{~min}$, an aliquot (ca. $0.2 \mathrm{~mL}$ ) was taken with a disposable $1 \mathrm{~mL}$ plastic syringe (flushed several times with Ar) and immediately quenched by injection into $2 \mathrm{~mL} \mathrm{H} \mathrm{H}_{2} / 2 \mathrm{~mL}$ pentane ( $\mathrm{t}=0 \mathrm{~min}$ ).

Then, $\left(\mathrm{Ph}_{3} \mathrm{P}\right)_{2} \mathrm{NiBr}_{2}(0.5 \mathrm{~mol} \%)$ in THF (prepared as stock solution inside the glove box) was added dropwise by difference with a $2.5 \mathrm{~mL}$ gastight Hamilton syringe (previously dried at $50{ }^{\circ} \mathrm{C}$ in a vacuum oven) over ca. $30 \mathrm{~s}(\mathrm{t}=0 \mathrm{~min}$ with first drop). After the addition was completed, the flask was sealed/closed to the Schlenk line again and only opened when an aliquot was taken.

After vigorous mixing of the aliquot with a vortex mixer, the organic phase was filtered through a plug of $\mathrm{MgSO}_{4}$ and analyzed by GC-FID. The yield was determined by the integral ratio of the product versus undecane as internal standard using a previously determined calibration curve. 


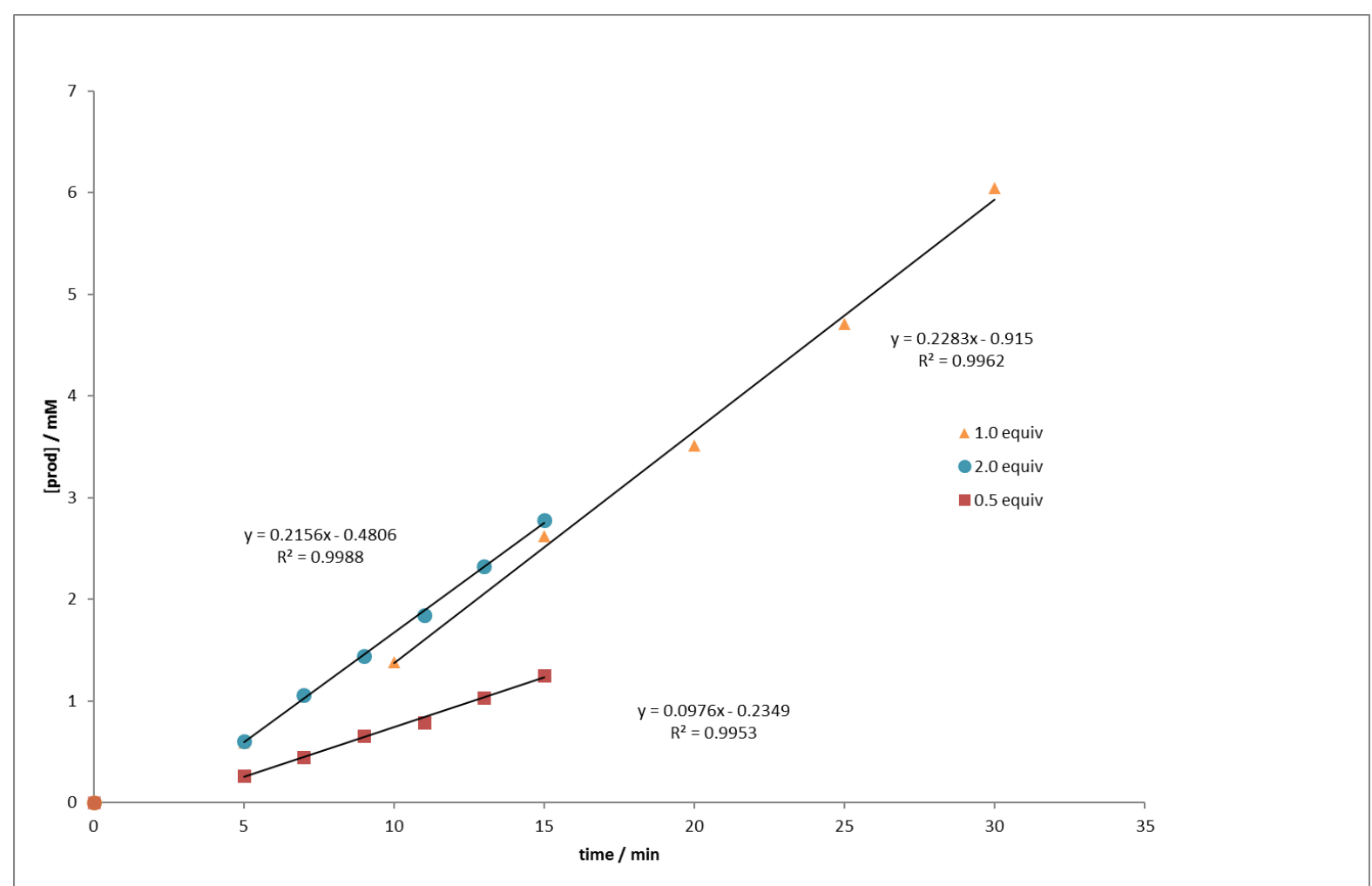

Figure S10. Plot of time versus product concentration for three different ammonium ylide concentrations with $0.5 \mathrm{~mol}$ $\left(\mathrm{Ph}_{3} \mathrm{P}\right)_{2} \mathrm{NiBr}_{2}$. The black lines depict an initial rate fit with omission of the first few data points of the induction phase (lightly shaded) to obtain $\mathrm{k}_{\mathrm{obs}}$.

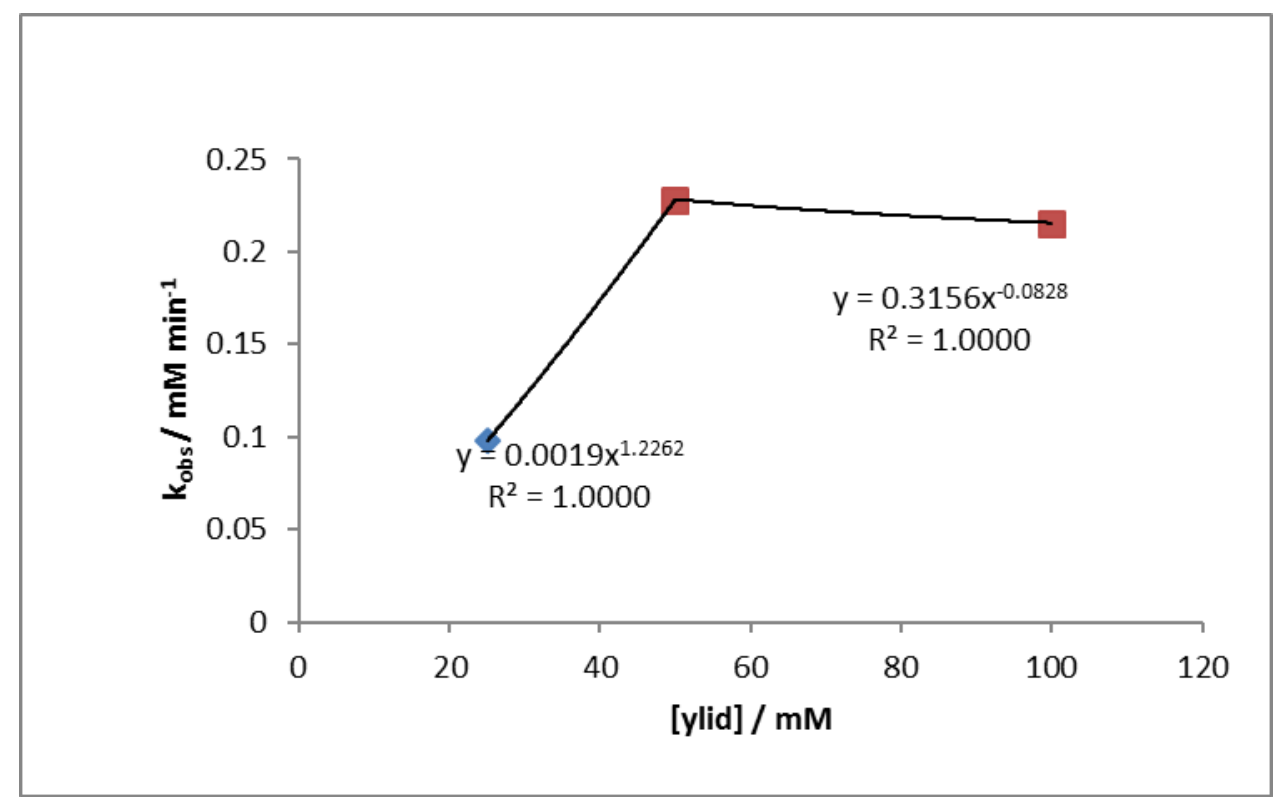

Figure S11. Plot of ylide concentration [ylide] versus $\mathrm{k}_{\mathrm{obs}}$ for product formation. The black curves depict a fit to the function $y=$ $a x^{b}$ to establish the order in [ylide] at high and at low concentration, $b=1.23$ and -0.08 , respectively.

The order in ylide shows a complex behavior. Pörschke et al. have detailed the Lewis acidic nature of $\mathrm{Ni}(0) .{ }^{6}$ The binding of a carbanion to $\mathrm{Ni}(0)$ can be imagined as a push-pull-system, i.e., the binding is determined by the $\sigma$-donor strength of the carbanion and the $(\pi$-)acceptor strength of the ligands on $\mathrm{Ni}(0)$ in a temperature-dependent equilibrium. The qualitative order was given as $\mathrm{LiCH}_{3}>\left[\mathrm{Me}_{3} \mathrm{PCH}_{2}\right]>\left[\mathrm{Ph}_{3} \mathrm{PCH}_{2}\right]>\left[\mathrm{Me}_{2}(\mathrm{O}) \mathrm{SCH}_{2}\right]$ for the carbanion and as $\mathrm{Ni}(\mathrm{CO})_{3}>\mathrm{Ni}\left(\mathrm{C}_{2} \mathrm{H}_{4}\right)_{2}>\mathrm{Ni}(\mathrm{CDT})$ for the $\mathrm{Ni}(0)$ fragment $(\mathrm{CDT}=$ all-trans-1,5,9-Cyclododecatriene) in ref. S6. 
Thus, one can conclude that the nature and concentration of the alkene in solution (or absence thereof) will also affect the additional equilibrium of ylide binding (without changing the turnover-limiting transition state).

One sees this behavior by comparing reaction profiles for the reaction in presence and absence of a substrate. The reaction profile for the consumption of ylide in the absence of substrate displays a well-behaved $1^{\text {st }}$ order decay (Figure S12). This is consistent with a weak acceptor fragment $\mathrm{Ni}(0)\left(\mathrm{PPh}_{3}\right)_{2}$ and the ylide not coordinated in the resting state. In the case of norbornene as substrate, a relatively good $\pi$-acceptor, the reaction profile for product formation displays a much longer initial phase of linearity than one would expect for a simple $1^{\text {st }}$ order dependence on ylide (see, e.g., Figure S17). This is consistent with a concentration dependent switch from $0^{\text {th }}$ to $1^{\text {st }}$ order in ylide at high conversion. Although there is insufficient data in Figure S11, the general behavior shown therein is also consistent with our mechanistic model.

\title{
9. Kinetic Measurements of Ylide decomposition / Homocoupling with $\mathrm{Ni}\left(\mathrm{PPh}_{3}\right)_{4}$ in the Absence of Alkene
}

\author{
Scheme S8. Reaction Scheme for the Determination of the Order in Catalyst in the Absence of Added Alkene.

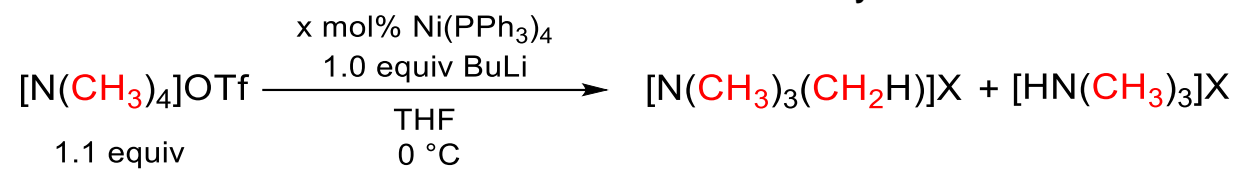

Inside the glove box, an oven-dried $50 \mathrm{~mL}$ Schlenk flask equipped with a J. Young inlet valve, glass stopper, screw cap with septum and a glass-coated stir bar was charged with [NMe $\left.{ }_{4}\right] \mathrm{OTf}(245.5 \mathrm{mg}, 1.1 \mathrm{mmol}, 1.1$ equiv). The flask was removed from the glove box and attached to a Schlenk line. Dry THF ( $\mathrm{x} \mathrm{mL}+$ (catalyst in THF) $\mathrm{mL}=19.5 \mathrm{~mL}$ THF) was added via syringe. Cyclooctane $(100 \mu \mathrm{L})$ was added via a $100 \mu \mathrm{L}$ micro syringe as internal standard. The flask was immersed in an ice bath and the reaction allowed to equilibrate (over ca. $20 \mathrm{~min}$ ).

BuLi (500 $\mu \mathrm{L}, 1 \mathrm{mmol}, 1$ equiv; $2 \mathrm{M}$ in cyclohexane) was added dropwise over ca. $30 \mathrm{~s}$ via a $1 \mathrm{~mL}$ gastight Hamilton syringe (by difference; previously dried at $50^{\circ} \mathrm{C}$ in a vacuum oven). The flask was sealed/closed to the Schlenk line unless reagents were added or aliquots collected.

After $15 \mathrm{~min}$, an aliquot (ca. $0.2 \mathrm{~mL}$ ) was taken with a disposable $1 \mathrm{~mL}$ plastic syringe (flushed several times with Ar) and immediately quenched by injection into $0.2 \mathrm{~mL} 1 \mathrm{M}$ TFA in DCM ( $\mathrm{t}=0 \mathrm{~min})$.

Then, $\mathrm{Ni}\left(\mathrm{PPh}_{3}\right)_{4}(\mathrm{x}$ mol\%) in THF (prepared as stock solution inside the glove box) was added dropwise by difference with a $2.5 \mathrm{~mL}$ gastight Hamilton syringe (previously dried at $50{ }^{\circ} \mathrm{C}$ in a vacuum oven) over ca. $30 \mathrm{~s}$ ( $\mathrm{t}=0$ min with first drop). After the addition was completed, the flask was sealed/closed to the Schlenk line again and only opened when an aliquot was taken.

Aliquots were diluted with $0.3 \mathrm{~mL} \mathrm{CD} \mathrm{CD}_{3} \mathrm{O}$ and analyzed by ${ }^{1} \mathrm{H}$ NMR. Spectra were subsequently analyzed with MestReNova. The integrated 'Full Auto (Bernstein Polynomials)' baseline correction was applied. The spectrum was referenced to the residual solvent peak of $\mathrm{CD}_{3} \mathrm{OD}(\delta=3.31)$. Signals of cyclooctane $(\delta=1.55, \mathrm{~s})$ and trimethylammonium $(\delta=2.90, \mathrm{~s})$ were integrated using the peak integration function. The signal of tetramethylammonium $(\delta=3.20$, t) was integrated using the sum function.

The integral ratio of tetramethylammonium to cyclooctane at $\mathrm{t}=0 \mathrm{~min}$ was set to $55 \mathrm{mM}$ and all other integral ratios at later time points were referenced to that value.

The integral ratio of trimethylammonium to cyclooctane was also referenced to the integral ratio of tetramethylammonium to cyclooctane at $\mathrm{t}=0 \mathrm{~min}$ and scaled by $4 / 3$ to account for the number of protons. 


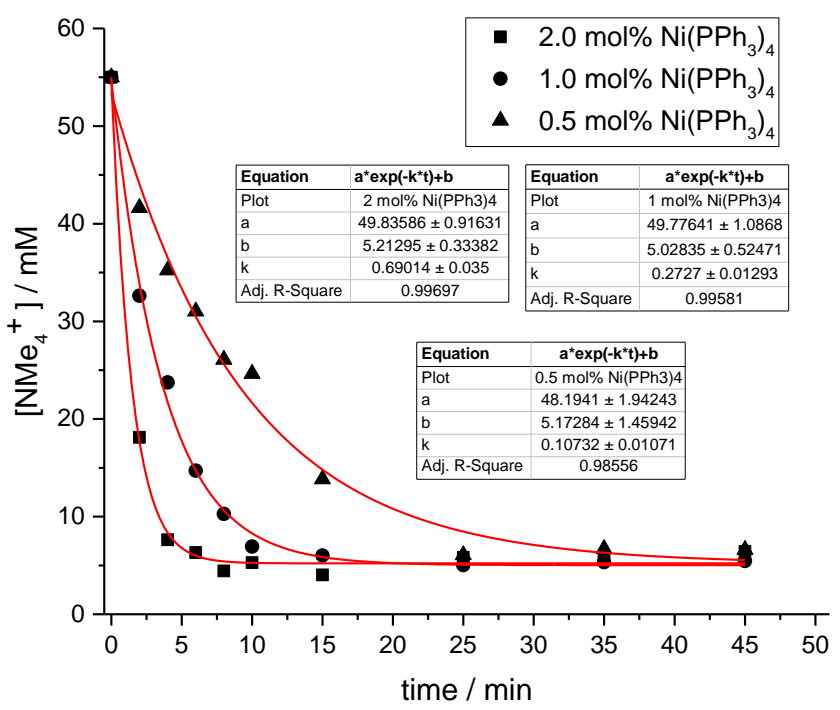

Figure S12. Plot of time versus tetramethylammonium concentration for three different catalyst concentrations. The red curves depict a fit to the function $y=a e^{-k t}+b$ to obtain $k_{o b s}$.

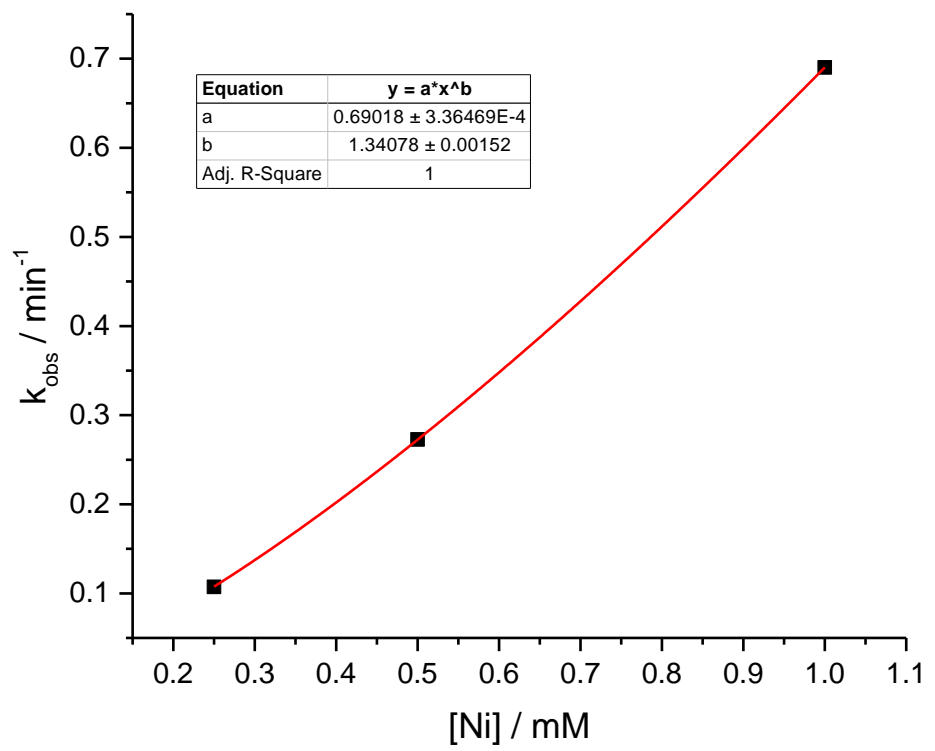

Figure S13. Plot of the catalyst concentration [Ni] of $\mathrm{Ni}\left(\mathrm{PPh}_{3}\right)_{4}$ versus $\mathrm{k}_{\mathrm{obs}}$ for tetramethylammonium disappearance. The red curve depicts a fit to the function $y=a x^{b}$ to establish the order in [Ni], $b=1.341 \pm 0.002$. 


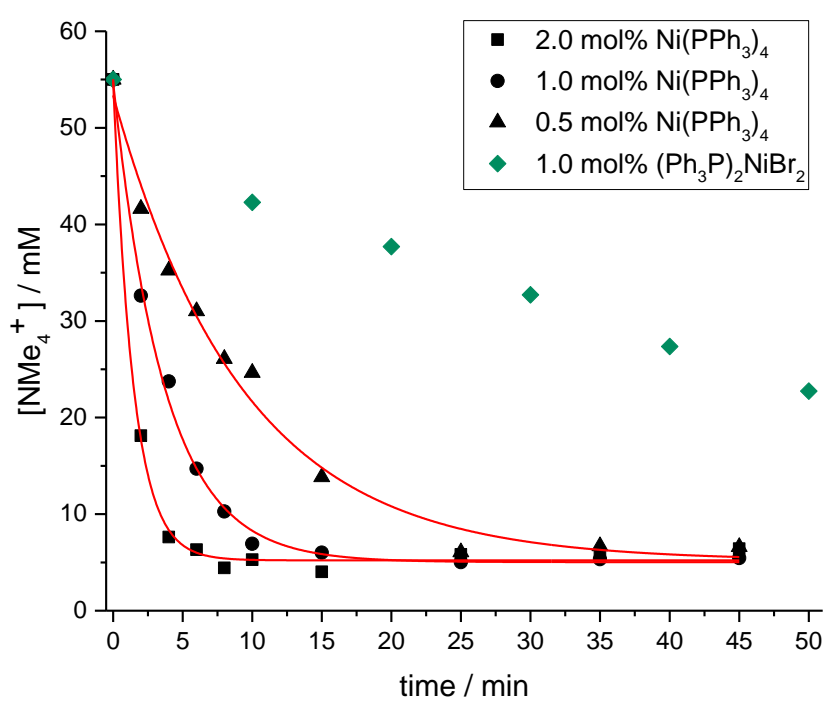

Figure S14. Plot of time versus tetramethylammonium concentration for three different $\mathrm{Ni}\left(\mathrm{PPh}_{3}\right)_{4}$ concentrations and one $\left(\mathrm{Ph}_{3} \mathrm{P}\right)_{2} \mathrm{NiBr}_{2}$ concentration as comparison. The red curves depict a fit to the function $\mathrm{y}=\mathrm{a} \mathrm{e}^{-\mathrm{kt}}+\mathrm{b}$ to obtain $\mathrm{k}_{\mathrm{obs}}$.

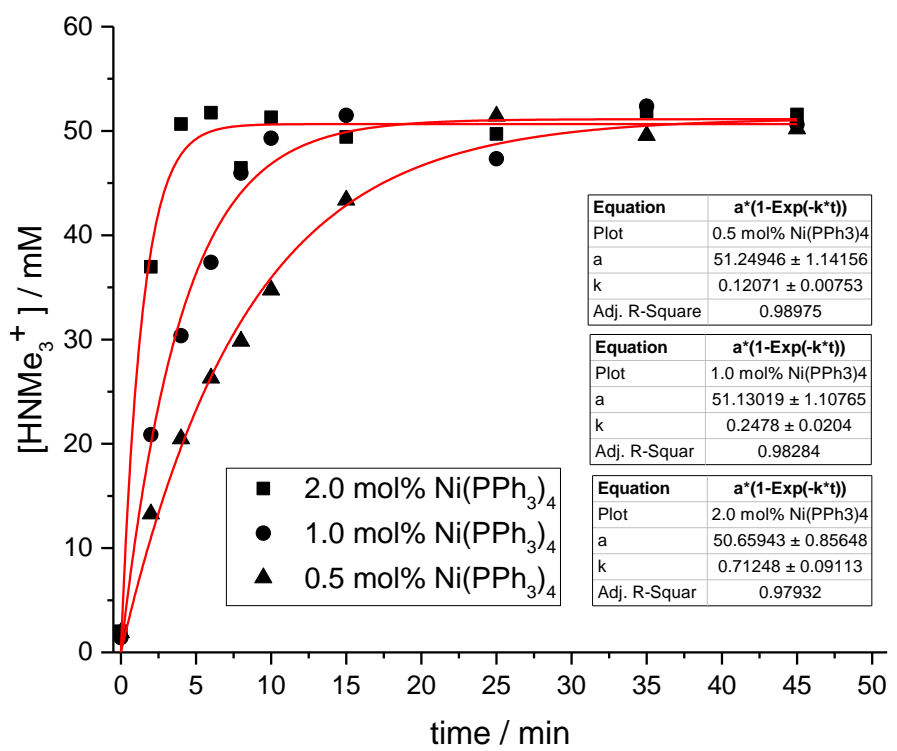

Figure S15. Plot of time versus trimethylammonium concentration after an acidic quench for three different catalyst concentrations. The red curves depict a fit to the function $y=a\left(1-e^{-k t}\right)$ to obtain $k_{o b s}$ for the formation of trimethylamine. 


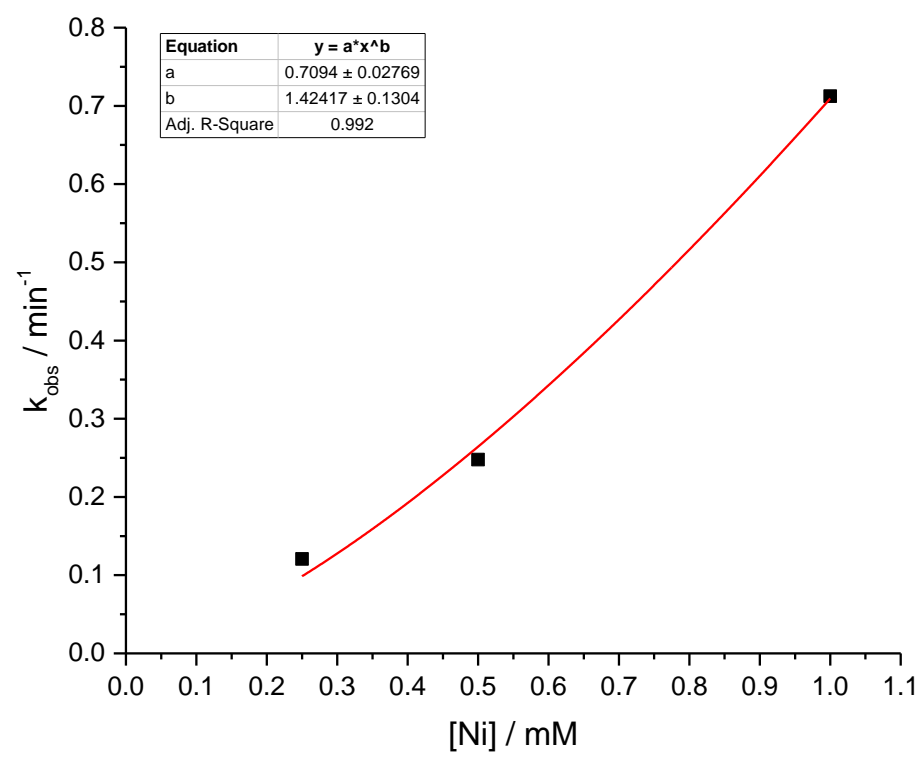

Figure S16. Plot of the catalyst concentration [Ni] of $\mathrm{Ni}\left(\mathrm{PPh}_{3}\right)_{4}$ versus $\mathrm{k}_{\mathrm{obs}}$ for trimethylammonium formation after an acidic quench. The red curve depicts a fit to the function $y=a x^{b}$ to establish the order in $[\mathrm{Ni}], b=1.4 \pm 0.1$.

\section{Kinetic Measurements of Norbornene Cyclopropanation with $\mathrm{Ni}\left(\mathrm{PPh}_{3}\right)_{4}$}

Scheme S9. Reaction Scheme for the Determination of the Order in Catalyst using $\mathrm{Ni}\left(\mathrm{PPh}_{3}\right)_{4}$.

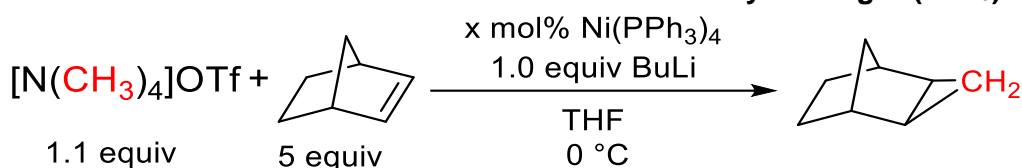

Inside the glove box, an oven-dried $50 \mathrm{~mL}$ Schlenk flask equipped with a J. Young inlet valve, glass stopper, screw cap with septum and a glass-coated stir bar was charged with [NMe 4 ] OTf (245.5 mg, $1.1 \mathrm{mmol}, 1.1$ equiv), and norbornene (471 mg, $5.0 \mathrm{mmol}, 5$ equiv). The flask was removed from the glove box and attached to a Schlenk line. Dry THF (x mL + (catalyst in THF) $\mathrm{mL}=19.5 \mathrm{~mL}$ THF) was added via syringe. Undecane $(50 \mu \mathrm{L})$ was added via a $50 \mu \mathrm{L}$ micro syringe as internal standard. The flask was immersed in an ice bath and the reaction allowed to equilibrate (over ca. $20 \mathrm{~min}$ ).

$\mathrm{Ni}\left(\mathrm{PPh}_{3}\right)_{4}(\mathrm{x}$ mol\%) in THF (prepared as stock solution inside the glove box) was added dropwise by difference with a $2.5 \mathrm{~mL}$ gastight Hamilton syringe (previously dried at $50{ }^{\circ} \mathrm{C}$ in a vacuum oven) over ca. $30 \mathrm{~s} \mathrm{(} \mathrm{t}=0$ min with first drop). Then, an aliquot (ca. $0.2 \mathrm{~mL}$ ) was taken with a disposable $1 \mathrm{~mL}$ plastic syringe (flushed several times with Ar) and immediately quenched by injection into $2 \mathrm{~mL} \mathrm{H} \mathrm{H}_{2} \mathrm{O} 2 \mathrm{~mL}$ pentane ( $\mathrm{t}=0 \mathrm{~min}$ ).

BuLi (500 $\mu \mathrm{L}, 1 \mathrm{mmol}, 1$ equiv; $2 \mathrm{M}$ in cyclohexane) was added dropwise over ca. $30 \mathrm{~s}$ via a $1 \mathrm{~mL}$ gastight Hamilton syringe (by difference; previously dried at $50^{\circ} \mathrm{C}$ in a vacuum oven) ( $\mathrm{t}=0 \mathrm{~min}$ with first drop).

After the addition was completed, the flask was sealed/closed to the Schlenk line again and only opened when an aliquot was taken.

After vigorous mixing of the aliquot with a vortex mixer, the organic phase was filtered through a plug of $\mathrm{MgSO}_{4}$ and analyzed by GC-FID. The yield was determined by the integral ratio of the product versus undecane as internal standard using a previously determined calibration curve. 


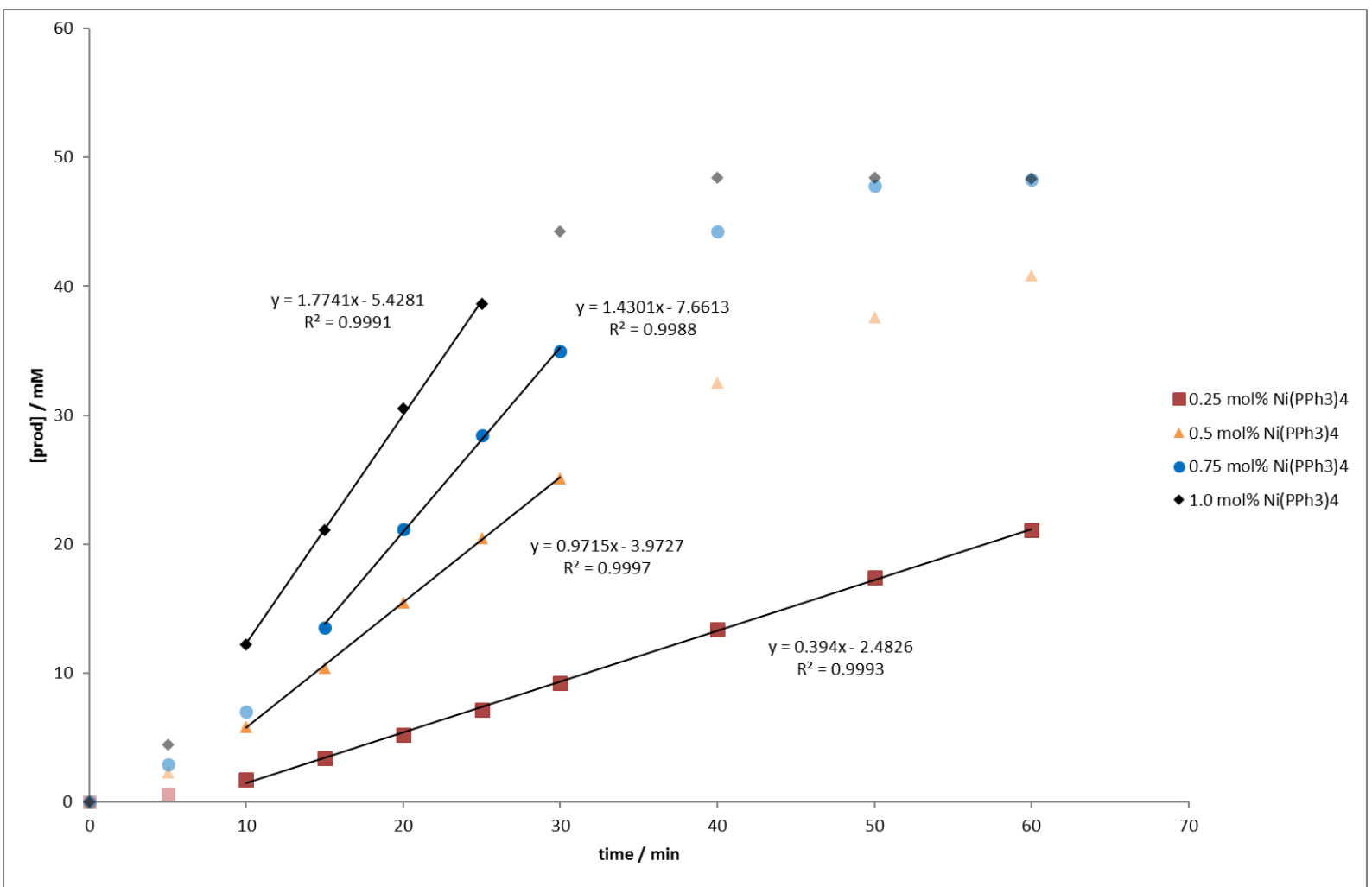

Figure S17. Plot of time versus product concentration for four different catalyst concentrations. The black lines depict an initial rate fit with omission of the first few data points of the induction phase and the later data points at high conversions (lightly shaded) to obtain $\mathrm{k}_{\mathrm{obs}}$.

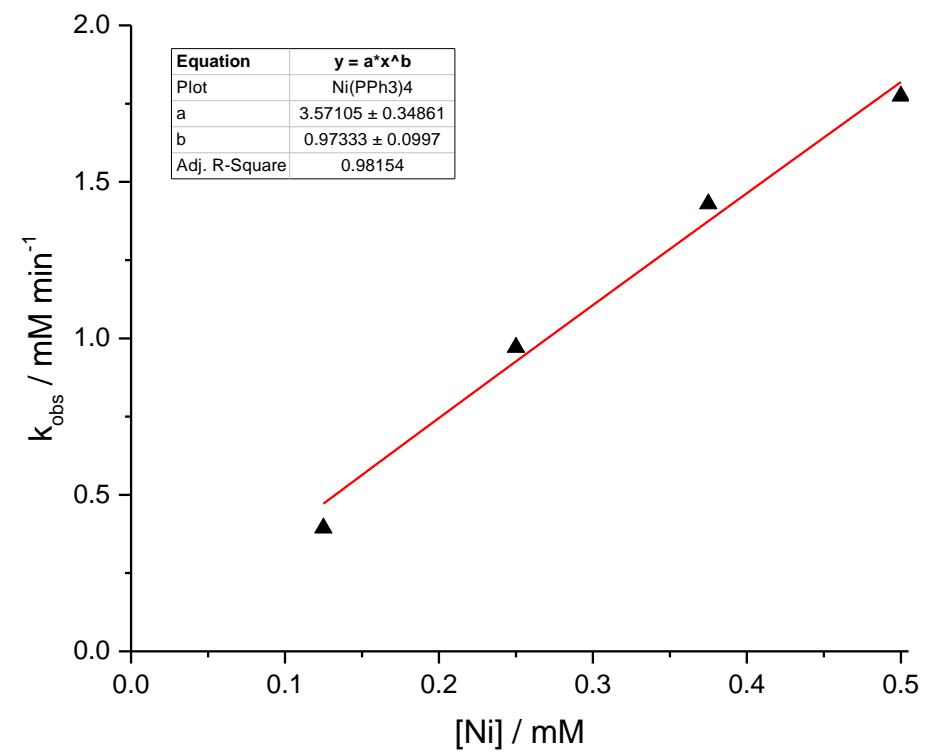

Figure S18. Plot of the catalyst concentration [Ni] of $\mathrm{Ni}\left(\mathrm{PPh}_{3}\right)_{4}$ versus $\mathrm{k}_{\mathrm{obs}}$ for product formation. The red curve depicts a fit to the function $y=a x^{b}$ to establish the order in $[\mathrm{Ni}], \mathrm{b}=1.0 \pm 0.1$.

\section{Influence of Catalyst Loading on the Cyclopropanation of Different Alkenes}

Scheme S10. Influence of Different Precatalyts and Loading on Product Formation. 


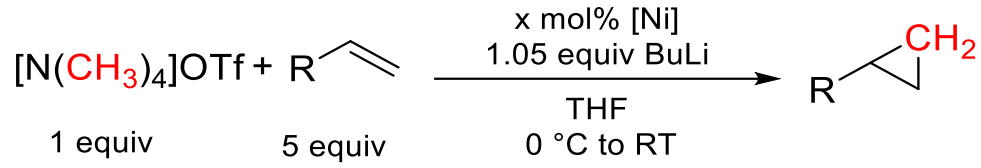

Inside the glove box, an oven-dried $5 \mathrm{~mL}$ Schlenk flask equipped with a Teflon and a glass-coated stir bar was charged with [NMe $\left.{ }_{4}\right] \mathrm{OTf}$ (22.3 mg, $0.1 \mathrm{mmol}, 1$ equiv), alkene ( $0.5 \mathrm{mmol}, 5$ equiv, as stock solution (NBE) or neat (cyclooctene, 1-octene)), catalyst in THF (prepared as stock solution), and THF (tot. vol. THF: $2 \mathrm{~mL}, 0.05 \mathrm{M}$ ). The flask was removed from the glove box, cooled to $0^{\circ} \mathrm{C}$ in an ice/water bath, and BuLi (2 M in cyclohexane; $53 \mu \mathrm{L}, 0.105 \mathrm{mmol}, 1.05$ equiv) was added dropwise via micro syringe under a counterflow of Ar. The flask was sealed (no gas exchange). After $16 \mathrm{~h}$, undecane (10 $\mu \mathrm{L}$; internal standard) was added and an aliquot (ca. $0.2 \mathrm{~mL}$ ) was partitioned between $2 \mathrm{~mL}$ pentane and $2 \mathrm{~mL}$ water. After vigorous mixing of the aliquot with a vortex mixer, the organic phase was filtered through a plug of $\mathrm{MgSO}_{4}$ and analyzed by GC-FID. The yield was determined by the integral ratio of the product versus undecane as internal standard using a previously determined calibration curve.

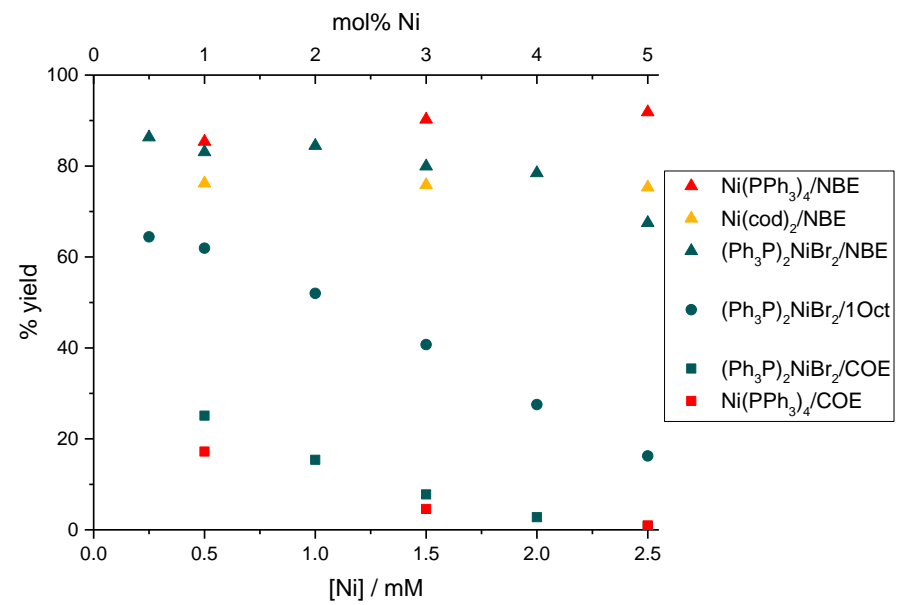

Figure S19. Plot of catalyst concentration $[\mathrm{Ni}]_{\text {tot }}$ versus \% yield of product for three different alkenes, cyclooctene (COE, squares), 1-octene (1Oct, circles), and norbornene (NBE, triangles), and three different catalysts, $\left(\mathrm{Ph}_{3} \mathrm{P}\right)_{2} \mathrm{NiBr}_{2}(\mathrm{green}), \mathrm{Ni}\left(\mathrm{PPh}_{3}\right)_{4}$ (red), and $\mathrm{Ni}(\mathrm{cod})_{2}$ (yellow).

Table S2. Influence of Catalyst Loading on the Cyclopropanation of Different Alkenes.

\begin{tabular}{|c|c|c|c|c|}
\hline Entry & Alkene & Precatalyst & {$[\mathrm{Ni}] / \mathrm{mM}$} & Yield / \% \\
\hline 1 & Norbornene & $\mathrm{Ni}\left(\mathrm{PPh}_{3}\right)_{4}$ & 0.5 & 85.4 \\
\hline 2 & & & 1.5 & 90.2 \\
\hline 3 & & & 2.5 & 91.9 \\
\hline 4 & & $\mathrm{Ni}(\mathrm{cod})_{2}$ & 0.5 & 76.2 \\
\hline 5 & & & 1.5 & 75.8 \\
\hline 6 & & & 2.5 & 75.3 \\
\hline 7 & & $\left(\mathrm{Ph}_{3} \mathrm{P}\right)_{2} \mathrm{NiBr}_{2}$ & 0.25 & 86.3 \\
\hline 8 & & & 0.5 & 83.1 \\
\hline 9 & & & 1.0 & 84.5 \\
\hline 10 & & & 1.5 & 79.9 \\
\hline 11 & & & 2.0 & 78.4 \\
\hline 12 & & & 2.5 & 67.5 \\
\hline 13 & 1-Octene & $\left(\mathrm{Ph}_{3} \mathrm{P}\right)_{2} \mathrm{NiBr}_{2}$ & 0.25 & 64.4 \\
\hline 14 & & & 0.5 & 61.9 \\
\hline 15 & & & 1.0 & 52.0 \\
\hline 16 & & & 1.5 & 40.7 \\
\hline 17 & & & 2.0 & 27.5 \\
\hline 18 & & & 2.5 & 16.3 \\
\hline 19 & Cyclooctene & $\mathrm{Ni}\left(\mathrm{PPh}_{3}\right)_{4}$ & 0.5 & 17.2 \\
\hline 20 & & & 1.5 & 4.6 \\
\hline 21 & & & 2.5 & 1.0 \\
\hline 22 & & $\left(\mathrm{Ph}_{3} \mathrm{P}\right)_{2} \mathrm{NiBr}_{2}$ & 0.5 & 25.1 \\
\hline
\end{tabular}




\begin{tabular}{llc}
23 & 1.0 & 15.4 \\
24 & 1.5 & 7.8 \\
25 & 2.0 & 2.8 \\
26 & 2.5 & 0.8 \\
\hline
\end{tabular}

\section{Fit for $\mathbf{k c p} / \mathbf{k H}$ for Different Catalyst Loadings}

Data was taken from section 11 using $\left(\mathrm{Ph}_{3} \mathrm{P}\right)_{2} \mathrm{NiBr}_{2}$ as catalyst and norbornene $(\mathrm{K}=4.4)$, 1-octene $(\mathrm{K}=0.5)$, or cyclooctene $(\mathrm{K}=0.062)$ as the substrate. ${ }^{7}$ The experimental data was fit to equation (S33) using $\mathrm{k}_{\mathrm{CP}} / \mathrm{K}_{\mathrm{H}}$ as parameter for each catalyst concentration separately (see Scheme S15 and equations (S16) and (S17)).

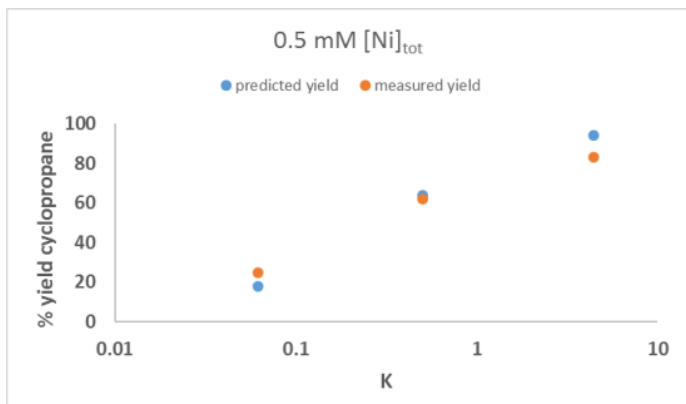

c)

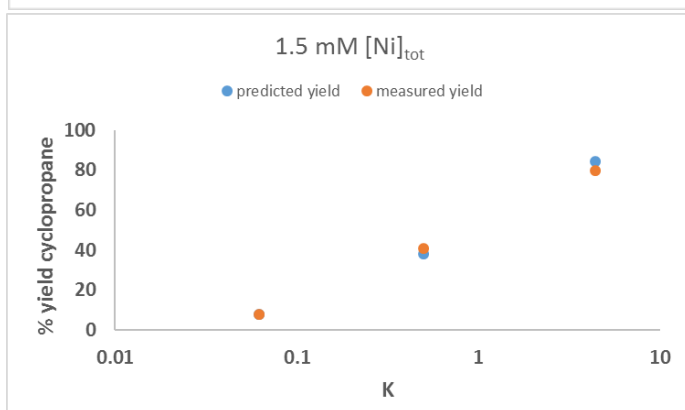

e)

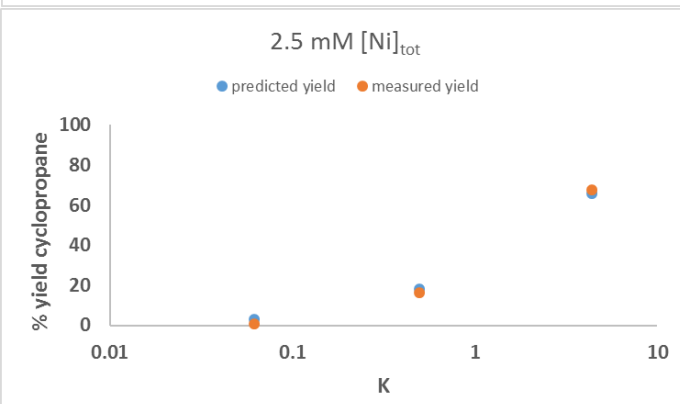

b)

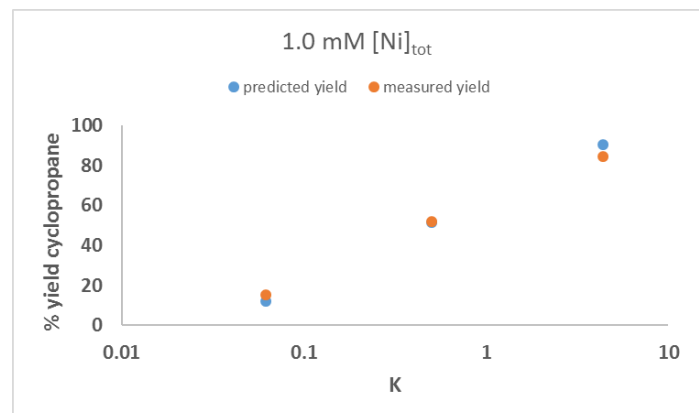

d)

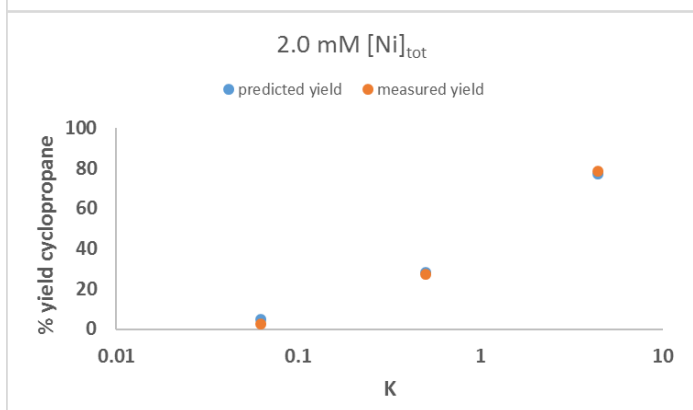

f)

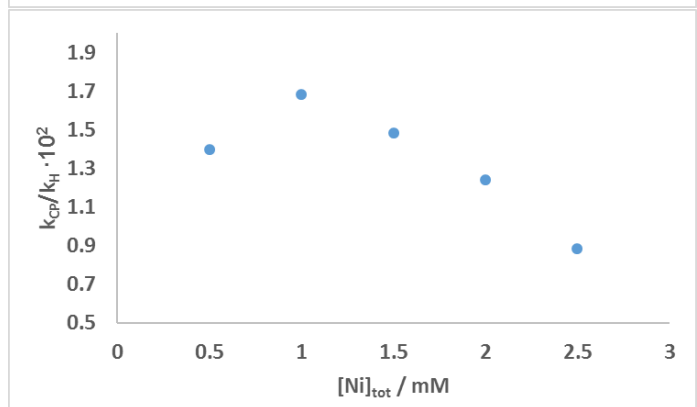

Figure S20. a)-e) Plots of $\mathrm{K}$ (log scale) versus the experimental yield and the predicted yield based on equation (S33) for different concentrations of $\left(\mathrm{Ph}_{3} \mathrm{P}\right)_{2} \mathrm{NiBr}_{2}$ as catalyst. $\left.{ }^{7} \mathrm{f}\right)$ Plot of $\mathrm{k}_{\mathrm{CP}} / \mathrm{k}_{\mathrm{H}}$ versus catalyst concentration $[\mathrm{Ni}]_{\text {tot }}$.

\section{Method of Continuous Variation - Alkene Competition}

Scheme S11. MCV Competition Experiment between Two Alkenes.

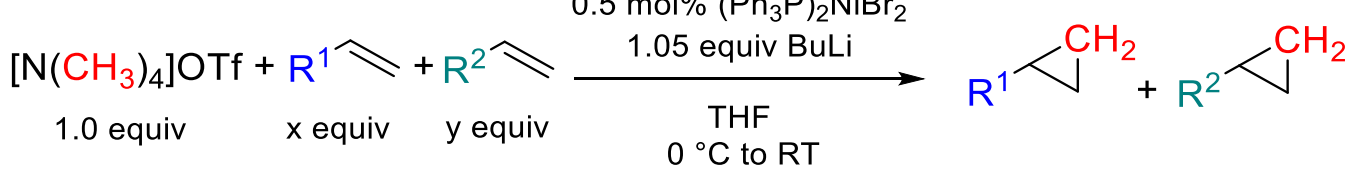


Inside the glove box, an oven-dried $5 \mathrm{~mL}$ Schlenk flask equipped with a Teflon tap and a glass-coated stir bar was charged with [ $\mathrm{NMe}_{4}$ ] OTf (22.3 mg, $0.1 \mathrm{mmol}, 1$ equiv), $\left(\mathrm{Ph}_{3} \mathrm{P}\right)_{2} \mathrm{NiBr}_{2}$ in $0.1 \mathrm{~mL}$ THF (0.5 mol\%, prepared as stock solution), alkene 1 in THF (prepared as stock solution, $500 \mathrm{mM}$ ), alkene 2 in THF (prepared as stock solution, $500 \mathrm{mM}$ ) and $0.9 \mathrm{~mL}$ THF (tot. vol. THF: $2 \mathrm{~mL}, 0.05 \mathrm{M}$ ). The flask was removed from the glove box, cooled to $0{ }^{\circ} \mathrm{C}$ in an ice/water bath, and BuLi $(2 \mathrm{M}$ in cyclohexane; $53 \mu \mathrm{L}, 0.105 \mathrm{mmol}, 1.05$ equiv) was added dropwise via micro syringe under a counterflow of Ar. The flask was sealed (no gas exchange).

After $6 \mathrm{~h}$, the reaction was worked up (NBE/1Oct).

After $30 \mathrm{~min}$, the reaction was quenched with $0.1 \mathrm{~mL} \mathrm{H}_{2} \mathrm{O}$ (NBE/COE and 1Oct/1Non).

Undecane ( $10 \mu \mathrm{L}$; internal standard) was added and an aliquot (ca. $0.2 \mathrm{~mL}$ ) was partitioned between $2 \mathrm{~mL}$ pentane and $2 \mathrm{~mL}$ water. After vigorous mixing of the aliquot with a vortex mixer, the organic phase was filtered through a plug of $\mathrm{MgSO}_{4}$ and analyzed by GC-FID. The yield was determined by the integral ratio of the products versus undecane as internal standard using a previously determined calibration curve.

The total concentration of added alkene 1 and alkene 2 was kept constant, $[A 1]_{\text {tot }}+[A 2]_{\text {tot }}=250 \mathrm{mM}$.

Table S3. MCV Alkene Comp etition Experiment with Norbornene and Cyclooctene.

\begin{tabular}{cccccc}
\hline $\mathrm{X}_{\mathrm{NBE}}$ & $\begin{array}{c}{[\mathrm{NBE}]_{\text {tot }} /} \\
\mathrm{mM}\end{array}$ & $\begin{array}{c}\mathrm{V}_{\text {NBEstock }} / \\
\mathrm{mL}\end{array}$ & {$[\mathrm{COE}]_{\text {tot }} / \mathrm{mM}$} & $\begin{array}{c}\mathrm{V}_{\text {COEstock }} / \\
\mathrm{mL}\end{array}$ & {$\left[\mathrm{P}_{\mathrm{NBE}}\right] /\left[\mathrm{P}_{\mathrm{COE}}\right]$} \\
\hline 0.1 & 25 & 0.1 & 225 & 0.9 & 1.464770072 \\
0.2 & 50 & 0.2 & 200 & 0.8 & 2.485806392 \\
0.3 & 75 & 0.3 & 175 & 0.7 & 3.716750536 \\
0.4 & 100 & 0.4 & 150 & 0.6 & 5.382796308 \\
0.5 & 125 & 0.5 & 125 & 0.5 & 7.202673907 \\
0.6 & 150 & 0.6 & 100 & 0.4 & 12.87358766 \\
0.7 & 175 & 0.7 & 75 & 0.3 & 17.697543 \\
0.8 & 200 & 0.8 & 50 & 0.2 & 26.31536905 \\
0.9 & 225 & 0.9 & 25 & 0.1 & 53.71648742 \\
\hline
\end{tabular}

Table S4. MCV Alkene Competition Experiment with Norbornene and 1-Octene.

\begin{tabular}{|c|c|c|c|c|c|}
\hline $\mathrm{X}_{\mathrm{NBE}}$ & $\begin{array}{c}{[\mathrm{NBE}]_{\mathrm{tot}} /} \\
\mathrm{mM}\end{array}$ & $\begin{array}{c}\mathrm{V}_{\text {NBEstock }} / \\
\mathrm{mL}\end{array}$ & {$[10 \mathrm{ct}]_{\mathrm{tot}} / \mathrm{mM}$} & $\begin{array}{c}\mathrm{V}_{1 \text { Octstock }} / \\
\mathrm{mL}\end{array}$ & {$\left[P_{\mathrm{NBE}}\right] /\left[\mathrm{P}_{10 \mathrm{Ct}}\right]$} \\
\hline 0.1 & 25 & 0.1 & 225 & 0.9 & 0.25236 \\
\hline 0.2 & 50 & 0.2 & 200 & 0.8 & 0.576194 \\
\hline 0.3 & 75 & 0.3 & 175 & 0.7 & 0.91573 \\
\hline 0.4 & 100 & 0.4 & 150 & 0.6 & 1.550245 \\
\hline 0.5 & 125 & 0.5 & 125 & 0.5 & 2.096557 \\
\hline 0.6 & 150 & 0.6 & 100 & 0.4 & 4.033734 \\
\hline 0.7 & 175 & 0.7 & 75 & 0.3 & 7.189614 \\
\hline 0.8 & 200 & 0.8 & 50 & 0.2 & 14.03366 \\
\hline 0.9 & 225 & 0.9 & 25 & 0.1 & 34.18419 \\
\hline
\end{tabular}

Table S5. MCV Alkene Competition Experiment with 1-Octene and 1-Nonene.

\begin{tabular}{|c|c|c|c|c|c|}
\hline $\mathrm{X}_{10 \mathrm{ct}}$ & 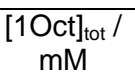 & $\begin{array}{l}\mathrm{V}_{1 \text { 1Octstock }} / \\
\mathrm{mL}\end{array}$ & {$[1 \text { Non }]_{\text {tot }} / \mathrm{mM}$} & $\begin{array}{c}\mathrm{V}_{\text {1 Nonstock }} / \\
\mathrm{mL}\end{array}$ & {$\left[P_{10 c t}\right] /\left[P_{1 \text { Non }}\right]$} \\
\hline 0.1 & 25 & 0.1 & 225 & 0.9 & 0.114310346 \\
\hline 0.2 & 50 & 0.2 & 200 & 0.8 & 0.257989186 \\
\hline 0.3 & 75 & 0.3 & 175 & 0.7 & 0.435932707 \\
\hline 0.4 & 100 & 0.4 & 150 & 0.6 & 0.679684628 \\
\hline 0.5 & 125 & 0.5 & 125 & 0.5 & 1.021350891 \\
\hline 0.6 & 150 & 0.6 & 100 & 0.4 & 1.533079553 \\
\hline 0.7 & 175 & 0.7 & 75 & 0.3 & 2.403979384 \\
\hline 0.8 & 200 & 0.8 & 50 & 0.2 & 4.036792419 \\
\hline 0.9 & 225 & 0.9 & 25 & 0.1 & 8.462446599 \\
\hline
\end{tabular}




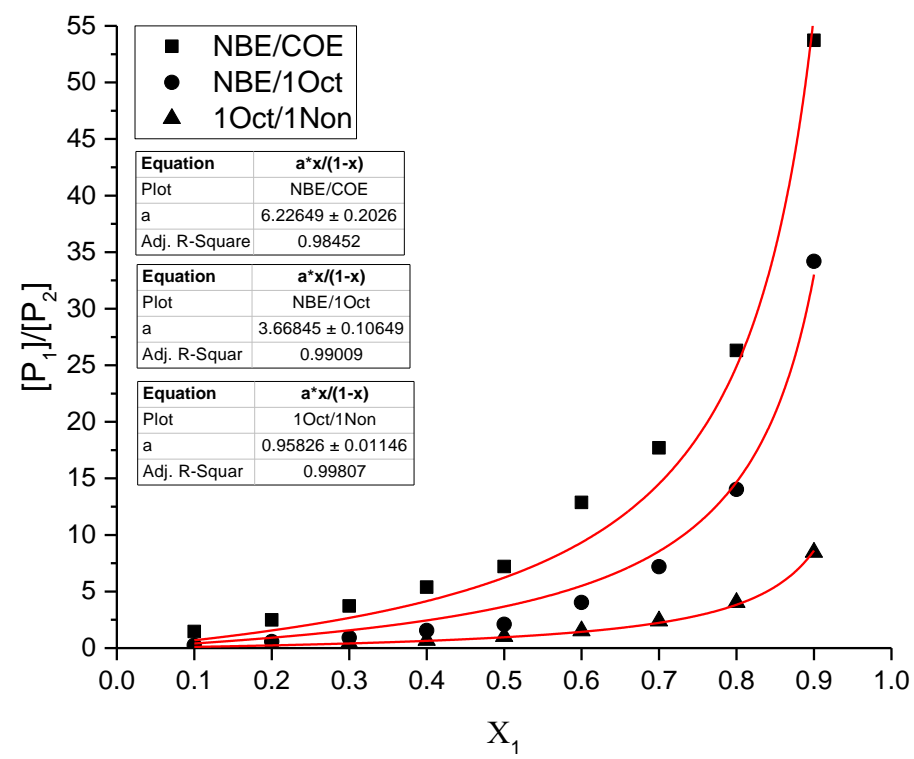

Figure S21. Plot of mole fraction of alkene $1 \mathrm{X}_{1}$ versus product ratio $\left[\mathrm{P}_{1}\right] /\left[\mathrm{P}_{2}\right]$ derived from alkene 1 and alkene 2. Nummeration is as follows: 1: Norbornene (NBE), 2: Cyclooctene (COE) (squares); 1: Norbornene, 2: 1-Octene (1Oct) (circles); 1: 1-Octene, 2: 1-Nonene (1Non) (triangles). The red curves depict a fit to the function $y=a X_{1} /\left(1-X_{1}\right)$ (equation (S15)).

The fit parameter a from Figure $\mathbf{S 2 1}$ is defined as (see equation (S15))

$$
a=\frac{\mathrm{k}_{1} \mathrm{~K}_{1}}{\mathrm{k}_{2} \mathrm{~K}_{2}}
$$

Setting $k(N B E) \equiv k_{\text {rel }}(N B E)=1$, one can obtain relative rate constants $k_{\text {rel }}$ with respect to norbornene for the alkenes using the fit parameter a as follows

$$
\mathrm{k}_{\mathrm{rel}, 2}=\frac{\mathrm{k}_{\mathrm{rel}, \mathrm{NBE}} \mathrm{K}_{\mathrm{NBE}}}{\mathrm{aK}_{2}}=\frac{\mathrm{K}_{\mathrm{NBE}}}{\mathrm{aK}_{2}}
$$

Table S6. Relative Rate Constants $k_{\text {rel }}$ for Several Alkenes.

\begin{tabular}{lccc}
\hline \multicolumn{1}{c}{ Alkene } & $\mathrm{K}^{a}$ & $\mathrm{a}^{b}$ & $\mathrm{k}_{\text {rel }}$ \\
\hline Norbornene & 4.4 & - & 1 \\
1-Octene & 0.5 & 3.7 & 2.4 \\
Cyclooctene & 0.062 & 6.2 & 11.4 \\
\hline
\end{tabular}

${ }^{a}$ Taken from ref. S7. ${ }^{b}$ Fit parameter a taken from Figure

S21.

\section{Kinetic Measurements of Cyclopropanation with Norbornene and Cyclooctene - Competition Experiment}

Scheme S12. Competition Experiment between Norbornene and Cyclooctene.

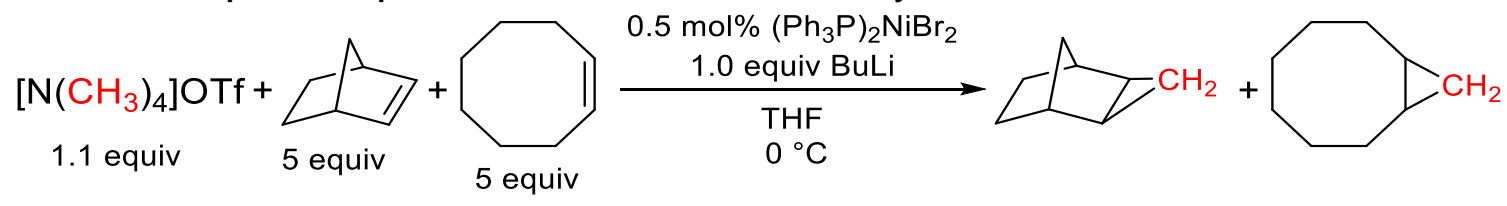

Inside the glove box, an oven-dried $50 \mathrm{~mL}$ Schlenk flask equipped with a J. Young inlet valve, glass stopper, screw cap with septum and a glass-coated stir bar was charged with [NMe $\mathrm{NOTf}_{4} \mathrm{O} 245.5 \mathrm{mg}, 1.1 \mathrm{mmol}, 1.1$ equiv), $\left(\mathrm{Ph}_{3} \mathrm{P}\right)_{2} \mathrm{NiBr}_{2}$ in $\mathrm{THF}(0.5$ mol\%, prepared as stock solution, added by difference with a $2.5 \mathrm{~mL}$ gastight Hamilton syringe (previously dried at $50{ }^{\circ} \mathrm{C}$ in a vacuum oven)), cyclooctene ( $650 \mu \mathrm{L}, 5.0 \mathrm{mmol}, 5$ equiv), and norbornene ( $471 \mathrm{mg}, 5.0 \mathrm{mmol}, 5$ equiv). The flask was removed 
from the glove box and attached to a Schlenk line. Dry THF ( $\mathrm{mL}+$ (catalyst in THF) $\mathrm{mL}=19.5 \mathrm{~mL}$ THF) was added via syringe. Undecane $(50 \mu \mathrm{L})$ was added via a $50 \mu \mathrm{L}$ micro syringe as internal standard. The flask was immersed in an ice bath and the reaction allowed to equilibrate (over ca. $20 \mathrm{~min}$ ).

Then, an aliquot (ca. $0.2 \mathrm{~mL}$ ) was taken with a disposable $1 \mathrm{~mL}$ plastic syringe (flushed several times with Ar) and immediately quenched by injection into $2 \mathrm{~mL} \mathrm{H} \mathrm{H}_{2} / 2 \mathrm{~mL}$ pentane ( $\mathrm{t}=0 \mathrm{~min}$ ).

BuLi (500 $\mu \mathrm{L}, 1 \mathrm{mmol}, 1$ equiv; $2 \mathrm{M}$ in cyclohexane) was added dropwise over ca. $30 \mathrm{~s}$ via a $1 \mathrm{~mL}$ gastight Hamilton syringe (by difference; previously dried at $50^{\circ} \mathrm{C}$ in a vacuum oven) ( $\mathrm{t}=0$ min with first drop).

After the addition was completed, the flask was sealed/closed to the Schlenk line again and only opened when an aliquot was taken.

After vigorous mixing of the aliquot with a vortex mixer, the organic phase was filtered through a plug of $\mathrm{MgSO}_{4}$ and analyzed by GC-FID. The yield was determined by the integral ratio of the product versus undecane as internal standard using a previously determined calibration curve.

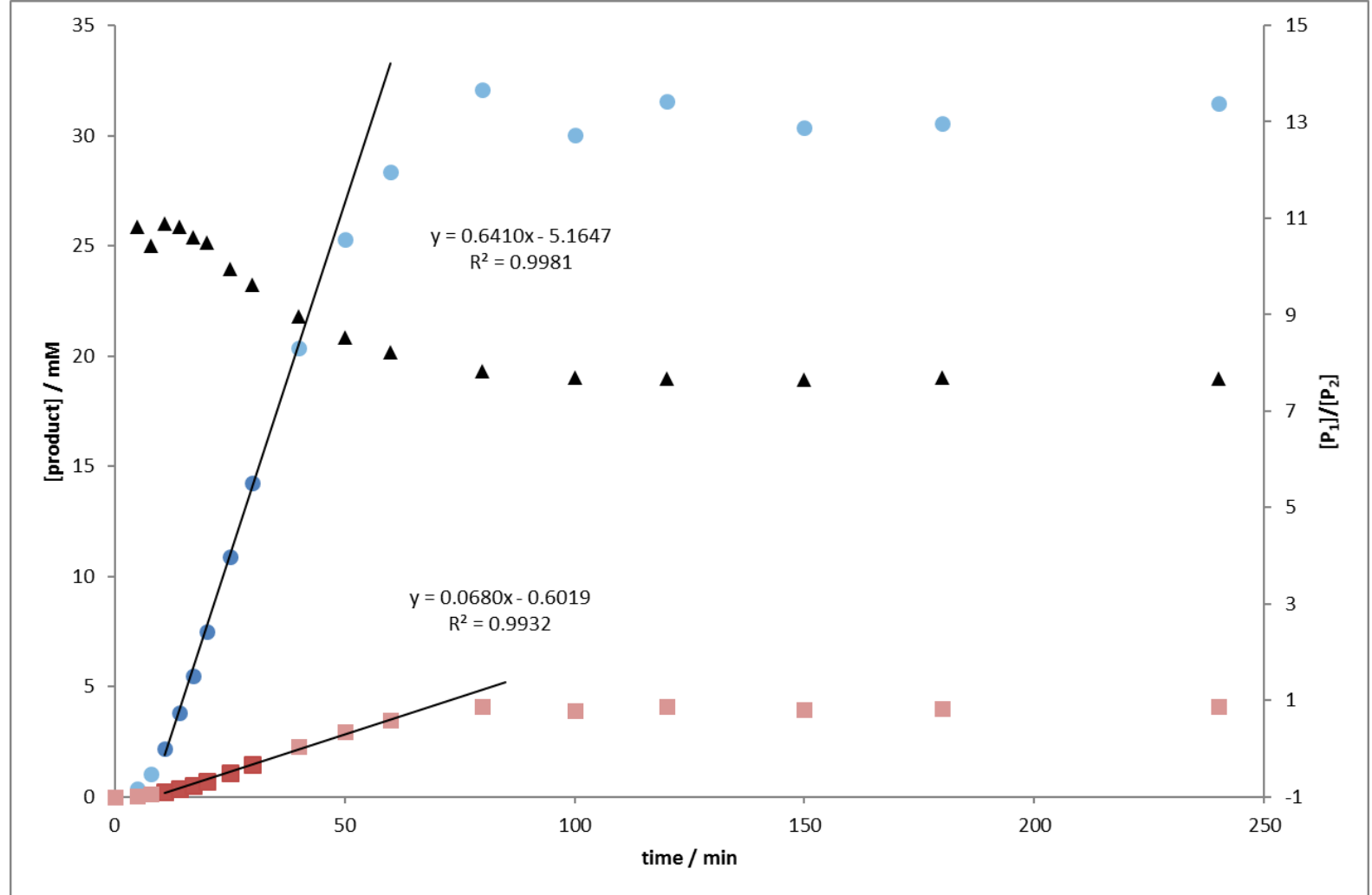

Figure S22. Left axis: Plot of time versus product concentration using norbornene (1) and cyclooctene (2) as substrates in a competition experiment. The black lines depict an initial rate fit with omission of the first few data points of the induction phase and the later data points at high conversions (lightly shaded) to obtain $\mathrm{k}_{\text {obs. }}$. The products are tricyclo[3.2.1.0 $0^{2,4}$ ]octane (blue circles) and bicyclo[6.1.0]nonane (red squares). Right axis: Plot of time versus product ratio $\left[\mathrm{P}_{1}\right] /\left[\mathrm{P}_{2}\right]$ (black triangles).

The values from Figure S22 can be compared to the results from Figure S21 and Table S3 from section 13. Both have $\mathrm{X}_{\mathrm{NBE}}=$ 0.5 , albeit with a different total concentration of alkenes (500 mM versus $250 \mathrm{mM}$ ). $\left[\mathrm{P}_{1}\right] /\left[\mathrm{P}_{2}\right]=7.7$ after 240 min compared to 7.2 (Table S3).

Using equation (S15) and inserting $\mathrm{X}_{1}=0.5$ we arrive at the following approximation

$$
\frac{\mathrm{k}_{\mathrm{obs}, 1}}{\mathrm{k}_{\mathrm{obs}, 2}} \approx \frac{\mathrm{k}_{1} \mathrm{~K}_{1}}{\mathrm{k}_{2} \mathrm{~K}_{2}}
$$

Setting $\mathrm{k}$ for NBE again as $1\left(\mathrm{k}_{\mathrm{rel}, 1}=1\right)$ as in section 13 and taking $\mathrm{k}_{\mathrm{obs}}$ from the initial rate fit from Figure S22, we obtained $\mathrm{k}_{\text {rel, }, 2}$ for COE

$$
\mathrm{k}_{\mathrm{rel}, 2}=\frac{\mathrm{K}_{1}}{\mathrm{~K}_{2}} \frac{\mathrm{k}_{\mathrm{obs}, 2}}{\mathrm{k}_{\mathrm{obs}, 1}} \mathrm{k}_{\mathrm{rel}, 1}=7.5
$$


This can again be compared to the result from section 13 for COE: $\mathrm{k}_{\mathrm{rel}}=11.4$.

\section{Method of Continuous Variation - Ni/PPh}

\section{Scheme S13. MCV Experiment with Varying Ratio of $\mathrm{Ni}$ to $\mathrm{PPh}_{3}$.}

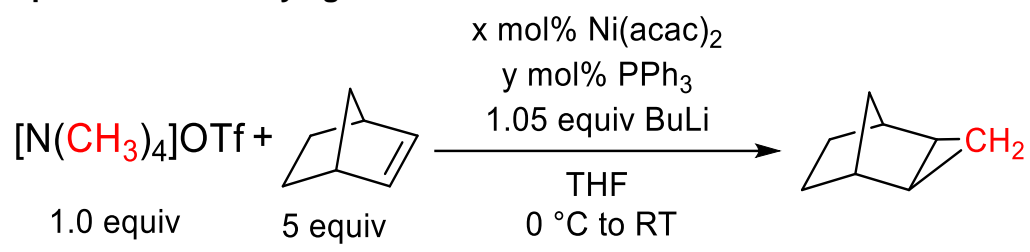

Inside the glove box, an oven-dried $5 \mathrm{~mL}$ Schlenk flask equipped with a Teflon tap and a glass-coated stir bar was charged with [ $\mathrm{NMe}_{4}$ ] OTf (22.3 mg, $0.1 \mathrm{mmol}, 1$ equiv), norbornene ( $47 \mathrm{mg}, 0.5 \mathrm{mmol}, 5$ equiv), Ni(acac) 2 in THF (prepared as stock solution, $5 \mathrm{mM}$ ), $\mathrm{PPh}_{3}$ in THF (prepared as stock solution, $5 \mathrm{mM}$ ), and $1.8 \mathrm{~mL}$ THF (tot. vol. THF: $2 \mathrm{~mL}, 0.05 \mathrm{M}$ ). The flask was removed from the glove box, cooled to $0{ }^{\circ} \mathrm{C}$ in an ice/water bath, and BuLi ( $2 \mathrm{M}$ in cyclohexane; $53 \mu \mathrm{L}, 0.105 \mathrm{mmol}, 1.05$ equiv) was added dropwise via micro syringe under a counterflow of Ar. The flask was sealed (no gas exchange). After 30 min, the reaction was quenched with $0.1 \mathrm{~mL} \mathrm{H} \mathrm{H}_{2} \mathrm{O}$. Undecane (10 $\mu \mathrm{L}$; internal standard) was added and an aliquot (ca. $\left.0.2 \mathrm{~mL}\right)$ was partitioned between $2 \mathrm{~mL}$ pentane and $2 \mathrm{~mL}$ water.

After vigorous mixing of the aliquot with a vortex mixer, the organic phase was filtered through a plug of $\mathrm{MgSO}_{4}$ and analyzed by GC-FID. The yield was determined by the integral ratio of the products versus undecane as internal standard using a previously determined calibration curve.

The total concentration of added $\mathrm{Ni}$ and $\mathrm{PPh}_{3}$ was kept constant, $[\mathrm{Ni}]_{\text {tot }}+\left[\mathrm{PPh}_{3}\right]_{\text {tot }}=0.5 \mathrm{mM}$.

Table S7. MCV Ni/PPh

\begin{tabular}{ccccccc}
\hline $\mathrm{X}_{\mathrm{Ni}}$ & {$[\mathrm{Ni}]_{\text {tot }} / \mathrm{mM}$} & $\mathrm{V}_{\text {Nistock }} / \mathrm{mL}$ & {$\left[\mathrm{PPh}_{3}\right]_{\text {tot }} / \mathrm{mM}$} & $\mathrm{V}_{\text {Pstock }} / \mathrm{mL}$ & \% yield $30 \mathrm{~min}$ & \% yield $16 \mathrm{~h}$ \\
\hline 0.1 & 0.05 & 0.02 & 0.45 & 0.18 & 6.768188684 & 90.733705 \\
0.2 & 0.1 & 0.04 & 0.4 & 0.16 & 14.63634768 & 92.883315 \\
0.3 & 0.15 & 0.06 & 0.35 & 0.14 & 22.08597692 & 85.754546 \\
0.4 & 0.2 & 0.08 & 0.3 & 0.12 & 27.66665363 & 85.441463 \\
0.5 & 0.25 & 0.1 & 0.25 & 0.1 & 31.13132601 & 83.052698 \\
0.6 & 0.3 & 0.12 & 0.2 & 0.08 & 38.3908584 & \\
0.7 & 0.35 & 0.14 & 0.15 & 0.06 & 39.92518041 & 83.611353 \\
0.8 & 0.4 & 0.16 & 0.1 & 0.04 & 43.74514148 & \\
0.9 & 0.45 & 0.18 & 0.05 & 0.02 & 43.4492871 & \\
\hline
\end{tabular}

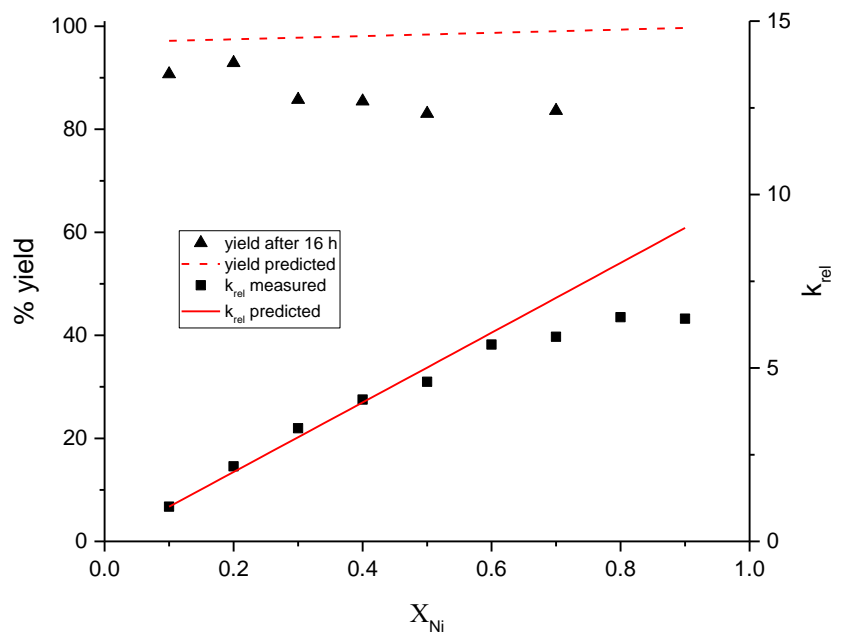

Figure S23. Plot of mole fraction of nickel $\mathrm{X}_{\mathrm{Ni}}$ (using $\mathrm{Ni}(\mathrm{acac})_{2}$ ) versus the measured rate (squares) and predicted rate (red solid curve) (approximated as initial yield after $30 \mathrm{~min}$ ) based on our model (eqs (S33) and (S35)) and the measured (triangles) and predicted yield (red dashed curve) (after $16 \mathrm{~h}$ ) for the cyclo-propanation of NBE, all with no further adjustment of parameters. $\mathrm{kCP} / \mathrm{kH}=0.014$, [Ni]tot $+[\mathrm{P}] \mathrm{tot}=0.5 \mathrm{mM},[\mathrm{A}] \mathrm{tot}=250 \mathrm{mM}$. 


\section{Derivation for Alkene Competition Equation}

Scheme S14. Simplified Mechanistic Scenario with an Alkene Exchange Equilibrium Cyclopropanation.

$$
\mathrm{K}
$$
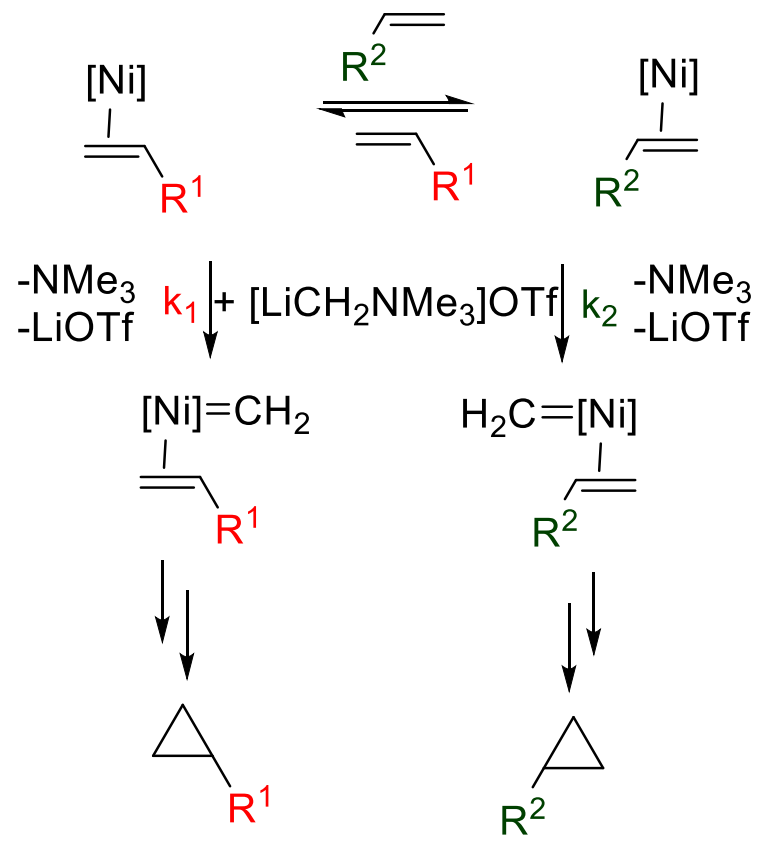

$$
\frac{\mathrm{d}[\mathrm{Pi}]}{\mathrm{dt}}=\mathrm{k}_{i}[\mathrm{NiAi}][\mathrm{Y}]
$$

where $[\mathrm{Y}]$ is the concentration of ylide.

The product ratio [P1]/[P2] for two competing alkenes $A 1$ and $A 2$ is then given by

$$
\frac{\left[\mathrm{P}_{1}\right]}{\left[\mathrm{P}_{2}\right]}=\frac{\mathrm{k}_{1}[\mathrm{NiA} 1][\mathrm{Y}]}{\mathrm{k}_{2}[\mathrm{NiA} 2][\mathrm{Y}]}=\frac{\mathrm{k}_{1}[\mathrm{NiA} 1]}{\mathrm{k}_{2}[\mathrm{NiA} 2]}
$$

Before the turnover-limiting transition state (nickel carbene formation), an equilibrium establishes in which A1 and A2 are competing for $\mathrm{Ni}([\mathrm{A} 1],[\mathrm{A} 2]$ >> [Ni]), i.e. a Curtin-Hammett scenario.

$$
\mathrm{A} 1+\mathrm{NiA} 2 \stackrel{\mathrm{K}}{\mathrm{K}=\frac{[\mathrm{NiA} 1][\mathrm{A} 2]}{[\mathrm{NiA} 2][\mathrm{A} 1]}}
$$

The unknown equilibrium constant $\mathrm{K}$ in equation (S7) can be redefined using the values determined by Tolman via a hypothetical displacement of the alkene with the ligand $\mathrm{P}$ to give NiP (defined by Tolman as alkene displacing ligand $\mathrm{P}$ )

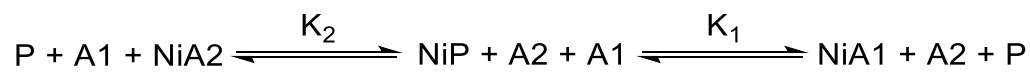




$$
\mathrm{K}_{1}=\frac{[\mathrm{NiA} 1][\mathrm{P}][\mathrm{A} 2]}{[\mathrm{NiP}][\mathrm{A} 1][\mathrm{A} 2]}=\frac{[\mathrm{NiA} 1][\mathrm{P}]}{[\mathrm{NiP}][\mathrm{A} 1]} \quad(\mathrm{S} 8) \quad \mathrm{K}_{2}=\frac{[\mathrm{NiA} 2][\mathrm{P}][\mathrm{A} 1]}{[\mathrm{NiP}][\mathrm{A} 2][\mathrm{A} 1]}=\frac{[\mathrm{NiA} 2][\mathrm{P}]}{[\mathrm{NiP}][\mathrm{A} 2]}
$$

Going from the left hand side of the equilibrium to the right hand side as defined above gives

$$
\mathrm{K}=\frac{\mathrm{K}_{1}}{\mathrm{~K}_{2}}=\frac{[\mathrm{NiA} 1][\mathrm{P}][\mathrm{NiP}][\mathrm{A} 2]}{[\mathrm{NiP}][\mathrm{A} 1][\mathrm{NiA} 2][\mathrm{P}]}=\frac{[\mathrm{NiA} 1][\mathrm{A} 2]}{[\mathrm{A} 1][\mathrm{NiA} 2]} \quad(\mathrm{S} 10) \quad[\mathrm{NiA} 2]=\frac{\mathrm{K}_{2}}{\mathrm{~K}_{1}} \frac{[\mathrm{NiA} 1][\mathrm{A} 2]}{[\mathrm{A} 1]}
$$

Inserting equation (S11) into the equation (S6) gives

$r$

$$
\frac{\left[\mathrm{P}_{1}\right]}{\left[\mathrm{P}_{2}\right]}=\frac{\mathrm{k}_{1}[\mathrm{NiA} 1]}{\mathrm{k}_{2}[\mathrm{NiA} 2]}=\frac{\mathrm{k}_{1} \mathrm{~K}_{1}}{\mathrm{k}_{2} \mathrm{~K}_{2}} \frac{[\mathrm{NiA} 1][\mathrm{A} 1]}{[\mathrm{NiA} 1][\mathrm{A} 2]}=\frac{\mathrm{k}_{1} \mathrm{~K}_{1}}{\mathrm{k}_{2} \mathrm{~K}_{2}} \frac{[\mathrm{A} 1]}{[\mathrm{A} 2]}
$$

For the Job plot the total alkene concentration is kept constant, $[A]_{\text {tot }}=[A 1]+[A 2]=$ const., and we can define the molar fraction $\mathrm{X}$ of alkene 1 and 2 , respectively,

$$
\mathrm{X}_{1}=\frac{[\mathrm{A} 1]}{[\mathrm{A}]_{\mathrm{tot}}} \quad(\mathrm{S} 13) \quad \mathrm{X}_{2}=\frac{[\mathrm{A} 2]}{[\mathrm{A}]_{\mathrm{tot}}}=1-\mathrm{X}_{1}
$$

and insert equations (S13) and (S14) in equation (S12) to give

$$
\frac{\left[\mathrm{P}_{1}\right]}{\left[\mathrm{P}_{2}\right]}=\frac{\mathrm{k}_{1} \mathrm{~K}_{1}}{\mathrm{k}_{2} \mathrm{~K}_{2}} \frac{[\mathrm{A} 1]}{[\mathrm{A} 2]}=\frac{\mathrm{k}_{1} \mathrm{~K}_{1}}{\mathrm{k}_{2} \mathrm{~K}_{2}} \frac{\mathrm{X}_{1}[\mathrm{~A}]_{\text {tot }}}{\mathrm{X}_{2}[\mathrm{~A}]_{\text {tot }}}=\frac{\mathrm{k}_{1} \mathrm{~K}_{1}}{\mathrm{k}_{2} \mathrm{~K}_{2}} \frac{\mathrm{X}_{1}}{\mathrm{X}_{2}}=\frac{\mathrm{k}_{1} \mathrm{~K}_{1}}{\mathrm{k}_{2} \mathrm{~K}_{2}} \frac{\mathrm{X}_{1}}{\left(1-\mathrm{X}_{1}\right)}
$$

\section{Derivation for Alkene-Ligand Competition Equation}

Scheme S15. Simplified Mechanistic Scenario with an

Alkene-Phosphine Exchange Equilibrium Before

Cyclopropanation. 

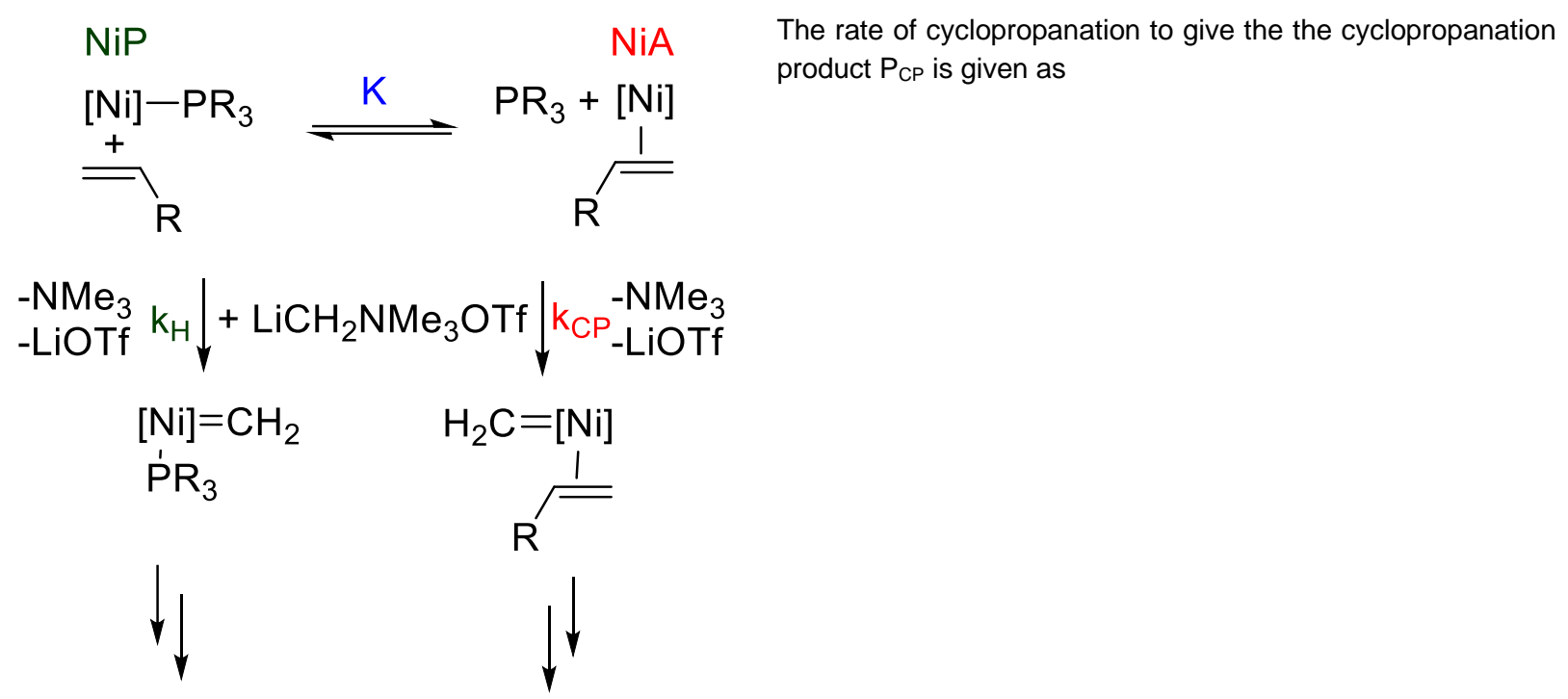

side-products

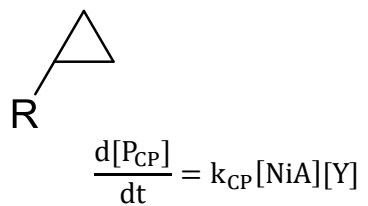

where $\mathrm{NiA}$ is the alkene-ligated resting state before turnover-limiting nickel carbene formation.

On the other hand, all side-products resulting from homocoupling we term $\mathrm{P}_{\mathrm{H}}$ and the rate of formation is given as

$$
\frac{\mathrm{d}\left[\mathrm{P}_{\mathrm{H}}\right]}{\mathrm{dt}}=\mathrm{k}_{\mathrm{H}}[\mathrm{NiP}][\mathrm{Y}]
$$

where $\mathrm{NiP}$ is the non-alkene-ligated resting state before turnover-limiting nickel carbene formation that does not engage in cyclopropanation.

Before the turnover-limiting transition state (nickel carbene formation), an equilibrium is established in which alkene $\mathrm{A}$ and ligand $\mathrm{P}$ are competing for $\mathrm{Ni}$, i.e., a Curtin-Hammett scenario.

$$
\mathrm{A}+\mathrm{NiP} \rightleftharpoons \mathrm{K}=\mathrm{NiA}+\mathrm{P}=\frac{[\mathrm{NiA}][\mathrm{P}]}{[\mathrm{NiP}][\mathrm{A}]}
$$

In addition the following boundary conditions with the known concentrations $[\mathrm{Ni}]_{\text {tot, }}[\mathrm{P}]_{\text {tot }}$, and $[\mathrm{A}]_{\text {tot }}$ apply :

- The total amount of nickel $[\mathrm{Ni}]_{\text {tot }}$ (added as precatalyst) is distributed among the possible resting states $\mathrm{NiA}$ and $\mathrm{NiP}$

$$
\begin{aligned}
{[\mathrm{Ni}]_{\text {tot }} } & =[\mathrm{NiA}]+[\mathrm{NiP}] \\
\rightarrow[\mathrm{NiA}] & =[\mathrm{Ni}]_{\text {tot }}-[\mathrm{NiP}]
\end{aligned}
$$

- The total amount of ligand $[\mathrm{P}]_{\text {tot }}$ is either free or bound to nickel

$$
\begin{gathered}
{[\mathrm{P}]_{\text {tot }}=[\mathrm{P}]+[\mathrm{NiP}]} \\
\rightarrow[\mathrm{P}]=[\mathrm{P}]_{\text {tot }}-[\mathrm{NiP}]
\end{gathered}
$$


- The total amount of alkene $[\mathrm{A}]_{\text {tot }}$ is either free or bound to nickel and approximately constant over the reaction (excess alkene)

$$
\begin{gathered}
{[\mathrm{A}]_{\text {tot }}=[\mathrm{A}]+[\mathrm{NiA}]} \\
\rightarrow[\mathrm{A}]=[\mathrm{A}]_{\text {tot }}-[\mathrm{NiA}]=[\mathrm{A}]_{\text {tot }}-[\mathrm{Ni}]_{\text {tot }}+[\mathrm{NiP}]
\end{gathered}
$$

Inserting the above three boundary conditions (S20), (S22), and (S24) into the equation (S18) one gets

$$
\mathrm{K}=\frac{[\mathrm{P}][\mathrm{NiA}]_{\text {boundary cond. }}}{[\mathrm{A}][\mathrm{NiP}]} \mathrm{K}=\frac{\left([\mathrm{P}]_{\text {tot }}-[\mathrm{NiP}]\right)\left([\mathrm{Ni}]_{\text {tot }}-[\mathrm{NiP}]\right)}{\left([\mathrm{A}]_{\text {tot }}-[\mathrm{Ni}]_{\text {tot }}+[\mathrm{NiP}]\right)[\mathrm{NiP}]}=\frac{[\mathrm{P}]_{\text {tot }}[\mathrm{Ni}]_{\text {tot }}-\left([\mathrm{P}]_{\text {tot }}+[\mathrm{Ni}]_{\text {tot }}\right)[\mathrm{NiP}]+[\mathrm{NiP}]^{2}}{\left([\mathrm{~A}]_{\text {tot }}-[\mathrm{Ni}]_{\text {tot }}\right)[\mathrm{NiP}]+[\mathrm{NiP}]^{2}}
$$

Further rearranging leads to the quadratic equation (S26) in [NiP]

$$
\begin{aligned}
& \Rightarrow \mathrm{K}\left([\mathrm{A}]_{\text {tot }}-[\mathrm{Ni}]_{\text {tot }}\right)[\mathrm{NiP}]+\mathrm{K}[\mathrm{NiP}]^{2}=[\mathrm{P}]_{\text {tot }}[\mathrm{Ni}]_{\text {tot }}-\left([\mathrm{P}]_{\text {tot }}+[\mathrm{Ni}]_{\text {tot }}\right)[\mathrm{NiP}]+[\mathrm{NiP}]^{2} \\
& \Rightarrow 0=[\mathrm{P}]_{\text {tot }}[\mathrm{Ni}]_{\text {tot }}-\left([\mathrm{P}]_{\text {tot }}+[\mathrm{Ni}]_{\text {tot }}\right)[\mathrm{NiP}]-\mathrm{K}\left([\mathrm{A}]_{\text {tot }}-[\mathrm{Ni}]_{\text {tot }}\right)[\mathrm{NiP}]+[\mathrm{NiP}]^{2}-\mathrm{K}[\mathrm{NiP}]^{2} \\
& \Rightarrow 0=[\mathrm{P}]_{\text {tot }}[\mathrm{Ni}]_{\text {tot }}-\left(\left([\mathrm{P}]_{\mathrm{tot}}+[\mathrm{Ni}]_{\text {tot }}\right)+\mathrm{K}\left([\mathrm{A}]_{\mathrm{tot}}-[\mathrm{Ni}]_{\mathrm{tot}}\right)\right)[\mathrm{NiP}]+(1-\mathrm{K})[\mathrm{NiP}]^{2} \\
& \Rightarrow 0=[\mathrm{P}]_{\text {tot }}[\mathrm{Ni}]_{\text {tot }}-\left([\mathrm{P}]_{\text {tot }}+[\mathrm{Ni}]_{\text {tot }}+\mathrm{K}[\mathrm{A}]_{\text {tot }}-\mathrm{K}[\mathrm{Ni}]_{\text {tot }}\right)[\mathrm{NiP}]+(1-\mathrm{K})[\mathrm{NiP}]^{2} \\
& \Rightarrow 0=[\mathrm{P}]_{\text {tot }}[\mathrm{Ni}]_{\text {tot }}-\left([\mathrm{P}]_{\text {tot }}+\mathrm{K}[\mathrm{A}]_{\text {tot }}+(1-\mathrm{K})[\mathrm{Ni}]_{\text {tot }}\right)[\mathrm{NiP}]+(1-\mathrm{K})[\mathrm{NiP}]^{2} \text { quadratic eq. in }[\mathrm{NiP}] \\
& {[\mathrm{NiP}]=\frac{-\mathrm{b} \pm \sqrt{\mathrm{b}^{2}-4 \mathrm{ac}}}{2 \mathrm{a}}} \\
& \mathrm{a}=(1-\mathrm{K}), \mathrm{b}=-\left([\mathrm{P}]_{\mathrm{tot}}+\mathrm{K}[\mathrm{A}]_{\mathrm{tot}}+(1-\mathrm{K})[\mathrm{Ni}]_{\mathrm{tot}}\right), \mathrm{c}=[\mathrm{P}]_{\mathrm{tot}}[\mathrm{Ni}]_{\mathrm{tot}}
\end{aligned}
$$

Solving for [NiP] and checking for the physically meaningful (-) solution one arrives at equation (S27)

$$
[\mathrm{NiP}]=\frac{\left([\mathrm{P}]_{\text {tot }}+\mathrm{K}[\mathrm{A}]_{\mathrm{tot}}+(1-\mathrm{K})[\mathrm{Ni}]_{\mathrm{tot}}\right)-\sqrt{\left([\mathrm{P}]_{\mathrm{tot}}+\mathrm{K}[\mathrm{A}]_{\text {tot }}+(1-\mathrm{K})[\mathrm{Ni}]_{\mathrm{tot}}\right)^{2}-4(1-\mathrm{K})[\mathrm{P}]_{\text {tot }}[\mathrm{Ni}]_{\text {tot }}}}{2(1-\mathrm{K})}
$$

The same can be done for [NiA] to give equation (S28)

$$
[\mathrm{NiA}]=\frac{-\left([\mathrm{P}]_{\text {tot }}+\mathrm{K}[\mathrm{A}]_{\text {tot }}+(\mathrm{K}-1)[\mathrm{Ni}]_{\text {tot }}\right)+\sqrt{\left([\mathrm{P}]_{\text {tot }}+\mathrm{K}[\mathrm{A}]_{\text {tot }}+(\mathrm{K}-1)[\mathrm{Ni}]_{\text {tot }}\right)^{2}+4 \mathrm{~K}(1-\mathrm{K})[\mathrm{A}]_{\text {tot }}[\mathrm{Ni}]_{\text {tot }}}}{2(1-\mathrm{K})}
$$

We can define the ratio of cyclopropanation product $\mathrm{P}_{\mathrm{CP}}$ to all side-products deriving from homocoupling $\mathrm{P}_{H}$ using equations (S16) and (S17) and simplify by inserting equation (S19)

$$
\frac{\left[\mathrm{P}_{\mathrm{CP}}\right]}{\left[\mathrm{P}_{\mathrm{H}}\right]}=\frac{\mathrm{k}_{\mathrm{CP}}[\mathrm{NiA}][\mathrm{Y}]}{\mathrm{k}_{\mathrm{H}}[\mathrm{NiP}][\mathrm{Y}]}=\frac{\mathrm{k}_{\mathrm{CP}}[\mathrm{NiA}]}{\mathrm{k}_{\mathrm{H}}[\mathrm{NiP}]}=\frac{\mathrm{k}_{\mathrm{CP}}}{\mathrm{k}_{\mathrm{H}}} \frac{\left([\mathrm{Ni}]_{\mathrm{tot}}-[\mathrm{NiP}]\right)}{[\mathrm{NiP}]}=\mathrm{f}(\mathrm{x}) \rightarrow\left[\mathrm{P}_{\mathrm{H}}\right]=\frac{\left[\mathrm{P}_{\mathrm{CP}}\right]}{\mathrm{f}(\mathrm{x})}
$$

Assuming that we have full conversion, i.e., all ylide is consumed, and that all ylide reacts via our proposed reaction scheme, i.e., either cyclopropanation or homocoupling-derived side-products, the yield of the reaction is given by

$$
\frac{\% \text { yield }}{100}=\frac{\left[\mathrm{P}_{\mathrm{CP}}\right]}{\left[\mathrm{P}_{\mathrm{CP}}\right]+\left[\mathrm{P}_{\mathrm{H}}\right]}
$$

Using the rearranged equation (S29) and inserting into equation (S30) one arrives at 


$$
\frac{\text { \% yield }}{100}=\frac{\left[\mathrm{P}_{\mathrm{CP}}\right]}{\left[\mathrm{P}_{\mathrm{CP}}\right]+\left[\mathrm{P}_{\mathrm{H}}\right]}=\frac{\left[\mathrm{P}_{\mathrm{CP}}\right]}{\left[\mathrm{P}_{\mathrm{CP}}\right]+\frac{\left[\mathrm{P}_{\mathrm{CP}}\right]}{\mathrm{f}(\mathrm{x})}}=\frac{\left[\mathrm{P}_{\mathrm{CP}}\right]}{\left[\mathrm{P}_{\mathrm{CP}}\right]+\frac{\left[\mathrm{P}_{\mathrm{CP}}\right]}{\mathrm{f}(\mathrm{x})} \frac{\mathrm{f}(\mathrm{x})}{\mathrm{f}(\mathrm{x})}}=\frac{\left[\mathrm{P}_{\mathrm{CP}}\right]}{\left[\mathrm{P}_{\mathrm{CP}}\right]\left(1+\frac{1}{\mathrm{f}(\mathrm{x})}\right)} \frac{\mathrm{f}(\mathrm{x})}{\mathrm{f}(\mathrm{x})}=\frac{\left[\mathrm{P}_{\mathrm{CP}}\right] \mathrm{f}(\mathrm{x})}{\left[\mathrm{P}_{\mathrm{CP}}\right]\left(\mathrm{f}(\mathrm{x})+\frac{\mathrm{f}(\mathrm{x})}{\mathrm{f}(\mathrm{x})}\right)}=\frac{\mathrm{f}(\mathrm{x})}{\mathrm{f}(\mathrm{x})+1}
$$

Resubstituting $f(x)$ from equation (S29) into equation (S31) and rearranging gives equation (S32)

$$
\begin{aligned}
\frac{\% \text { yield }}{100}=\frac{\mathrm{f}(\mathrm{x})}{\mathrm{f}(\mathrm{x})+1} & =\frac{\frac{\mathrm{k}_{\mathrm{CP}}}{\mathrm{k}_{\mathrm{H}}} \frac{\left([\mathrm{Ni}]_{\text {tot }}-[\mathrm{NiP}]\right)}{[\mathrm{NiP}]}}{\frac{\mathrm{k}_{\mathrm{CP}}}{\mathrm{k}_{\mathrm{H}}} \frac{\left([\mathrm{Ni}]_{\mathrm{tot}}-[\mathrm{NiP}]\right)}{[\mathrm{NiP}]}+1} \frac{[\mathrm{NiP}]}{[\mathrm{NiP}]}=\frac{\frac{\mathrm{k}_{\mathrm{CP}}}{\mathrm{k}_{\mathrm{H}}}\left([\mathrm{Ni}]_{\text {tot }}-[\mathrm{NiP}]\right)}{\frac{\mathrm{k}_{\mathrm{CP}}}{\mathrm{k}_{\mathrm{H}}}\left([\mathrm{Ni}]_{\text {tot }}-[\mathrm{NiP}]\right)+[\mathrm{NiP}]}=\frac{\frac{\mathrm{k}_{\mathrm{CP}}}{\mathrm{k}_{\mathrm{H}}}\left([\mathrm{Ni}]_{\text {tot }}-[\mathrm{NiP}]\right)}{\frac{\mathrm{k}_{\mathrm{CP}}}{\mathrm{k}_{\mathrm{H}}}[\mathrm{Ni}]_{\text {tot }}-\frac{\mathrm{k}_{\mathrm{CP}}}{\mathrm{k}_{\mathrm{H}}}[\mathrm{NiP}]+[\mathrm{NiP}]} \\
& =\frac{\frac{\mathrm{k}_{\mathrm{CP}}}{\mathrm{k}_{\mathrm{H}}}\left([\mathrm{Ni}]_{\mathrm{tot}}-[\mathrm{NiP}]\right)}{\frac{\mathrm{k}_{\mathrm{CP}}}{\mathrm{k}_{\mathrm{H}}}[\mathrm{Ni}]_{\text {tot }}+\left(1-\frac{\mathrm{k}_{\mathrm{CP}}}{\mathrm{k}_{\mathrm{H}}}\right)[\mathrm{NiP}]}
\end{aligned}
$$

Finally, one can insert equation (S27) into equation (S32) to arrive at the final equation (S33)

$$
\frac{\% \text { yield }}{100}=\frac{\frac{\mathrm{k}_{\mathrm{CP}}}{\mathrm{k}_{\mathrm{H}}}\left([\mathrm{Ni}]_{\text {tot }}-\frac{\left([\mathrm{P}]_{\text {tot }}+\mathrm{K}[\mathrm{A}]_{\text {tot }}+(1-\mathrm{K})[\mathrm{Ni}]_{\text {tot }}\right)-\sqrt{\left([\mathrm{P}]_{\text {tot }}+\mathrm{K}[\mathrm{A}]_{\text {tot }}+(1-\mathrm{K})[\mathrm{Ni}]_{\text {tot }}\right)^{2}-4(1-\mathrm{K})[\mathrm{P}]_{\text {tot }}[\mathrm{Ni}]_{\text {tot }}}}{2(1-\mathrm{K})}\right)}{\frac{\mathrm{k}_{\mathrm{CP}}}{\mathrm{k}_{\mathrm{H}}}[\mathrm{Ni}]_{\text {tot }}+\left(1-\frac{\mathrm{k}_{\mathrm{CP}}}{\mathrm{k}_{\mathrm{H}}}\right) \frac{\left([\mathrm{P}]_{\text {tot }}+\mathrm{K}[\mathrm{A}]_{\text {tot }}+(1-\mathrm{K})[\mathrm{Ni}]_{\text {tot }}\right)-\sqrt{\left([\mathrm{P}]_{\text {tot }}+\mathrm{K}[\mathrm{A}]_{\text {tot }}+(1-\mathrm{K})[\mathrm{Ni}]_{\text {tot }}\right)^{2}-4(1-\mathrm{K})[\mathrm{P}]_{\text {tot }}[\mathrm{Ni}]_{\text {tot }}}}{2(1-\mathrm{K})}}
$$

With our simplified model and assumptions we made, equation (S33) predicts the yield for cyclopropanation based on the known concentration $[\mathrm{Ni}]_{\text {tot }}$ and $[\mathrm{P}]_{\text {tot }}$ (added amounts of the precatalyst), and $[\mathrm{A}]_{\text {tot }}$ (in large excess, 5 equiv, approx. constant).

By analogy to equation (S16), the initial rate constant of cyclopropanation $\mathrm{k}_{\mathrm{obs}}$ is given as

$$
\mathrm{k}_{\mathrm{obs}}=\mathrm{k}_{\mathrm{CP}}[\mathrm{NiA}]
$$

With the general equation (S34) in hand, we can define a relative rate constant $k_{\text {rel }}$ normalized to the first $k_{\text {obs }}$ (e.g. lowest $[\mathrm{Ni}]_{\text {tot }}$ ) in a series of measurements as

$$
\mathrm{k}_{\mathrm{rel}, \mathrm{n}}=\frac{\mathrm{k}_{\mathrm{obs}, \mathrm{n}}}{\mathrm{k}_{\mathrm{obs}, 1}}=\frac{\mathrm{k}_{\mathrm{CP}}[\mathrm{NiA}]_{\mathrm{n}}}{\mathrm{k}_{\mathrm{CP}}[\mathrm{NiA}]_{1}}=\frac{[\mathrm{NiA}]_{\mathrm{n}}}{[\mathrm{NiA}]_{1}}
$$

\section{Comparison of Rate Data to Model Prediction}

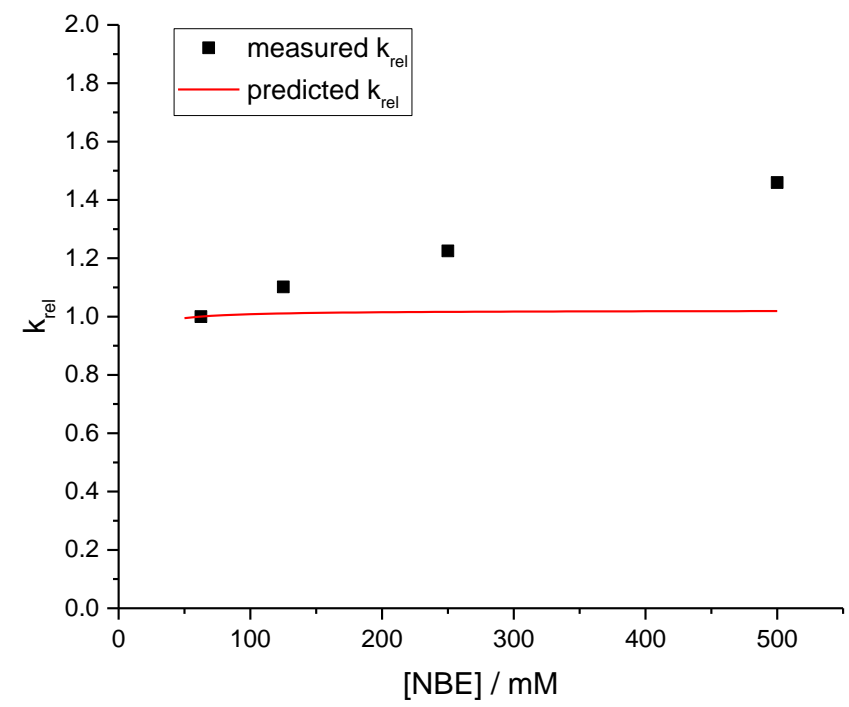

Figure S24. Plot of NBE concentration versus the normalized measured rate (squares) and predicted rate (red curve) based on our 
model (eq (S35) for cyclopropanation with no further adjustment of parameters. $\mathrm{k}_{\mathrm{CP}} / \mathrm{k}_{\mathrm{H}}=0.014,[\mathrm{Ni}]_{\mathrm{tot}}=0.25 \mathrm{mM},[\mathrm{P}]_{\mathrm{tot}}=0.5 \mathrm{mM}$.

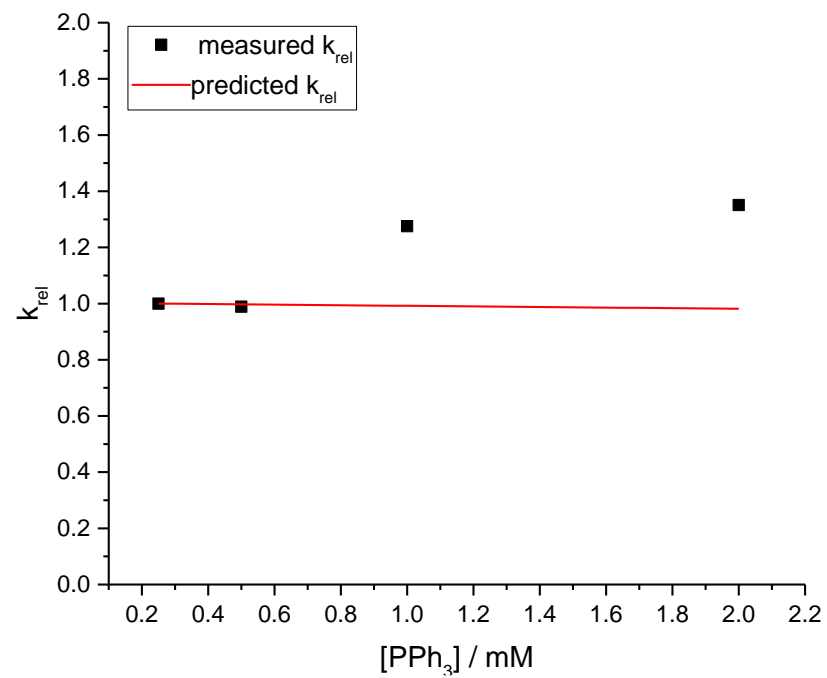

Figure S25. Plot of ligand (PPh3) concentration versus the normalized measured rate (squares) and predicted rate (red curve) based on our model (eq (S35)) for the cyclopropanation of NBE with no further adjustment of parameters. $\mathrm{k}_{\mathrm{CP}} / \mathrm{k}_{\mathrm{H}}=0.014$, $[\mathrm{Ni}]_{\text {tot }}=0.25 \mathrm{mM}$, $[A]_{\text {tot }}=250 \mathrm{mM}$.

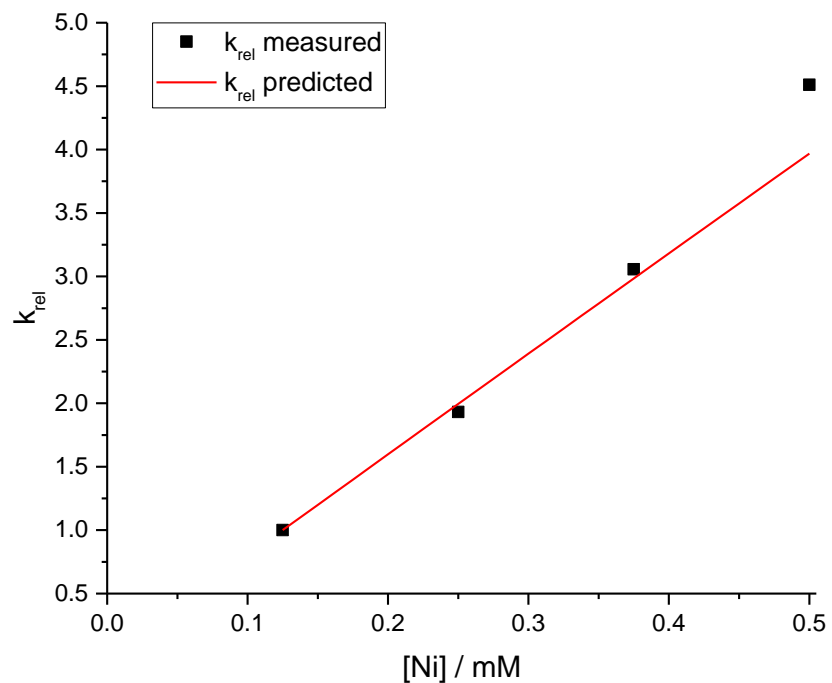

Figure S26. Plot of catalyst, $\left(\mathrm{Ph}_{3} \mathrm{P}\right)_{2} \mathrm{NiBr}_{2}$, concentration versus the measured rate (squares) using method $A$ and predicted rate (red curve) based on our model (eq (S35)), with no further adjustment of parameters. $\mathrm{k}_{\mathrm{CP}} / \mathrm{k}_{\mathrm{H}}=0.014,[\mathrm{P}]_{\mathrm{tot}}=2[\mathrm{Ni}]_{\text {tot }},[\mathrm{A}]_{\text {tot }}=250 \mathrm{mM}$.

\section{Headspace Analysis}

Scheme S16. Headspace Analysis in the Absence of Added Alkene.

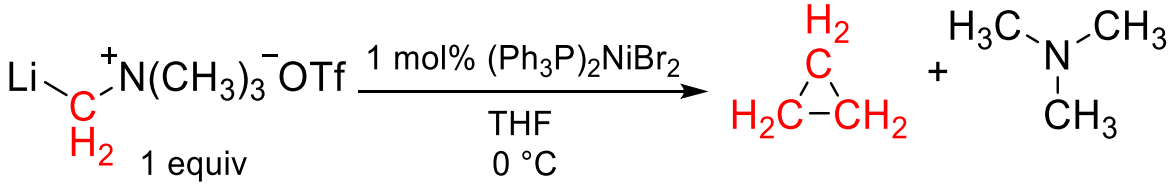


Inside the glove box, an oven-dried $50 \mathrm{~mL}$ Schlenk flask equipped with a J. Young inlet valve, glass stopper, screw cap with septum and a glass-coated stir bar was charged with [NMe $\left.{ }_{4}\right] \mathrm{OTf}$ (245.5 mg, $\left.1.1 \mathrm{mmol}, 1.1 \mathrm{equiv}\right)$. The flask was removed from the glove box and attached to a Schlenk line. Dry THF $(18.5 \mathrm{~mL})$ was added via syringe. Cyclooctane $(100 \mu \mathrm{L})$ was added via a $100 \mu \mathrm{L}$ micro syringe as internal standard. The flask was immersed in an ice bath and the reaction allowed to equilibrate (over ca. $20 \mathrm{~min}$ ).

BuLi (500 $\mu \mathrm{L}, 1 \mathrm{mmol}, 1$ equiv; $2 \mathrm{M}$ in cyclohexane) was added dropwise over ca. $30 \mathrm{~s}$ via a $1 \mathrm{~mL}$ gastight Hamilton syringe (by difference; previously dried at $50^{\circ} \mathrm{C}$ in a vacuum oven). The flask was sealed/closed to the Schlenk line unless reagents were added or aliquots collected.

After $15 \mathrm{~min}$, an aliquot (ca. $0.2 \mathrm{~mL}$ ) was taken with a disposable $1 \mathrm{~mL}$ plastic syringe (flushed several times with $\mathrm{Ar}$ ) and immediately quenched by injection into $0.2 \mathrm{~mL} 1 \mathrm{M}$ TFA in DCM ( $\mathrm{t}=0 \mathrm{~min})$.

Then, $\left(\mathrm{Ph}_{3} \mathrm{P}\right)_{2} \mathrm{NiBr}_{2}(1 \mathrm{~mol} \%, 0.01 \mathrm{mmol})$ in $1 \mathrm{~mL}$ THF (prepared as stock solution inside the glove box) was added dropwise by difference with a $2.5 \mathrm{~mL}$ gastight Hamilton syringe (previously dried at $50{ }^{\circ} \mathrm{C}$ in a vacuum oven) over ca. $30 \mathrm{~s}(\mathrm{t}=0 \mathrm{~min}$ with first drop). After the addition was completed, the flask was sealed/closed to the Schlenk line again until after the headspace aliquot was taken.

After $60 \mathrm{~min}$, the headspace was sampled with a $2.5 \mathrm{~mL}$ gastight Hamilton syringe (previously dried at $50{ }^{\circ} \mathrm{C}$ in a vacuum oven). Another aliquot ( $\mathrm{t}=60 \mathrm{~min}$ ) was then taken as described above.

The headspace sample (ca. $1 \mathrm{~mL}$ gas volume) was then analyzed by GC-MS.

Aliquots were diluted with $0.3 \mathrm{~mL} \mathrm{CD}_{3} \mathrm{OD}$ and analyzed by NMR.

An analogous reaction was conducted with $\left[\mathrm{N}\left(\mathrm{CD}_{3}\right)_{4}\right] \mathrm{OTf}(258.8 \mathrm{mg}, 1.1 \mathrm{mmol}, 1.1$ equiv). 
RT: $0.00-18.59$
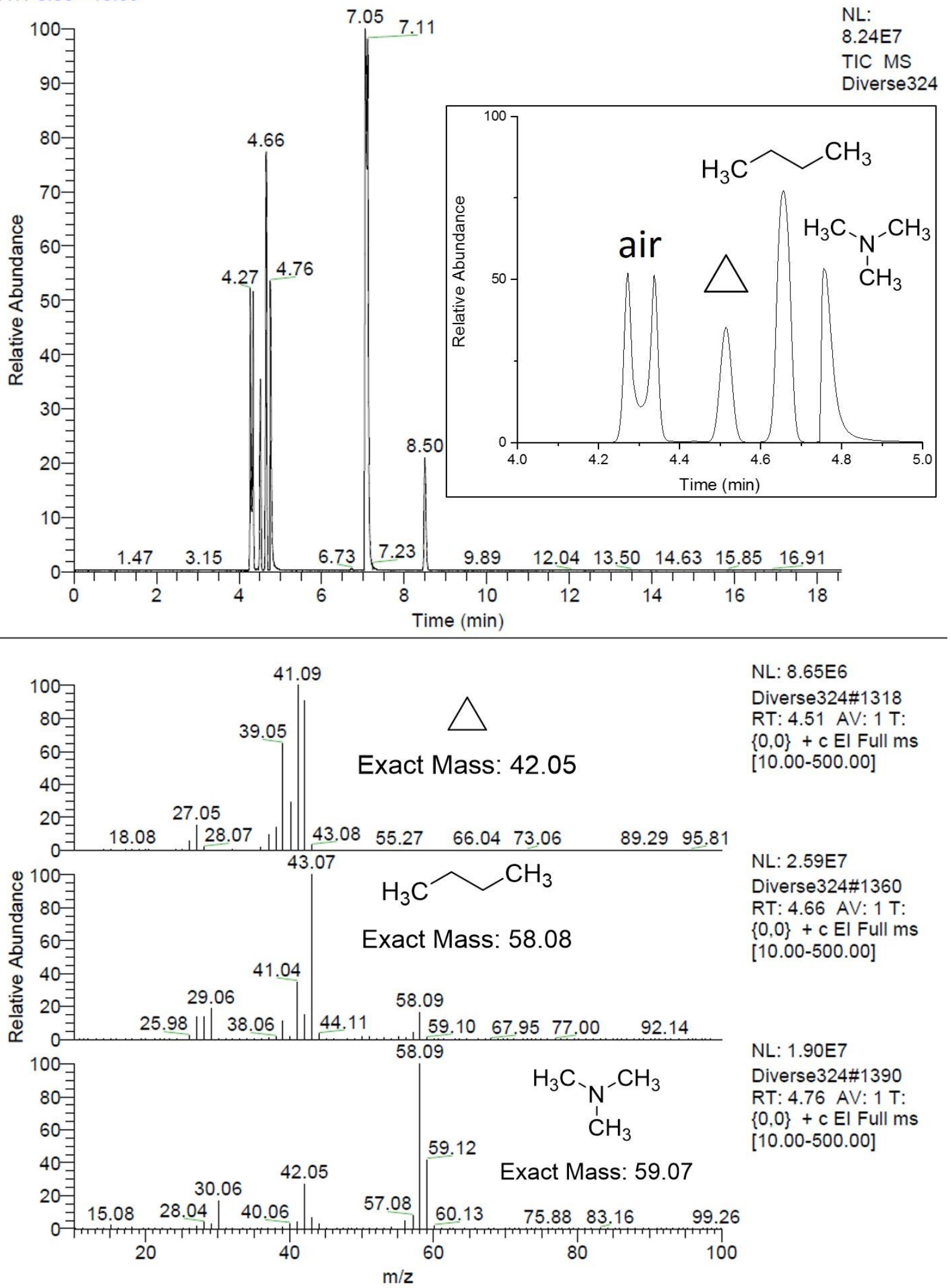

NL: 8.65E6

Diverse324\#1318

RT: 4.51 AV: $1 \mathrm{~T}$ :

$\{0,0\}+c$ El Full ms [10.00-500.00]

NL: $2.59 E 7$

Diverse324\#1360

RT: 4.66 AV: $1 \mathrm{~T}$ :

$\{0,0\}+c$ El Full ms

[10.00-500.00]

NL: $1.90 E 7$

Diverse324\#1390

RT: 4.76 AV: $1 \mathrm{~T}$ :

$\{0,0\}+c$ El Full ms [10.00-500.00]

Figure S27. Top: GC-MS chromatogram of a headspace sample after $60 \mathrm{~min}$ as described above with $\left[\mathrm{N}\left(\mathrm{CH}_{3}\right)_{4}\right] \mathrm{OTf}$. Peaks at $\mathrm{t}$ $=7.05$ and $7.11 \mathrm{~min}$ are THF. Peak at $\mathrm{t}=8.50 \mathrm{~min}$ is cyclohexane. Double peaks are due to detector overload (air (inset) and 
THF). Top, inset: Magnified chromatogram between 4 and 5 min with labeled peaks. Bottom: Mass spectra of selected compounds and their assigned structures with mass. 
RT: $0.00-9.13$
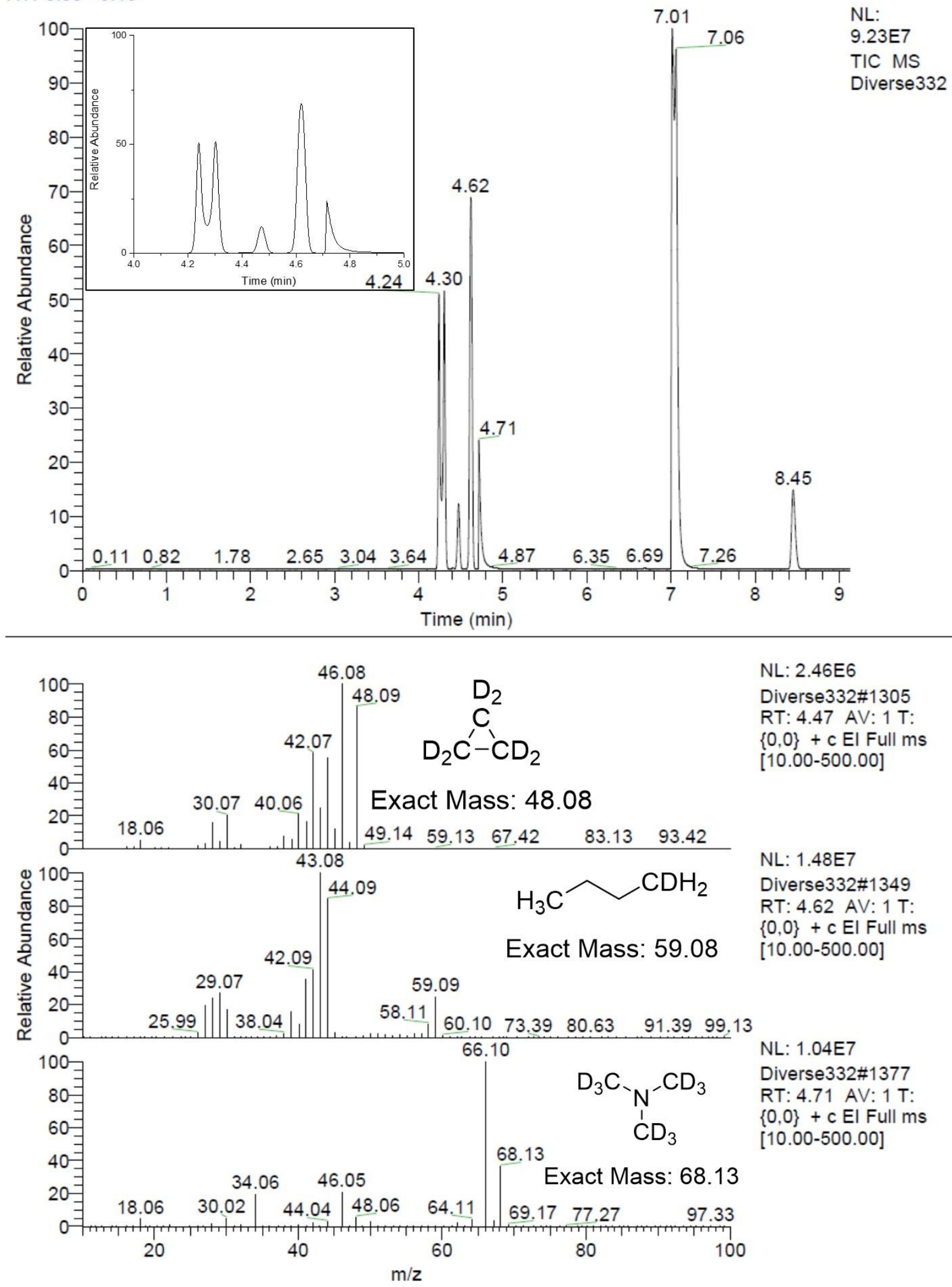

Figure S28. Top: GC-MS chromatogram of a headspace sample after $60 \mathrm{~min}$ as described above with $\left[\mathrm{N}\left(\mathrm{CD}_{3}\right)_{4}\right] \mathrm{OTf}$. Peaks at $\mathrm{t}$ $=7.01$ and $7.06 \mathrm{~min}$ are THF. Peak at $\mathrm{t}=8.45 \mathrm{~min}$ is cyclohexane. Double peaks are due to detector overload (air (inset) and 
THF). Top, inset: Magnified chromatogram between 4 and 5 min with analogous peak assignment as in Figure S27. Bottom: Mass spectra of selected compounds and their assigned structures with mass.

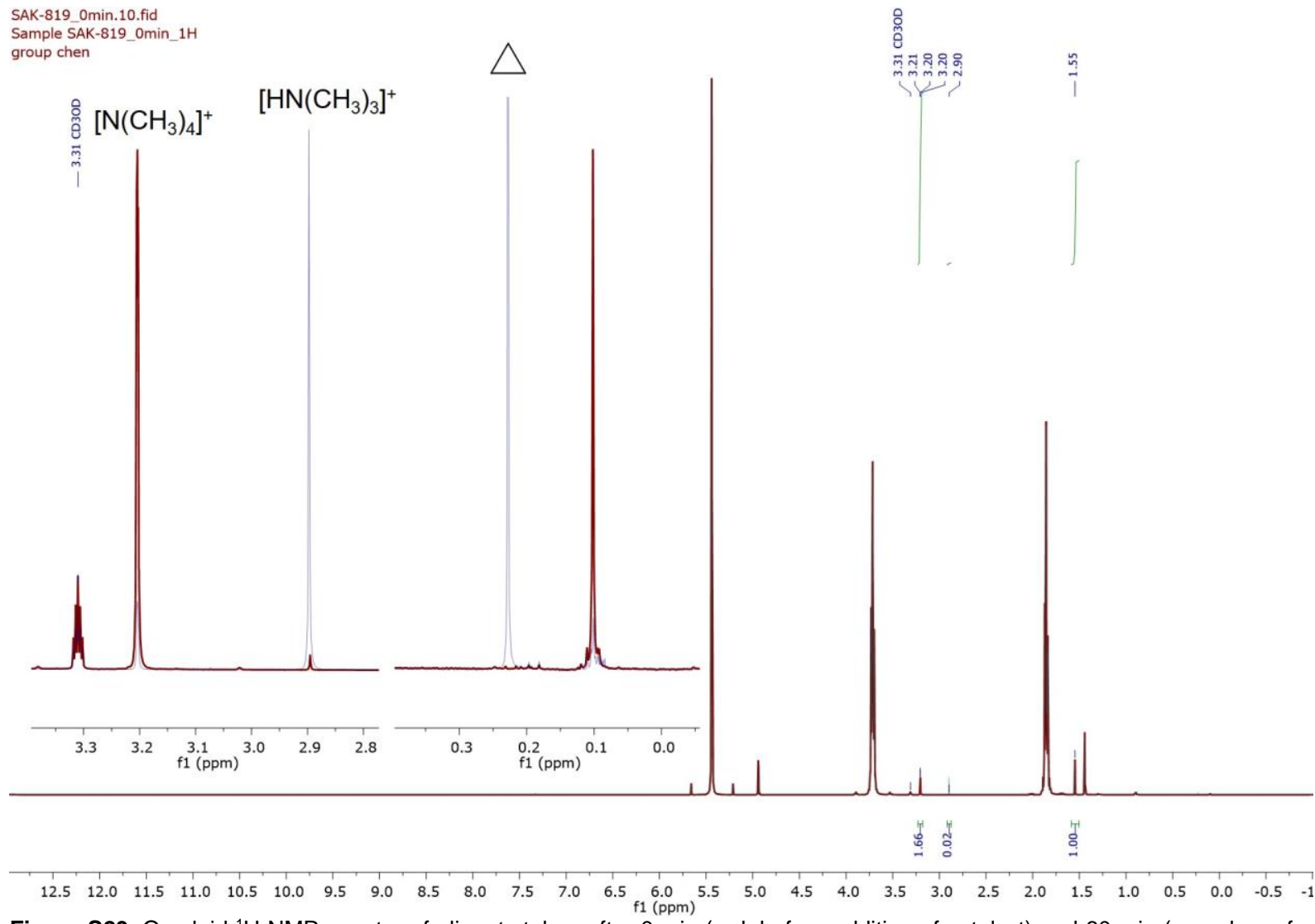

Figure S29. Overlaid ${ }^{1} \mathrm{H}$ NMR spectra of aliquots taken after 0 min (red, before addition of catalyst) and 60 min (see above for detailed description) using $\left[\mathrm{N}\left(\mathrm{CH}_{3}\right)_{4}\right]$ OTf. Inset: Enlarged regions show disappearance of $\left[\mathrm{N}\left(\mathrm{CH}_{3}\right)_{4}\right]^{+}$, formation of $\left[\mathrm{HN}\left(\mathrm{CH}_{3}\right)_{3}\right]^{+}$, and formation of cyclopropane $\mathrm{C}_{3} \mathrm{H}_{6}$ (assignment based on GC-MS and D-labelling). 


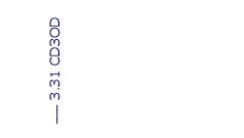

$\left[\mathrm{N}\left(\mathrm{CD}_{3}\right)_{3}\left(\mathrm{CD}_{2} \mathrm{H}\right)\right]^{+}$
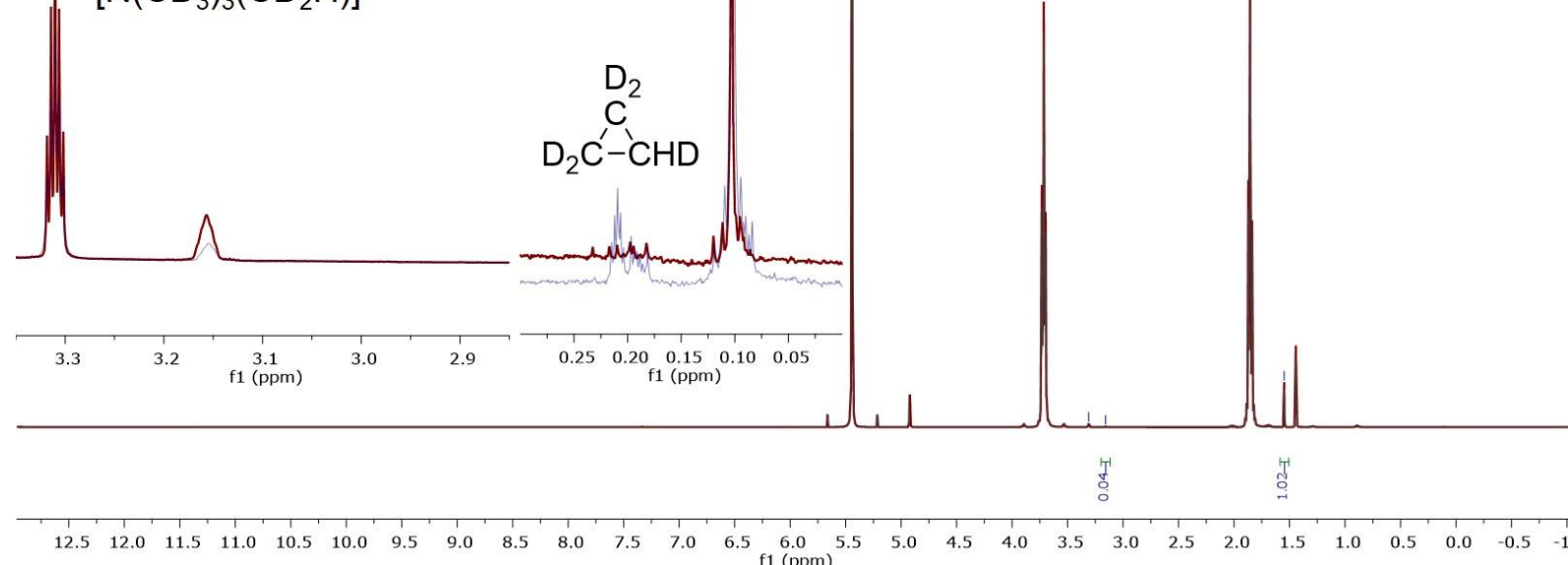

Figure S30. Overlaid ${ }^{1} \mathrm{H}$ NMR spectra of aliquots taken after $0 \mathrm{~min}$ (red, before addition of catalyst) and 60 min (see above for detailed description) using $\left[\mathrm{N}\left(\mathrm{CD}_{3}\right)_{4}\right] \mathrm{OTf}$. Inset: Enlarged regions show disappearance of $\left[\mathrm{N}\left(\mathrm{CD}_{3}\right)_{3}\left(\mathrm{CHD}_{2}\right)\right]^{+}\left(\right.$from $\mathrm{H}^{+}$quench) and formation of cyclopropane $\mathrm{C}_{3} \mathrm{HD}_{5}$ (assignment based on GC-MS and D-labelling).

\section{Trapping Experiments with BnNMe}

Scheme S17. Attempted Cyclopropanation of Norbornene with Methyltriphenylphosphonium Triflate in the Presence of N,N-Dimethylbenzylamine.

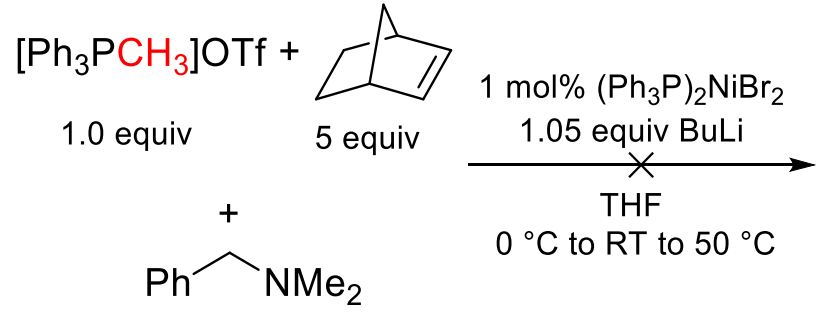

10 equiv<smiles>CN(C)C[PH2+]CC1C2CCC1C1CCC12</smiles><smiles>Cc1ccccc1CN(C)CCOc1cccc(C(C)N(C)C)c1</smiles>

Inside the glove box, an oven-dried $5 \mathrm{~mL}$ Schlenk flask equipped with a Teflon tap and a glass-coated stir bar was charged with [ $\mathrm{NMe}_{4}$ ] OTf (22.3 mg, $0.1 \mathrm{mmol}, 1$ equiv), $\left(\mathrm{Ph}_{3} \mathrm{P}\right)_{2} \mathrm{NiBr}_{2}$ in $0.2 \mathrm{~mL}$ THF (1 mol\%, prepared as stock solution), norbornene (47 mg, $0.5 \mathrm{mmol}, 5$ equiv), and $1.8 \mathrm{~mL}$ THF (tot. vol. THF: $2 \mathrm{~mL}, 0.05 \mathrm{M}$ ). The flask was removed from the glove box, cooled to $0{ }^{\circ} \mathrm{C}$ in an ice/water bath. BnNMe $(150 \mu \mathrm{L}, 1.0 \mathrm{mmol}, 10$ equiv) and BuLi (2 M in cyclohexane; $53 \mu \mathrm{L}, 0.105 \mathrm{mmol}, 1.05$ equiv) were added dropwise via micro syringe under a counterflow of Ar. The flask was sealed (no gas exchange). The flask was removed from the cooling bath and stirred at room temperature for $2 \mathrm{~h}$. An aliquot was taken and showed no product formation by GC.

The reaction was heated to $50{ }^{\circ} \mathrm{C}$ for an additional $14 \mathrm{~h}$. Another aliquot was analyzed by GC and showed no product formation. 
Aliquots (ca. $0.2 \mathrm{~mL}$ ) were partitioned between $2 \mathrm{~mL}$ pentane and $2 \mathrm{~mL}$ water. After vigorous mixing of the aliquot with a vortex mixer, the organic phase was filtered through a plug of $\mathrm{MgSO}_{4}$ and analyzed by GC-FID.

The reaction was repeated in the absence of norbornene.

In both cases no rearrangement product stemming from carbene trapping and formation of $N, N, N$-trimethylbenzylammonium ylide was observed, namely $N, N$-dimethyl-1-(o-tolyl)methanamine and/or $N, N$-dimethyl-1-phenylethan-1-amine.

Scheme S18. Cyclopropanation of Norbornene in the Presence of N,N-Dimethylbenzylamine.

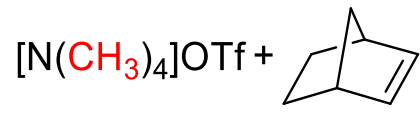<smiles>O=C(O)C1CCCC1C(=O)O</smiles>
$1 \mathrm{~mol} \%\left(\mathrm{Ph}_{3} \mathrm{P}\right)_{2} \mathrm{NiBr}_{2}$<smiles>CN(C)C[Pb]CC1CC2CCC1C2</smiles>
$71 \%$<smiles>Cc1ccccc1CN(C)CCOCCOCCOCCOCCOCCO</smiles>

Inside the glove box, an oven-dried $5 \mathrm{~mL}$ Schlenk flask equipped with a Teflon tap and a glass-coated stir bar was charged with [ $\mathrm{NMe}_{4}$ ]OTf (22.3 mg, $0.1 \mathrm{mmol}, 1$ equiv), norbornene ( $47 \mathrm{mg}, 0.5 \mathrm{mmol}, 5$ equiv), and $1.8 \mathrm{~mL}$ THF (tot. vol. THF: $2 \mathrm{~mL}$, $0.05 \mathrm{M})$. The flask was removed from the glove box, cooled to $0^{\circ} \mathrm{C}$ in an ice/water bath. BuLi $(2 \mathrm{M}$ in cyclohexane; $53 \mu \mathrm{L}$, $0.105 \mathrm{mmol}, 1.05$ equiv) was added dropwise via micro syringe under a counterflow of Ar. The flask was sealed (no gas exchange). After $10 \mathrm{~min}, \mathrm{BnNMe}_{2}\left(150 \mu \mathrm{L}, 1.0 \mathrm{mmol}, 10\right.$ equiv) was added, followed immediately by $\left(\mathrm{Ph}_{3} \mathrm{P}\right)_{2} \mathrm{NiBr}_{2}$ in $0.2 \mathrm{~mL}$ THF (1 mol\%, prepared as stock solution). The reaction was allowed to warm to RT inside the ice/water bath overnight. Undecane ( $10 \mu \mathrm{L}$; internal standard) was added and an aliquot (ca. $0.2 \mathrm{~mL}$ ) was partitioned between $2 \mathrm{~mL}$ pentane and $2 \mathrm{~mL}$ water. After vigorous mixing of the aliquot with a vortex mixer, the organic phase was filtered through a plug of $\mathrm{MgSO}_{4}$ and analyzed by GC-FID. The yield was determined by the integral ratio of the cyclopropane product versus undecane as internal standard using a previously determined calibration curve.

The reaction was repeated in the absence of norbornene.

In both cases no rearrangement product stemming from carbene trapping and formation of $\mathrm{N}, \mathrm{N}, \mathrm{N}$-trimethylbenzylammonium ylide was observed, namely $N, N$-dimethyl-1-(o-tolyl)methanamine and/or $N, N$-dimethyl-1-phenylethan-1-amine.

\section{Scheme S19. Rearrangement of N,N,N-Trimethylbenzylammonium Ylide.}

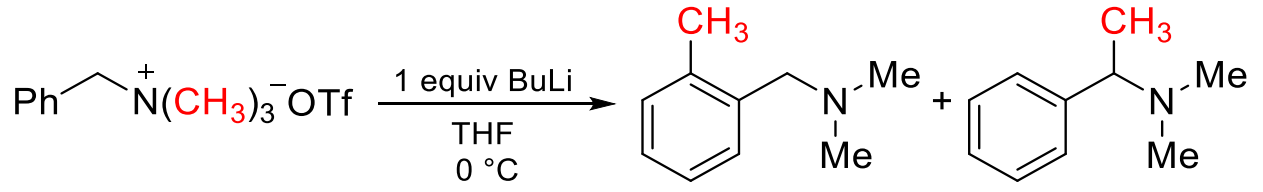

Inside the glove box, an oven-dried $5 \mathrm{~mL}$ Schlenk flask equipped with a Teflon tap and a glass-coated stir bar was charged with $\left[\mathrm{BnNMe}_{3}\right] \mathrm{OTf}\left(29.9 \mathrm{mg}, 0.1 \mathrm{mmol}, 1\right.$ equiv) and $2 \mathrm{~mL}$ THF. The flask was removed from the glove box, cooled to $0{ }^{\circ} \mathrm{C}$ in an ice/water bath. BuLi ( $2 \mathrm{M}$ in cyclohexane; $50 \mu \mathrm{L}, 0.1 \mathrm{mmol}, 1.0$ equiv) was added dropwise via micro syringe under a counterflow of Ar. The flask was sealed (no gas exchange).

After $45 \mathrm{~min}$, the reaction was quenched with a few drops of $\mathrm{CD}_{3} \mathrm{OD}$. An aliquot (ca. $0.2 \mathrm{~mL}$ ) was partitioned between $2 \mathrm{~mL}$ $\mathrm{Et}_{2} \mathrm{O}$ and $2 \mathrm{~mL}$ water. After vigorous mixing of the aliquot with a vortex mixer, the organic phase was filtered through a plug of $\mathrm{MgSO}_{4}$ and analyzed by GC-MS. The remaining mixture was evaporated to dryness and analyzed by NMR.

The products were identified by GC-MS and by comparison to literature NMR data. ${ }^{8}$ 


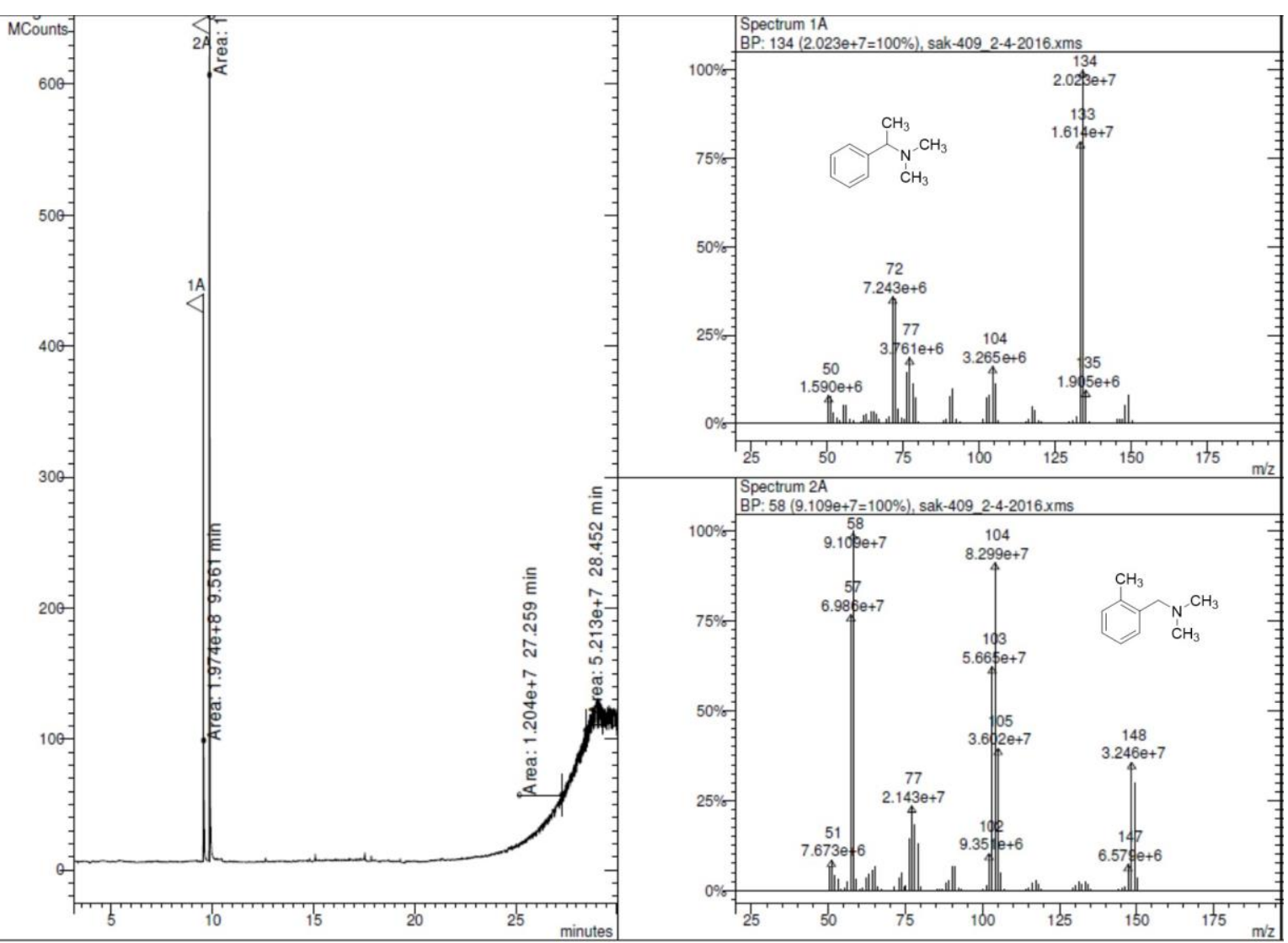

Figure S31. Left: GC-MS chromatogram of the $N, N, N$-trimethylbenzylammonium ylide rearrangement after 45 min. Right: Mass spectra of the rearrangement products.

\section{Addition of Excess $\mathrm{PPh}_{3}$}

Scheme S20. Cyclopropanation of Cyclooctene in the Presence of Excess $\mathrm{PPh}_{3}$.

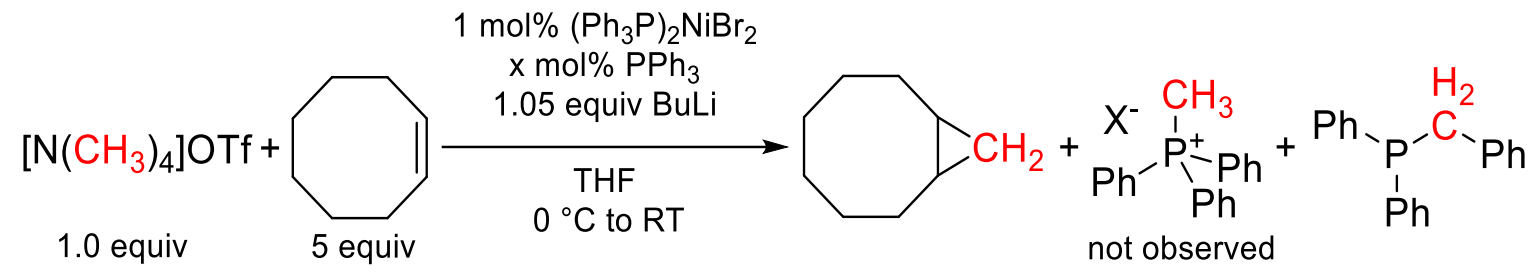

Inside the glove box, an oven-dried $5 \mathrm{~mL}$ Schlenk flask equipped with a Teflon and a glass-coated stir bar was charged with [NMe ${ }_{4}$ OTf (22.3 mg, $0.1 \mathrm{mmol}, 1$ equiv), $\mathrm{PPh}_{3}(\mathrm{~A}: 7.2 \mathrm{mg}, 0.027 \mathrm{mmol}, 27 \mathrm{~mol} \%$ or B: $26.6 \mathrm{mg}, 0.101 \mathrm{mmol}, 101 \mathrm{~mol} \%), \mathrm{COE}$ (65 $\mu \mathrm{L}, 0.5 \mathrm{mmol}, 5$ equiv), $\left(\mathrm{Ph}_{3} \mathrm{P}\right)_{2} \mathrm{NiBr}_{2}$ in THF $(0.001 \mathrm{mmol}, 0.01$ equiv, prepared as stock solution), and THF (tot. vol. THF: $2 \mathrm{~mL}, 0.05 \mathrm{M})$. The flask was removed from the glove box, cooled to $0{ }^{\circ} \mathrm{C}$ in an ice/water bath, and BuLi (2 M in cyclohexane; $53 \mu \mathrm{L}, 0.105 \mathrm{mmol}, 1.05$ equiv) was added dropwise via micro syringe under a counterflow of Ar. The flask was sealed (no gas exchange)and the reaction was allowed to warm to RT inside the ice/water bath. After $16 \mathrm{~h}$, the reaction was quenched with $0.1 \mathrm{~mL} \mathrm{CD} \mathrm{CD}_{3} \mathrm{OD}$. Undecane $(10 \mu \mathrm{L}$; internal standard) was added and an aliquot (ca. $0.2 \mathrm{~mL}$ ) was partitioned between 2 $\mathrm{mL}$ pentane and $2 \mathrm{~mL}$ water. After vigorous mixing of the aliquot with a vortex mixer, the organic phase was filtered through a plug of $\mathrm{MgSO}_{4}$ and analyzed by GC-MS.

The remaining reaction mixture was evaporated to dryness on the Schlenk line. The solid residue was dissolved in $\mathrm{CD}_{3} \mathrm{OD} / \mathrm{CDCl}_{3}(0.35 \mathrm{~mL} / 0.35 \mathrm{~mL})$ and analyzed by NMR. (Some solid remained undissolved, most likely polyethylene. Solubility tests showed $\left[\mathrm{PMePh}_{3}\right] \mathrm{Br}$, [NMe 4$] \mathrm{OTf}$, and $\mathrm{PPh}_{3}$ to be soluble in this solvent mixture at comparable concentrations).

Mixtures of authentic samples of $\left[\mathrm{PMePh}_{3}\right] \mathrm{Br} / \mathrm{PPh}_{3}, \mathrm{PBnPh}_{2} / \mathrm{PPh}_{3}$, and $\left[\mathrm{NMe}_{4}\right] \mathrm{OTf} / \mathrm{PPh}_{3}$ were prepared in the same solvent mixture at comparable concentration (ca. $0.1 \mathrm{mmol} / 0.7 \mathrm{~mL}$ per compound) and analyzed by NMR. 
Addition of an excess of $\mathrm{PPh}_{3}$ resulted in a strongly or even completely suppressed cyclopropanation of COE. A small amount of $\mathrm{PBnPh}_{2}$ (>10:1 $\mathrm{PPh}_{3}: \mathrm{PBnPh}_{2}$ by ${ }^{31} \mathrm{P} \mathrm{NMR}$ ) had formed (Figure S32), likely via a Ni(0)-promoted/catalyzed phospha-Stevens rearrangement of a small amount of in situ formed $\mathrm{Ph}_{3} \mathrm{P}=\mathrm{CH}_{2}{ }^{9}$

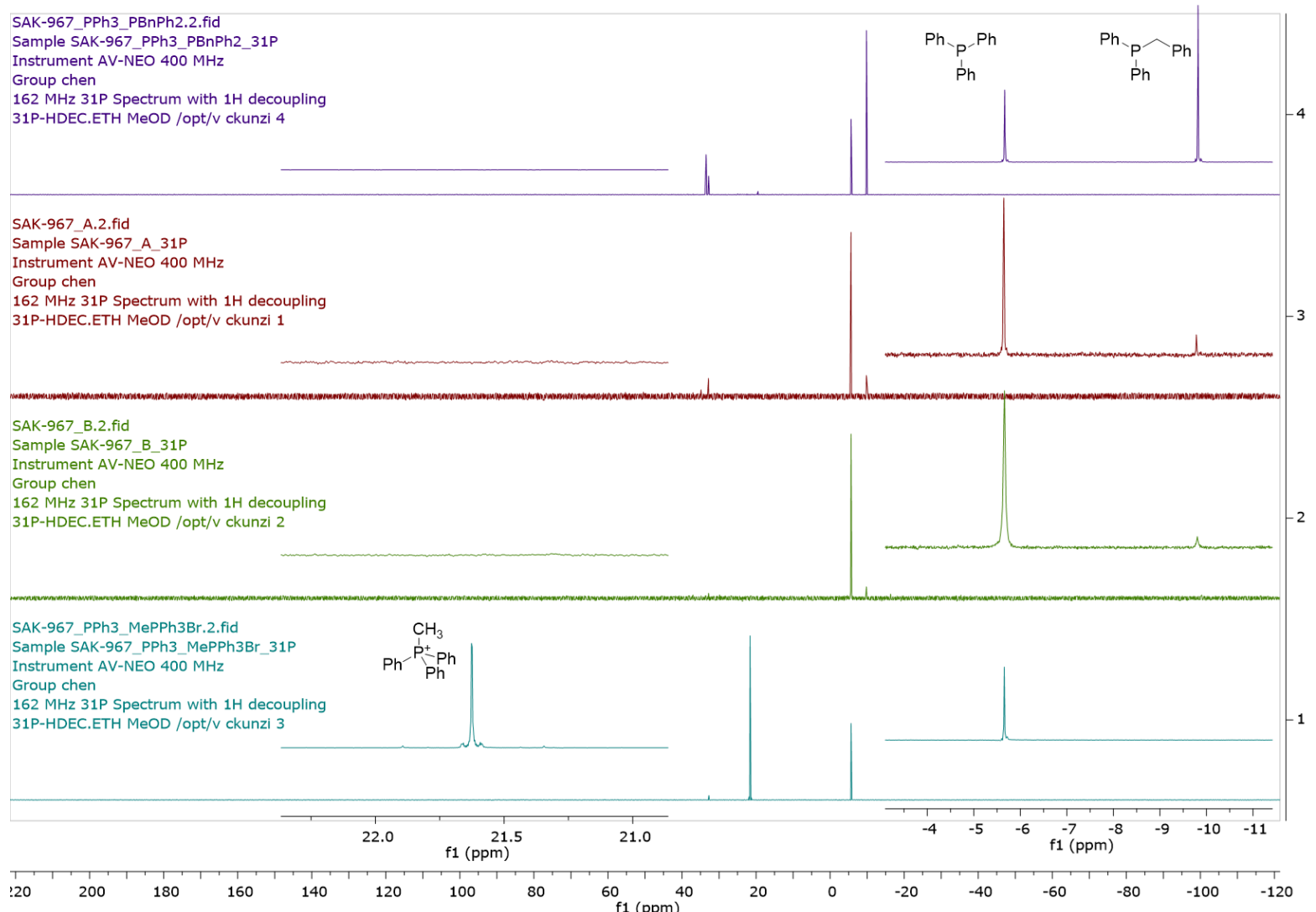

Figure S32. Stacked ${ }^{31} \mathrm{P}\left\{{ }^{1} \mathrm{H}\right\}$ spectra plot for a mixture of authentic $\mathrm{PPh}_{3}$ and $\mathrm{PBnPh}_{2}$ (Spectrum 4), reaction $\mathrm{A}$ with additional 27 mol\% $\mathrm{PPh}_{3}$ (Spectrum 3), reaction B with additional $101 \mathrm{~mol} \% \mathrm{PPh}_{3}$ (Spectrum 2), and a mixture of authentic $\mathrm{PPh}_{3}$ and $[\mathrm{PMePPh}] \mathrm{Br}$ (Spectrum 1). Left inset: Expansion of the $\left[\mathrm{PMePh}_{3}\right]^{+}$region. Right inset: Expansion of the $\mathrm{PPh}_{3} / \mathrm{PBnPh}_{2}$ region. 
SAK-967_A.2.fid

Sample SAK-967_A_31

Instrument AV-NEO $400 \mathrm{MHz}$

Group chen

$162 \mathrm{MHz}$ 31P Spectrum with $1 \mathrm{H}$ decoupling

31P-HDEC.ETH MeOD /opt/v ckunzi 1

$\mathrm{Ph}_{\mathrm{P}_{1}} \widehat{\mathrm{Ph}}_{\mathrm{Ph}}$

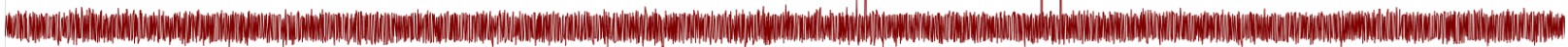

\section{पे}

$\begin{array}{lllllllllllllllllllllllllllllllllll}20 & 210 & 200 & 190 & 180 & 170 & 160 & 150 & 140 & 130 & 120 & 110 & 100 & 90 & 80 & 70 & 60 & 50 & 40 & 30 & 20 & 10 & 0 & -10 & -20 & -30 & -40 & -50 & -60 & -70 & -80 & -90 & -100 & -110 & -1\end{array}$

Figure S33. ${ }^{31} \mathrm{P}\left\{{ }^{1} \mathrm{H}\right\}$ spectrum for reaction $\mathrm{A}$ with additional $27 \mathrm{~mol} \% \mathrm{PPh}_{3}$ 
SAK-967_B.2.fid

Sample SAK-967_B_31P

Instrument AV-NEO $400 \mathrm{MHz}$

Group chen

$162 \mathrm{MHz}$ 31P Spectrum with $1 \mathrm{H}$ decoupling

31P-HDEC.ETH MeOD /opt/v ckunzi 2

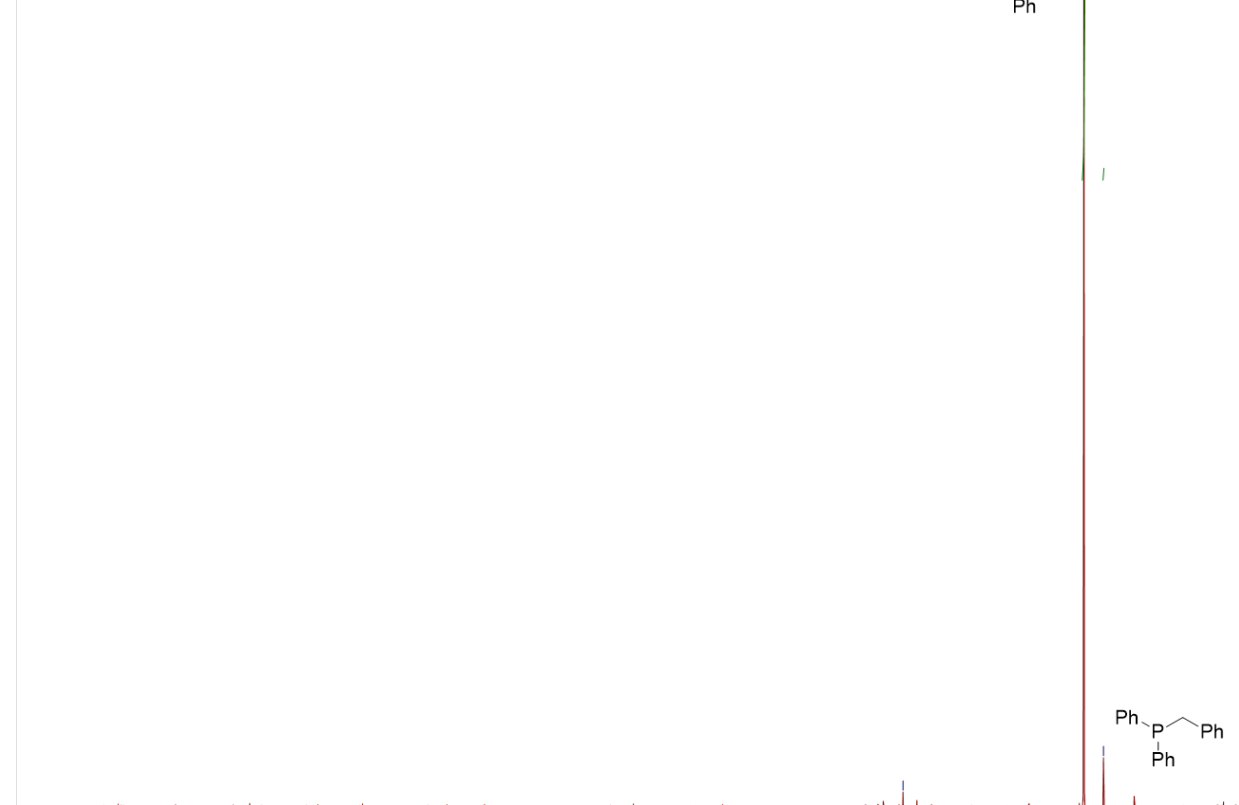

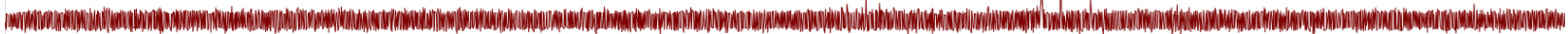

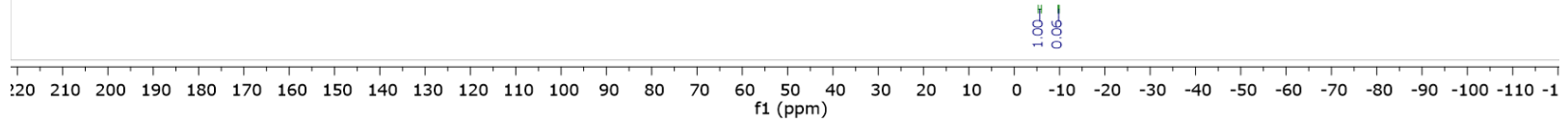

Figure S34. ${ }^{31} \mathrm{P}\left\{{ }^{1} \mathrm{H}\right\}$ spectrum for reaction $\mathrm{B}$ with additional $101 \mathrm{~mol}^{\circ} \mathrm{PPh}_{3}$ 


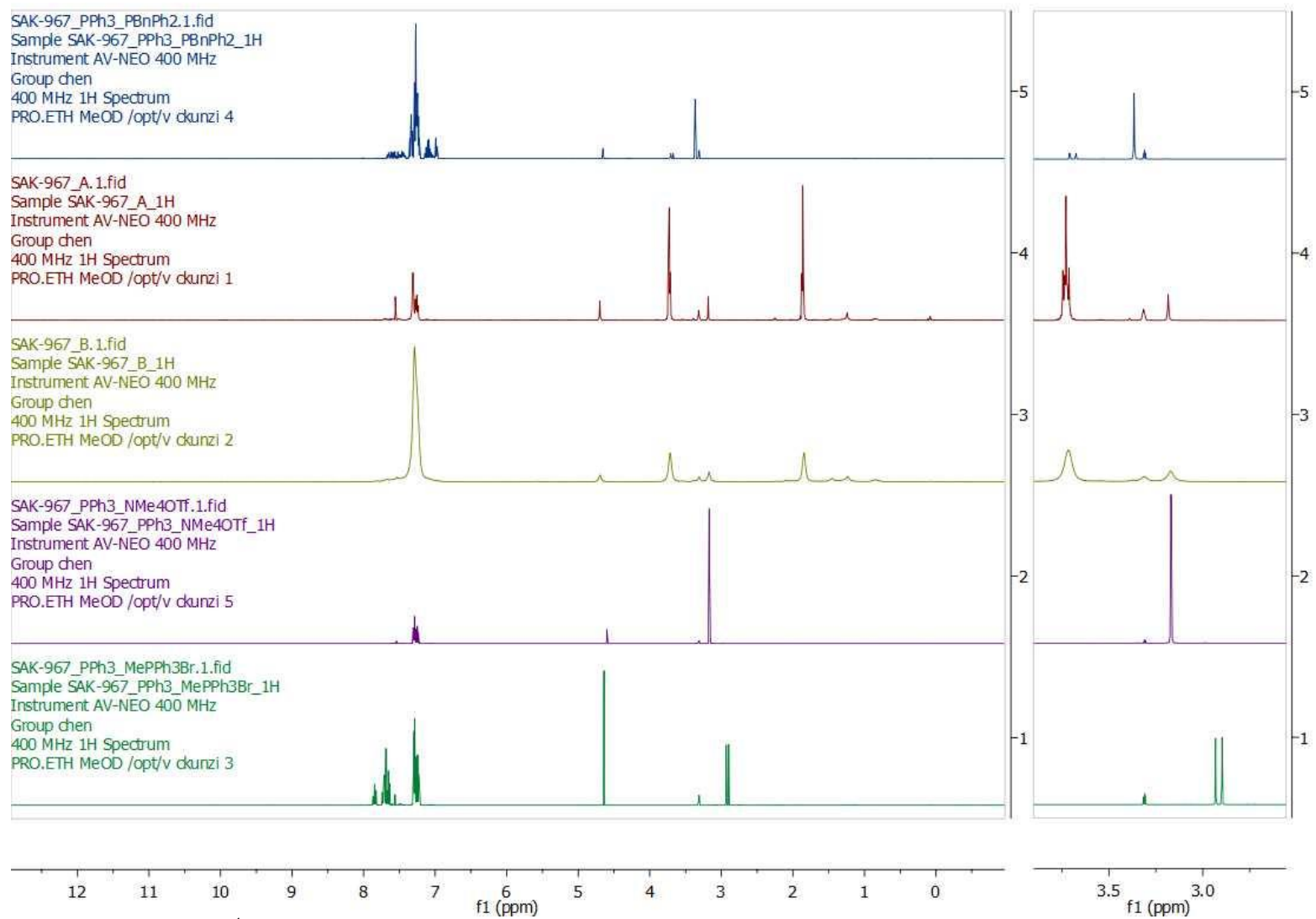

Figure S35. Stacked ${ }^{1} \mathrm{H}$ spectra plot for a mixture of authentic $\mathrm{PPh}_{3}$ and $\mathrm{PBnPh}_{2}$ (Spectrum 5), reaction A with additional 27 mol\% $\mathrm{PPh}_{3}$ (Spectrum 4), reaction B with additional 101 mol\% $\mathrm{PPh}_{3}$ (Spectrum 3), a mixture of authentic $\mathrm{PPh}_{3}$ and $\left[\mathrm{NMe}_{4}\right] \mathrm{OTf}(\mathrm{Spectrum}$ 2), and a mixture of authentic $\mathrm{PPh}_{3}$ and $[\mathrm{PMePPh}] \mathrm{Br}$ (Spectrum 1). Right inset: Expansion of the $\mathrm{P}\left(\mathrm{CH}_{2} \mathrm{Ph}\right) \mathrm{Ph}_{2} /\left[\mathrm{PPh}_{3}\left(\mathrm{CH}_{3}\right)\right]^{+} /\left[\mathrm{N}\left(\mathrm{CH}_{3}\right)_{4}\right]^{+}$region. 


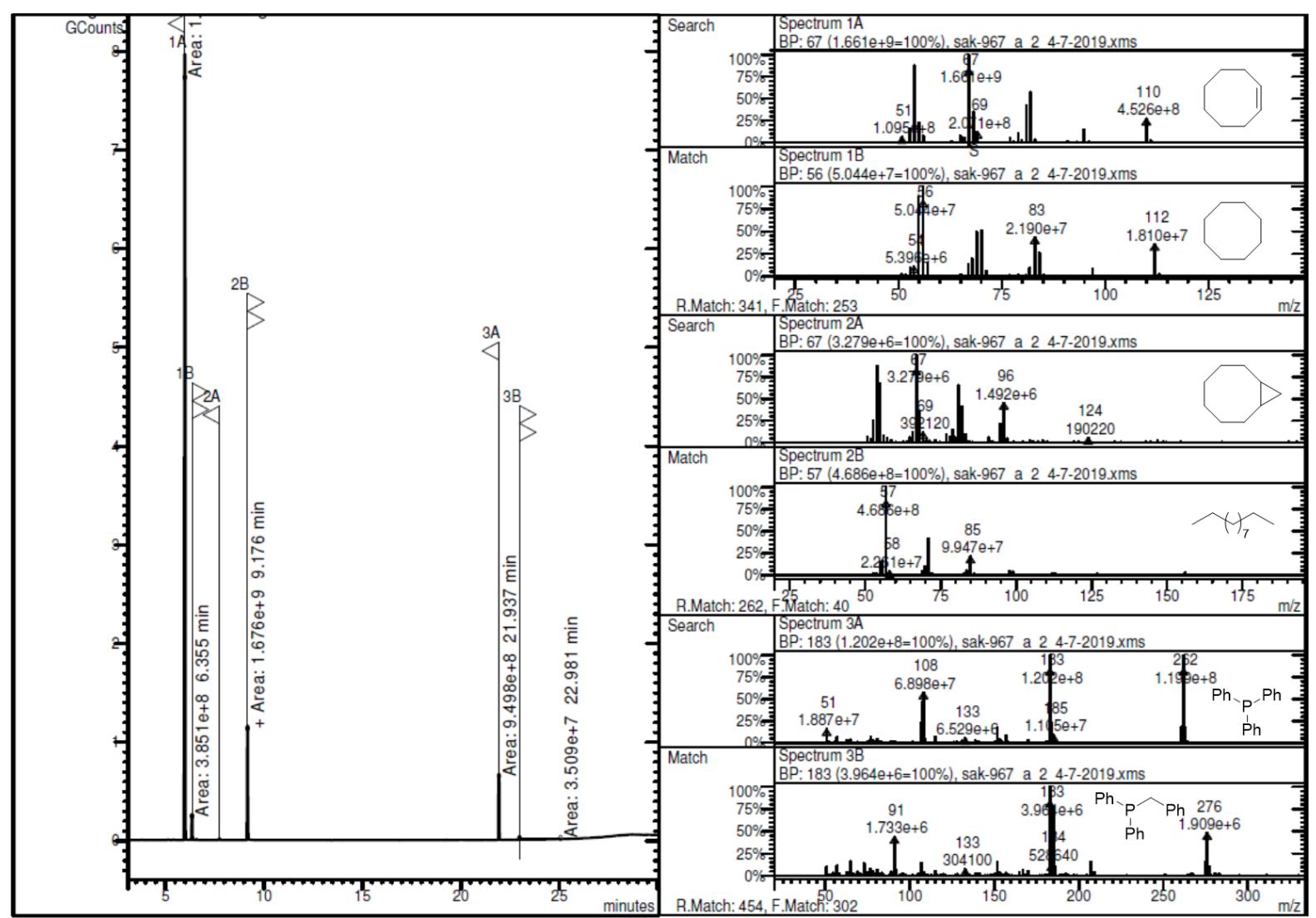

Figure S36. GC-MS chromatogram and mass spectra for reaction A with additional $27 \mathrm{~mol} \% \mathrm{PPh}_{3}$. Note: Cyclooctane is an impurity in cyclooctene. 


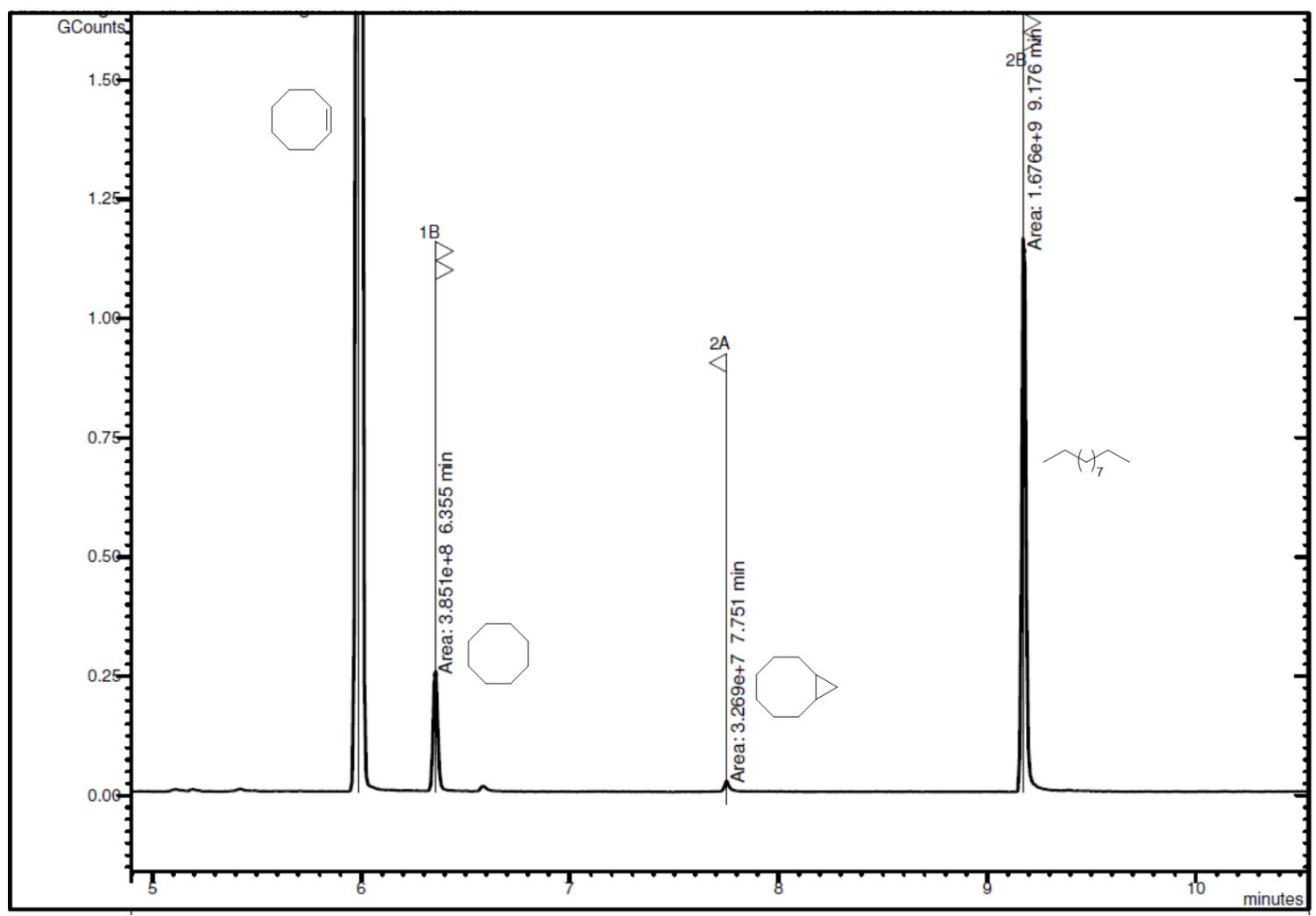

Figure S37. Enlarged GC-MS chromatogram for reaction A with additional $27 \mathrm{~mol} \% \mathrm{PPh}_{3}$ for the product region. Note: Cyclooctane is an impurity in cyclooctene.

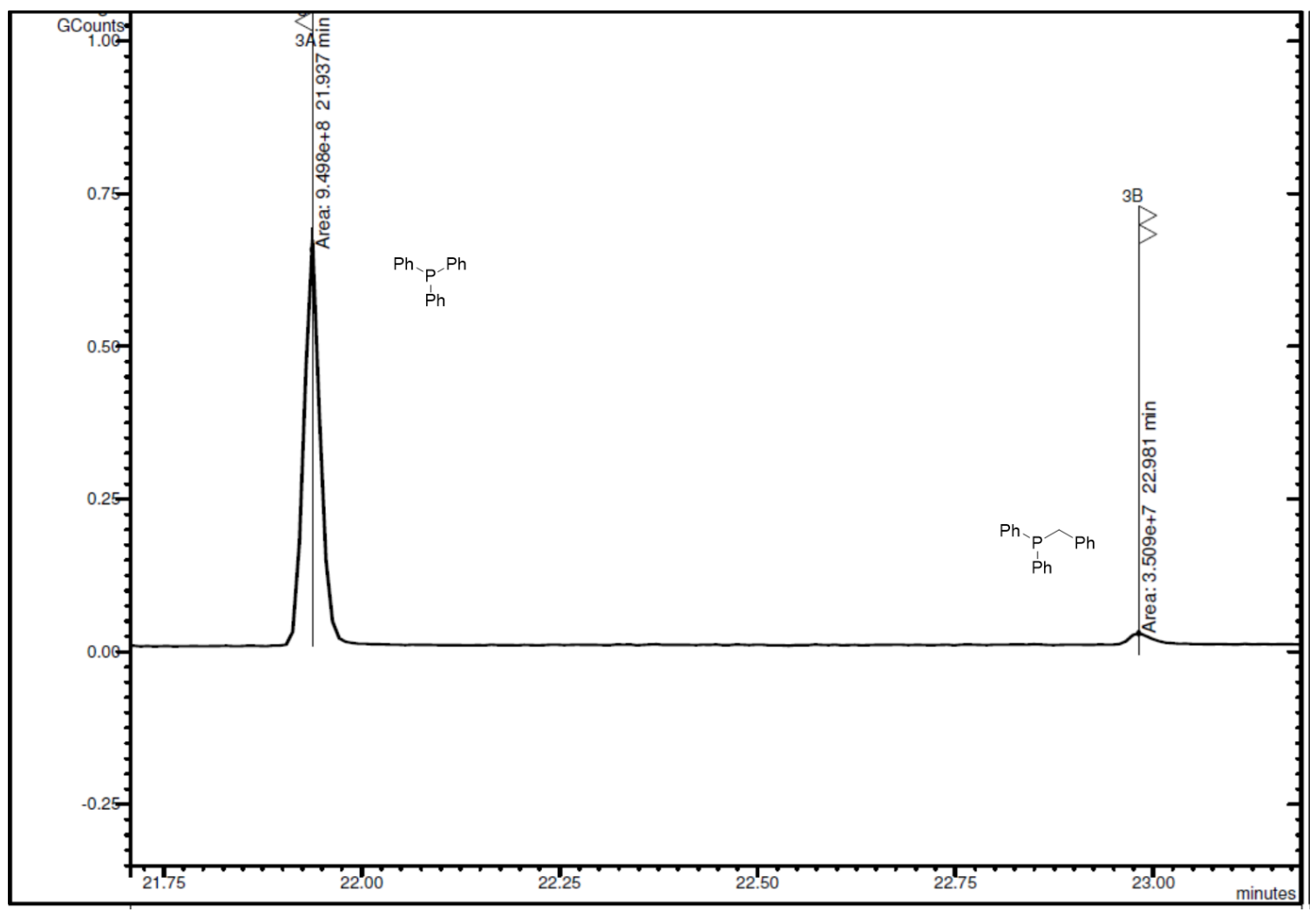

Figure S38. Enlarged GC-MS chromatogram for reaction A with additional $27 \mathrm{~mol}_{0} \mathrm{PPh}_{3}$ for the phosphine region.

S43 


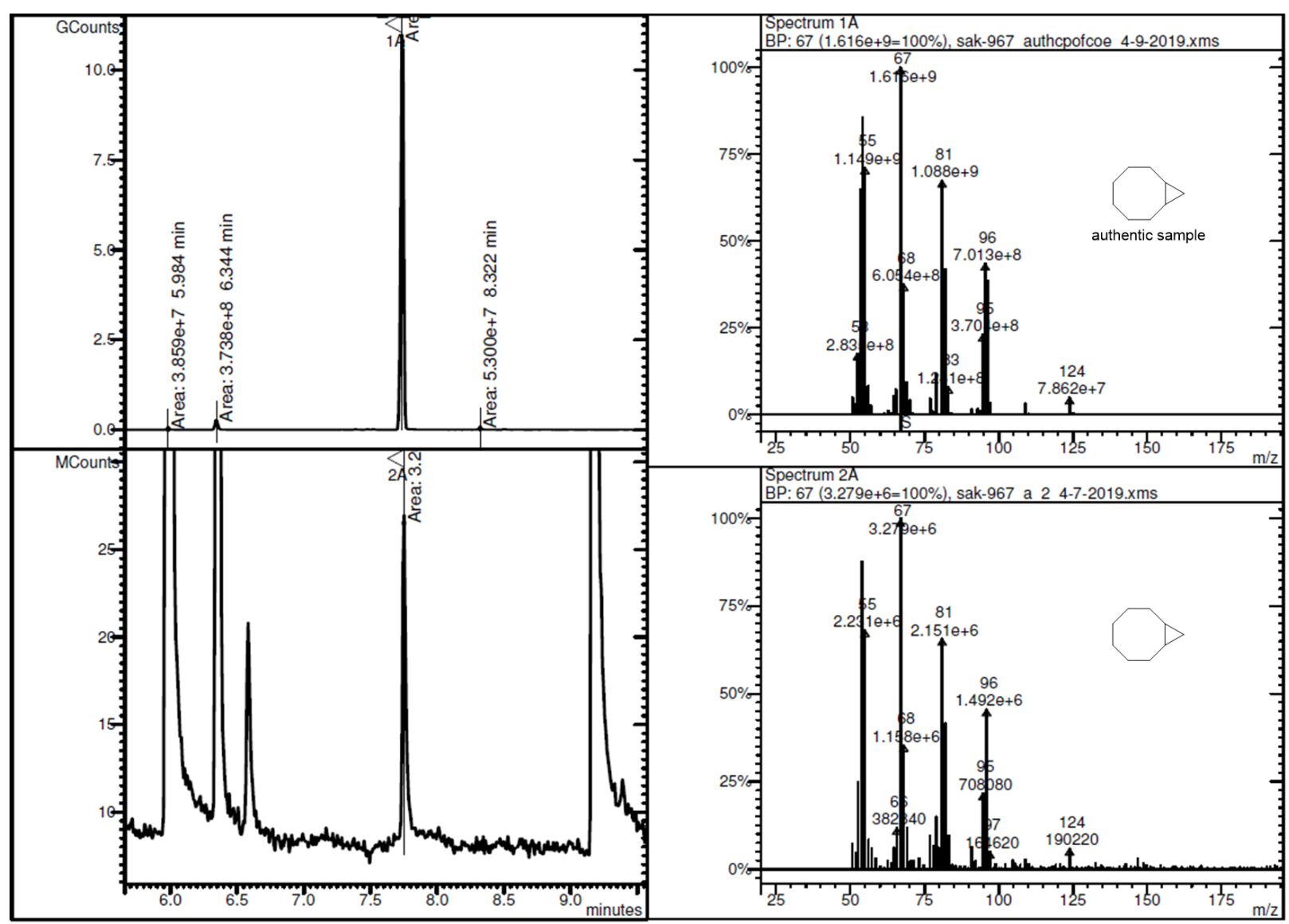

Figure S39. Enlarged GC-MS chromatogram and mass spectrum for reaction A with additional $27 \mathrm{~mol}_{\%} \mathrm{PPh}_{3}$ for the product region (bottom) and an authentic sample of the cyclopropanation product (top). 


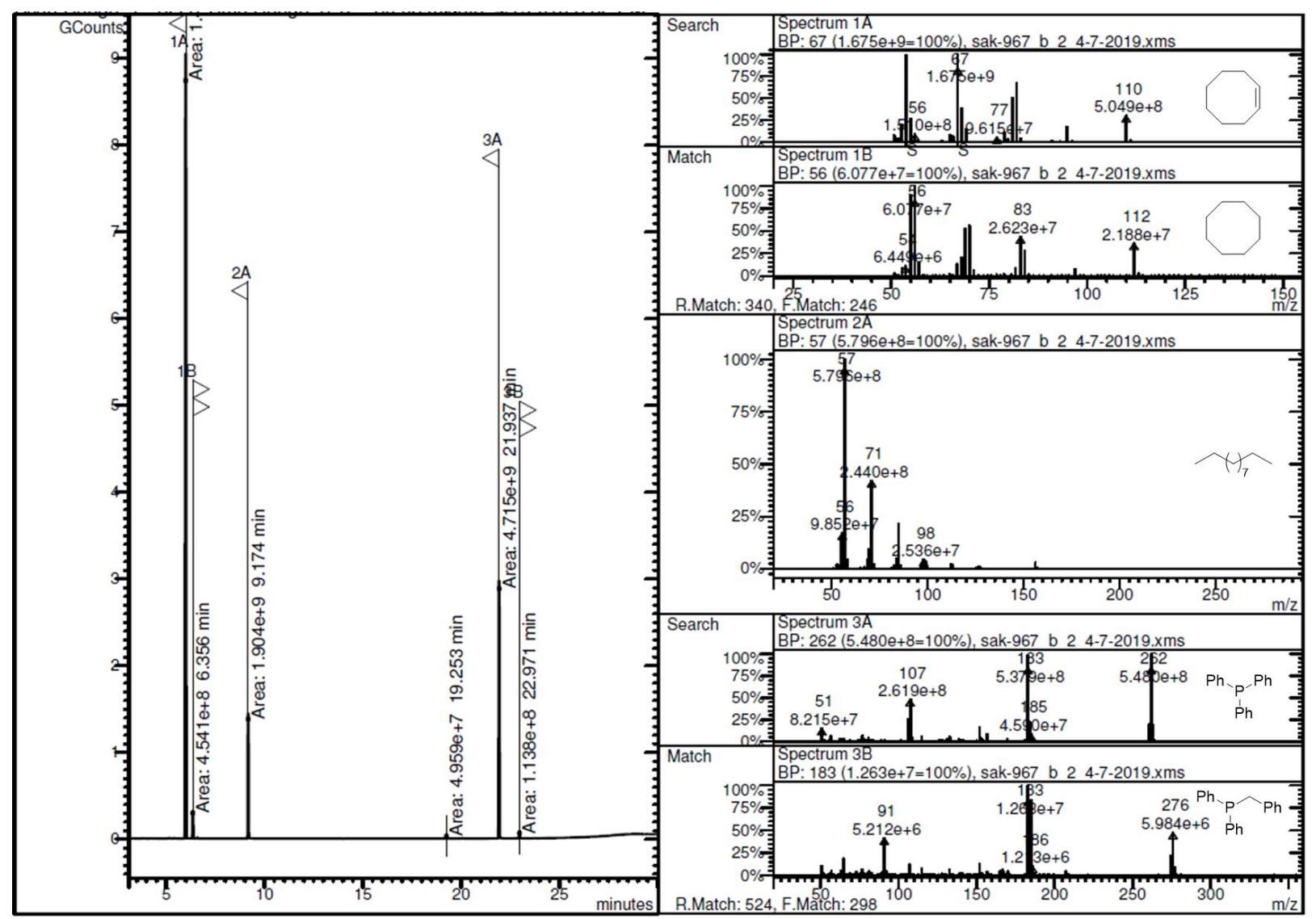

Figure S40. GC-MS chromatogram and mass spectra for reaction B with additional $101 \mathrm{~mol} \% \mathrm{PPh}_{3}$. Note: Cyclooctane is an impurity in cyclooctene. 


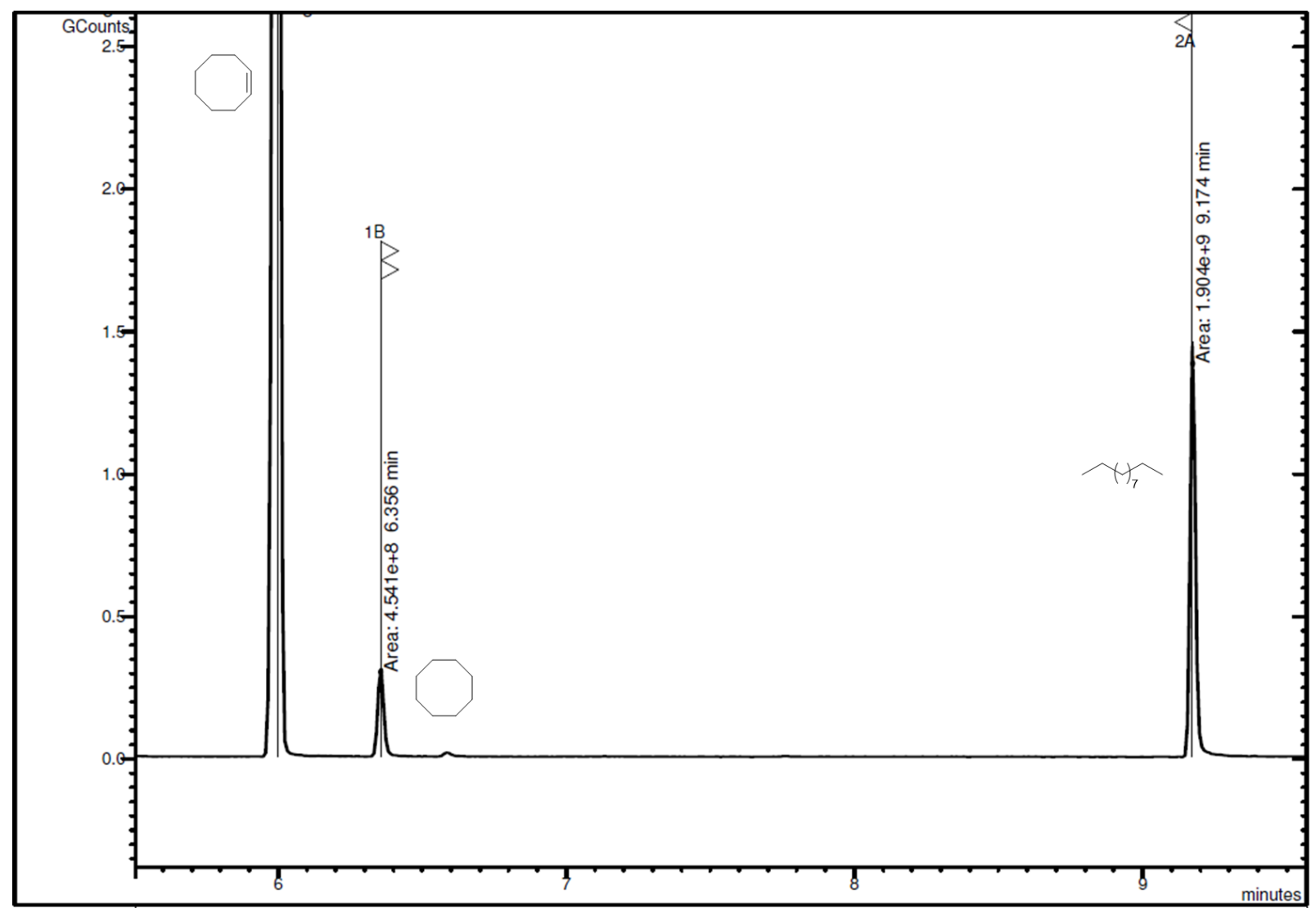

Figure S41. Enlarged GC-MS chromatogram for reaction B with additional $101 \mathrm{~mol}^{2} \mathrm{PPh}_{3}$ for the product region. No cyclopropanation of COE occurred. Note: Cyclooctane is an impurity in cyclooctene. 


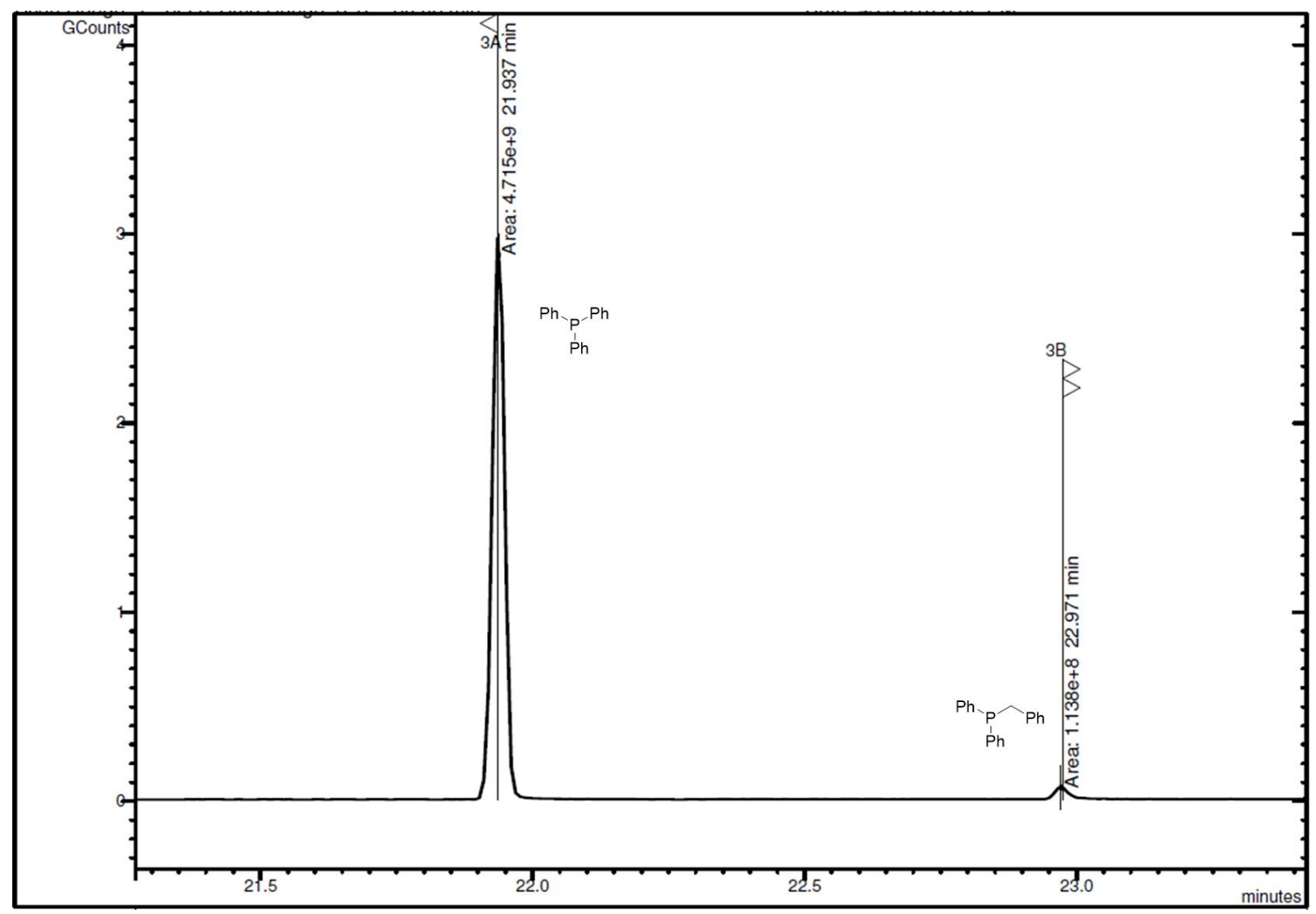

Figure S42. Enlarged GC-MS chromatogram for reaction B with additional $101 \mathrm{~mol} \% \mathrm{PPh}_{3}$ for the phosphine region.

\section{Synthesis of $\left[\mathrm{N}\left(\mathrm{CD}_{3}\right)_{4}\right] \mathrm{OTf}$}

Tetramethylammonium- $\mathrm{d}_{12}$ triflate was prepared in analogy to the protiated compound as reported previously, dried under vacuum and stored in the glove box..$^{1,2}$

The elemental analysis values for $\mathrm{C}, \mathrm{H}$ are outside the tolerance, most likely due to the level of deuteration. All other analysis techniques confirmed the purity.

Elemental analysis: Found: $\mathrm{C}, 25.02 ; \mathrm{H}, 4.61 ; \mathrm{N}, 6.05$. Calc. for $\mathrm{C}_{5} \mathrm{D}_{12} \mathrm{~F}_{3} \mathrm{NO}_{3} \mathrm{~S}$ : C, 25.52; D, 10.27, N, 5.95; O, 20.40; F, 24.22; S, 13.63. D determined as $\mathrm{H}: \mathrm{H}, 5.42$.

${ }^{1} \mathrm{H}$ NMR (400 MHz, $\left.\mathrm{CD}_{3} \mathrm{OD}\right)$ : $\delta 3.15$ (m, small amount of $\left.\left[\mathrm{N}\left(\mathrm{CD}_{3}\right)_{3}\left(\mathrm{CD}_{2} \mathrm{H}\right)\right]^{+}\right)$.

${ }^{1} \mathrm{H}$ NMR (600 MHz, $\left.\mathrm{D}_{2} \mathrm{O}\right): \delta 3.16\left(\mathrm{~m}\right.$, small amount of $\left.\left[\mathrm{N}\left(\mathrm{CD}_{3}\right)_{3}\left(\mathrm{CD}_{2} \mathrm{H}\right)\right]^{+}\right)$.

${ }^{2} \mathrm{H}$ NMR (92 MHz, $\left.\mathrm{D}_{2} \mathrm{O}\right)$ : $\delta 3.04$ (s).

${ }^{13} \mathrm{C}$ NMR (101 MHz, CD ${ }_{3}$ OD): $\delta 121.8\left(\mathrm{q},{ }^{1} \mathrm{~J}_{(\mathrm{C}-\mathrm{F})}=319 \mathrm{~Hz}\right), 54.7(\mathrm{~m})$.

${ }^{13} \mathrm{C}$ NMR (150 MHz, $\left.\mathrm{D}_{2} \mathrm{O}\right): \delta 119.6\left(\mathrm{q},{ }^{1} \mathrm{~J}_{(\mathrm{C}-\mathrm{F})}=317 \mathrm{~Hz}\right), 54.1(\mathrm{~m})$.

${ }^{19}$ F NMR (376 MHz, CD $\left.{ }_{3} \mathrm{OD}\right): \delta-80.1$.

${ }^{19} \mathrm{~F}$ NMR (470 MHz, $\left.\mathrm{D}_{2} \mathrm{O}\right): \delta-78.8$.

HRMS (ESI, $\left.\mathbf{M}^{+},\left[\mathrm{N}\left(\mathrm{CD}_{3}\right)_{4}\right]^{+}\right): \mathrm{m} / \mathrm{z}$ calcd for $\mathrm{C}_{4} \mathrm{D}_{12} \mathrm{~N}$ 86.1717; Found $86.1716(100 \%), 85.1655\left(2.7 \%,\left[\mathrm{~N}\left(\mathrm{CD}_{3}\right)_{3}\left(\mathrm{CD}_{2} \mathrm{H}\right)\right]^{+}\right)$. 
SAK-845_02052018.1.fid

5_02052018_1H

Instrument AV-NEO $400 \mathrm{MHZ}$

Group chen

PRO ETH MeOD /opt/V ckunzi 19

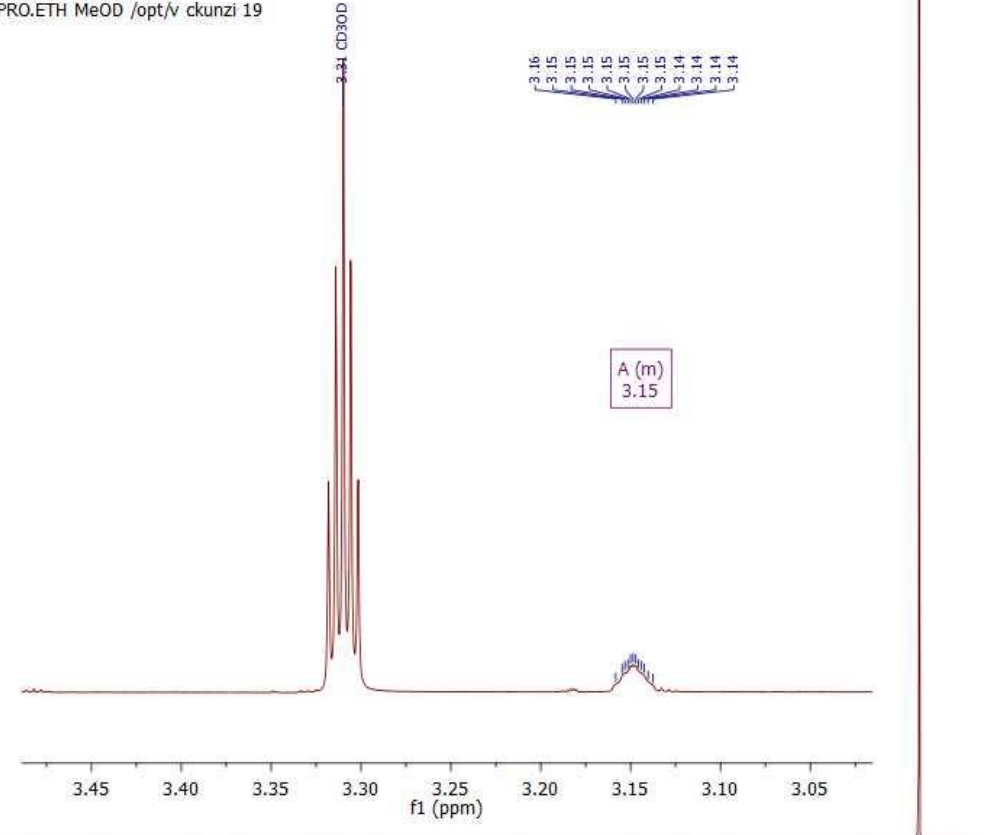

$\begin{array}{llllllllllllllll}12.5 & 12.0 & 11.5 & 11.0 & 10.5 & 10.0 & 9.5 & 9.0 & 8.5 & 8.0 & 7.5 & 7.0 & 6.5 & 6.0 & 5.5 & 5.0\end{array}$

Figure S43. ${ }^{1} \mathrm{H} \mathrm{NMR}\left(400 \mathrm{MHz}, \mathrm{CD}_{3} \mathrm{OD}\right)$ spectrum of $\left[\mathrm{N}\left(\mathrm{CD}_{3}\right)_{4}\right] \mathrm{OTf}$.
A (m)

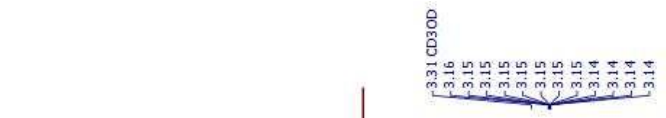

$\mathrm{D}_{3} \mathrm{C}, \mathrm{CD}_{3} \quad \mathrm{O}_{1} \mathrm{O}$

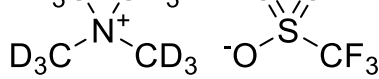

3.15

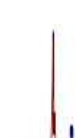


H3429.1.fid

Chen SAK-845 OPR:SB

$600 \mathrm{MHz} 1 \mathrm{H}$ NMR

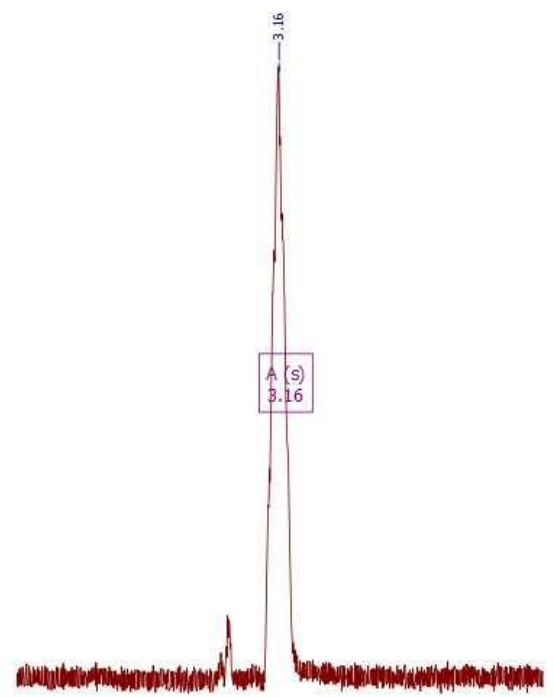

$\mathrm{D}_{3} \mathrm{C}, \mathrm{CD}_{3} \quad \mathrm{O}, \mathrm{O}$

$\mathrm{D}_{3} \mathrm{C}^{-\mathrm{N}^{+}-\mathrm{CD}_{3}}-\mathrm{O}^{-} \mathrm{S}^{\prime \prime} \mathrm{CF}_{3}$

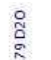

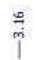

$A(s)$

\begin{tabular}{ll|llllllll}
\hline & 1 & 1 & 1 & 1 & 1 & 1 \\
& 13 & 12 & 11 & 10 & 9 & 8 & 7 & $\mathrm{f1}(\mathrm{ppm})$
\end{tabular}

Figure S44. ${ }^{1} \mathrm{H}$ NMR $\left(600 \mathrm{MHz}, \mathrm{D}_{2} \mathrm{O}\right)$ spectrum of $\left[\mathrm{N}\left(\mathrm{CD}_{3}\right)_{4}\right] \mathrm{OTf}$. 


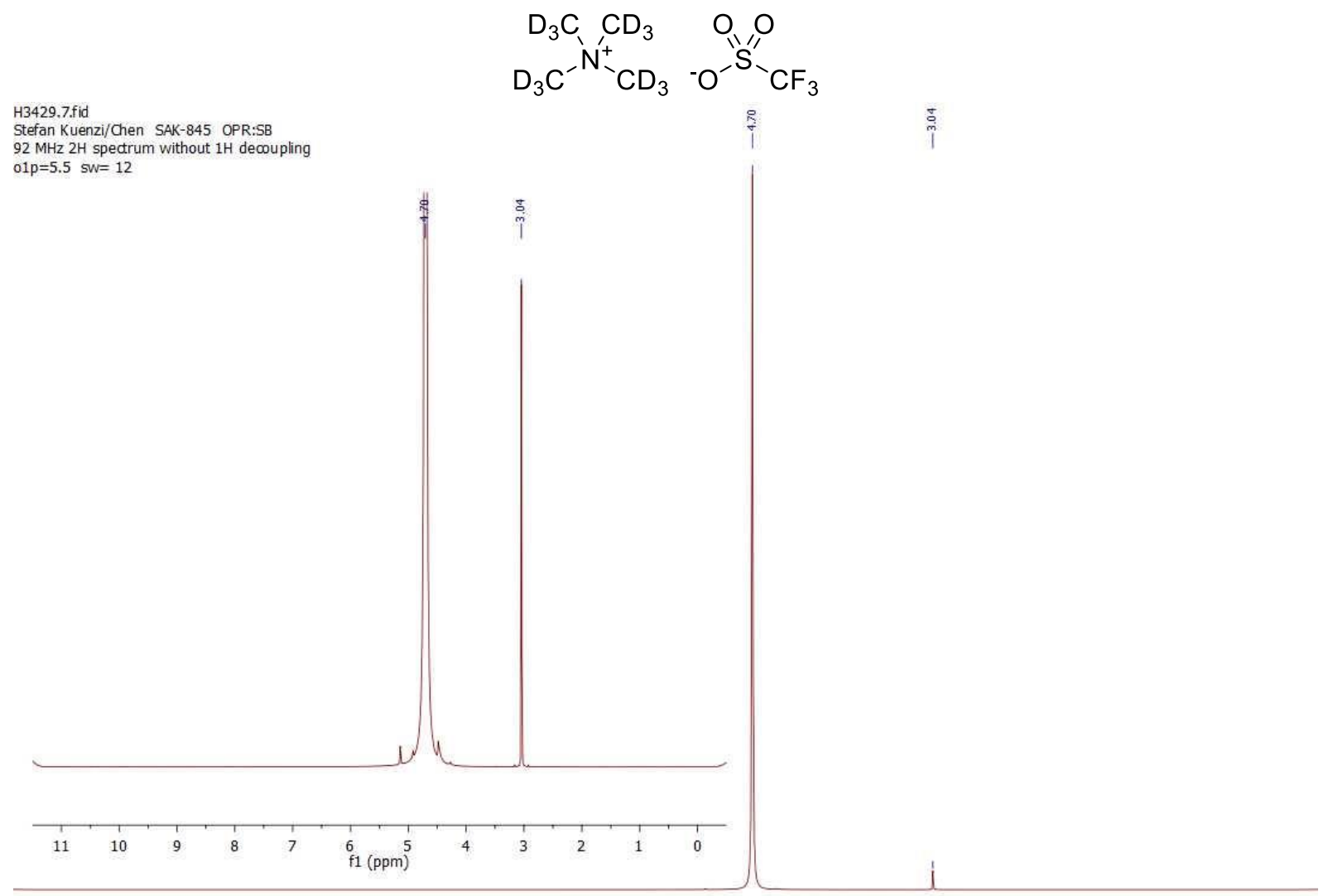

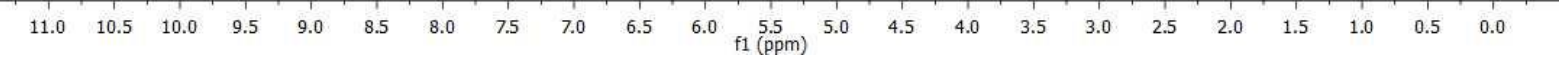

Figure S45. ${ }^{2} \mathrm{H}$ NMR $\left(92 \mathrm{MHz}, \mathrm{D}_{2} \mathrm{O}\right)$ spectrum of $\left[\mathrm{N}\left(\mathrm{CD}_{3}\right)_{4}\right] \mathrm{OTf}$. 
SAK-845_02052018.3.fid

Sample SAK-845_02052018_13C

Instrument AV-NEO $400 \mathrm{MH}$

Group chen

CAR-LONG.ETH MeOD /opt/v ckunzi 19

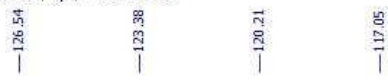

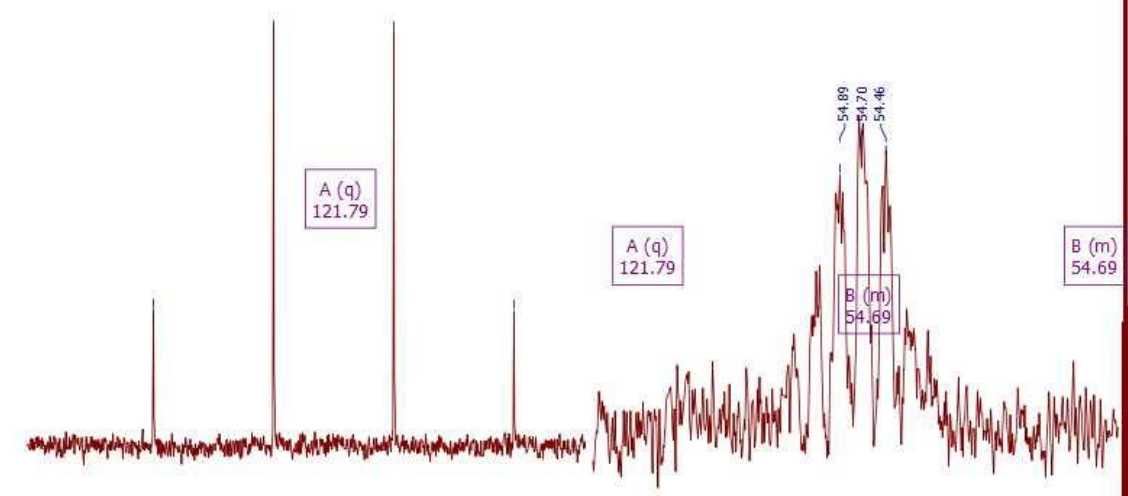

$\begin{array}{lllllllllll}116 & 57.0 & 56.5 & 56.0 & 55.5 & 55.0 & 54.5 & 54.0 & 53.5 & 53.0 & 52.5\end{array}$ $\mathrm{f1}(\mathrm{ppm})$

55.0
$\mathrm{f} 1(\mathrm{ppm})$

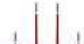

1

Figure S46. ${ }^{13} \mathrm{C}$ NMR $\left(101 \mathrm{MHz}, \mathrm{CD}_{3} \mathrm{OD}\right)$ spectrum of $\left[\mathrm{N}\left(\mathrm{CD}_{3}\right)_{4}\right] \mathrm{OTf}$. 


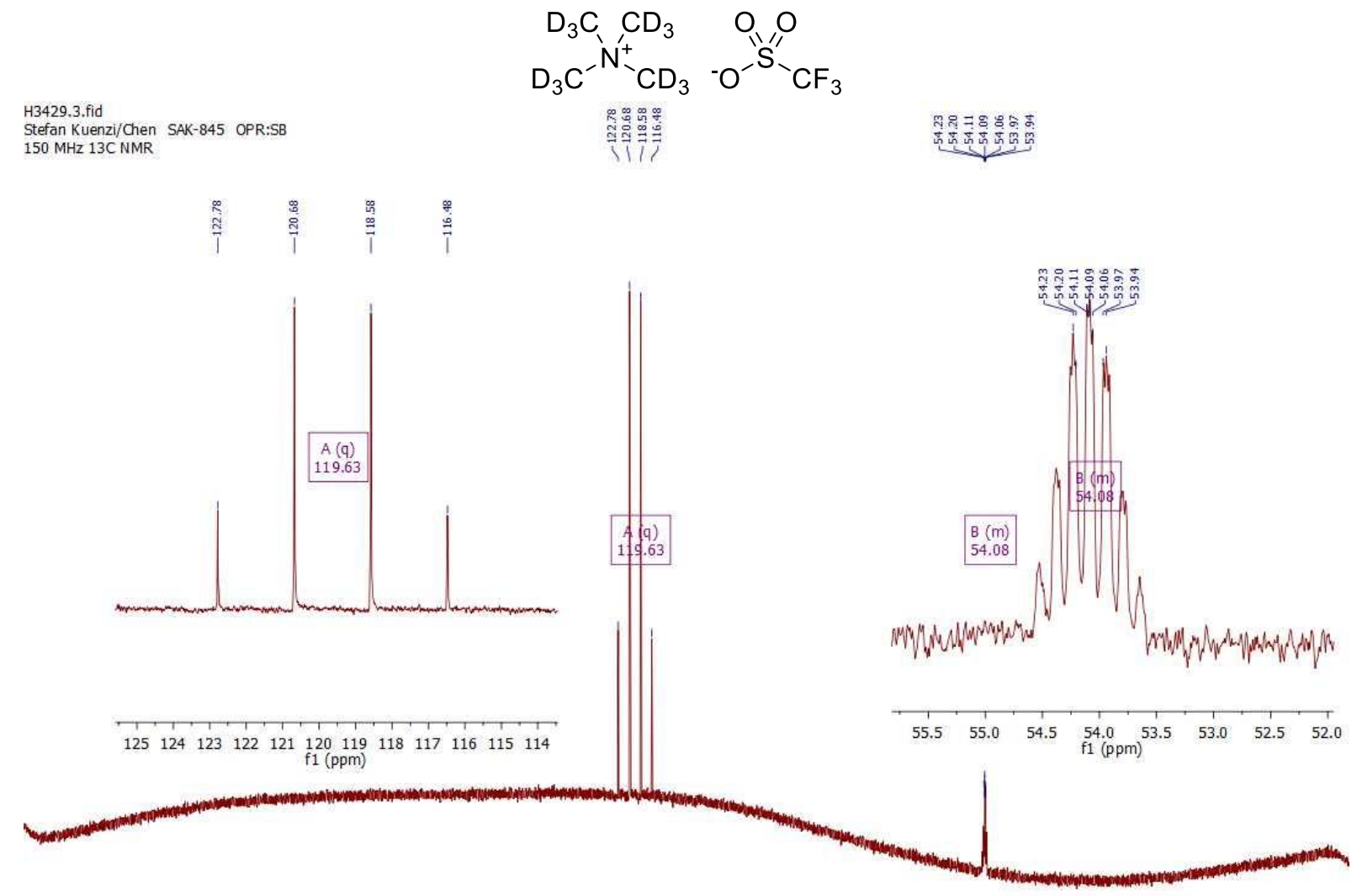

\begin{tabular}{llllllllllllllllllllllllll}
\hline & 230 & 220 & 210 & 200 & 190 & 180 & 170 & 160 & 150 & 140 & 130 & 120 & 110 & 100 & 90 & 80 & 70 & 60 & 50 & 40 & 30 & 20 & 10 & 0 & -10
\end{tabular}

Figure S47. ${ }^{13} \mathrm{C}$ NMR $\left(150 \mathrm{MHz}, \mathrm{D}_{2} \mathrm{O}\right)$ spectrum of $\left[\mathrm{N}\left(\mathrm{CD}_{3}\right)_{4}\right] \mathrm{OTf}$. 


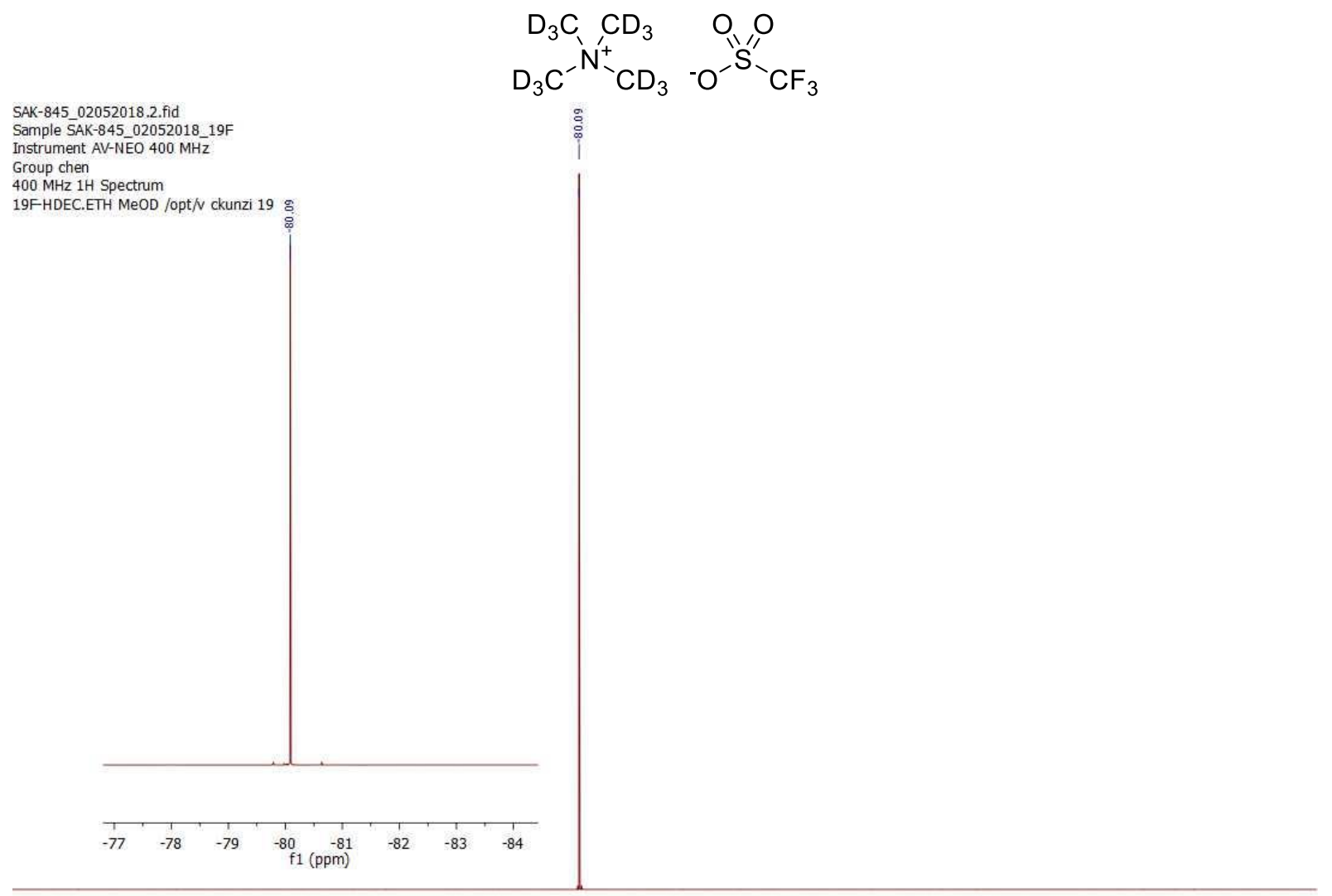

\begin{tabular}{lllllllllllllllllllllllllllllllll}
\hline 0 & 40 & 30 & 20 & 10 & 0 & -10 & -20 & -30 & -40 & -50 & -60 & -70 & -80 & -90 & -100 & -110 & -120 & -130 & -140 & -150 & -160 & -170 & -180 & -190 & -200 & -210 & -220 & -230 & -240 & -25
\end{tabular} Figure S48. ${ }^{19} \mathrm{~F}$ NMR (376 $\left.\mathrm{MHz}, \mathrm{CD}_{3} \mathrm{OD}\right)$ spectrum of $\left[\mathrm{N}\left(\mathrm{CD}_{3}\right)_{4}\right] \mathrm{OTf}$. 


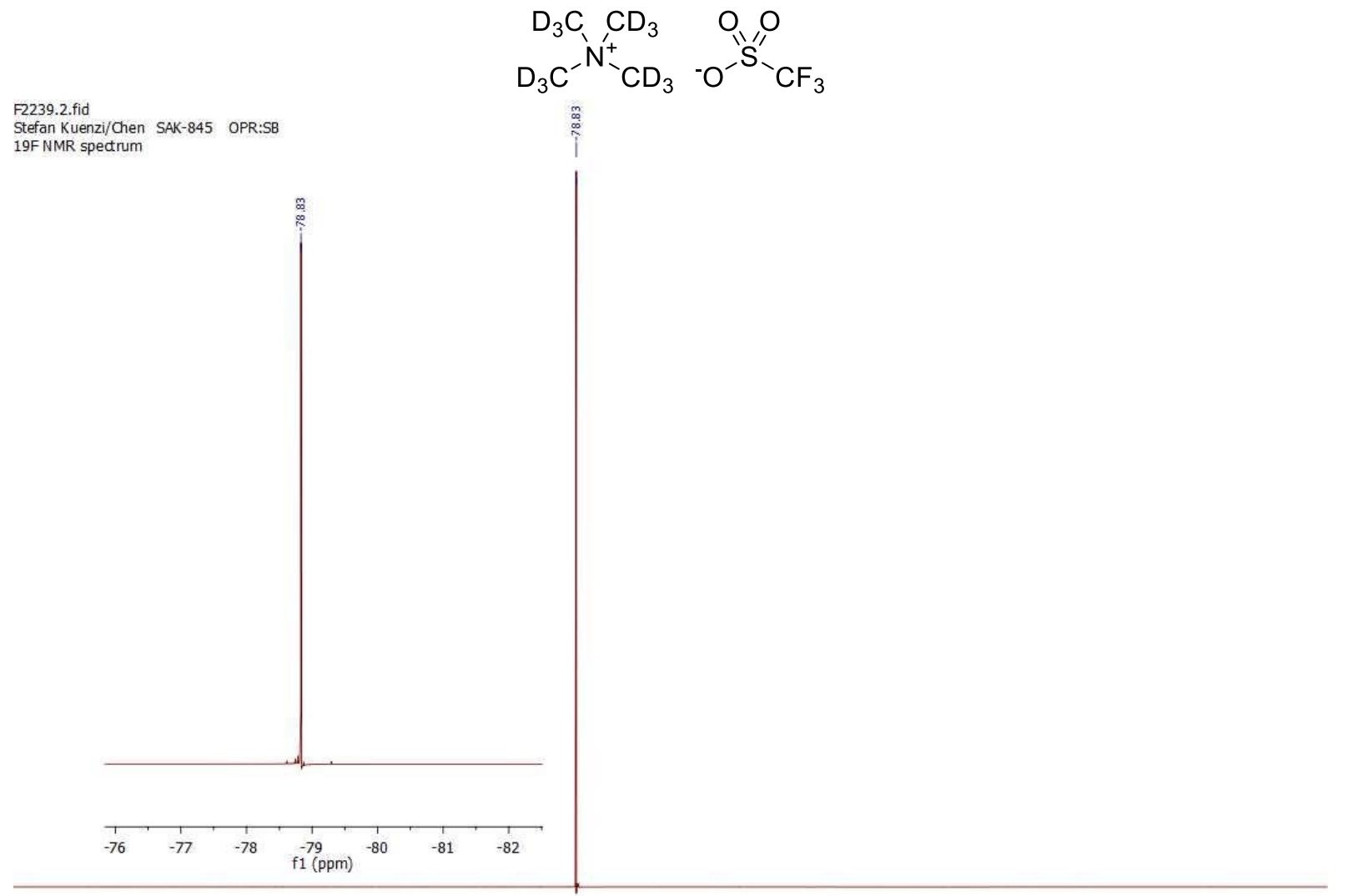

$\begin{array}{lllllllllllllllllllllllllllll}40 & 30 & 20 & 10 & 0 & -10 & -20 & -30 & -40 & -50 & -60 & -70 & -80 & -90 & -100 & -110 & -120 & -130 & -140 & -150 & -160 & -170 & -180 & -190 & -200 & -210 & -220 & -230 & -240\end{array}$

Figure S49. ${ }^{19} \mathrm{~F} \mathrm{NMR}\left(470 \mathrm{MHz}, \mathrm{D}_{2} \mathrm{O}\right)$ spectrum of $\left[\mathrm{N}\left(\mathrm{CD}_{3}\right)_{4}\right] \mathrm{OTf}$.

\section{Deprotonation Kinetics of $\left[\mathrm{N}\left(\mathrm{CH}_{3}\right)_{4}\right] \mathrm{OTf}$ and $\left[\mathrm{N}\left(\mathrm{CD}_{3}\right)_{4}\right] \mathrm{OTf}$}

Scheme S21. Deprotonation and Deuterium Quench with Subsequent Analysis by ESI-MS. ${ }^{1}$

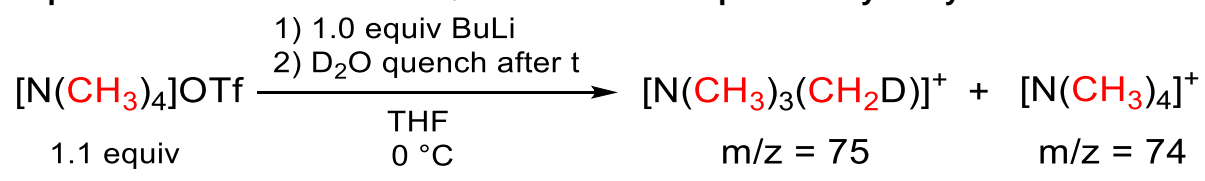

Inside the glove box, an oven-dried $50 \mathrm{~mL}$ Schlenk flask equipped with a J. Young inlet valve, glass stopper, screw cap with septum and a glass-coated stir bar was charged with [ $\left.\mathrm{NMe}_{4}\right] \mathrm{OTf}$ ( $245.5 \mathrm{mg}, 1.1 \mathrm{mmol}, 1.1$ equiv). The flask was removed from the glove box and attached to a Schlenk line. Dry THF $(19.5 \mathrm{~mL})$ was added via syringe. The flask was immersed in an ice bath and the reaction allowed to equilibrate (over ca. $20 \mathrm{~min}$ ).

BuLi (500 $\mu \mathrm{L}, 1 \mathrm{mmol}, 1$ equiv; $2 \mathrm{M}$ in cyclohexane) was added dropwise over ca. $30 \mathrm{~s}$ via a $1 \mathrm{~mL}$ gastight Hamilton syringe (by difference; previously dried at $50^{\circ} \mathrm{C}$ in a vacuum oven) ( $\mathrm{t}=0 \mathrm{~min}$ with the first drop). The flask was sealed/closed to the Schlenk line unless reagents were added or aliquots collected.

Aliquots (ca. $0.2 \mathrm{~mL}$ ) were taken with a disposable $1 \mathrm{~mL}$ plastic syringe (flushed several times with $\mathrm{Ar}$ ) and immediately quenched by injection into $0.5 \mathrm{~mL} \mathrm{D}_{2} \mathrm{O}$.

Aliquots were diluted with $\mathrm{MeOH}$ and analyzed by ESI-MS.

Assuming that all ammonium ylide is quenched by deuterium incorporation from $\mathrm{D}_{2} \mathrm{O}$, then the ratio of the peak areas at $\mathrm{m} / \mathrm{z}$ $=75$ to $74, A_{75} / A_{74}$ can be taken as extent of deprotonation and is proportional to the ylide concentration in solution. ${ }^{1}$ 


$$
\text { ratio }=\frac{\mathrm{A}_{75}-0.043 \mathrm{~A}_{74}}{\mathrm{~A}_{74}}
$$

The peak area for $\mathrm{m} / \mathrm{z}=75$ has to be corrected for the natural abundance of ${ }^{13} \mathrm{C}$ for $\left[\mathrm{N}\left(\mathrm{CH}^{3}\right)^{4}\right]^{+}$at $\mathrm{m} / \mathrm{z}=74(4.3 \%)$. At natural abundance before deprotonation and deuterium labelling the ratio should be 0.043 .

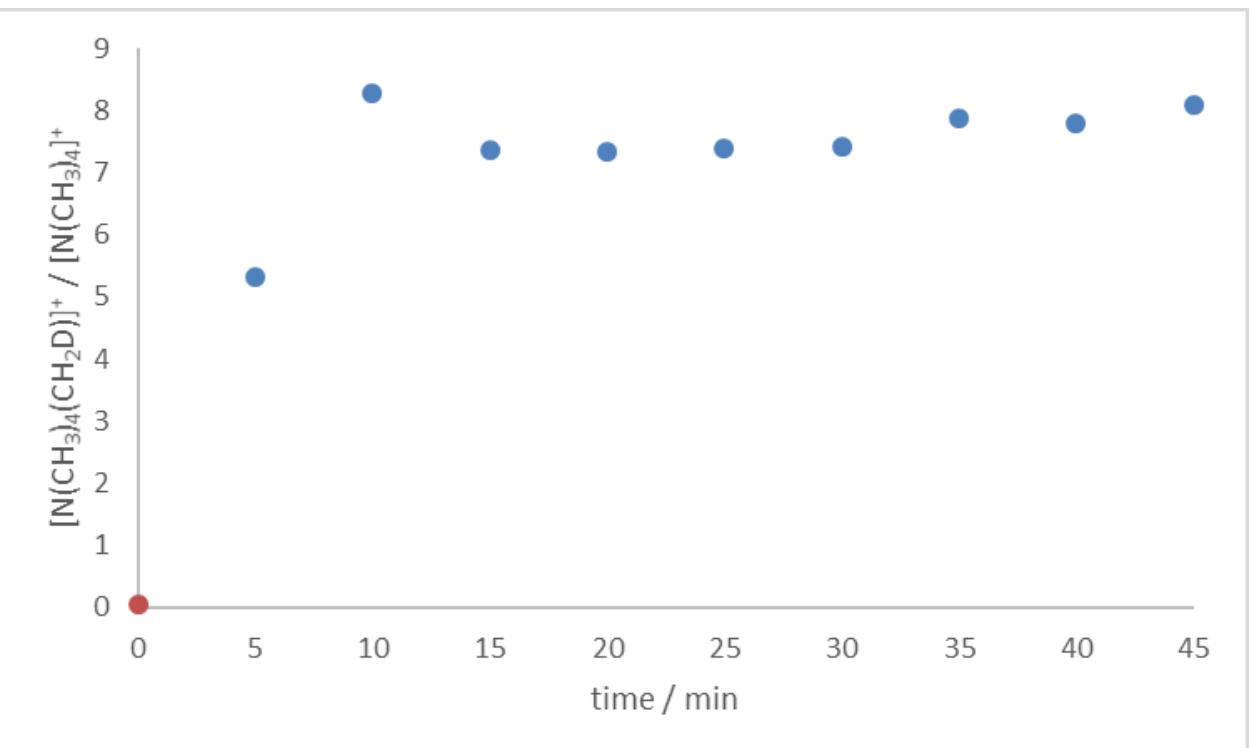

Figure S50. Plot of time versus the peak ratio as defined in eq (S36). The red circle denotes the theoretical value at $t=0 \mathrm{~min}$. A maximal ratio is achieved after 10 to $15 \mathrm{~min}$ and the ratio stays approximately constant until the last time point at $45 \mathrm{~min}$.

Figure S50 indicates that the deprotonation is finished after 10 to $15 \mathrm{~min}$ and that the ylide is stable in solution for at least 45 min under these conditions.

Scheme S22. Deprotonation and Deuterium Quench with Subsequent Analysis by ${ }^{1} \mathrm{H}$ NMR.

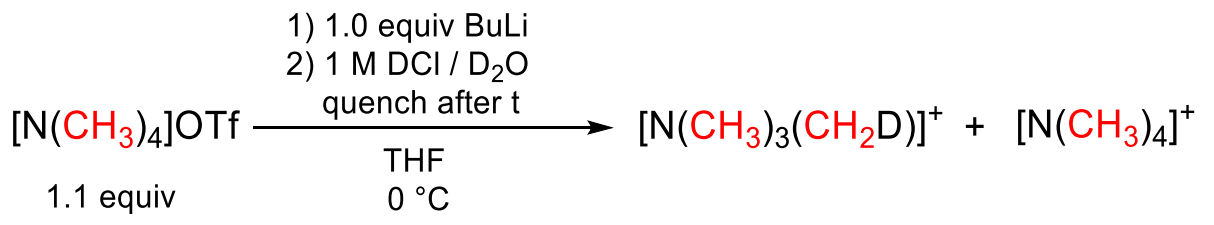

Inside the glove box, an oven-dried $50 \mathrm{~mL}$ Schlenk flask equipped with a J. Young inlet valve, glass stopper, screw cap with septum and a glass-coated stir bar was charged with [NMe $\left.{ }_{4}\right] \mathrm{OTf}(245.5 \mathrm{mg}, 1.1 \mathrm{mmol}, 1.1$ equiv). The flask was removed from the glove box and attached to a Schlenk line. Dry THF $(19.5 \mathrm{~mL})$ was added via syringe. The flask was immersed in an ice bath and the reaction allowed to equilibrate (over ca. $20 \mathrm{~min}$ ).

An aliquot (ca. $0.2 \mathrm{~mL}$ ) was taken and immediately quenched by injection into $0.2 \mathrm{~mL} 1 \mathrm{M} \mathrm{DCl} / \mathrm{D}_{2} \mathrm{O}$ ( $\left.\mathrm{t}=0 \mathrm{~min}\right)$.

BuLi (500 $\mu \mathrm{L}, 1 \mathrm{mmol}, 1$ equiv; $2 \mathrm{M}$ in cyclohexane) was added dropwise over ca. $30 \mathrm{~s}$ via a $1 \mathrm{~mL}$ gastight Hamilton syringe (by difference; previously dried at $50{ }^{\circ} \mathrm{C}$ in a vacuum oven) ( $\mathrm{t}=0 \mathrm{~min}$ with the first drop). The flask was sealed/closed to the Schlenk line unless aliquots collected.

Aliquots (ca. $0.2 \mathrm{~mL}$ ) were taken with a disposable $1 \mathrm{~mL}$ plastic syringe (flushed several times with $\mathrm{Ar}$ ) and immediately quenched by injection into $0.2 \mathrm{~mL} 1 \mathrm{M} \mathrm{DCl} / \mathrm{D}_{2} \mathrm{O}(\mathrm{t}=0 \mathrm{~min})$.

Aliquots were diluted with $0.3 \mathrm{~mL} \mathrm{CD} \mathrm{CD}_{3} \mathrm{O}$ and analyzed by ${ }^{1} \mathrm{H}$ NMR. Spectra were subsequently analyzed with MestReNova. The integrated 'Full Auto (Bernstein Polynomials)' baseline correction was applied. The spectrum was referenced to the residual solvent peak of $\mathrm{CD}_{3} \mathrm{OD}(\delta=3.31)$. Signals of cyclooctane $(\delta=1.55$, s $)$ and the signal of $\left[\mathrm{N}(\mathrm{CH})_{4}\right]^{+}(\delta=3.24, \mathrm{t})$ (overlap with $\left.\left[\mathrm{N}\left(\mathrm{CH}_{3}\right)_{3}\left(\mathrm{CH}_{2} \mathrm{D}\right)\right]^{+}\right)$and $\left[\mathrm{N}\left(\mathrm{CH}_{3}\right)_{3}\left(\mathrm{CH}_{2} \mathrm{D}\right)\right]^{+}(\delta=3.23$, br $\mathrm{m}$ ) were integrated using the sum function. 


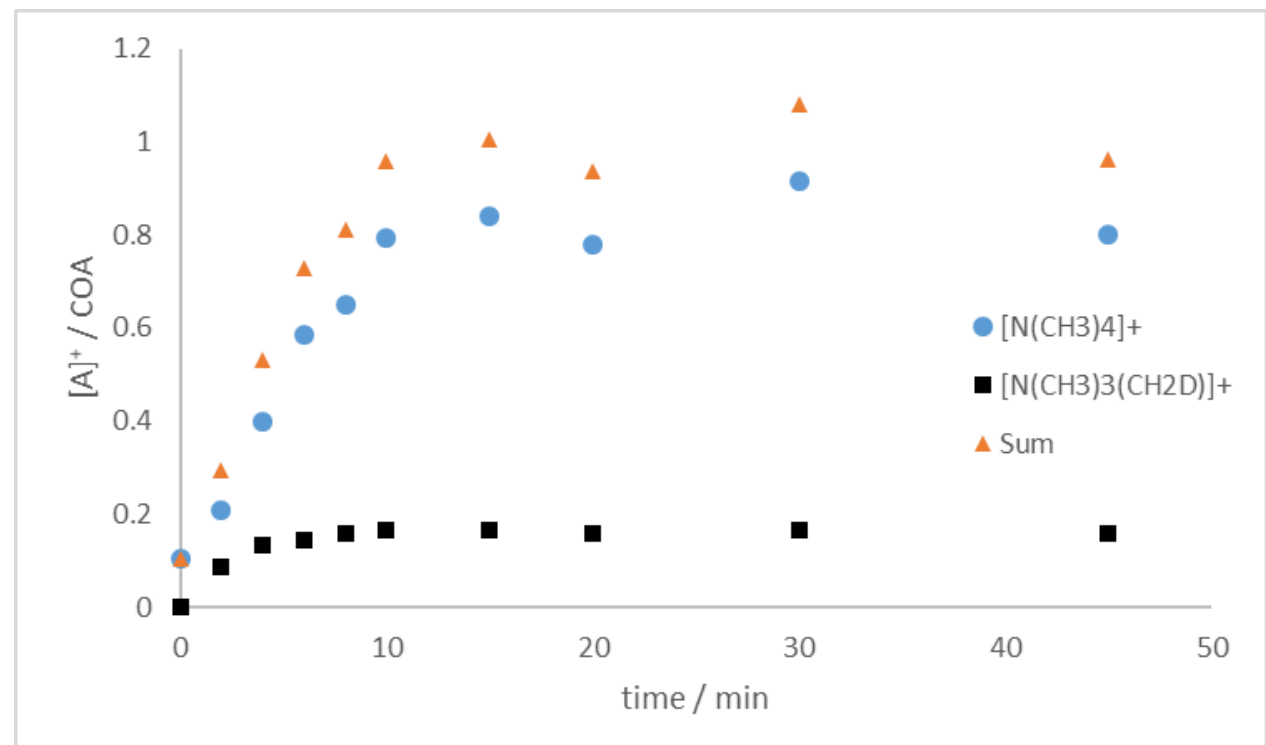

Figure S51. Plot of time versus integral ratio of ammonium species $[\mathrm{A}]^{+}$to $\mathrm{COA}$ (cyclooctane, internal standard) with the following integral areas of ammonium species: $\left[\mathrm{N}\left(\mathrm{CH}_{3}\right)_{3}\left(\mathrm{CH}_{2} \mathrm{D}\right)\right]^{+}$(black squares), $\left[\mathrm{N}\left(\mathrm{CH}_{3}\right)_{4}\right]^{+}$plus $\left[\mathrm{N}\left(\mathrm{CH}_{3}\right)_{3}\left(\mathrm{CH}_{2} \mathrm{D}\right)\right]^{+}($blue circles), sum of both species, $\left[\mathrm{N}\left(\mathrm{CH}_{3}\right)_{4}\right]^{+}$plus $\left[\mathrm{N}\left(\mathrm{CH}_{3}\right)_{3}\left(\mathrm{CH}_{2} \mathrm{D}\right)\right]^{+}$(orange triangles).
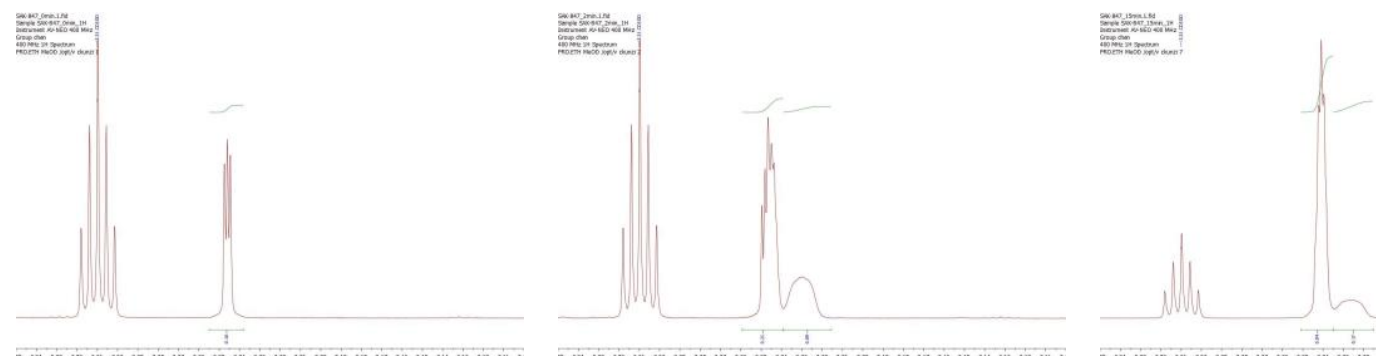

Figure S52. ${ }^{1} \mathrm{H}$ NMR spectrum expanded from $3.35 \mathrm{ppm}$ to $3.10 \mathrm{ppm}$ after 0 min (left, before BuLi addition), a , and after $(15 \mathrm{~min})$. Residual solvent signal of $\mathrm{CD}_{3} \mathrm{OD}$ at $3.31 \mathrm{ppm}$, $\left[\mathrm{N}\left(\mathrm{CH}_{3}\right)_{4}\right]^{+}$at $3.24 \mathrm{ppm}$ overlapping with $\left[\mathrm{N}\left(\mathrm{CH}_{3}\right)_{3}\left(\mathrm{CH}_{2} \mathrm{D}\right)\right]^{+}$, and $\left[\mathrm{N}\left(\mathrm{CH}_{3}\right)_{3}\left(\mathrm{CH}_{2} \mathrm{D}\right)\right]^{+}$at $3.23 \mathrm{ppm}$.

\section{Scheme S23. Deprotonation of Tetramethylammonium-d ${ }_{12}$ and Proton Quench with Subsequent Analysis by ${ }^{1} \mathrm{H}$} NMR.

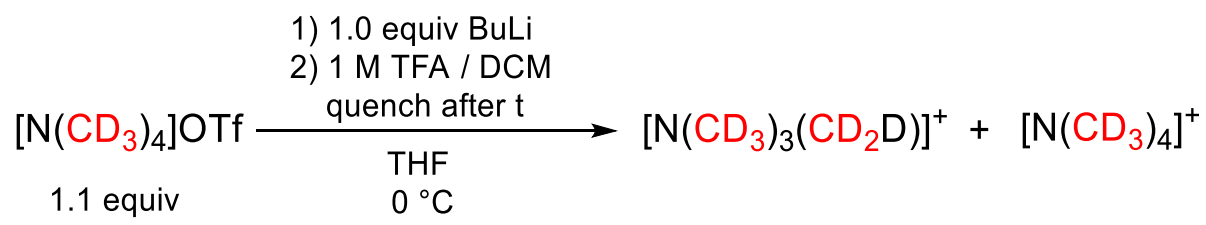

Inside the glove box, an oven-dried $50 \mathrm{~mL}$ Schlenk flask equipped with a J. Young inlet valve, glass stopper, screw cap with septum and a glass-coated stir bar was charged with $\left[\mathrm{N}\left(\mathrm{CD}_{3}\right)_{4}\right] \mathrm{OTf}(258.8 \mathrm{mg}, 1.1 \mathrm{mmol}, 1.1$ equiv). The flask was removed from the glove box and attached to a Schlenk line. Dry THF $(19.5 \mathrm{~mL})$ was added via syringe. The flask was immersed in an ice bath and the reaction allowed to equilibrate (over ca. $20 \mathrm{~min}$ ).

An aliquot (ca. $0.2 \mathrm{~mL}$ ) was taken and immediately quenched by injection into $0.2 \mathrm{~mL} 1 \mathrm{M} \mathrm{TFA}$ in DCM ( $\mathrm{t}=0 \mathrm{~min}$ ).

BuLi (500 $\mu \mathrm{L}, 1 \mathrm{mmol}, 1$ equiv; $2 \mathrm{M}$ in cyclohexane) was added dropwise over ca. $30 \mathrm{~s}$ via a $1 \mathrm{~mL}$ gastight Hamilton syringe (by difference; previously dried at $50^{\circ} \mathrm{C}$ in a vacuum oven) ( $\mathrm{t}=0 \mathrm{~min}$ with the first drop). The flask was sealed/closed to the Schlenk line unless aliquots collected.

Aliquots (ca. $0.2 \mathrm{~mL}$ ) were taken with a disposable $1 \mathrm{~mL}$ plastic syringe (flushed several times with Ar) and immediately quenched by injection into $0.2 \mathrm{~mL} 1 \mathrm{M}$ TFA in DCM.

Aliquots were diluted with $0.3 \mathrm{~mL} \mathrm{CD} \mathrm{CD}_{3} \mathrm{O}$ and analyzed by ${ }^{1} \mathrm{H}$ NMR. Spectra were subsequently analyzed with MestReNova. The integrated 'Full Auto (Bernstein Polynomials)' baseline correction was applied. The spectrum was referenced to the 
residual solvent peak of $\mathrm{CD}_{3} \mathrm{OD}(\delta=3.31)$. Signals of cyclooctane $(\delta=1.55, \mathrm{~s})$ and the signal of tetramethylammonium- $\mathrm{d}_{11}$ $\left[\mathrm{N}\left(\mathrm{CD}_{3}\right)_{3}\left(\mathrm{CD}_{2} \mathrm{H}\right)\right]^{+}(\delta=3.16, \mathrm{~m})$ were integrated using the sum function.

The integral ratio of $\left[\mathrm{N}\left(\mathrm{CD}_{3}\right)_{3}\left(\mathrm{CD}_{2} \mathrm{H}\right)\right]^{+}$to cyclooctane (internal standard) is taken as the extent of deprotonation.

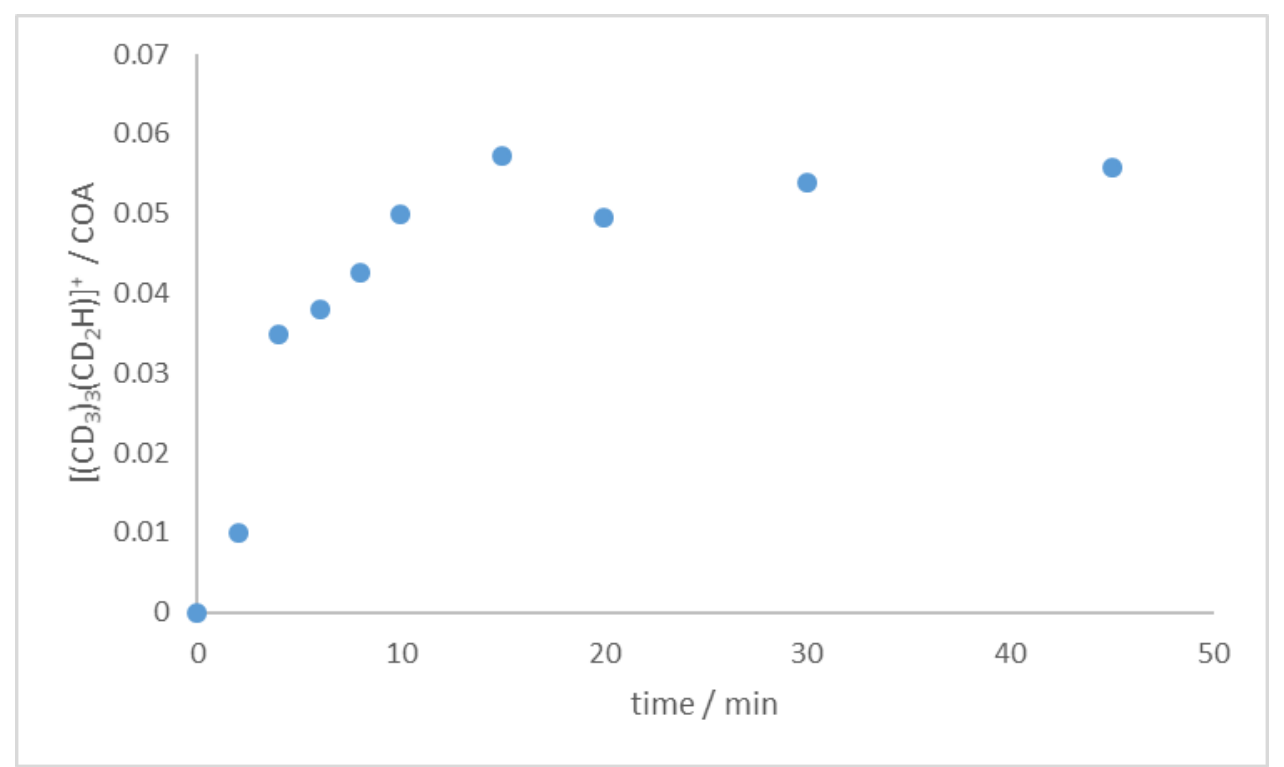

Figure S53. Plot of time versus integral ratio of $\left[\mathrm{N}\left(\mathrm{CD}_{3}\right)_{3}\left(\mathrm{CD}_{2} \mathrm{H}\right)\right]^{+}$to $\mathrm{COA}$ (cyclooctane, internal standard).
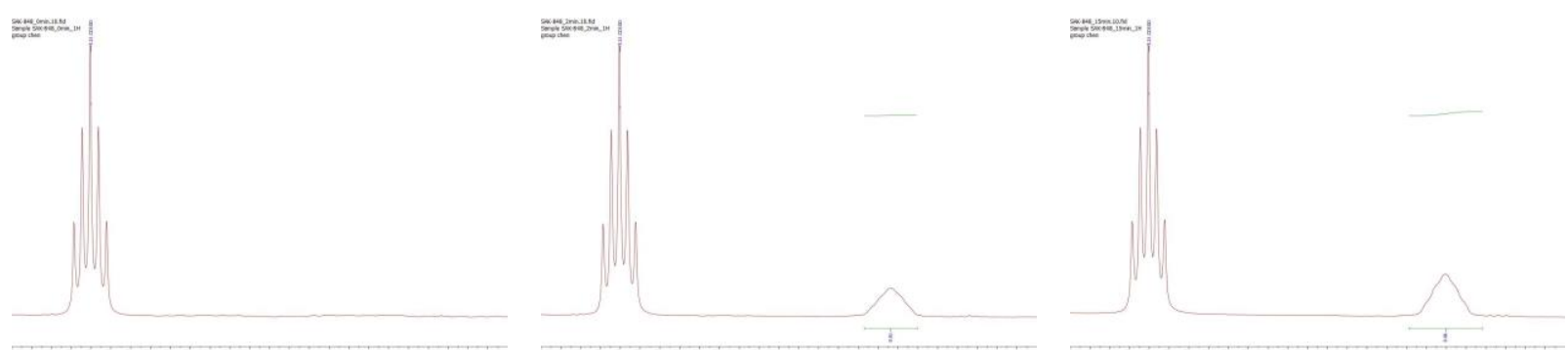

Figure S54. ${ }^{1} \mathrm{H}$ NMR spectrum expanded from $3.35 \mathrm{ppm}$ to $3.10 \mathrm{ppm}$ after 0 min (left, before BuLi addition), after 2 min (middle) ,and after (15 min). Residual solvent signal of $\mathrm{CD}_{3} \mathrm{OD}$ at $3.31 \mathrm{ppm}$ and $\left[\mathrm{N}\left(\mathrm{CD}_{3}\right)_{3}\left(\mathrm{CD}_{2} \mathrm{H}\right)\right]^{+}$at $3.16 \mathrm{ppm}$.

For all deprotonation experiments (Figure S50, Figure S51, and Figure S53) one can see that the ylide-derived species after quenching, either $\left[\mathrm{N}\left(\mathrm{CH}_{3}\right)_{3}\left(\mathrm{CH}_{2} \mathrm{D}\right)\right]^{+}$or $\left[\mathrm{N}\left(\mathrm{CD}_{3}\right)_{3}\left(\mathrm{CD}_{2} \mathrm{H}\right)\right]^{+}$, reaches its maximum concentration after about 10 to 15 min. After that time, the concentration is approximately constants at least up to $45 \mathrm{~min}$. There is no apparent difference in the deprotonation rate between the perprotiated and the perdeuterated tetramethylammonium salt. Thus, there is no (large) primary KIE for the deprotonation and the rate appears to be dictated by the limited solubility of the ammonium reagent in THF.

\section{UV-Vis Alkene Binding Titrations}

Inside the glove box, a vacuum-oven dried quartz cuvette (10 $\mathrm{mm}$ path length) with septum screw cap was charged with phosphine (ca. $10 \mathrm{mM}, 20$ equiv relative to $\mathrm{Ni}$, see below) and $1.8 \mathrm{~mL}$ THF. To this solution was added $\mathrm{Ni}(\mathrm{cod})_{2}$ in $0.2 \mathrm{~mL}$ (prepared as stock solution, ca. $4.1 \mathrm{mg}$ in $3 \mathrm{~mL}$ THF, ca. $0.5 \mathrm{mM}$, see below). A separate oven-dried $4 \mathrm{~mL}$ vial with septum screw cap was charged with alkene, either neat or as stock solution in THF. The cuvette and vial were removed from the glove box and wrapped with parafilm. The vial containing the alkene was placed under an $\mathrm{N}_{2}$-atmosphere using a needle inlet. The first measurement was taken without any added alkene and denoted as ' $0 \mu \mathrm{L}$ alkene'. Then, alkene was added (by difference) using a gastight $25 \mu \mathrm{L}$ Hamilton microsyringe and the cuvette was agitated for several seconds to mix. Measurements were taken at room temperature.

The data was analyzed by measuring the absorbance at a specific wavelength as indicated (see below), converting this value to $[\mathrm{NiP}]$, the phosphine-only ligated $\mathrm{Ni}$ species, using $[\mathrm{NiP}]_{0}$ (no alkene added) $=\left[\mathrm{Ni}(\mathrm{cod})_{2}\right]$. The resulting plot of $[$ alkene] versus 
$[\mathrm{NiP}]$ is fitted to equation (S27) in Excel using a least square method with the binding constant $\mathrm{K}$ as fit parameter. ([Ni $]_{\text {tot }}=$ $\left[\mathrm{Ni}(\mathrm{cod})_{2}\right],[\mathrm{A}]_{\text {tot }}=[$ alkene $],[\mathrm{P}]_{\text {tot }}=[$ phosphine]). The volume increase by adding alkene was neglected for the concentration.

Table S8. Binding Constants K for Different Alkenes and Phosphines

\begin{tabular}{|c|c|c|c|}
\hline Phosphine & $\mathrm{K}_{\mathrm{COE}}$ & $\mathrm{K}_{1-\text { Octene }}$ & $\mathrm{K}_{\mathrm{NBE}}$ \\
\hline $\mathrm{PPh}_{3}$ & 0.081 & 0.95 & 33 \\
\hline $\mathrm{P}(\mathrm{O}-\text { o-tolyl })_{3}(\text { Tolman })^{a}$ & 0.062 & 0.5 & 4.4 \\
\hline $\mathrm{P}(\mathrm{O}-\text { o-tolyl })_{3}$ & 0.071 & - & - \\
\hline $\mathrm{PPhMe}_{2}$ & 0.0014 & - & - \\
\hline $\mathrm{PPh}_{2} \mathrm{Me}$ & 0.0013 & - & - \\
\hline $\mathrm{P}\left(3,5\right.$-dit'BuPh) $\mathrm{Ph}_{2}$ & $0.11^{b}$ & - & - \\
\hline $\mathrm{P}\left(3,5-\mathrm{dit}^{\mathrm{t}} \mathrm{BuPh}\right){ }_{2} \mathrm{Ph}$ & 0.090 & - & - \\
\hline
\end{tabular}

${ }^{a}$ Values are taken from ref. S7 (in benzene). ${ }^{b}$ Average of two independent runs.

Table S9. UV-Vis Binding Titration for COE in the Presence of $\mathrm{PPh}_{3}$

\begin{tabular}{|c|c|c|c|c|}
\hline & $\mathrm{V}_{\mathrm{COE}} / \mu \mathrm{L}$ & {$[\mathrm{COE}] / \mathrm{mM}$} & Abs(500 nm) /a.u. & {$[\mathrm{NiP}] / \mathrm{mM}$} \\
\hline$[\mathrm{Ni}]_{\text {tot }} / \mathrm{mM}$ & 0 & 0 & 2.469 & 0.54535539 \\
\hline \multirow[t]{2}{*}{0.54535539} & 5 & 19.23949542 & 2.137 & 0.472022871 \\
\hline & 10 & 38.47899083 & 1.863 & 0.411501455 \\
\hline$\left[\mathrm{PPh}_{3}\right] / \mathrm{mM}$ & 15 & 57.71848625 & 1.658 & 0.366220833 \\
\hline \multirow[t]{2}{*}{9.912692058} & 20 & 76.95798167 & 1.488 & 0.328671049 \\
\hline & 30 & 115.4369725 & 1.249 & 0.275880471 \\
\hline $\mathrm{K}$ & 40 & 153.9159633 & 1.07 & 0.236342757 \\
\hline \multirow[t]{2}{*}{0.081278083} & 50 & 192.3949542 & 0.944 & 0.208511741 \\
\hline & $\begin{array}{l}60 \\
70 \\
80\end{array}$ & $\begin{array}{c}230.873945 \\
269.3529358 \\
307.8319267\end{array}$ & $\begin{array}{l}0.842 \\
0.765 \\
0.702\end{array}$ & $\begin{array}{l}0.185981871 \\
0.168974027 \\
0.155058519\end{array}$ \\
\hline
\end{tabular}
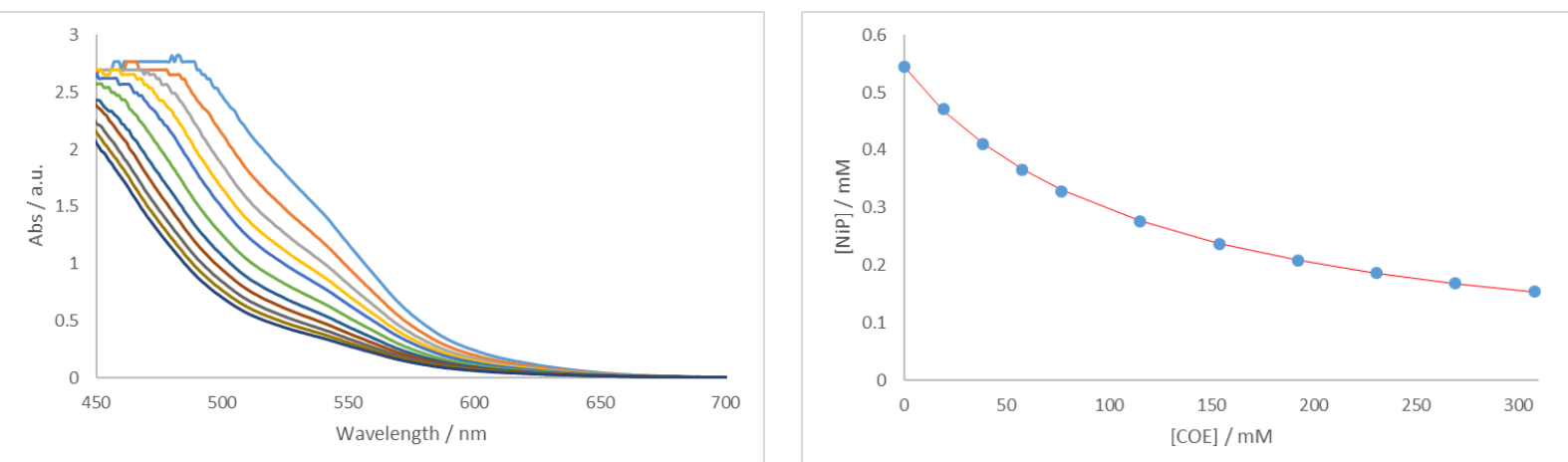

Figure S55. Left: Plot of UV-Vis spectra at different concentrations of COE and constant $\left[\mathrm{PPh}_{3}\right]$. Right: Absorbance at $500 \mathrm{~nm}$ transformed to $[\mathrm{NiP}]$ and plotted against [COE]. The red curve depicts a fit to equation (S27) using the binding constant $\mathrm{K}$ as fit parameter.

Table S10. UV-Vis Binding Titration for 1-Octene in the Presence of $\mathrm{PPh}_{3}$

\begin{tabular}{|c|c|c|c|c|}
\hline & $\mathrm{V}_{1 \mathrm{Oct}} / \mu \mathrm{L}$ & {$[1 \mathrm{Oct}] / \mathrm{mM}$} & Abs(500 nm) /a.u. & {$[\mathrm{NiP}] / \mathrm{mM}$} \\
\hline$[\mathrm{Ni}]_{\text {tot }} / \mathrm{mM}$ & 0 & 0 & 2.469 & 0.54535539 \\
\hline \multirow{2}{*}{0.54535539} & 5 & 15.92995277 & 0.94 & 0.207628216 \\
\hline & 10 & 31.85990553 & 0.577 & 0.127448384 \\
\hline$\left[\mathrm{PPh}_{3}\right] / \mathrm{mM}$ & 15 & 47.7898583 & 0.423 & 0.093432697 \\
\hline \multirow[t]{2}{*}{9.912692058} & 20 & 63.71981107 & 0.34 & 0.075099568 \\
\hline & 30 & 95.5797166 & 0.262 & 0.057870843 \\
\hline $\mathrm{K}$ & 40 & 127.4396221 & 0.227 & 0.050140005 \\
\hline \multirow[t]{2}{*}{0.952027012} & 50 & 159.2995277 & 0.209 & 0.046164146 \\
\hline & 60 & 191.1594332 & 0.197 & 0.043513573 \\
\hline
\end{tabular}




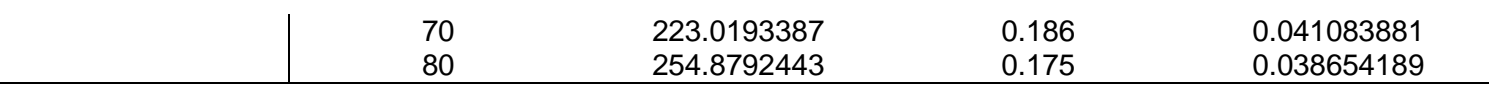
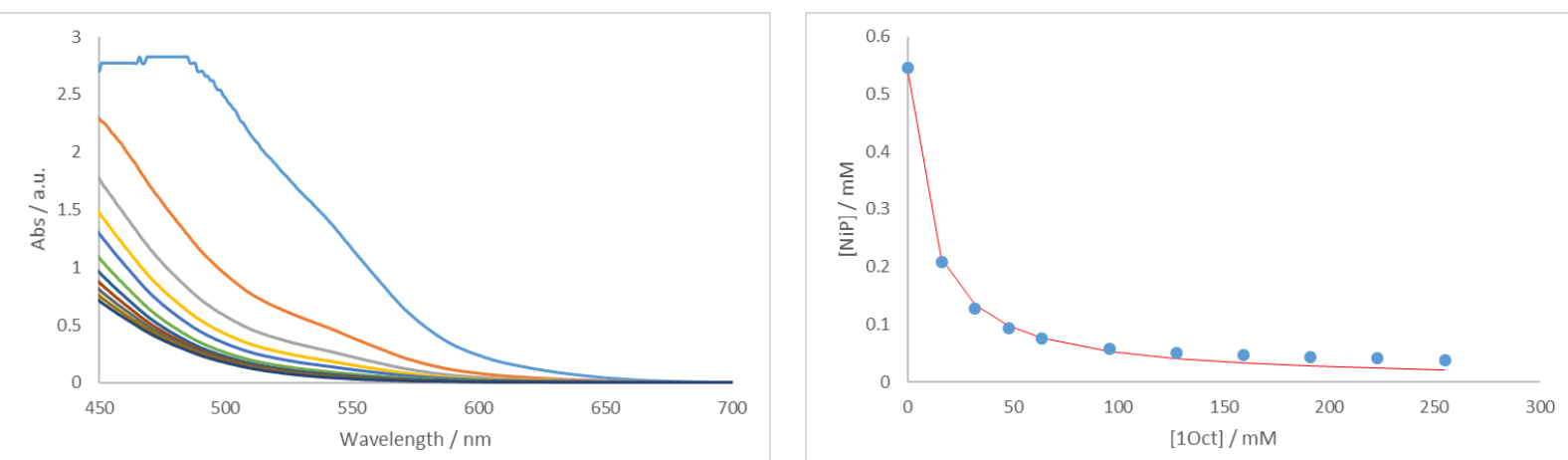

Figure S56. Left: Plot of UV-Vis spectra at different concentrations of 1-octene (1Oct) and constant [PPh $]$. Right: Absorbance at $500 \mathrm{~nm}$ transformed to [NiP] and plotted against [1Oct]. The red curve depicts a fit to equation (S27) using the binding constant $\mathrm{K}$ as fit parameter.

Table S11. UV-Vis Binding Titration for NBE in the Presence of $\mathrm{PPh}_{3}$

\begin{tabular}{|c|c|c|c|c|}
\hline & $\mathrm{V}_{\mathrm{NBE}} / \mu \mathrm{L}$ & [NBE] / mM & $\operatorname{Abs}(500 \mathrm{~nm}) / \mathrm{a} . u$. & {$[\mathrm{NiP}] / \mathrm{mM}$} \\
\hline$[\mathrm{Ni}]_{\text {tot }} / \mathrm{mM}$ & 0 & 0 & 2.31 & 0.484760347 \\
\hline \multirow[t]{2}{*}{0.484760347} & 5 & 0.503451938 & 1.288 & 0.270290618 \\
\hline & 10 & 1.006903877 & 0.79 & 0.165783841 \\
\hline$\left[\mathrm{PPh}_{3}\right] / \mathrm{mM}$ & 15 & 1.510355815 & 0.559 & 0.117307807 \\
\hline \multirow[t]{2}{*}{12.77212246} & 20 & 2.013807754 & 0.439 & 0.092125451 \\
\hline & 30 & 3.02071163 & 0.312 & 0.065474125 \\
\hline NBE stock sol. /mM & 40 & 4.027615507 & 0.253 & 0.0530928 \\
\hline \multirow[t]{2}{*}{201.3807754} & 50 & 5.034519384 & 0.217 & 0.045538093 \\
\hline & 60 & 6.041423261 & 0.192 & 0.040291769 \\
\hline $\mathrm{K}$ & 70 & 7.048327138 & 0.175 & 0.036724269 \\
\hline 32.85322907 & 80 & 8.055231014 & 0.162 & 0.03399618 \\
\hline
\end{tabular}
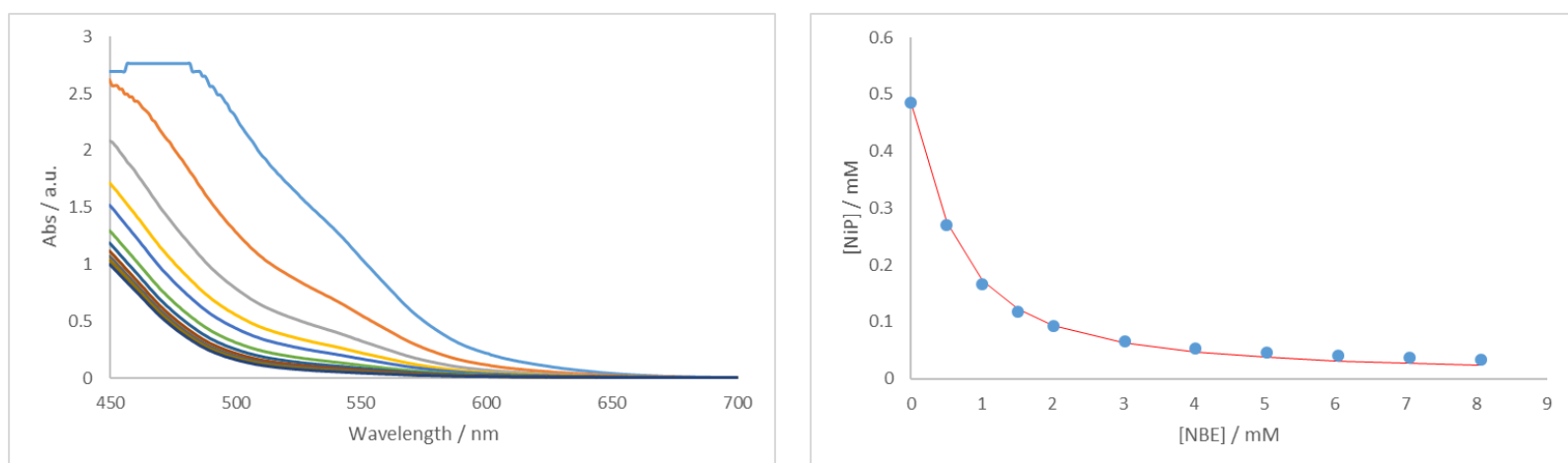

Figure S57. Left: Plot of UV-Vis spectra at different concentrations of NBE and constant [PPh $]$. Right: Absorbance at $500 \mathrm{~nm}$ transformed to [NiP] and plotted against [NBE]. The red curve depicts a fit to equation (S27) using the binding constant $\mathrm{K}$ as fit parameter.

Table S12. UV-Vis Binding Titration for COE in the Presence of $\mathrm{P}(\mathrm{O}-\mathrm{o} \text {-tolyl })_{3}$

\begin{tabular}{|c|c|c|c|c|}
\hline & $\mathrm{V}_{\mathrm{COE}} / \mu \mathrm{L}$ & {$[\mathrm{COE}] / \mathrm{mM}$} & Abs(450 nm) /a.u. & {$[\mathrm{NiP}] / \mathrm{mM}$} \\
\hline$[\mathrm{Ni}]_{\text {tot }} / \mathrm{mM}$ & 0 & 0 & 0.974 & 0.508998364 \\
\hline \multirow[t]{2}{*}{0.508998364} & 5 & 19.23949542 & 0.829 & 0.433223453 \\
\hline & 10 & 38.47899083 & 0.743 & 0.388281093 \\
\hline$\left[\mathrm{P}(\mathrm{O}-\mathrm{o} \text {-tolyl })_{3}\right] / \mathrm{mM}$ & 15 & 57.71848625 & 0.677 & 0.353790444 \\
\hline
\end{tabular}




\begin{tabular}{c|cccc}
\hline 11.35202634 & 20 & 76.95798167 & 0.627 & 0.327661164 \\
\hline \hline $\mathrm{K}$ & 96.19747709 & 0.588 & 0.307280326 \\
\cline { 1 - 1 } & 25 & 115.4369725 & 0.549 & 0.286899489 \\
\cline { 1 - 1 } & 30 & 153.9159633 & 0.493 & 0.257634696 \\
& 40 & 192.3949542 & 0.451 & 0.235686101 \\
& 50 & 230.873945 & 0.42 & 0.219485947 \\
& 60 & 269.3529358 & 0.394 & 0.205898722 \\
& 70 & 307.8319267 & 0.372 & 0.194401839 \\
\hline
\end{tabular}
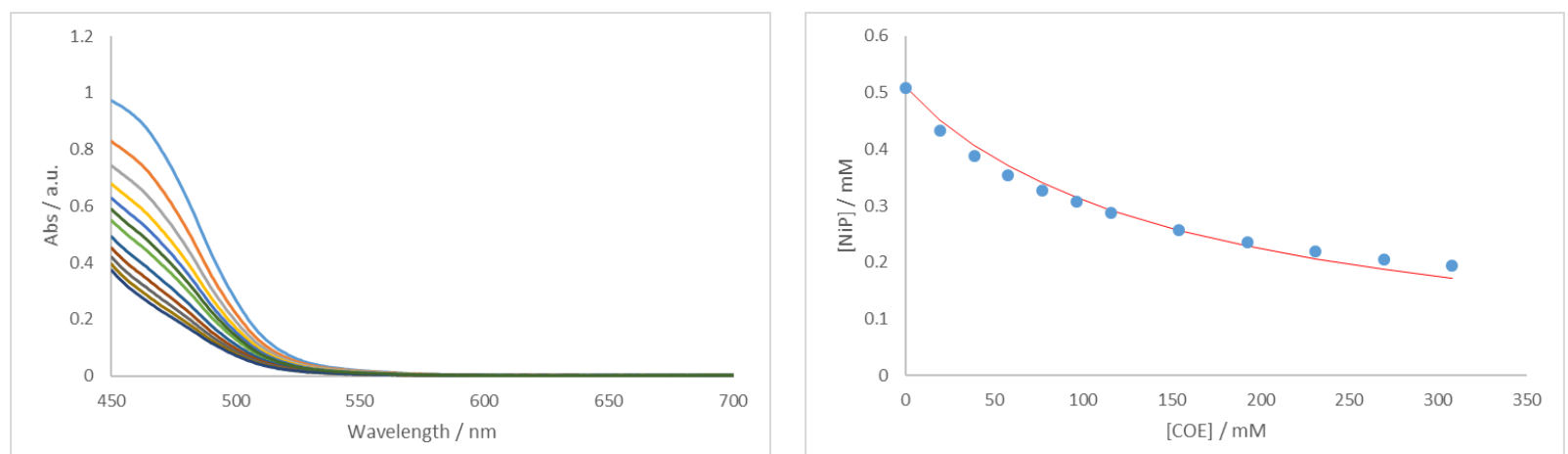

Figure S58. Left: Plot of UV-Vis spectra at different concentrations of COE and constant $\left[\mathrm{P}(\mathrm{O}-\mathrm{o} \text {-tolyl })_{3}\right]$. Right: Absorbance at 450 $\mathrm{nm}$ transformed to $[\mathrm{NiP}]$ and plotted against [COE]. The red curve depicts a fit to equation (S27) using the binding constant $\mathrm{K}$ as fit parameter.

Table S13. UV-Vis Binding Titration for COE in the Presence of $\mathrm{PPhMe}_{2}$

\begin{tabular}{|c|c|c|c|c|}
\hline & $\mathrm{V}_{\mathrm{COE}} / \mu \mathrm{L}$ & {$[\mathrm{COE}] / \mathrm{mM}$} & $\operatorname{Abs}(460 \mathrm{~nm}) / \mathrm{a} . \mathrm{u}$. & {$[\mathrm{NiP}] / \mathrm{mM}$} \\
\hline$[\mathrm{Ni}]_{\text {tot }} / \mathrm{mM}$ & 0 & 0 & 1.09 & 0.508998364 \\
\hline \multirow[t]{2}{*}{0.508998364} & 5 & 19.23949542 & 1.093 & 0.510399277 \\
\hline & 10 & 38.47899083 & 1.087 & 0.507597451 \\
\hline$\left[\mathrm{PPhMe}_{2}\right] / \mathrm{mM}$ & 15 & 57.71848625 & 1.084 & 0.506196538 \\
\hline \multirow[t]{2}{*}{11.22050094} & 20 & 76.95798167 & 1.081 & 0.504795625 \\
\hline & 30 & 115.4369725 & 1.075 & 0.501993799 \\
\hline $\mathrm{K}$ & 40 & 153.9159633 & 1.069 & 0.499191973 \\
\hline \multirow[t]{4}{*}{0.001442832} & 50 & 192.3949542 & 1.063 & 0.496390148 \\
\hline & 60 & 230.873945 & 1.055 & 0.49265438 \\
\hline & 70 & 269.3529358 & 1.053 & 0.491720438 \\
\hline & 80 & 307.8319267 & 1.044 & 0.487517699 \\
\hline
\end{tabular}
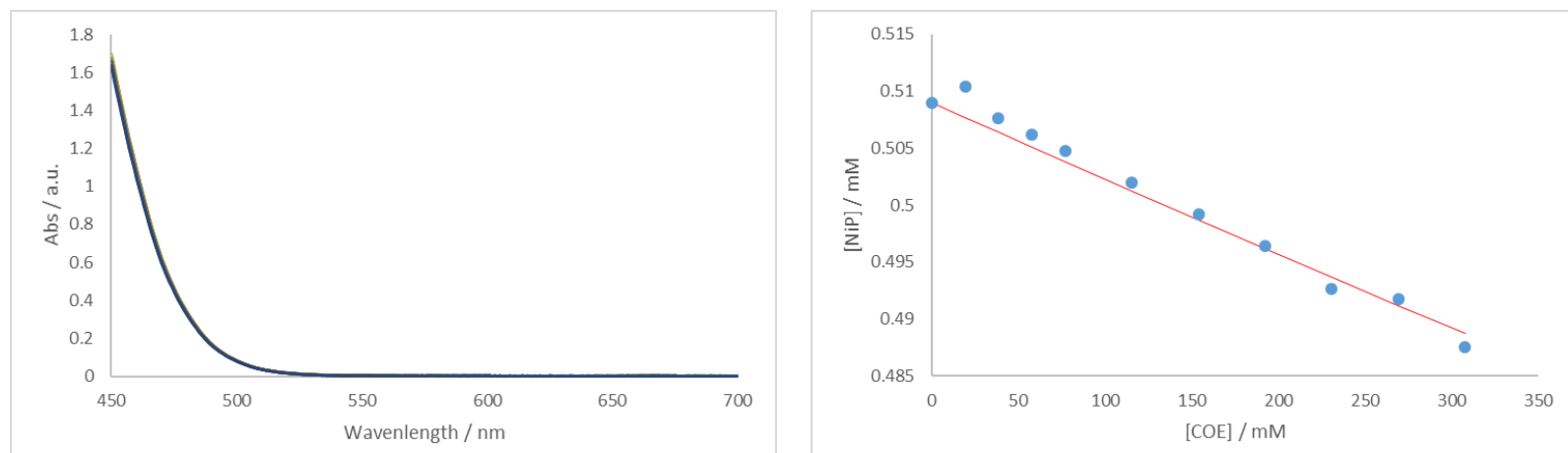

Figure S59. Left: Plot of UV-Vis spectra at different concentrations of COE and constant [PPhMe 2 . Right: Absorbance at $460 \mathrm{~nm}$ transformed to $[\mathrm{NiP}]$ and plotted against [COE]. The red curve depicts a fit to equation (S27) using the binding constant $\mathrm{K}$ as fit parameter. 
Table S14. UV-Vis Binding Titration for COE in the Presence of $\mathrm{PPh}_{2} \mathrm{Me}$

\begin{tabular}{|c|c|c|c|c|}
\hline & $\mathrm{V}_{\mathrm{COE}} / \mu \mathrm{L}$ & {$[\mathrm{COE}] / \mathrm{mM}$} & $\operatorname{Abs}(460 \mathrm{~nm}) / \mathrm{a} . \mathrm{u}$ & {$[\mathrm{NiP}] / \mathrm{mM}$} \\
\hline$[\mathrm{Ni}]_{\text {tot }} / \mathrm{mM}$ & 0 & 0 & 1.987 & 0.508998364 \\
\hline \multirow[t]{2}{*}{0.508998364} & 5 & 19.23949542 & 1.959 & 0.501825765 \\
\hline & 10 & 38.47899083 & 1.959 & 0.501825765 \\
\hline$\left[\mathrm{PPh}_{2} \mathrm{Me}\right] / \mathrm{mM}$ & 15 & 57.71848625 & 1.959 & 0.501825765 \\
\hline \multirow[t]{2}{*}{9.989511013} & 20 & 76.95798167 & 1.971 & 0.504899736 \\
\hline & 30 & 115.4369725 & 1.959 & 0.501825765 \\
\hline $\mathrm{K}$ & 40 & 153.9159633 & 1.951 & 0.499776451 \\
\hline \multirow[t]{4}{*}{0.001314885} & 50 & 192.3949542 & 1.939 & 0.49670248 \\
\hline & 60 & 230.873945 & 1.921 & 0.492091523 \\
\hline & 70 & 269.3529358 & 1.921 & 0.492091523 \\
\hline & 80 & 307.8319267 & 1.903 & 0.487480567 \\
\hline
\end{tabular}
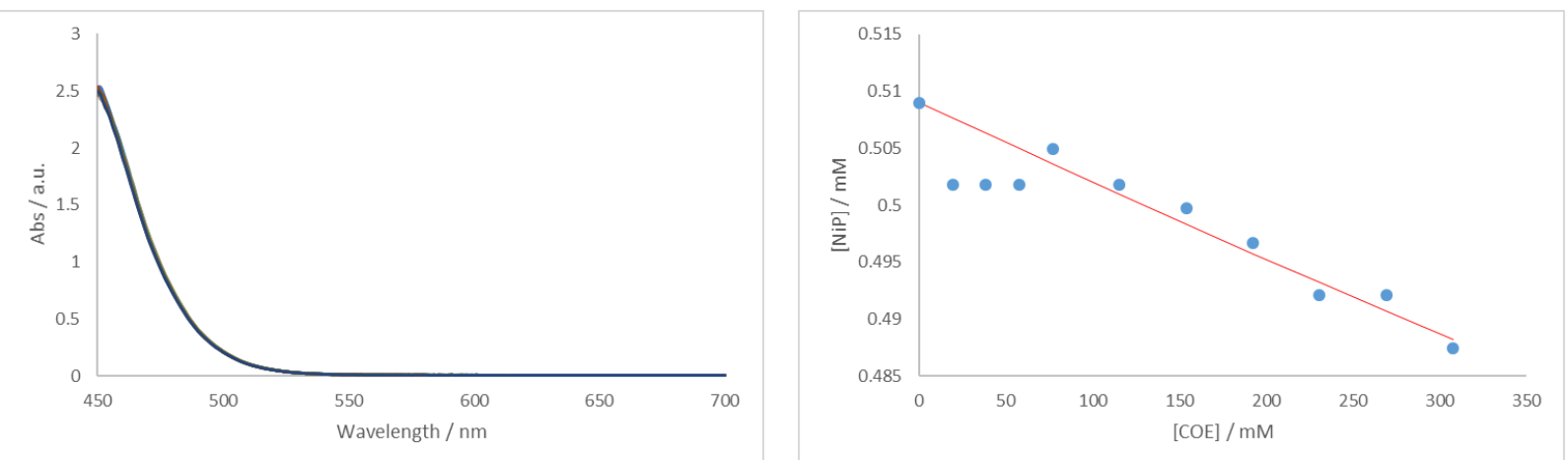

Figure S60. Left: Plot of UV-Vis spectra at different concentrations of COE and constant [PPh $2 \mathrm{Me}$. Right: Absorbance at $460 \mathrm{~nm}$ transformed to $[\mathrm{NiP}]$ and plotted against [COE]. The red curve depicts a fit to equation (S27) using the binding constant $\mathrm{K}$ as fit parameter.

Table S15. UV-Vis Binding Titration for COE in the Presence of $\mathrm{P}\left(3,5-\mathrm{di} \mathrm{B}^{\mathrm{B} u P h}\right) \mathrm{Ph}_{2}$ (run 1).

\begin{tabular}{|c|c|c|c|c|}
\hline & $\mathrm{V}_{\mathrm{COE}} / \mu \mathrm{L}$ & {$[\mathrm{COE}] / \mathrm{mM}$} & Abs(500 nm) /a.u. & {$[\mathrm{NiP}] / \mathrm{mM}$} \\
\hline$[\mathrm{Ni}]_{\text {tot }} / \mathrm{mM}$ & 0 & 0 & 2.538 & 0.496879355 \\
\hline \multirow[t]{2}{*}{0.496879355} & 5 & 19.23949542 & 2.119 & 0.414849233 \\
\hline & 10 & 38.47899083 & 1.827 & 0.357682656 \\
\hline$\left[\mathrm{P}\left(3,5-\right.\right.$ dit $\left.\left.^{t} \mathrm{BuPh}\right) \mathrm{Ph}_{2}\right] / \mathrm{mM}$ & 15 & 57.71848625 & 1.607 & 0.314611948 \\
\hline \multirow[t]{2}{*}{11.88219273} & 20 & 76.95798167 & 1.437 & 0.281330037 \\
\hline & 30 & 115.4369725 & 1.192 & 0.23336493 \\
\hline $\mathrm{K}$ & 40 & 153.9159633 & 1.025 & 0.200670346 \\
\hline \multirow[t]{4}{*}{0.113042717} & 50 & 192.3949542 & 0.898 & 0.175806801 \\
\hline & 60 & 230.873945 & 0.802 & 0.15701231 \\
\hline & 70 & 269.3529358 & 0.727 & 0.142329114 \\
\hline & 80 & 307.8319267 & 0.666 & 0.130386781 \\
\hline
\end{tabular}
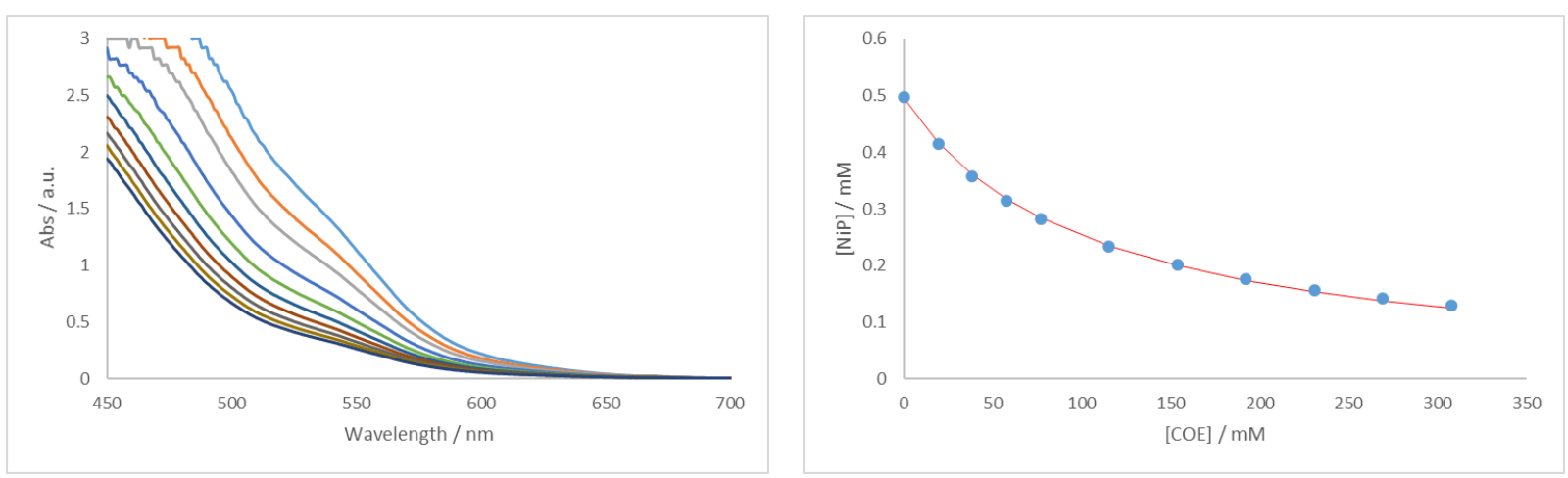
Figure S61. Left: Plot of UV-Vis spectra at different concentrations of COE and constant $\left[\mathrm{P}\left(3,5-\mathrm{di}^{\mathrm{t}} \mathrm{BuPh}\right) \mathrm{Ph}_{2}\right]($ run 1). Right: Absorbance at $500 \mathrm{~nm}$ transformed to $[\mathrm{NiP}]$ and plotted against [COE]. The red curve depicts a fit to equation (S27) using the binding constant $\mathrm{K}$ as fit parameter.

Table S16. UV-Vis Binding Titration for COE in the Presence of $\mathrm{P}\left(3,5-\mathrm{di} \mathrm{BuPh}^{\mathrm{B}} \mathrm{Ph}_{2}\right.$ (run 2).

\begin{tabular}{|c|c|c|c|c|}
\hline & $\mathrm{V}_{\mathrm{COE}} / \mu \mathrm{L}$ & {$[\mathrm{COE}] / \mathrm{mM}$} & Abs(500 nm) /a.u. & {$[\mathrm{NiP}] / \mathrm{mM}$} \\
\hline$[\mathrm{Ni}]_{\text {tot }} / \mathrm{mM}$ & 0 & 0 & 2.469 & 0.496879355 \\
\hline \multirow[t]{2}{*}{0.496879355} & 5 & 19.23949542 & 2.137 & 0.430065282 \\
\hline & 10 & 38.47899083 & 1.873 & 0.37693602 \\
\hline$\left[\mathrm{P}\left(3,5-\mathrm{di}^{\mathrm{t}} \mathrm{BuPh}\right) \mathrm{Ph}_{2}\right] / \mathrm{mM}$ & 15 & 57.71848625 & 1.688 & 0.339705286 \\
\hline \multirow[t]{2}{*}{14.01831727} & 20 & 76.95798167 & 1.533 & 0.308511969 \\
\hline & 30 & 115.4369725 & 1.29 & 0.259608898 \\
\hline $\mathrm{K}$ & 40 & 153.9159633 & 1.118 & 0.224994378 \\
\hline \multirow[t]{4}{*}{0.108069763} & 50 & 192.3949542 & 0.99 & 0.199234735 \\
\hline & 60 & 230.873945 & 0.892 & 0.179512509 \\
\hline & 70 & 269.3529358 & 0.811 & 0.163211485 \\
\hline & 80 & 307.8319267 & 0.743 & 0.149526675 \\
\hline
\end{tabular}
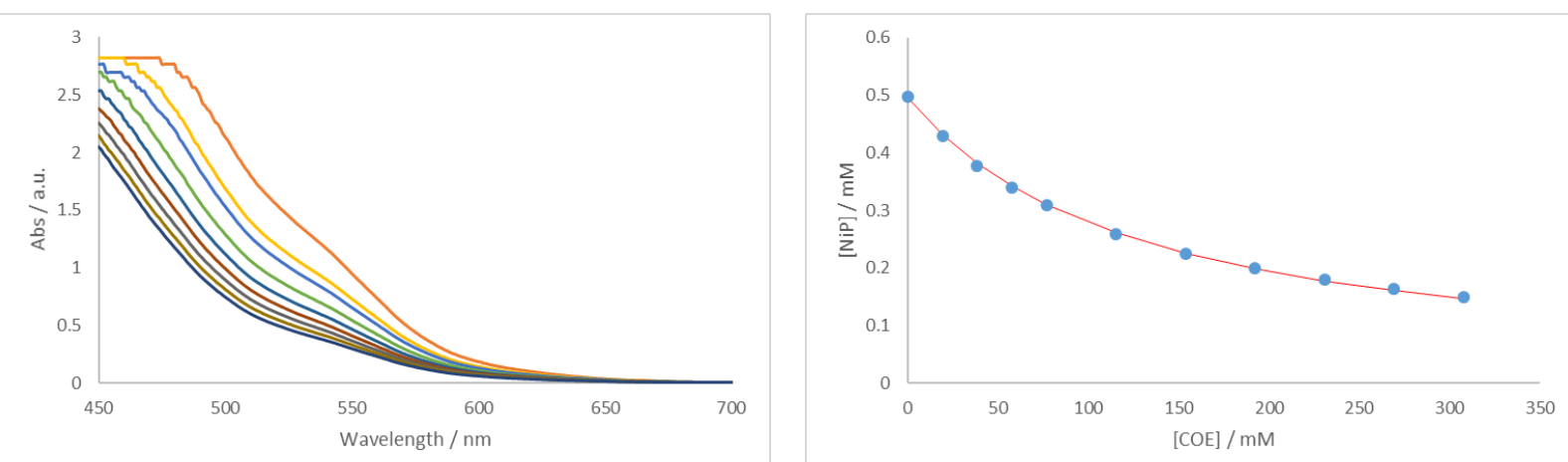

Figure S62. Left: Plot of UV-Vis spectra at different concentrations of COE and constant $\left[\mathrm{P}\left(3,5-\mathrm{di}^{\mathrm{t}} \mathrm{BuPh}\right) \mathrm{Ph}_{2}\right]\left(\mathrm{run}^{2}\right)$. Right: Absorbance at $500 \mathrm{~nm}$ transformed to [NiP] and plotted against [COE]. The red curve depicts a fit to equation (S27) using the binding constant $\mathrm{K}$ as fit parameter.

Table S17. UV-Vis Binding Titration for COE in the Presence of $\mathrm{P}\left(3,5-\mathrm{di}^{\mathrm{t}} \mathrm{BuPh}\right)_{2} \mathrm{Ph}$

\begin{tabular}{|c|c|c|c|c|}
\hline & $\mathrm{V}_{\mathrm{COE}} / \mu \mathrm{L}$ & {$[\mathrm{COE}] / \mathrm{mM}$} & Abs(500 nm) /a.u. & {$[\mathrm{NiP}] / \mathrm{mM}$} \\
\hline$[\mathrm{Ni}]_{\text {tot }} / \mathrm{mM}$ & 0 & 0 & 2.432 & 0.508998364 \\
\hline \multirow[t]{2}{*}{0.508998364} & 5 & 19.23949542 & 2.229 & 0.46651207 \\
\hline & 10 & 38.47899083 & 1.959 & 0.410003205 \\
\hline$\left[\mathrm{P}\left(3,5-\mathrm{di}^{t} \mathrm{BuPh}\right)_{2} \mathrm{Ph}\right] / \mathrm{mM}$ & 15 & 57.71848625 & 1.714 & 0.358726643 \\
\hline \multirow[t]{2}{*}{10.88921762} & 20 & 76.95798167 & 1.466 & 0.306822205 \\
\hline & 30 & 115.4369725 & 1.241 & 0.259731484 \\
\hline $\mathrm{K}$ & 40 & 153.9159633 & 1.061 & 0.222058908 \\
\hline \multirow[t]{4}{*}{0.090263004} & 50 & 192.3949542 & 0.899 & 0.188153589 \\
\hline & 60 & 230.873945 & 0.766 & 0.160317741 \\
\hline & 70 & 269.3529358 & 0.653 & 0.136667735 \\
\hline & 80 & 307.8319267 & 0.565 & 0.118250031 \\
\hline
\end{tabular}



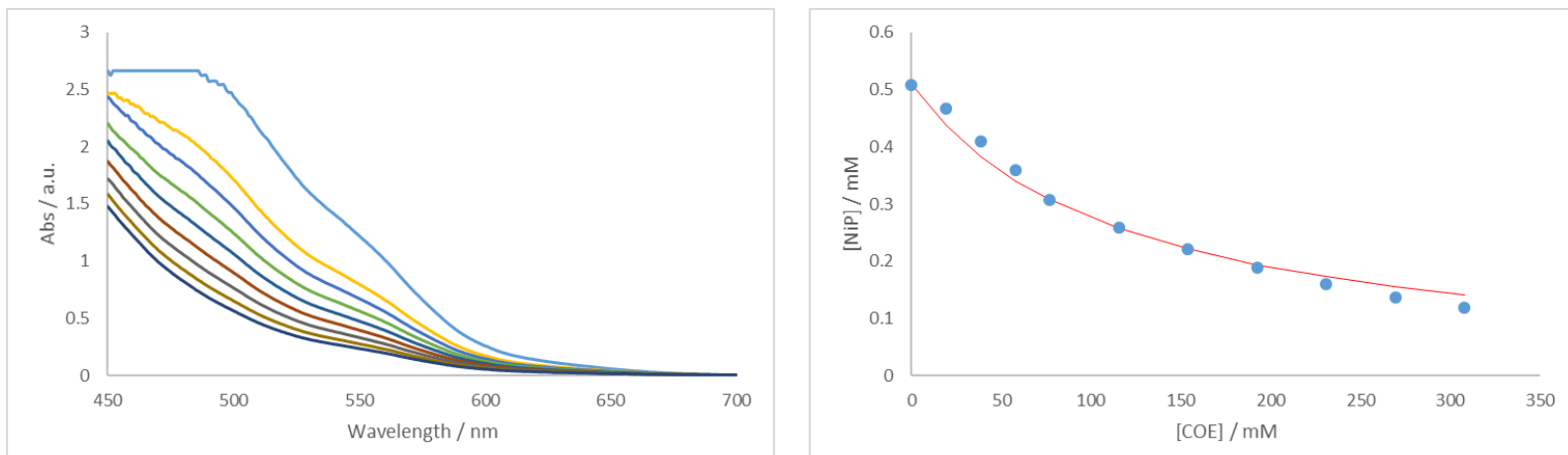

Figure S63. Left: Plot of UV-Vis spectra at different concentrations of COE and constant $\left[\mathrm{P}\left(3,5-\mathrm{di}{ }^{\mathrm{t}} \mathrm{BuPh}\right)_{2} \mathrm{Ph}\right]$. Right: Absorbance at $500 \mathrm{~nm}$ transformed to [NiP] and plotted against [COE]. The red curve depicts a fit to equation (S27) using the binding constant $\mathrm{K}$ as fit parameter.

\section{Synthesis and Evaluation of New Ligands}<smiles>CC(C)(C)c1cc(Br)cc(C(C)(C)C)c1</smiles>

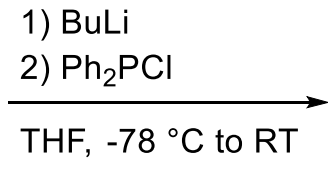<smiles>CC(C)(C)c1cc(P(c2ccccc2)c2ccccc2)cc(C(C)(C)C)c1</smiles>

(3,5-Di-tert-butylphenyl)diphenylphosphane. A flame-dried $50 \mathrm{~mL}$ Schlenk flask with rubber septum was charged with 1bromo-3,5-di-tert-butylbenzene (424 mg, $1.58 \mathrm{mmol}, 1.05$ equiv), evacuated and refilled with $\operatorname{Ar}(3 \mathrm{x})$. Dry THF (15 mL) was added via syringe and the reaction was cooled to $-78^{\circ} \mathrm{C}$ before BuLi $(0.75 \mathrm{~mL}, 2 \mathrm{M}$ in cyclohexane, $1.5 \mathrm{mmol}, 1$ equiv) was added dropwise via syringe over ca. $2 \mathrm{~min}$. The solution became slightly turbid.

The reaction was stirred at $-78^{\circ} \mathrm{C}$ for $1 \mathrm{~h}$, then $\mathrm{Ph}_{2} \mathrm{PCl}(277 \mu \mathrm{L}, 1.5 \mathrm{mmol}, 1$ equiv) was added dropwise via syringe over ca. 2 min.

The reaction was stirred at $-78{ }^{\circ} \mathrm{C}$ for $1 \mathrm{~h}$, removed from the cooling bath and stirred at $\mathrm{RT}$ for an additional $30 \mathrm{~min}$.

Silica $(3 \mathrm{~g})$ was added and all volatiles were removed under vacuum. The residue was loaded on a short column $\left(\mathrm{SiO}_{2}\right.$, length: $5 \mathrm{~cm}$, diameter: $2 \mathrm{~cm})$, and eluted with hexane $(3 \times 10 \mathrm{~mL})$, then toluene $(3 \times 10 \mathrm{~mL})$ using vacuum. The combined toluene fractions were evaporated to dryness and further dried under vacuum to give a colorless, viscous oil (503 mg, $1.34 \mathrm{mmol}, 90$ $\%)$. (The oil is prone to oxidation.)

${ }^{1} \mathrm{H}$ NMR (400 MHz, $\left.\mathrm{CDCl}_{3}\right): \delta 7.40(\mathrm{t}, J=1.8 \mathrm{~Hz}, 1 \mathrm{H}), 7.36-7.30(\mathrm{~m}, 10 \mathrm{H}), 7.17(\mathrm{dd}, J=8.5,1.8 \mathrm{~Hz}, 2 \mathrm{H}), 1.25(\mathrm{~s}, 18 \mathrm{H})$. ${ }^{31} \mathrm{P}\left\{{ }^{1} \mathrm{H}\right\}$ NMR (162 $\left.\mathrm{MHz}, \mathrm{CDCl}_{3}\right): \delta-3.89$.

${ }^{13} \mathrm{C}\left\{{ }^{1} \mathrm{H}\right\}$ NMR (100 MHz, $\left.\mathbf{C D C l}_{3}\right): \delta 150.77(\mathrm{~d}, J=6.9 \mathrm{~Hz}), 138.01(\mathrm{~d}, J=10.9 \mathrm{~Hz}), 135.67(\mathrm{~d}, J=8.8 \mathrm{~Hz}), 133.80(\mathrm{~d}, J=19.1$ $\mathrm{Hz}$ ), 128.64 (s), 128.47 (d, $J=6.8 \mathrm{~Hz}$ ), 128.37 (d, $J=20.2 \mathrm{~Hz}$ ), 122.89 (s), 35.07 (s), 31.52 (s).

HRMS (ESI, [M+H] $]^{+}$): m/z calcd for $\mathrm{C}_{26} \mathrm{H}_{32} \mathrm{P}$ 375.2236; Found 375.2235.

Elemental analysis: Calc. for $\mathrm{C}_{26} \mathrm{H}_{31} \mathrm{P}$ : C, 83.39; $\mathrm{H}, 8.34, \mathrm{P}, 8.27$. Found: $\mathrm{C}, 83.49 ; \mathrm{H}, 8.40$. 


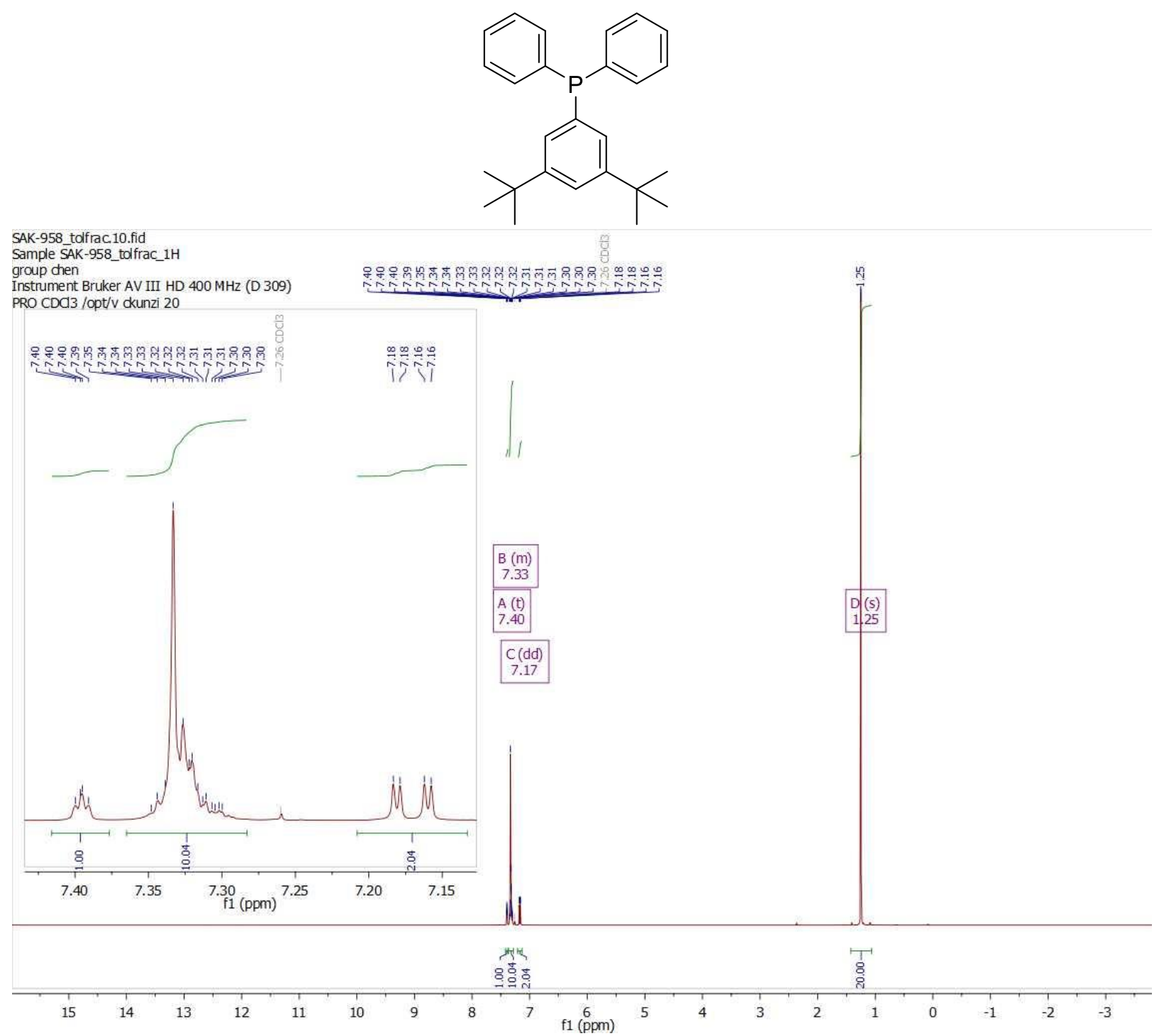

Figure S64. ${ }^{1} \mathrm{H}$ NMR $\left(400 \mathrm{MHz}, \mathrm{CDCl}_{3}\right)$ spectrum of (3,5-di-tert-butylphenyl)diphenylphosphane. 
SAK-958_tolfrac.11.fid

Sample SAK-958_tolfrac_31P

group chen

(D 309)

31P-HDEC CDA3 /opt/v dkunzi 20
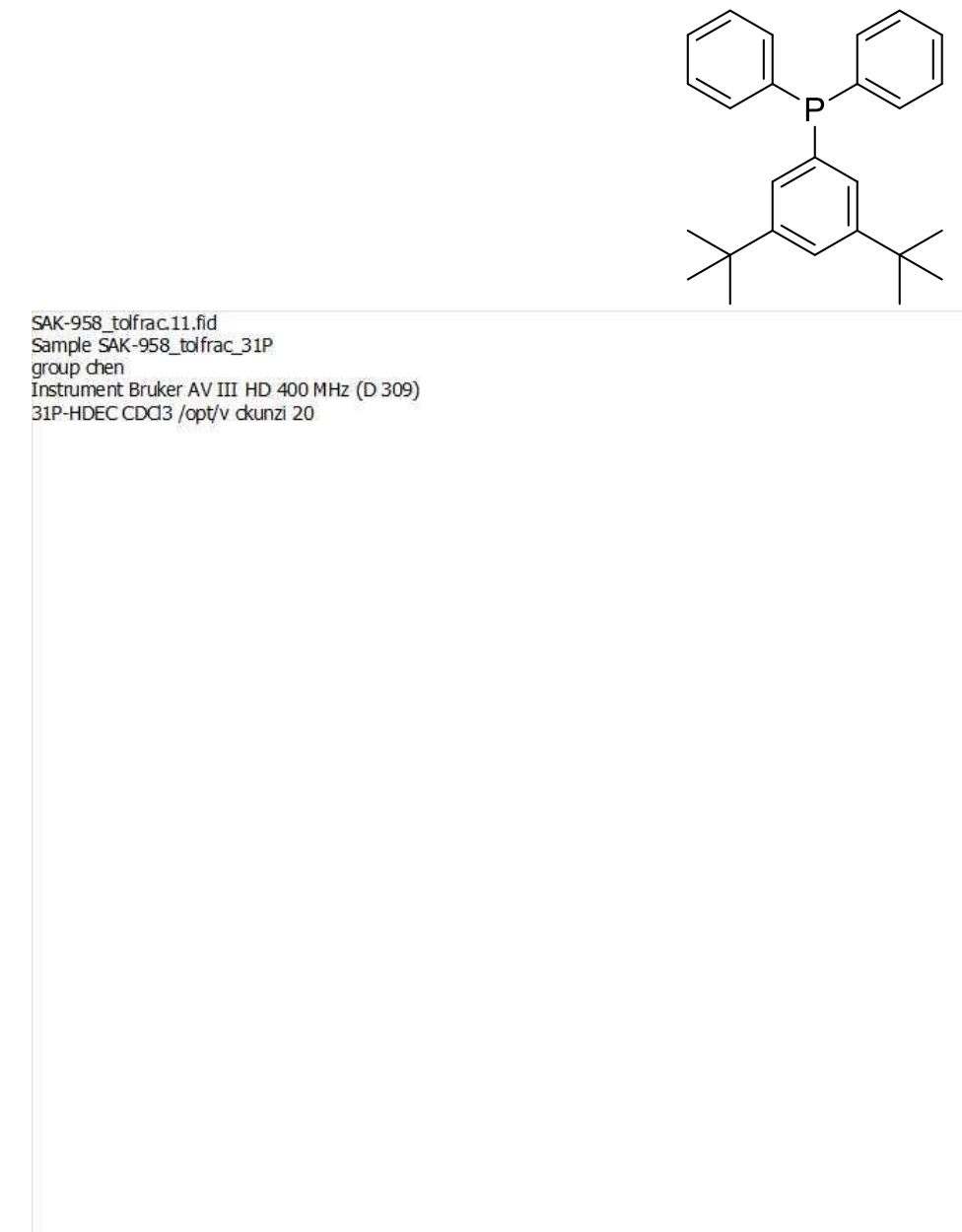

$\begin{array}{llllllllllllllllllllllllllllllllll}20 & 210 & 200 & 190 & 180 & 170 & 160 & 150 & 140 & 130 & 120 & 110 & 100 & 90 & 80 & 70 & 60 & 50 & 40 & 30 & 20 & 10 & 0 & -10 & -20 & -30 & -40 & -50 & -60 & -70 & -80 & -90 & -100 & -110-\end{array}$

Figure S65. ${ }^{31} \mathrm{P}\left\{{ }^{1} \mathrm{H}\right\} \mathrm{NMR}\left(162 \mathrm{MHz}, \mathrm{CDCl}_{3}\right)$ spectrum of (3,5-di-tert-butylphenyl)diphenylphosphane. 


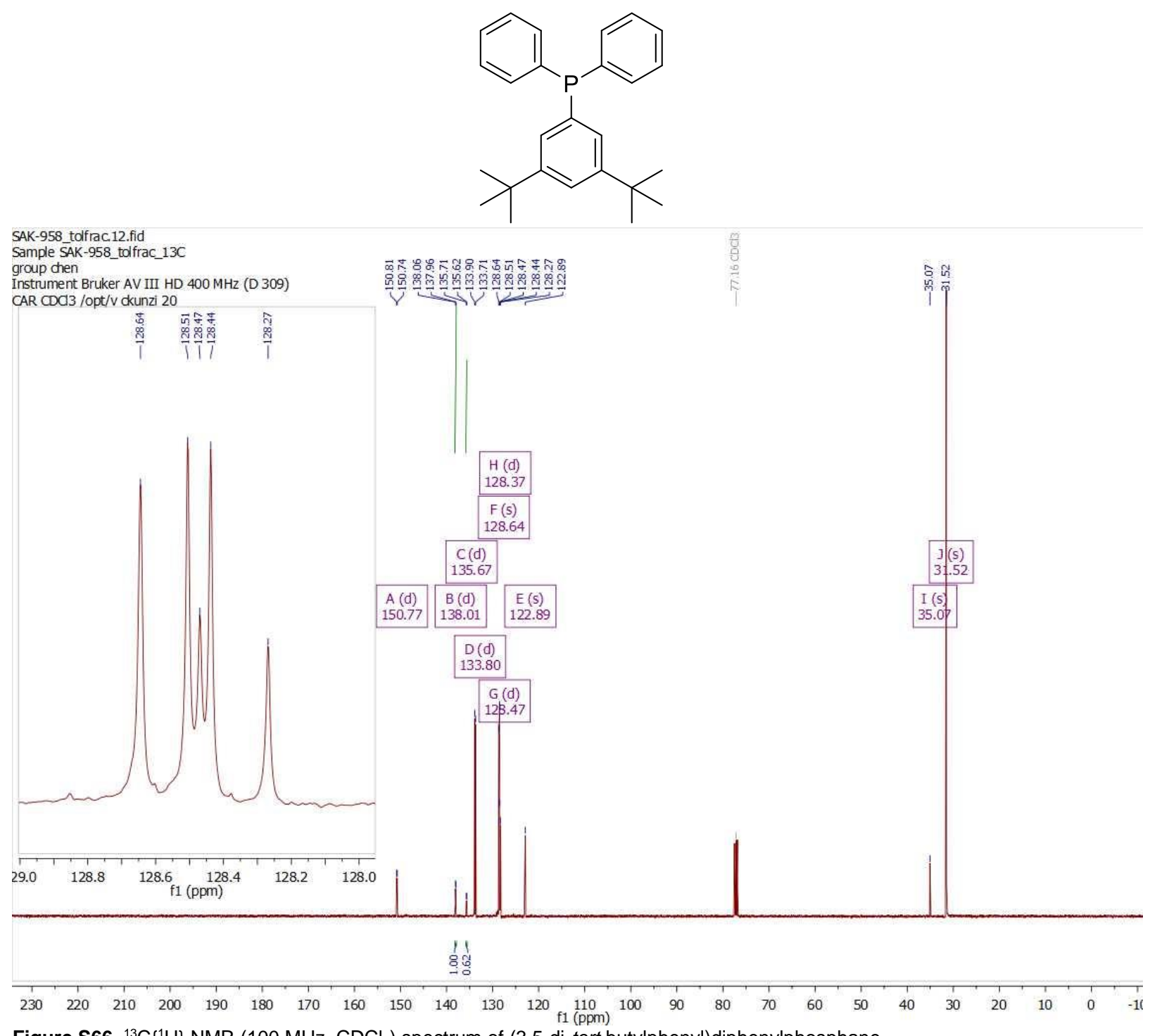

Figure S66. ${ }^{13} \mathrm{C}\left\{{ }^{1} \mathrm{H}\right\}$ NMR $\left(100 \mathrm{MHz}, \mathrm{CDCl}_{3}\right)$ spectrum of (3,5-di-tert-butylphenyl)diphenylphosphane.

$\mathrm{t}-\mathrm{Bu}$<smiles>CC(C)(C)c1cc(Br)cc(Br)c1</smiles>

1) BuLi 2) $\mathrm{PhPCl}_{2}$ THF, $-78{ }^{\circ} \mathrm{C}$ to $\mathrm{RT}$
$\mathrm{t}-\mathrm{Bu}$<smiles>CC(C)(C)c1cc(P(c2ccccc2)c2cc(C(C)(C)C)cc(C(C)(C)C)c2)cc(C(C)(C)C)c1</smiles>

Bis(3,5-di-tert-butylphenyl)(phenyl)phosphane. A flame-dried $50 \mathrm{~mL}$ Schlenk flask with rubber septum was charged with 1-bromo-3,5-di-tert-butylbenzene ( $848 \mathrm{mg}, 3.15 \mathrm{mmol}, 2.1$ equiv), evacuated and refilled with $\operatorname{Ar}(3 \mathrm{x})$. Dry THF (15 mL) was added via syringe and the reaction was cooled to $-78^{\circ} \mathrm{C}$ before BuLi ( $1.5 \mathrm{~mL}, 2 \mathrm{M}$ in cyclohexane, $3.0 \mathrm{mmol}, 2$ equiv) was added dropwise via syringe over ca. $5 \mathrm{~min}$. Within several minutes a white precipitate formed.

After $70 \mathrm{~min}$ at $-78^{\circ} \mathrm{C}, \mathrm{PhPCl}_{2}(102 \mu \mathrm{L}, 1.5 \mathrm{mmol}$, 1 equiv) was added dropwise via syringe. (The precipitate dissolved again within $30 \mathrm{~min}$ ).

The reaction was stirred at $-78^{\circ} \mathrm{C}$ for $1 \mathrm{~h}$, then removed from the cooling bath and stirred at room temperature for 30 min. Silica ( $4 \mathrm{~g})$ was added and all volatiles were removed under vacuum. The residue was loaded on a short column $\left(\mathrm{SiO}_{2}\right.$, length: 
ca. $5 \mathrm{~cm}$, diameter: $2 \mathrm{~cm})$, eluted with hexane $(3 \times 10 \mathrm{~mL})$, then toluene $(3 \times 10 \mathrm{~mL})$. The combined toluene fractions were evaporated to give the product as colorless oil that solidified to a white solid upon drying under vacuum $(550 \mathrm{mg}, 1.13 \mathrm{mmol}$, $75 \%)$.

${ }^{1} \mathrm{H}$ NMR (400 MHz, $\left.\mathrm{CDCl}_{3}\right): \delta 7.41$ (td, $\left.J=1.9,0.6 \mathrm{~Hz}, 2 \mathrm{H}\right), 7.36-7.33(\mathrm{~m}, 5 \mathrm{H}), 7.18(\mathrm{dd}, J=8.3,1.9 \mathrm{~Hz}, 4 \mathrm{H}), 1.27(\mathrm{~s}, 36 \mathrm{H})$. ${ }^{31} \mathrm{P}\left\{{ }^{1} \mathrm{H}\right\}$ NMR (162 $\left.\mathrm{MHz}, \mathrm{CDCl}_{3}\right): \delta-3.11$ (s).

${ }^{13} \mathrm{C}\left\{{ }^{1} \mathrm{H}\right\}$ NMR (100 MHz, $\left.\mathbf{C D C l}_{3}\right): \delta 150.62(\mathrm{~d}, J=6.8 \mathrm{~Hz}), 138.67(\mathrm{~d}, J=11.1 \mathrm{~Hz}), 136.34(\mathrm{~d}, J=9.0 \mathrm{~Hz}), 133.65(\mathrm{~d}, J=18.8$ $\mathrm{Hz}$ ), 128.42 (s), 128.30 (d, $J=6.7 \mathrm{~Hz}$ ), 128.26 (d, $J=19.8 \mathrm{~Hz}), 122.65$ (s), 35.03 (s), 31.53 (s).

HRMS (ESI, [M+H] ${ }^{+}$): $\mathrm{m} / \mathrm{z}$ calcd for $\mathrm{C}_{34} \mathrm{H}_{48} \mathrm{P}$ 487.3488; Found 487.3486.

Elemental analysis: Calc. for $\mathrm{C}_{34} \mathrm{H}_{47} \mathrm{P}: \mathrm{C}, 83.90 ; \mathrm{H}, 9.73, \mathrm{P}, 6.36$. Found: $\mathrm{C}, 84.15 ; \mathrm{H}, 9.73$.

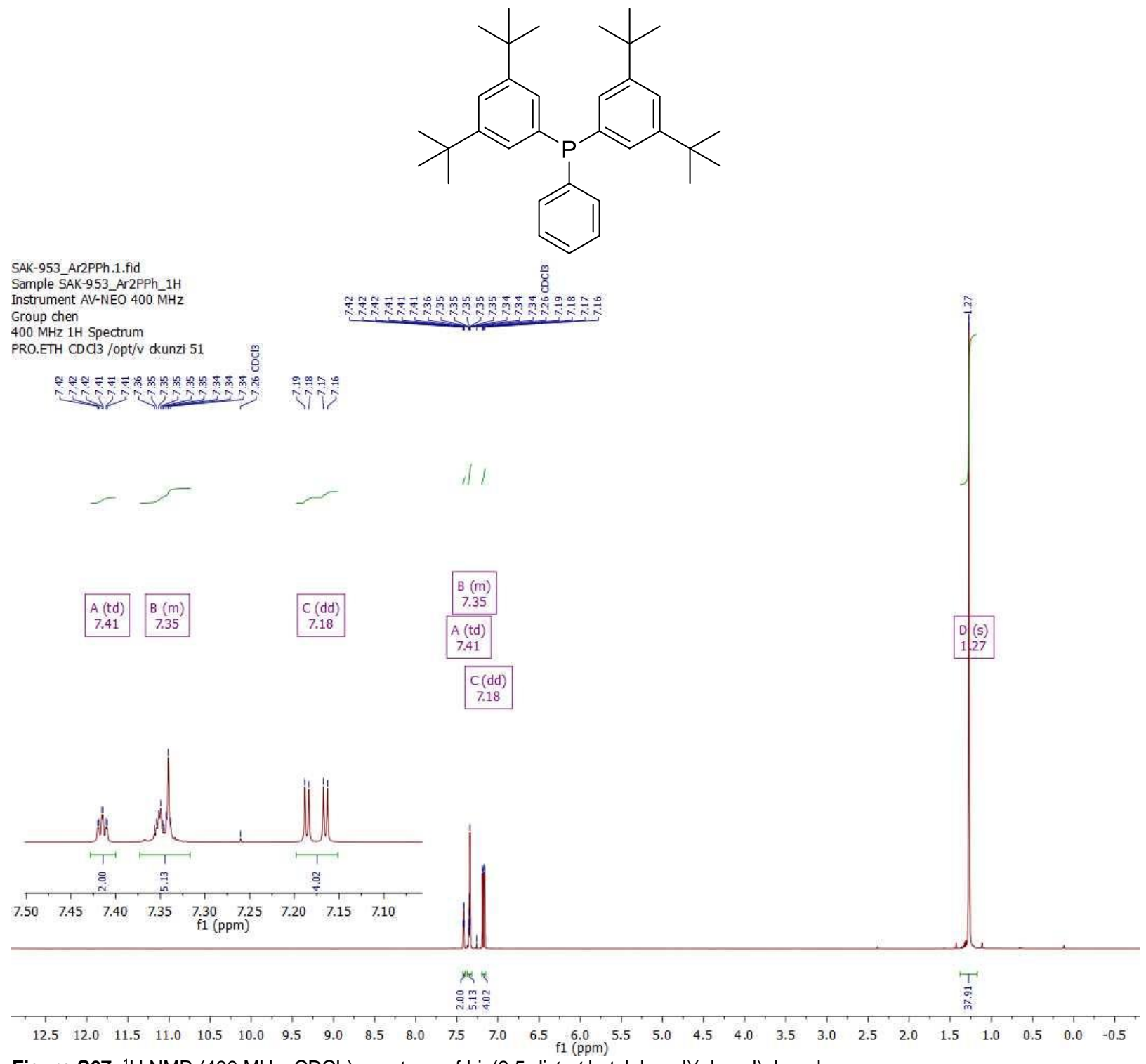

Figure S67. ${ }^{1} \mathrm{H}$ NMR $\left(400 \mathrm{MHz}, \mathrm{CDCl}_{3}\right.$ ) spectrum of bis(3,5-di-tert-butylphenyl)(phenyl)phosphane. 
$162 \mathrm{MHz} 31 \mathrm{P}$ Spectrum with $1 \mathrm{H}$ decoupling

31P-HDECETH CDC3 /opt/v ckunzi 51<smiles>CC(C)(C)c1cc(P(c2ccccc2)c2cc(C(C)(C)C)cc(C(C)(C)C)c2)cc(C(C)(C)C)c1</smiles>

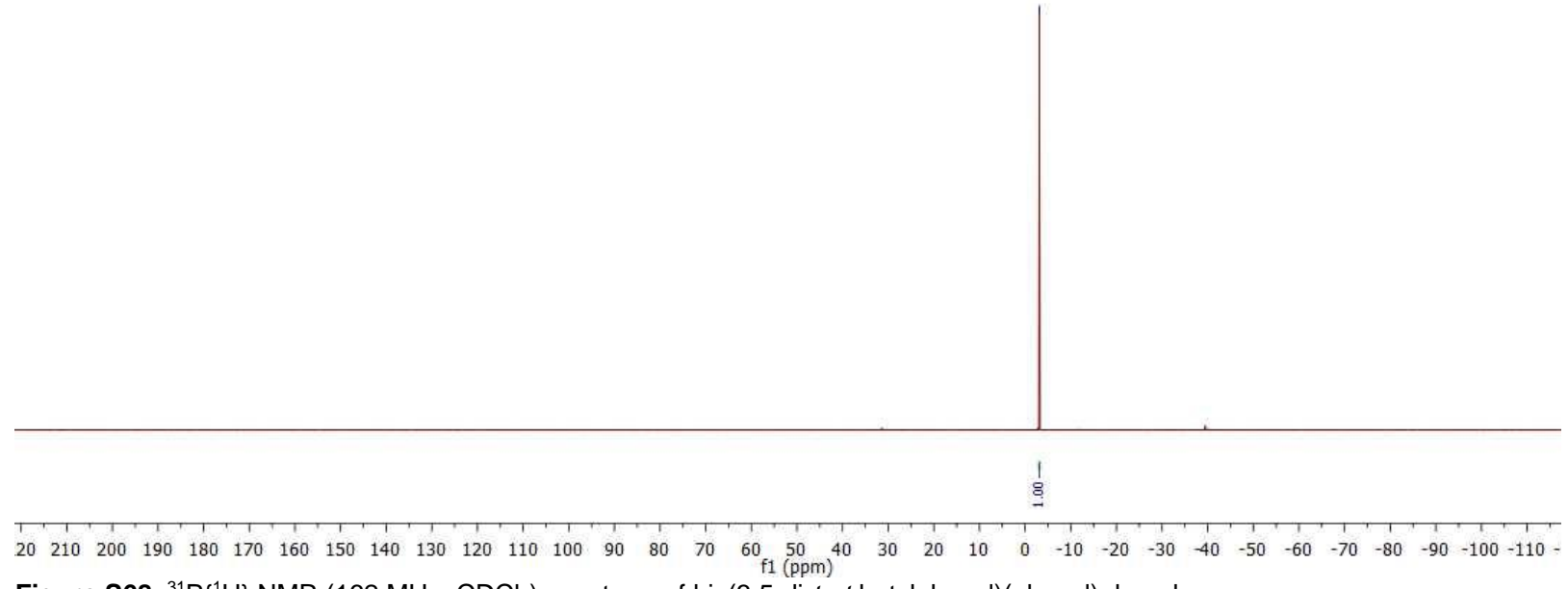

Figure S68. ${ }^{31} \mathrm{P}\left\{{ }^{1} \mathrm{H}\right\} \mathrm{NMR}\left(162 \mathrm{MHz}, \mathrm{CDCl}_{3}\right.$ ) spectrum of bis(3,5-di-tert-butylphenyl)(phenyl)phosphane. 
<smiles>CC(C)(C)c1cc(P(c2ccccc2)c2cc(C(C)(C)C)cc(C(C)(C)C)c2)cc(C(C)(C)C)c1</smiles>

\section{궁 \\ けो।}
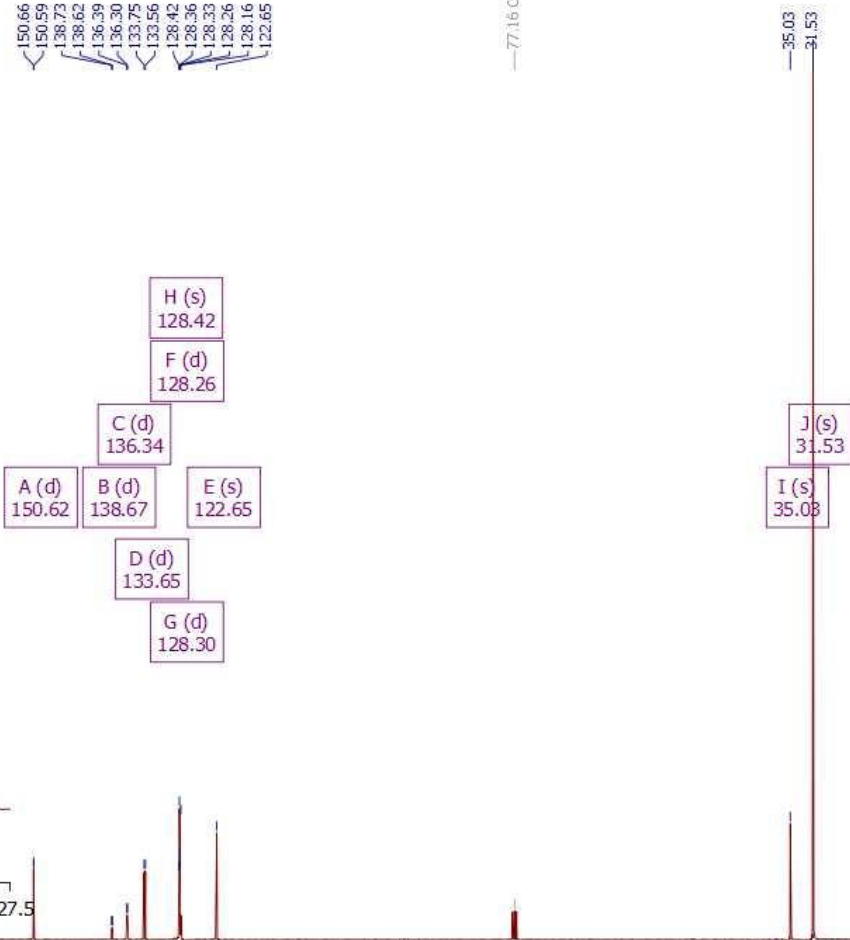

230

Figure S69. ${ }^{13} \mathrm{C}\left\{{ }^{1} \mathrm{H}\right\}$ NMR (100 $\left.\mathrm{MHz}, \mathrm{CDCl}_{3}\right)$ spectrum of bis(3,5-di-tert-butylphenyl)(phenyl)phosphane.

\section{Scheme S24. Evaluation of New Ligands.}

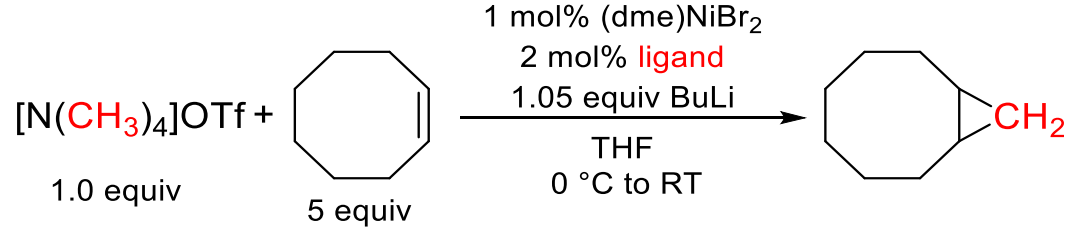

Inside the glove box, an oven-dried $5 \mathrm{~mL}$ Schlenk flask equipped with a Teflon and a glass-coated stir bar was charged with [NMe ${ }_{4}$ ]OTf (22.3 mg, $0.1 \mathrm{mmol}, 1$ equiv), COE (65 $\mu \mathrm{L}, 0.5 \mathrm{mmol}, 5$ equiv), (dme) $\mathrm{NiBr}_{2}$ in THF (0.001 mmol, 0.01 equiv, prepared as stock solution), ligand in THF ( $0.002 \mathrm{mmol}, 0.02$ equiv, prepared as stock solution), and THF (tot. vol. THF: $2 \mathrm{~mL}$, $0.05 \mathrm{M})$. The flask was removed from the glove box, cooled to $0{ }^{\circ} \mathrm{C}$ in an ice/water bath, and BuLi $(2 \mathrm{M}$ in cyclohexane; $53 \mu \mathrm{L}$, $0.105 \mathrm{mmol}, 1.05$ equiv) was added dropwise via micro syringe under a counterflow of Ar. The flask was sealed (no gas exchange) and the reaction was allowed to warm to RT overnight. After $16 \mathrm{~h}$, undecane (10 $\mu \mathrm{L}$; internal standard) was added and an aliquot (ca. $0.2 \mathrm{~mL}$ ) was partitioned between $2 \mathrm{~mL}$ pentane and $2 \mathrm{~mL}$ water. After vigorous mixing of the aliquot with a vortex mixer, the organic phase was filtered through a plug of $\mathrm{MgSO}_{4}$ and analyzed by GC-FID. The yield was determined by the integral ratio of the product versus undecane as internal standard using a previously determined calibration curve. 
Table S18. Evaluation of New Ligands.

\begin{tabular}{ccc}
\hline Entry & Ligand & Yield $/ \%^{a}$ \\
\hline 1 & $\mathrm{P}\left(3,5-\right.$ dit $\left.^{\mathrm{B}} \mathrm{BuPh}\right) \mathrm{Ph}_{2}$ & 32 \\
2 & $\mathrm{P}\left(3,5-\text { dit }^{t} \mathrm{BuPh}\right)_{2} \mathrm{Ph}$ & 48 \\
\hline
\end{tabular}

${ }^{a}$ Average of two independent runs.

\section{Ligand Parametrization Model}

The steric parameter were taken from section 27.6 (Table S27) for the DFT-optimized $\left(\mathrm{C}_{2} \mathrm{H}_{4}\right)_{2} \mathrm{NiPR}_{3}$ complexes. Multivariate ligand parametrization models were generated using the Multiple Linear Regression fit as implemented in the OriginPro software package.

Table S19. Steric Parameters, Binding Constants and Yields with COE for Several Phosphines

\begin{tabular}{|c|c|c|c|c|c|}
\hline Phosphine & Exact cone angle $\theta^{\circ}$ & Exact solid cone angle $\Theta^{\circ}$ & $\% \bigvee_{\text {Bur }}$ & $\mathrm{K}$ & $\%$ Yield \\
\hline $\mathrm{PPhMe}_{2}$ & 138.947 & 122.863 & 26.5 & 0.0014 & $3^{a}$ \\
\hline $\mathrm{PPh}_{2} \mathrm{Me}$ & 155.594 & 129.365 & 28.6 & 0.0013 & $0.3^{a}$ \\
\hline $\mathrm{PPh}_{3}$ & 168.196 & 135.023 & 30.4 & 0.081 & 25 \\
\hline $\mathrm{P}\left(3,5-\mathrm{di}^{t} \mathrm{BuPh}\right) \mathrm{Ph}_{2}$ & 188.849 & 142.79 & 31.2 & 0.11 & 32 \\
\hline $\mathrm{P}\left(3,5-\mathrm{di}^{\mathrm{B}} \mathrm{BuPh}\right)_{2} \mathrm{Ph}$ & 195.345 & 148.329 & 31.1 & 0.090 & 48 \\
\hline
\end{tabular}

${ }^{a}$ Data from ref. S2.

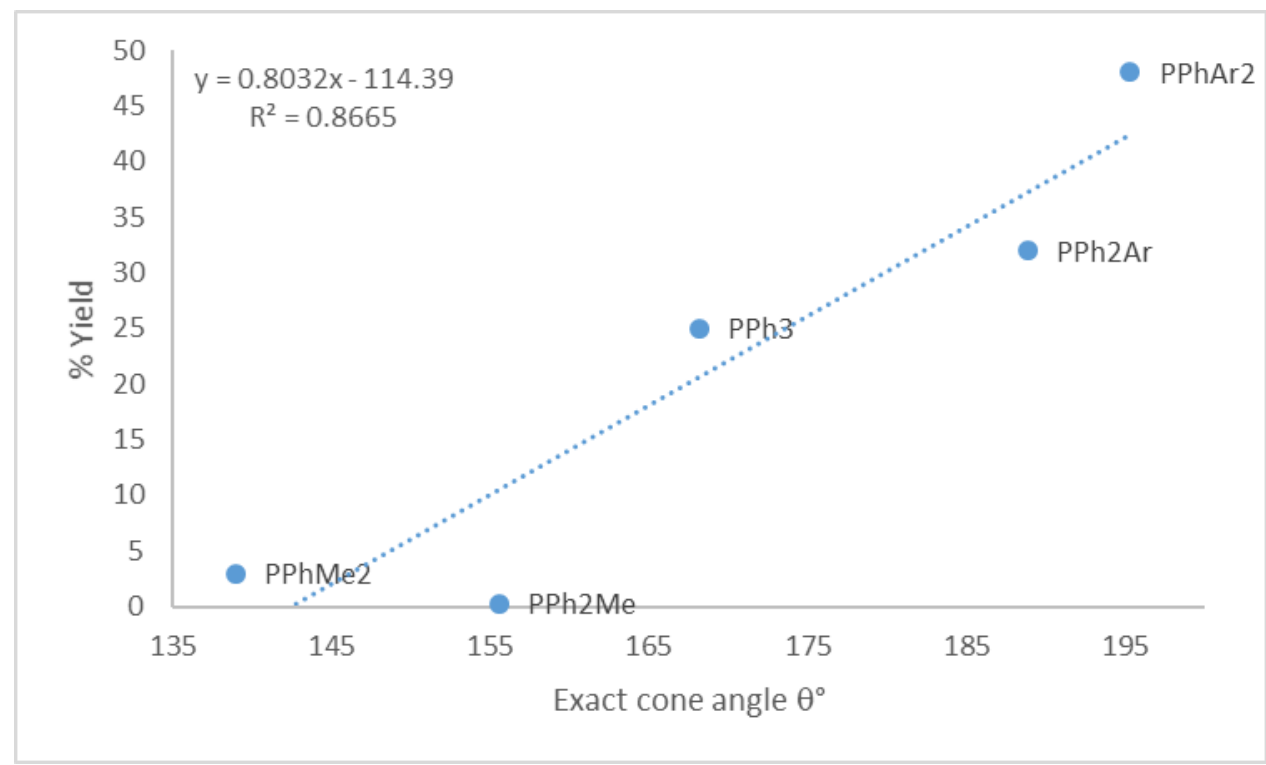

Figure S70. Plot of exact cone angle $\theta^{\circ}$ versus $\%$ yield for the cyclopropanation of $\mathrm{COE}$ with different phosphine ligands. Ar $=$ (3,5-ditBuPh). 


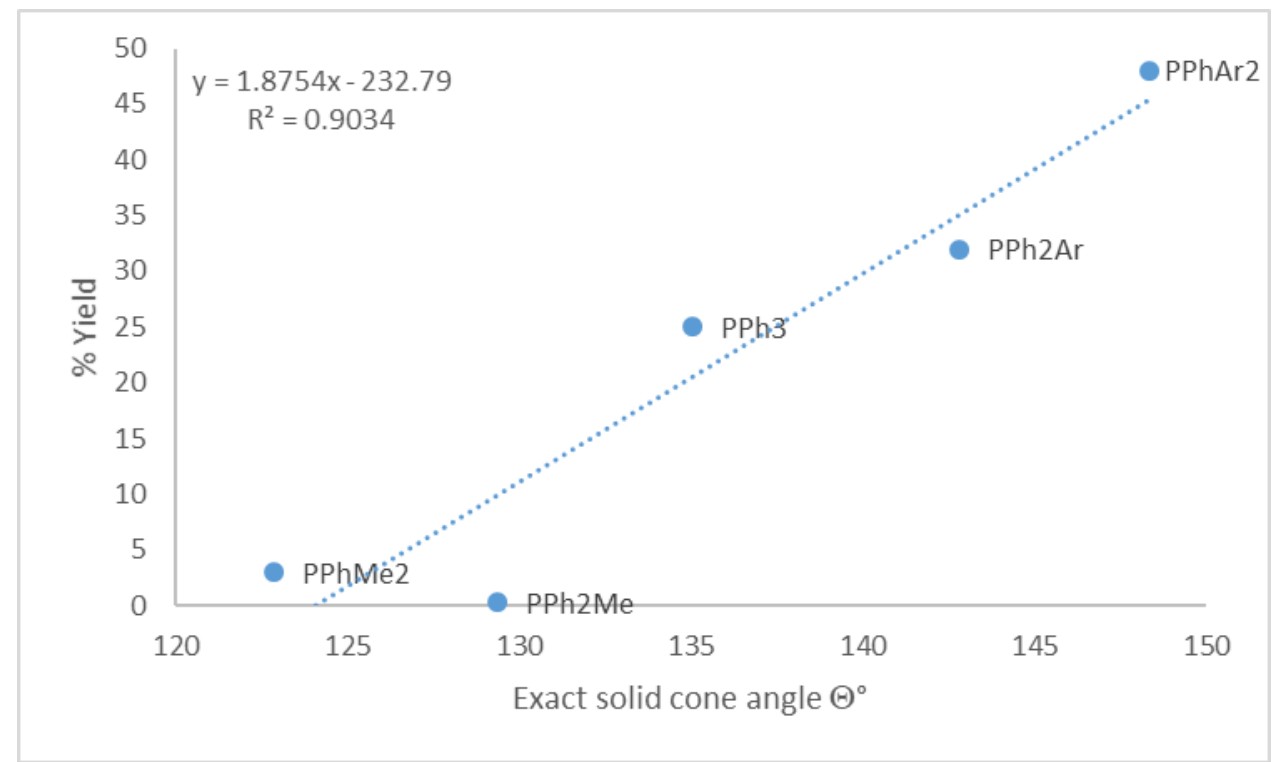

Figure S71. Plot of exact solid cone angle $\Theta^{\circ}$ versus \% yield for the cyclopropanation of COE with different phosphine ligands. $\operatorname{Ar}=\left(3,5-d^{t} B u P h\right)$.

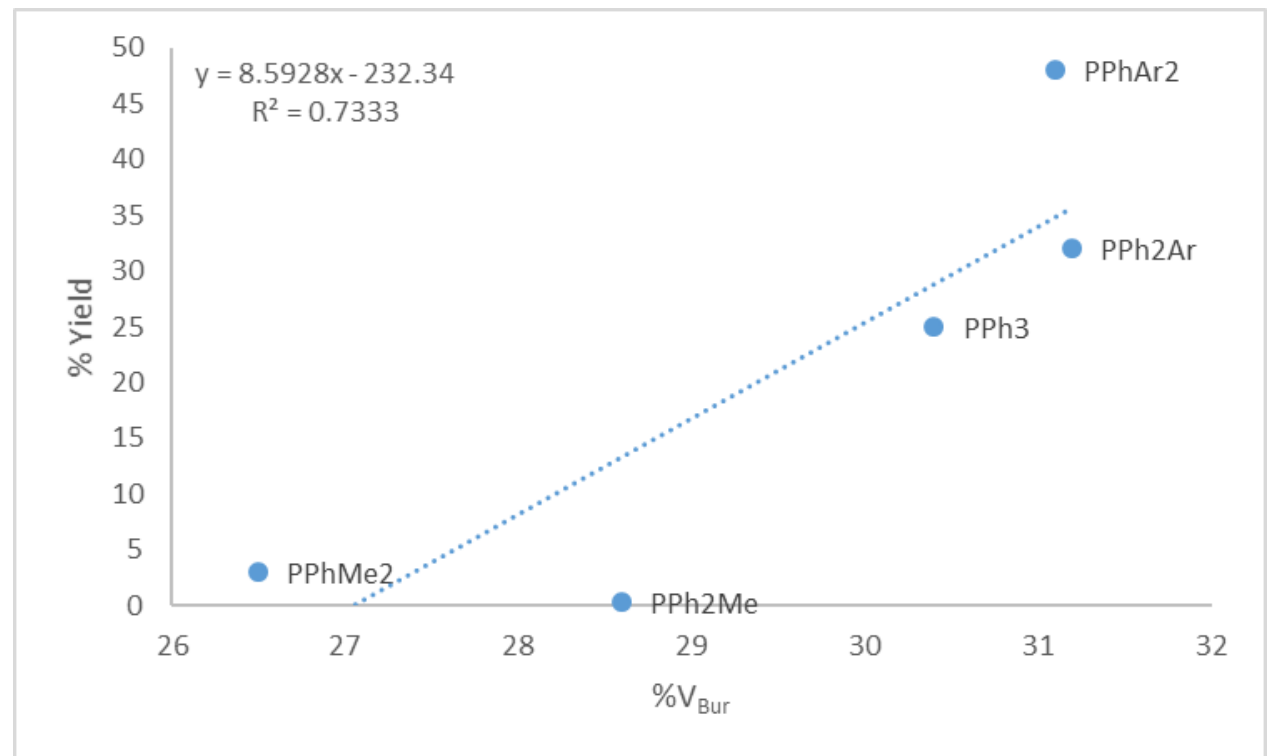

Figure S72. Plot of buried volume $\% \mathrm{~V}_{\mathrm{Bur}}$ versus $\%$ yield for the cyclopropanation of $\mathrm{COE}$ with different phosphine ligands. Ar = (3,5-di'BuPh). 


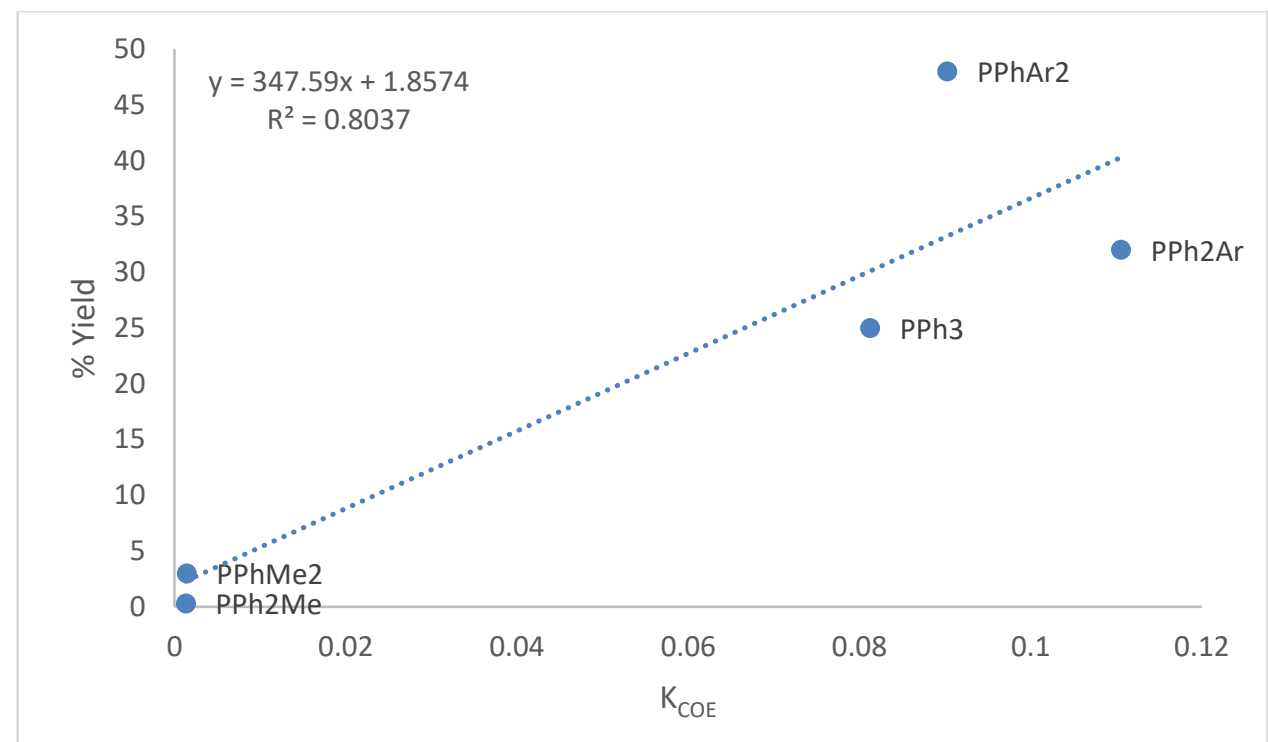

Figure S73. Plot of binding constant $\mathrm{K}_{\mathrm{COE}}$ versus \% yield for the cyclopropanation of COE with different phosphine ligands. Ar $=\left(3,5-\right.$ dit $\left.^{t} \mathrm{BuPh}\right)$.

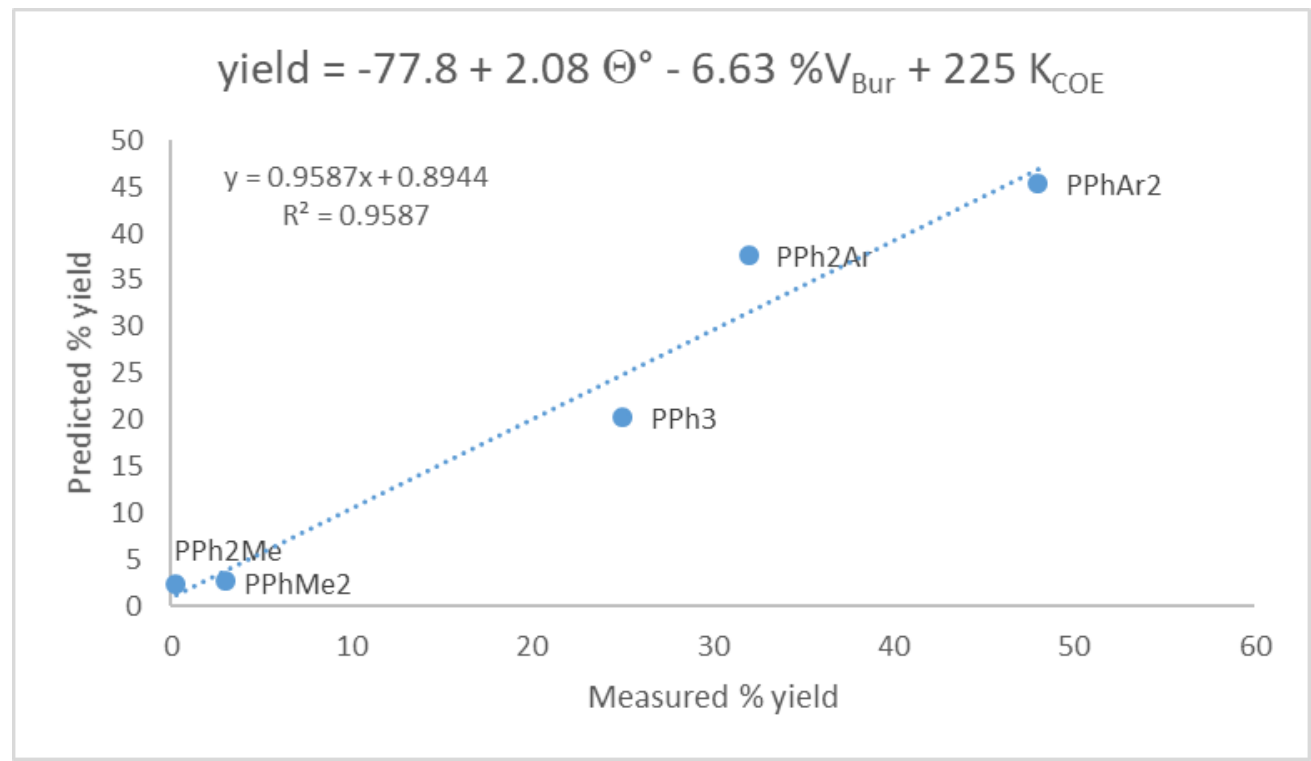

Figure S74. Plot of measured yield versus predicted yield for a ligand parametrization model using exact solid cone angle $\Theta^{\circ}$, buried volume $\% \mathrm{~V}_{\mathrm{Bur}}$, and binding constant $\mathrm{K}_{\mathrm{COE}} . \mathrm{Ar}=\left(3,5-\mathrm{di}{ }^{\mathrm{B}} \mathrm{BuPh}\right)$. 


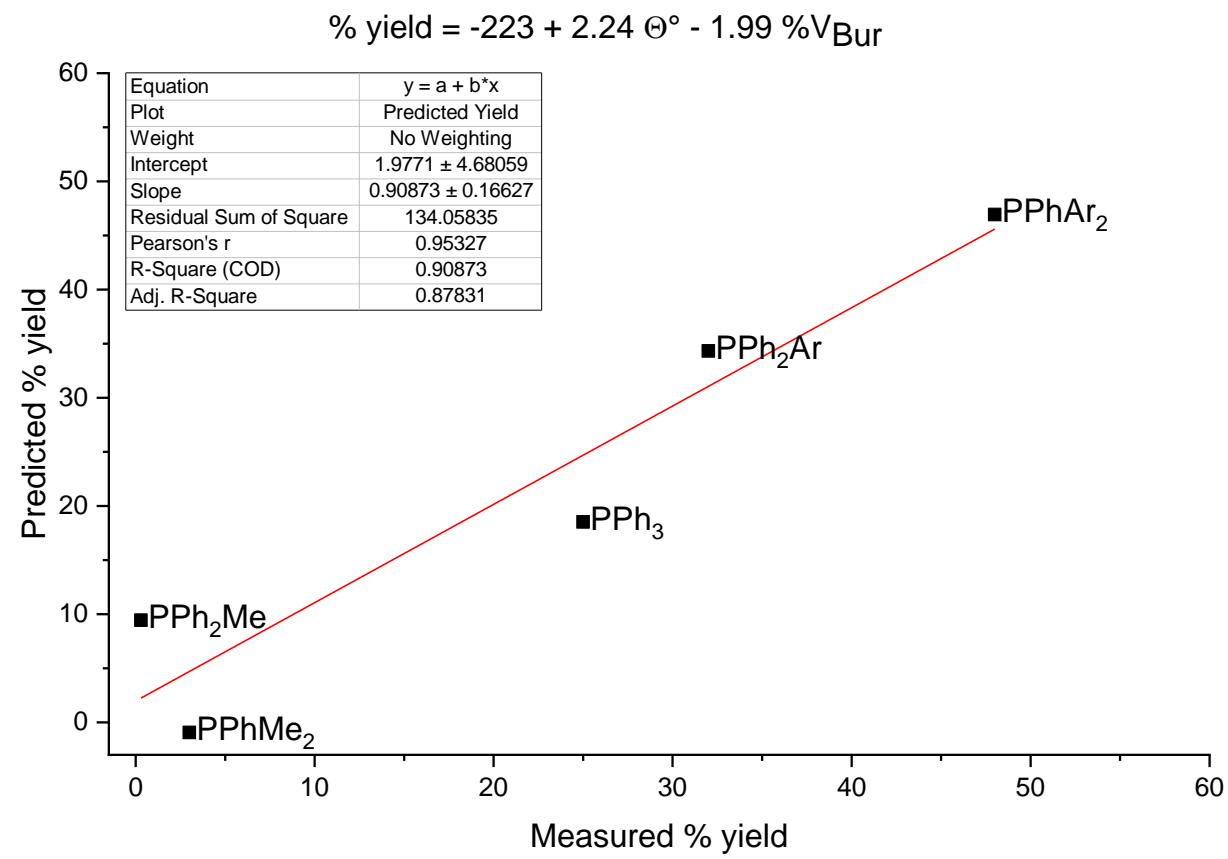

Figure S75. Plot of measured yield versus predicted yield for a ligand parametrization model using exact solid cone angle $\Theta^{\circ}$ and buried volume $\% \mathrm{~V}_{\text {Bur. }} \mathrm{Ar}=\left(3,5-\mathrm{di} \mathrm{B}^{\mathrm{B} u P h}\right)$.

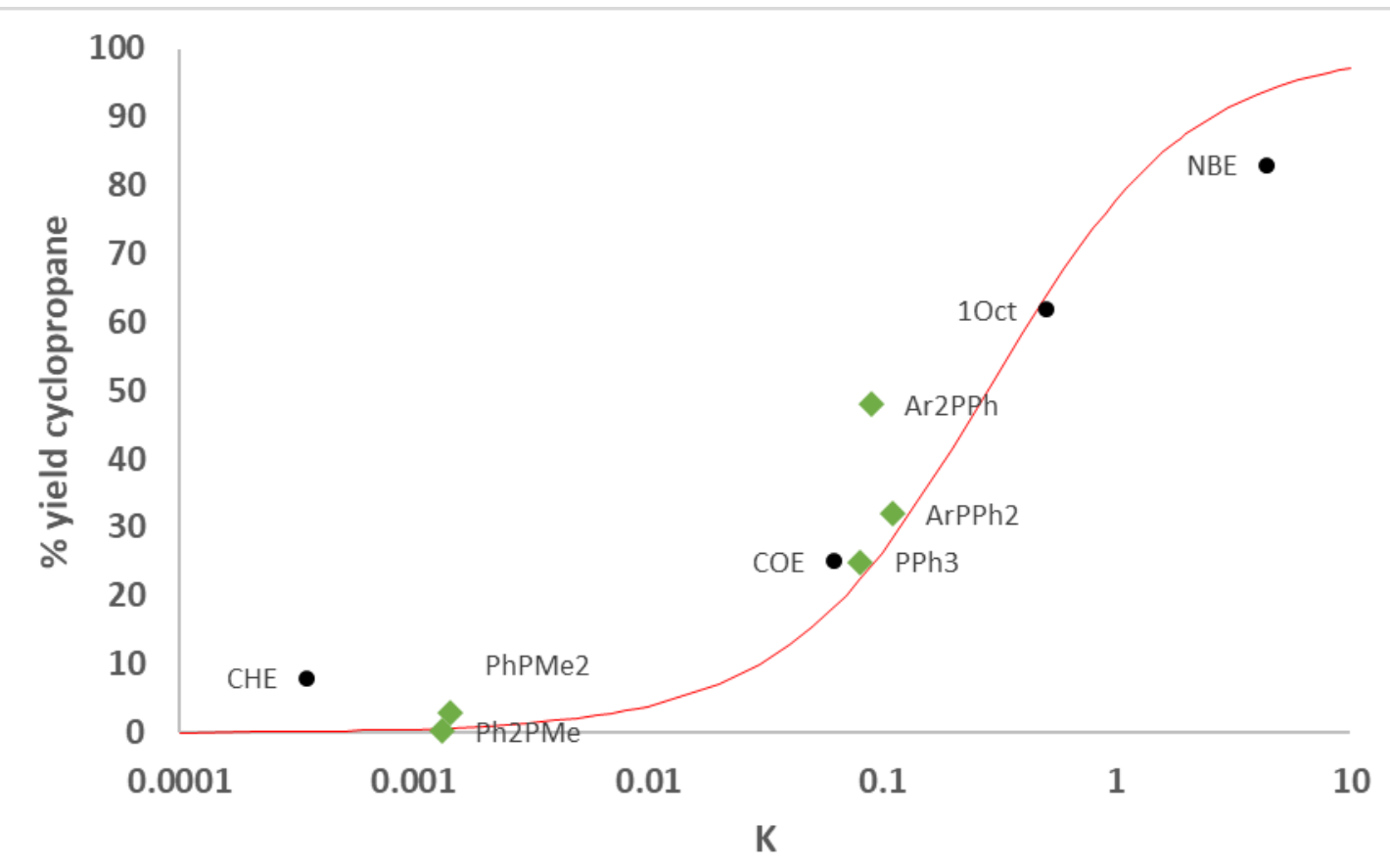

Figure S76. Plot of binding constant K (log scale) versus measured yields for the cyclopropanation for selected ligands and alkenes Black circles represent yields of alkenes as indicated with $\mathrm{PPh}_{3}$ as ligand and $\mathrm{K}$ from Tolman (see ref. S7) and the corresponding fit to our model as red curve. Green diamonds represent yields of COE with different phosphine ligands as indicated and $\mathrm{K}$ from Table S8. $\mathrm{Ar}=(3,5-\mathrm{di} \mathrm{BuPh}), \mathrm{CHE}=$ Cyclohexene, $\mathrm{COE}=$ Cyclooctene, 1 Oct $=1-$ Octene, NBE = Norbornene. 


\section{Computational Details}

All calculations were performed using Gaussian 09 Revision D. ${ }^{10}$ All geometries were optimized and frequencies calculations were performed to ensure real minima for the intermediates (i.e., $\mathrm{N}_{\text {imag }}=0$ ) and first-order saddle points for the transition states (i.e., $\mathrm{N}_{\text {imag }}=1$ ). The energies reported are zero-point corrected energies. We first performed a benchmarking procedure, in which we compared crystal structures of literature-reported compounds that are analogous to the intermediates in our system to computationally optimized structures (19 different combinations of density functionals and basis sets were tested, a table summarizing the results is provided in Section 27.1). Following this procedure, we settled on the functional/basis-set combination M06L/def2-SVP, and these results are presented in the text. In addition, we performed calculations at the same level with an implicit solvent model, which yielded similar results.

All geometries can be found in the accompanying .xyz file.

For the Kinetic Isotope Effect calculations, we employed the ISOEFF software, which calculates isotope effects based on the Bigeleisen equation, using input from a quantum mechanical calculation (i.e., the Hessian matrix obtained from Gaussian). ${ }^{11}$

\subsection{Results of Benchmarking Procedure}

To choose the best density functional for this work, we first performed a benchmarking procedure, whereby we computationally optimized the geometries of three structures and compared them to literature-reported crystal structures. The three structures chosen were the Pörschke nickel-lithium complex, and the two Hillhouse nickel carbenes. ${ }^{12}$ The structures and their respective CCDC identifiers are given in Figure S77.

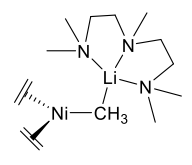

Pörschke

DAPMIQ

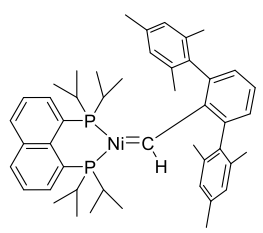

Hillhouse1

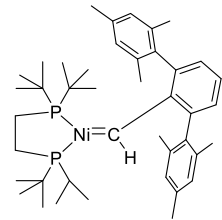

Hillhouse2

Figure S77. Structures and their respective CCDC identifiers that have been used as benchmark compounds in this study.

The root mean squared deviation (RMSD) was calculated for each optimized geometry against the respective crystal structure (except for some cases in which the geometry did not converge). The method of choice (highlighted in Table S20) is the one that consistently provided the best fit, coupled with a reasonable amount of computational resources and ease of convergence.

Table S20. Root Mean Squared Deviation (RMSD) for Optimized Geometries.

\begin{tabular}{llccc}
\hline Functional & \multicolumn{1}{c}{ Basis Set } & Pörschke & Hillhouse1 & Hillhouse2 \\
\hline BP86 & def2tzvp & & 0.0653 & 0.0940 \\
PBE1PBE & 6-31g* & 0.0787 & 0.1839 & 0.0811 \\
B3LYP & 6-311g** & 0.0718 & 0.2413 & 0.0860 \\
B3LYP & LANL2DZ & 0.0627 & 0.2323 & 0.0963 \\
B3LYP & LANL2DZ/6-31g* & 0.0617 & -- & 0.0881 \\
B3LYP & LANL2TZf/6-311+g** & 0.0607 & -- & - \\
TPSSTPSS & 6-31g* & 0.0964 & 0.2487 & 0.0732 \\
B97D & def2SVP & 0.1199 & 0.0535 & 0.1055 \\
M06L & 6-31g* & 0.1110 & 0.0622 & 0.1416 \\
WB97XD & def2SVP & 0.0792 & 0.0398 & - \\
M06 & 6-31g* & 0.0957 & 0.0860 & 0.1343 \\
PBEPBE & def2SVP & 0.1030 & 0.0485 & 0.0795 \\
TPSSTPSS & def2SVP & 0.1133 & 0.1295 & 0.0845 \\
B97D3 & def2SVP & 0.1037 & 0.0597 & 0.0849 \\
M06L & def2SVP & 0.1087 & 0.0676 & 0.0953 \\
PBEPBE & def2TZVP & 0.0753 & 0.0927 & 0.0691 \\
TPSSTPSS & def2TZVP & 0.0851 & 0.0512 & 0.3123 \\
B97D3 & def2TZVP & 0.0757 & 0.0859 & 0.0681 \\
M06L & def2TZVP & 0.0941 & 0.1616 & 0.0748 \\
\hline
\end{tabular}




\subsection{Energies of Structures for Ni-Phosphine-Alkene Cycle (NiPA) and KIEs}

All structures were optimized at the M06L/def2-SVP level of theory. Frequencies analysis was performed for all optimized structures to ensure that intermediates are real minima and transition states are first-order saddle points.

The product " $1+7$ " refers to a complex of the NiPA system and cyclopropane, which is obtained following the reductive elimination. The separated products lie at a slightly higher energy.

The product " $1 *+7$ " refers to the sum of the energies of the separated products.
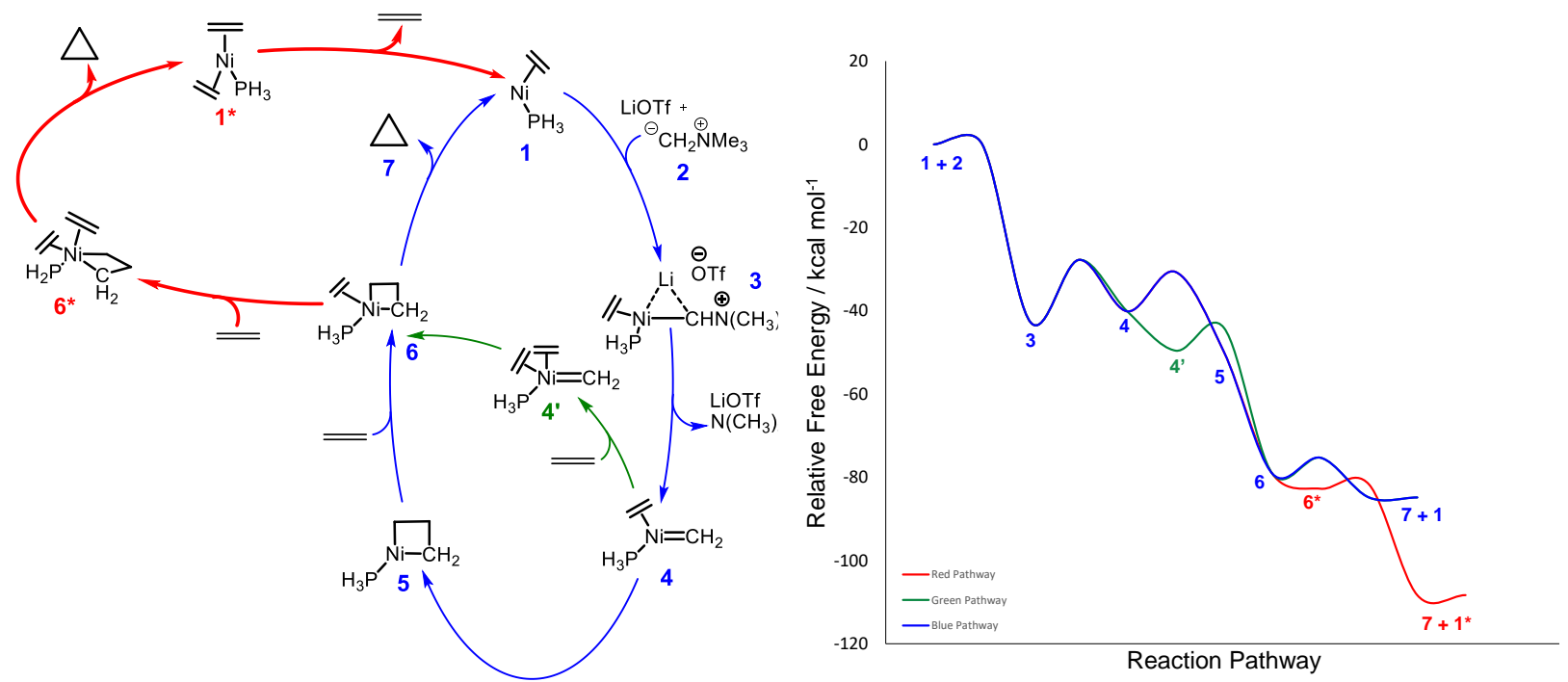

Figure S78. Left: Proposed catalytic cycles for the model system with one phosphine and one alkene. Right: Energy profile for the catalytic system with one phosphine ligand and one alkene.

Table S21. Computed Energies for the Blue Pathway for the catalytic system with one phosphine ligand and one alkene.

\begin{tabular}{lccc}
\hline & \multicolumn{2}{c}{ Chemical Transformation } & Energy / $\mathrm{kcal} \mathrm{mol}^{-1}$ \\
\hline $1+2$ & to & 3 & -42.78 \\
3 & to & TS3-4 & 15.02 \\
TS3-4 & to & $4+\mathrm{Me}_{3} \mathrm{~N}^{*}$ LiOTf & -12.37 \\
4 & to & TS4-5 & 9.47 \\
TS4-5 & to & 5 & -19.22 \\
$5+$ ethylene & to & 6 & -29.23 \\
6 & to & TS6-7 & 3.81 \\
TS6-7 & to & $7+1$ (complex) & -9.54 \\
\hline
\end{tabular}

Table S22. Computed Energies for the Red Pathway for the catalytic system with one phosphine ligand and one alkene.

\begin{tabular}{lclc}
\hline & \multicolumn{2}{c}{ Chemical Transformation } & Energy $/ \mathrm{kcal} \mathrm{mol}^{-1}$ \\
\hline $1+2$ & to & 3 & -42.78 \\
3 & to & TS3-4 & 15.02 \\
TS3-4 & to & $4+\mathrm{Me}_{3} \mathrm{~N}^{*}$ LiOTf & -12.37 \\
4 & to & TS4-5 & 9.47 \\
TS4-5 & to & 5 & -19.22 \\
$5+$ ethylene & to & 6 & -29.23 \\
$6+$ ethylene & to & $6^{*}$ & 9.47 \\
$6^{*}$ & to & TS6 & 1.06 \\
TS6*-7 & to & $7+1^{*}$ & -26.63 \\
\hline
\end{tabular}

Table S23. Computed Energies for the Green Pathway for the catalytic system with one phosphine ligand and one alkene. 


\begin{tabular}{lccc}
\hline & \multicolumn{2}{c}{ Chemical Transformation } & Energy / $\mathrm{kcal} \mathrm{mol}^{-1}$ \\
\hline $1+2$ & to & 3 & -42.78 \\
3 & to & TS3-4 & 15.02 \\
TS3-4 & to & $4+\mathrm{Me}_{3} \mathrm{~N}^{*}$ LiOTf & -12.37 \\
$4+$ ethylene & to & 4 & -9.44 \\
$4{ }^{\prime}$ & to & TS4'-6 & 5.48 \\
TS4'-6 & to & 6 & -35.03 \\
6 & to & TS6-7 & 3.81 \\
TS6-7 & to & $7+1$ (complex) & -9.54 \\
\hline
\end{tabular}

Table S24. Computed KIEs for the catalytic system with one phosphine ligand and one alkene with perdeuterated reagent $\left[\mathrm{LiCD}_{2} \mathrm{~N}\left(\mathrm{CD}_{3}\right)_{3}\right] \mathrm{OTf}$.

\begin{tabular}{cccc}
\hline & \multicolumn{2}{c}{ Chemical Transformation } & KIE \\
\hline 3 & to & 4 & 2.50 \\
4 & to & 5 & 0.63 \\
6 & to & 1 & 1.11 \\
\hline
\end{tabular}




\subsection{Energies of Structures for Ni-Phosphine 2 Cycle $\left(\mathrm{NiP}_{2}\right)$}

All structures were optimized at the M06L/def2-SVP level of theory. Frequencies analysis was performed for all optimized structures to ensure that intermediates are real minima and transition states are first-order saddle points.

The product " $1 \mathrm{P}_{2}+7$ " refers to a complex of the $\mathrm{NiP}_{2}$ system and cyclopropane, which is obtained following the reductive elimination. The separated products lie at a slightly higher energy.
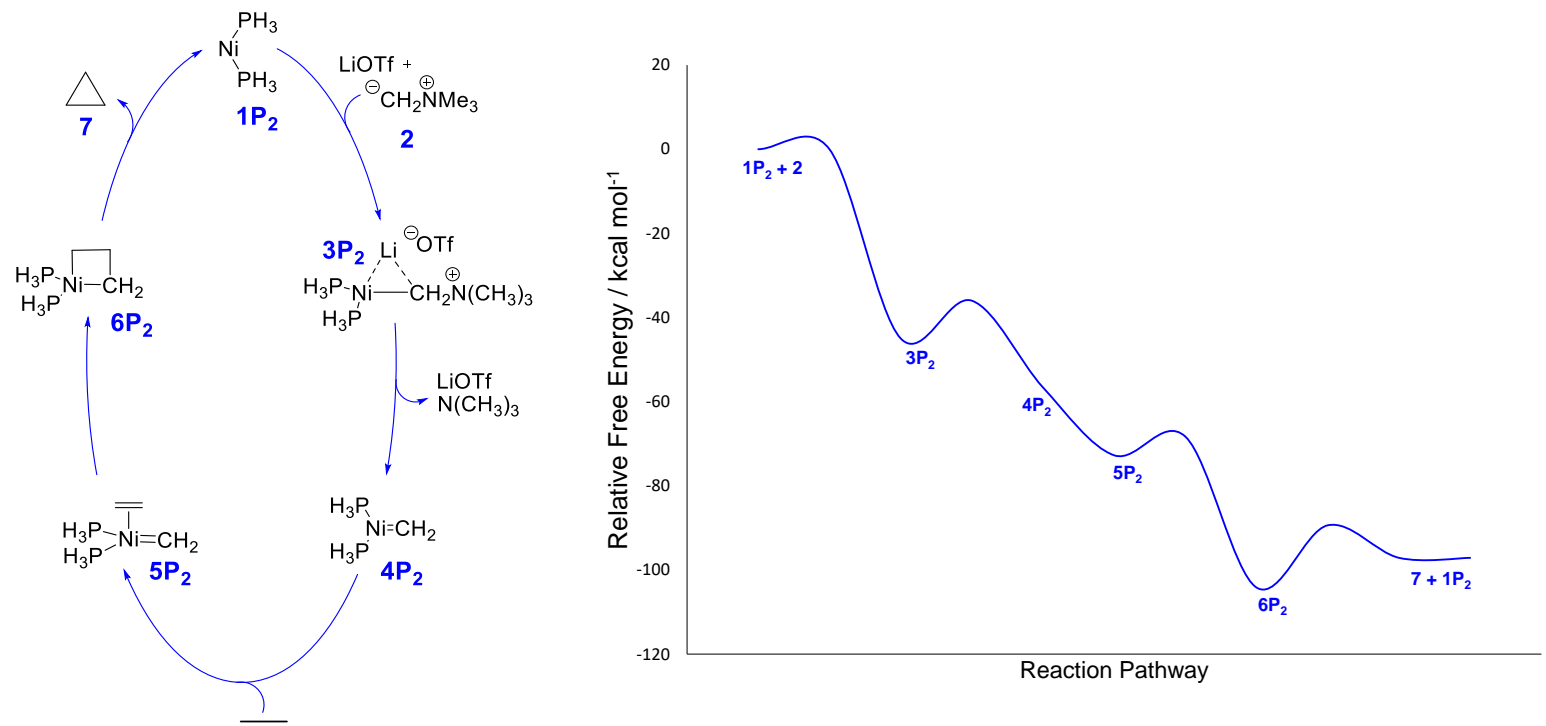

Figure S79. Left: Catalytic cycle for the model system with two phosphine ligands. Right: Energy profile for the catalytic system with two phosphine ligands.

Table S25. Computed Energies for the Blue Pathway for the catalytic system with two phosphine ligands.

\begin{tabular}{lclc}
\hline & \multicolumn{2}{c}{ Chemical Transformation } & Energy / $\mathrm{kcal} \mathrm{mol}^{-1}$ \\
\hline $1 \mathrm{P}_{2}+2$ & to & $3 \mathrm{P}_{2}$ & -44.96 \\
$3 \mathrm{P}_{2}$ & to & $\mathrm{TS}_{2} \mathrm{P}_{2}-4 \mathrm{P}_{2}$ & 8.97 \\
$\mathrm{TS}_{3} \mathrm{P}_{2}-4 \mathrm{P}_{2}$ & to & $4 \mathrm{P}_{2}+\mathrm{Me}_{3} \mathrm{~N}^{*} \mathrm{LiOTf}$ & -20.63 \\
$4 \mathrm{P}_{2}+$ ethylene & to & $5 \mathrm{P}_{2}$ & -16.13 \\
$5 \mathrm{P}_{2}$ & to & $\mathrm{TS}^{2} \mathrm{P}_{2}-6 \mathrm{P}_{2}$ & 4.43 \\
$\mathrm{TS}_{5} \mathrm{P}_{2}-6 \mathrm{P}_{2}$ & to & $6 \mathrm{P}_{2}$ & -35.87 \\
$6 \mathrm{P}_{2}$ & to & $\mathrm{TS}_{2} \mathrm{P}_{2}-7$ & 14.81 \\
$\mathrm{TS}_{6} \mathrm{P}_{2}-7$ & to & $7+1 \mathrm{P}_{2}$ (complex) & -7.74 \\
\hline
\end{tabular}




\subsection{Energies of Structures for Ni-Alkene 2 Cycle $\left(\mathrm{NiA}_{2}\right)$}

All structures were optimized at the M06L/def2-SVP level of theory. Frequencies analysis was performed for all optimized structures to ensure that intermediates are real minima and transition states are first-order saddle points.

As can be seen in the scheme below, when two alkene ligands were placed on $\mathrm{Ni}$, the overall pathway undergoes two significant changes. Firstly, the rate determining step $(3 \rightarrow 4$ in previous cases) does not afford the nickel carbene; rather, the nickelacyclobutane is formed concurrently with the cleavage of the C-N bond, affording intermediate 5 directly. Secondly, the complexation of a second alkene to the $\mathbf{5}$ does not afford a stable system ( $\mathbf{6}$ in previous cases). Instead, the complexation triggers the reductive elimination, which results in an intermediate that is a complex of the $\mathrm{Ni}_{2}$ and cyclopropane (the energy of this intermediate is the energy used to produce the plot below). We could not locate a transition state for the complexation of the alkene to $\mathbf{5}$ and the subsequent immediate formation of the cyclopropane.
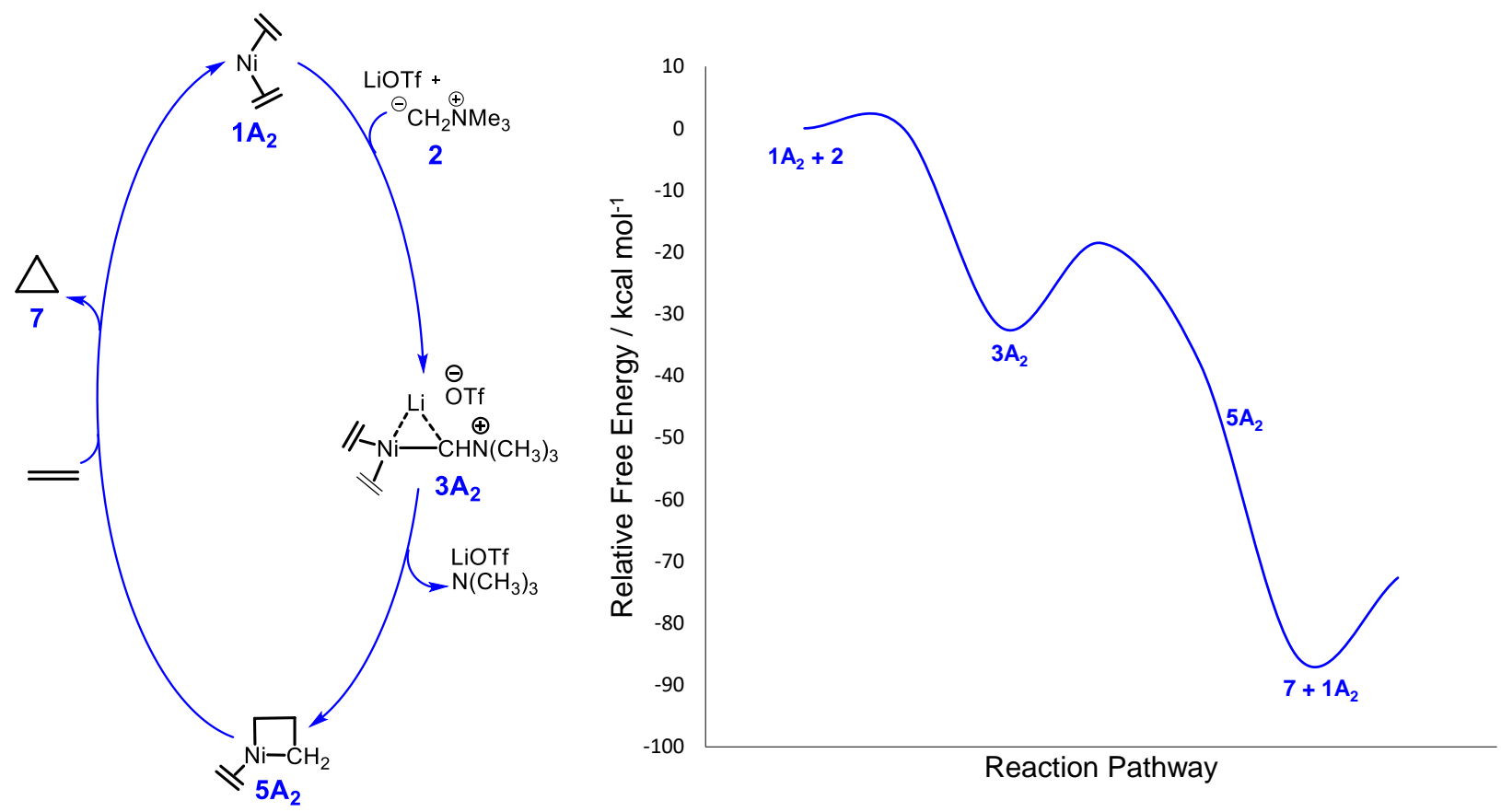

Figure S80. Left: Proposed catalytic cycle for the model system with two alkene ligands. Right: Energy profile for the catalytic system with two alkene ligands.

Table S26. Computed Energies for the pathway for the catalytic system with two alkene ligands.

\begin{tabular}{lccc}
\hline & \multicolumn{2}{c}{ Chemical Transformation } & Energy $/ \mathrm{kcal} \mathrm{mol}^{-1}$ \\
\hline $1 \mathrm{~A}_{2}+2$ & to & $3 \mathrm{~A}_{2}$ & -32.31 \\
$3 \mathrm{~A}_{2}$ & to & $\mathrm{TS}_{3} \mathrm{~A}_{2}-5 \mathrm{~A}_{2}$ & 13.76 \\
$\mathrm{TS}_{3} \mathrm{~A}_{2}-5 \mathrm{~A}_{2}$ & to & $5 \mathrm{~A}_{2}+\mathrm{Me}_{3} \mathrm{~N}^{*}$ LiOTf & -19.50 \\
$5 \mathrm{~A}_{2}+$ ethylene & to & $7+1 \mathrm{~A}_{2}$ (complexed) & -47.74 \\
\hline
\end{tabular}




\subsection{Observations regarding the Reductive Elimination Transition State}

In the course of our computational investigation, we observed that during the reductive elimination step for each of the types of catalysts proposed (Ni-Phosphine-Alkene, Ni-Phosphine ${ }_{2}$, and Ni-Alkene ${ }_{2}$ ), the nickelacyclobutane undergoes a twisting. The cyclopropane group leaves the complex only after having twisted $90^{\circ}$ from its orientation in the preceding intermediate.

We show below images from the three cases, comparing the relative orientation of the leaving cyclopropane group to the two remaining ligands, at the starting point and at the transition state of the reductive elimination. In each case, we have selected two perspectives: the top image positions the nickelacyclobutane in the plane perpendicular to the page; the bottom image positions the nickelacyclobutane in the plane of the page.

The rotation is probably clearest in the case of Ni-Phosphine-Alkene. It appears less pronounced in the case of Ni-Phosphine ${ }_{2}$, however this is because the cyclopropane continues to rotate after the transition state (see third column). For the $\mathrm{Ni}_{-}-\mathrm{Alken \textrm {e } _ { 2 }}$, interestingly, the relative positions of the groups on nickel remain the same, but the alkene ligands themselves rotate.

a) Ni-Phosphine-Alkene

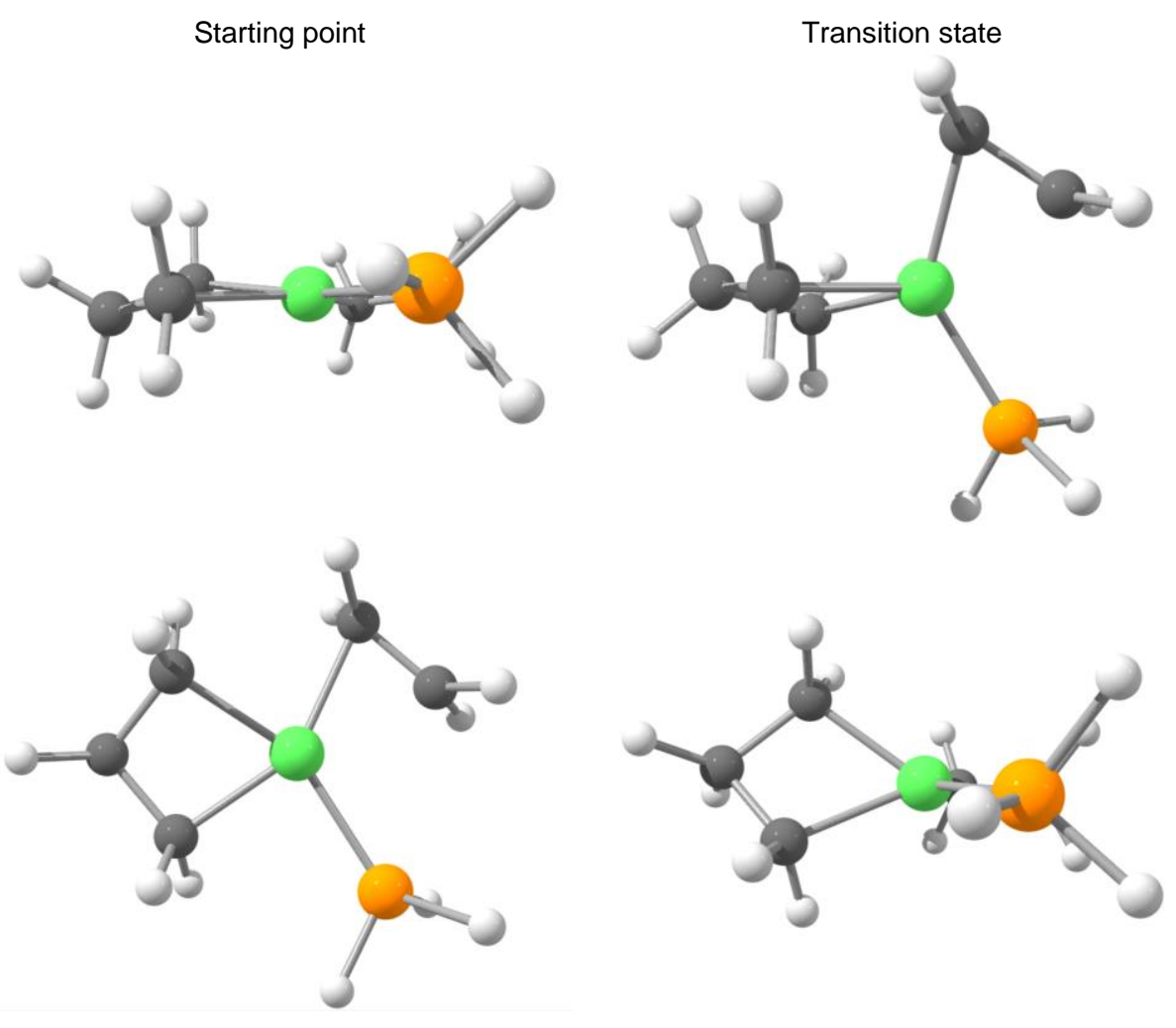

b) Ni-Phosphine 2 

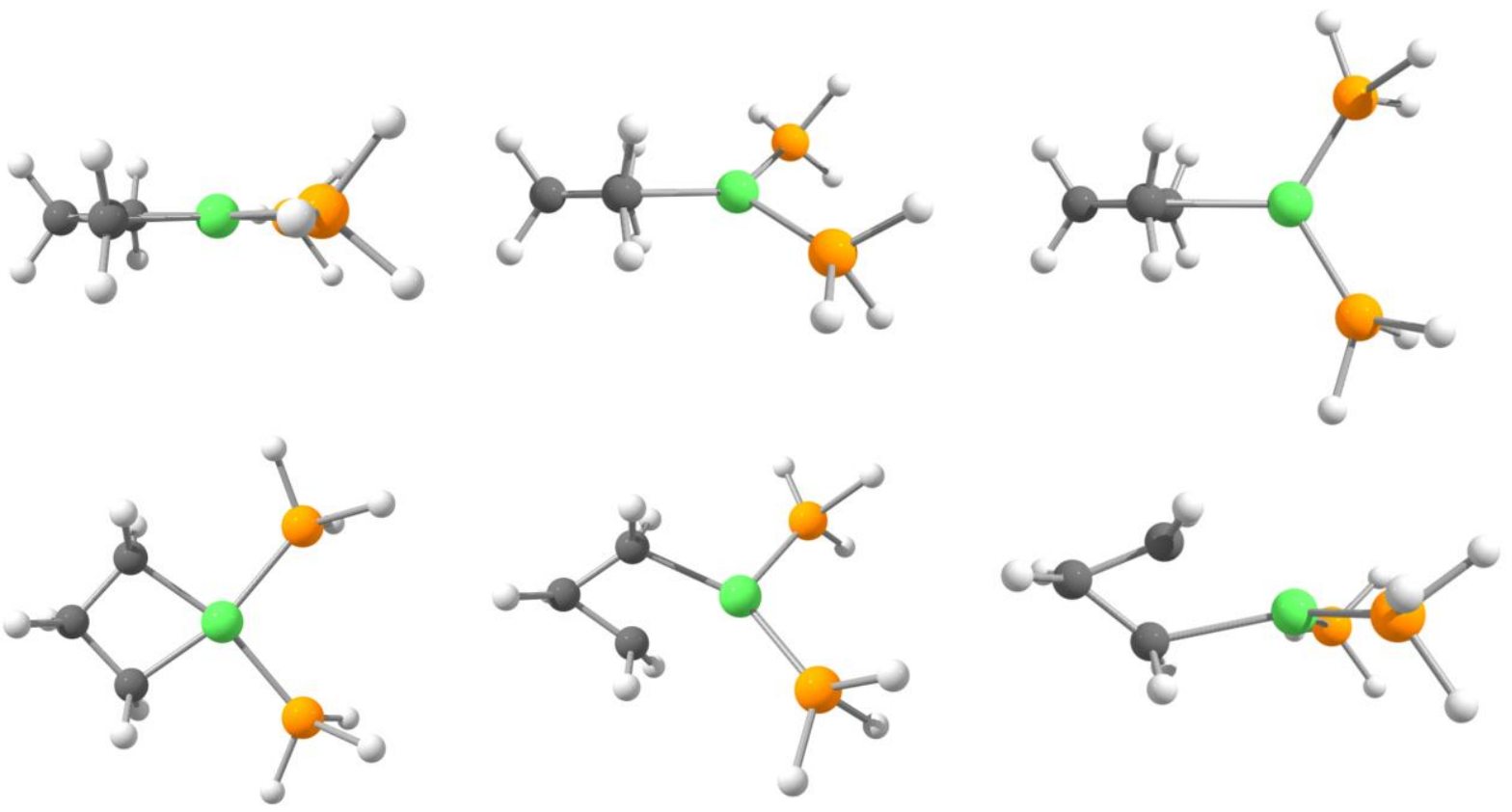

c) Ni-Alkene 2
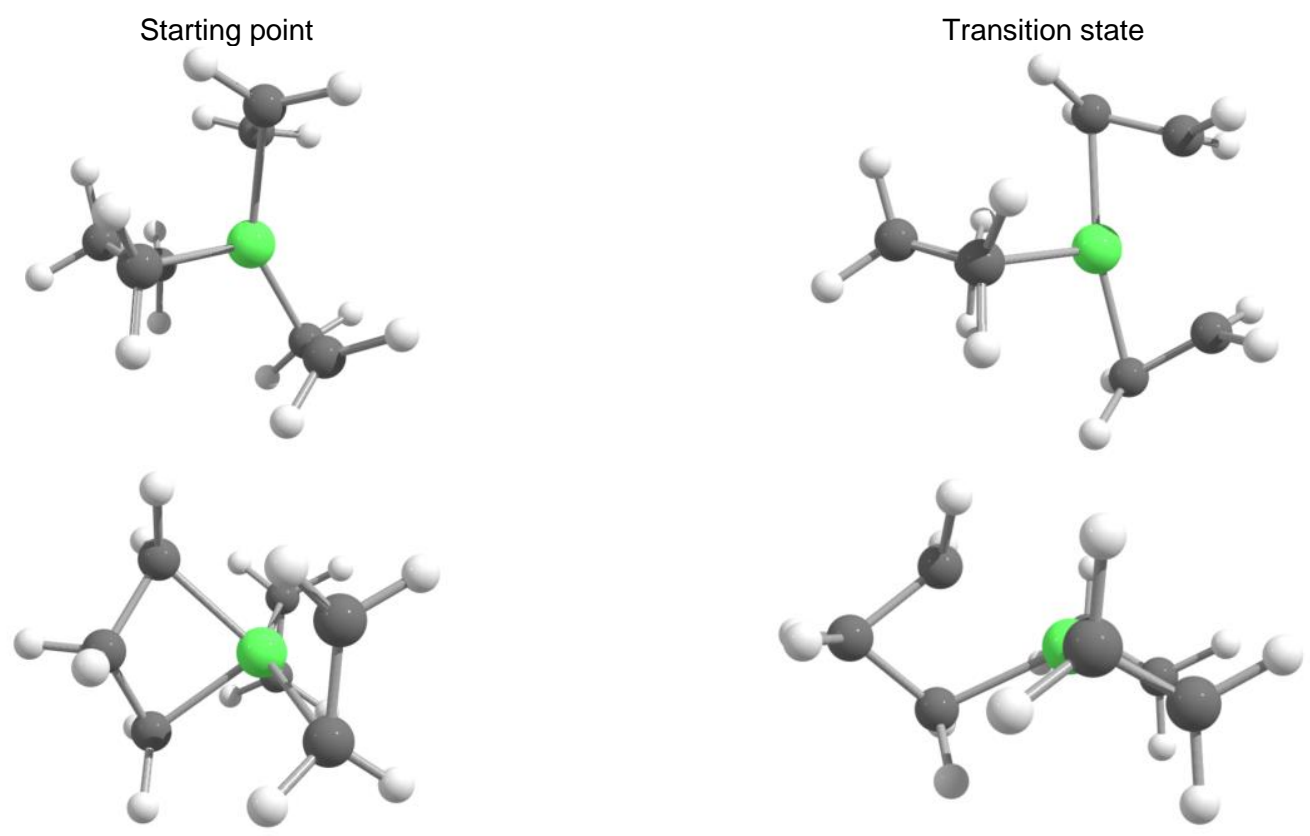

\subsection{Optimization of Model Compounds and Parameter Calculation for Ligands}

We studied five compounds differing in their ligands to calculate the (steric) properties of the phosphines. The bis-alkene complexes were chosen because they represent possible intermediates in the catalytic cycle and simplify the calculations 
without restricting the phosphine geometry too severely by the $\mathrm{Ni}\left(\mathrm{C}_{2} \mathrm{H}_{4}\right)_{2}$ fragment. The exact ligand cone angles $\theta^{\circ}$ and the exact ligand solid cone angles $\Theta^{\circ}$ were calculated and visualized using the freely available Mathematica packages, FindConeAngle and FindSolidAngle, respectively. ${ }^{13}$ For both packages the Bondi radii were used as implemented. The buried volume $\% \mathrm{~V}_{\text {Bur }}$ was calculated and visualized using the Web tool SambVca $2 .{ }^{14}$ For the $\% V_{\text {Bur }}$ calculation the following settings were employed as implemented in the Web tool: Bondi radii scaled by 1.17 , a sphere radius of $3.5 \AA$, a mesh spacing of 0.1 $\AA$, and $\mathrm{H}$ atoms were excluded from the calculations.

All structures were optimized at the M06L/def2-SVP level of theory. Frequencies analysis was performed for all optimized structures to ensure that the geometries are real minima.<smiles>C=CN(C=C)C[C@H](Cn1cccc1)P(C)(C)(c1ccccc1)c1ccccc1</smiles><smiles>C=CN(C=C)[PH](c1ccccc1)c1cc(C(C)(C)C)cc(C(C)(C)C)c1</smiles><smiles>C=CN(C)CP(c1ccccc1)c1cc(C(C)(C)C)cc(C(C)(C)C)c1</smiles>

Figure S81. Structures evaluated to generate ligand parameters.

Table S27. Steric Parameters for Several Phosphines

\begin{tabular}{lccc}
\hline \multicolumn{1}{c}{ Phosphine } & Exact cone angle $\theta^{\circ}$ & Exact solid cone angle $\Theta^{\circ}$ & $\%_{\text {Bur }}$ \\
\hline $\mathrm{PPhMe}_{2}$ & 138.947 & 122.863 & 26.5 \\
$\mathrm{PPh}_{2} \mathrm{Me}$ & 155.594 & 129.365 & 28.6 \\
$\mathrm{PPh}_{3}$ & 168.196 & 135.023 & 30.4 \\
$\mathrm{P}\left(3,5-\right.$ dit $\left.^{\mathrm{B} u P h}\right) \mathrm{Ph}_{2}$ & 188.849 & 142.79 & 31.2 \\
$\mathrm{P}\left(3,5-\right.$ ditBuPh$_{2} \mathrm{Ph}$ & 195.345 & 148.329 & 31.1 \\
\hline$a_{-}$. & & &
\end{tabular}
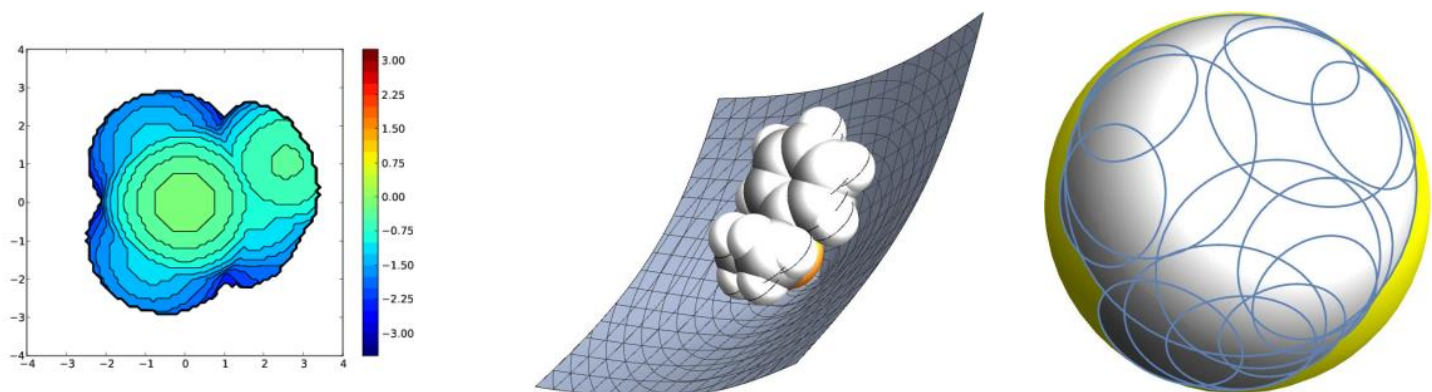

Figure S82. Left: Steric map of PPhMe $e_{2}$ Middle: Cone around $\mathrm{PPhMe}_{2}$. Right: $3 \mathrm{D}$ plot of the solid angle of $\mathrm{PPhMe}_{2}$.
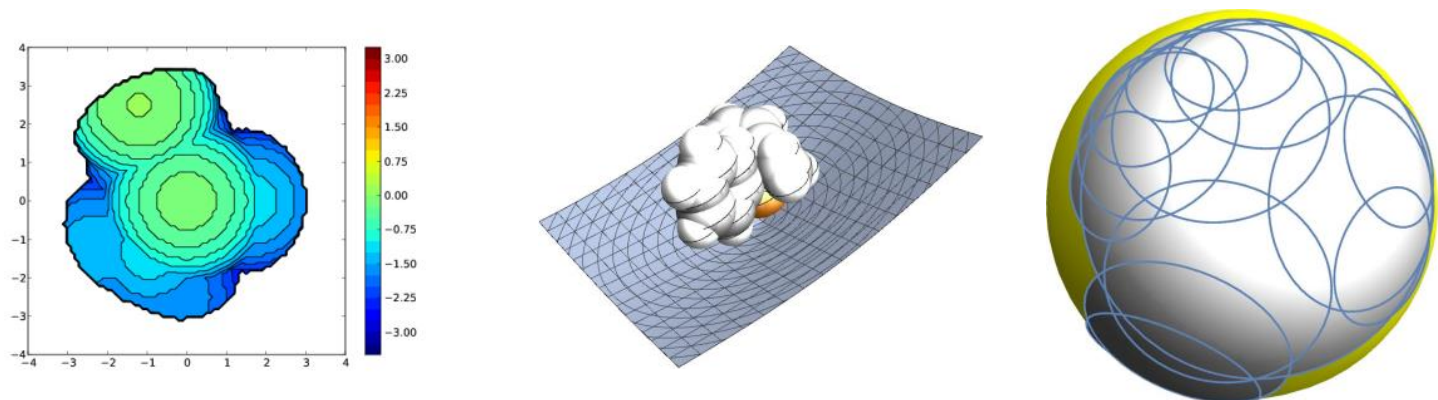

Figure S83. Left: Steric map of $\mathrm{PPh}_{2} \mathrm{Me}$. Middle: Cone around $\mathrm{PPh}_{2} \mathrm{Me}$. Right: 3D plot of the solid angle of $\mathrm{PPh}_{2} \mathrm{Me}$. 

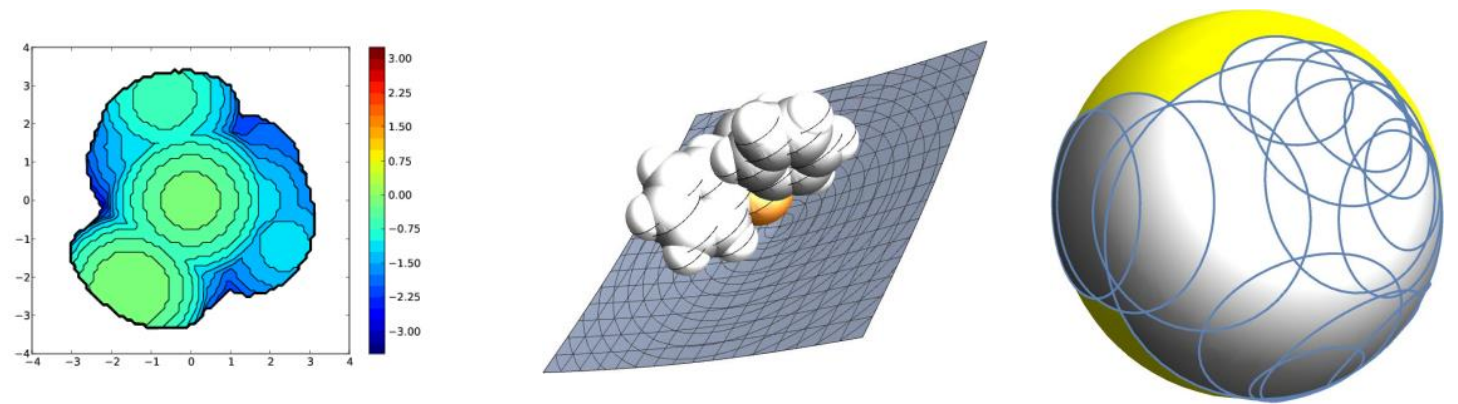

Figure S84. Left: Steric map of $\mathrm{PPh}_{3}$. Middle: Cone around $\mathrm{PPh}_{3}$. Right: 3D plot of the solid angle of $\mathrm{PPh}_{3}$.
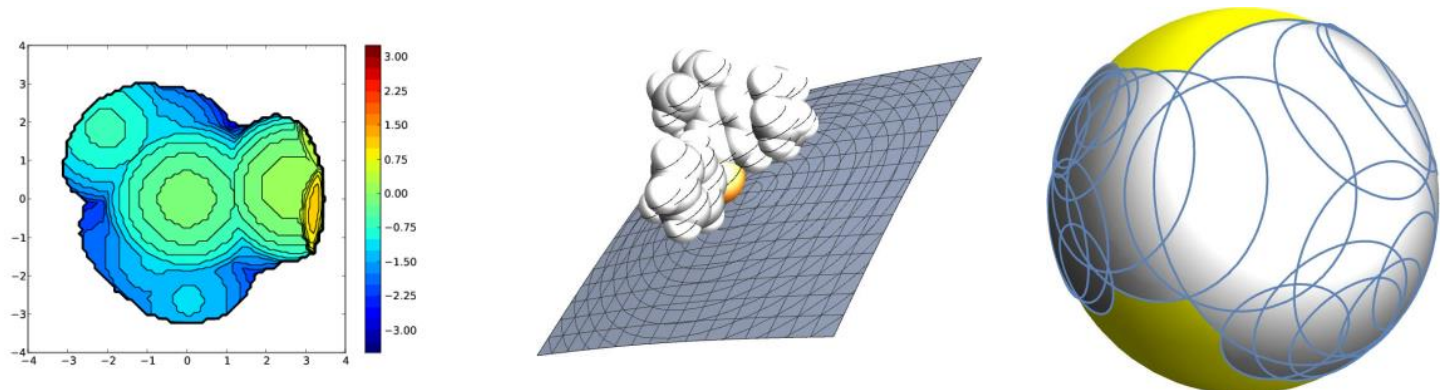

Figure S85. Left: Steric map of $\mathrm{P}\left(3,5-\mathrm{di}^{t} \mathrm{BuPh}\right) \mathrm{Ph}_{2}$. Middle: Cone around $\mathrm{P}\left(3,5-\mathrm{di}^{\mathrm{t}} \mathrm{BuPh}\right) \mathrm{Ph}_{2}$. Right: 3D plot of the solid angle of $\mathrm{P}\left(3,5-\mathrm{di}^{\mathrm{t} B u P h}\right) \mathrm{Ph}_{2}$.
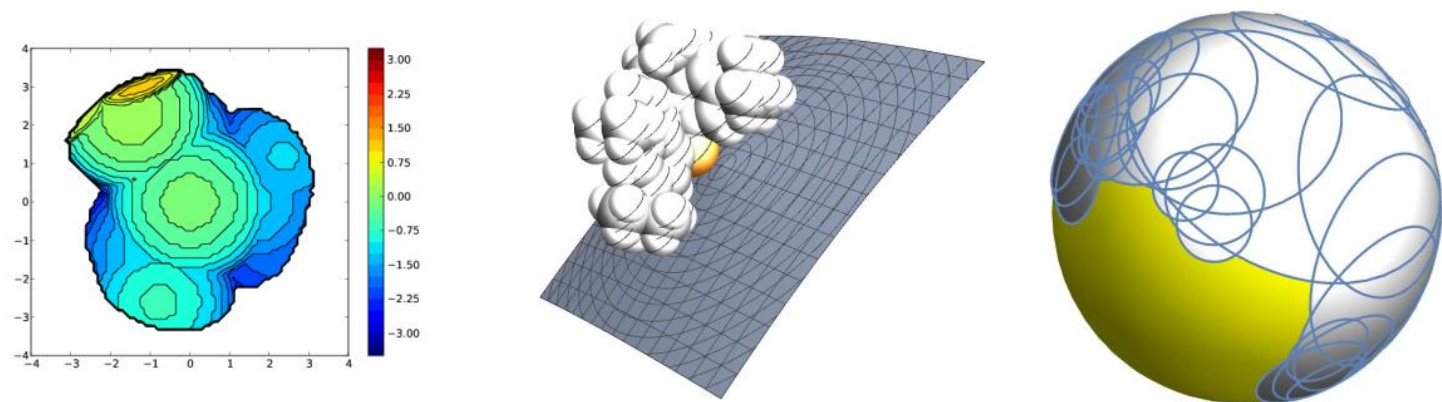

Figure S86. Left: Steric map of $\mathrm{P}\left(3,5-\mathrm{di}^{\mathrm{t}} \mathrm{BuPh}\right)_{2} \mathrm{Ph}$. Middle: Cone around $\mathrm{P}\left(3,5-\mathrm{dit}^{\mathrm{t}} \mathrm{BuPh}\right)_{2} \mathrm{Ph}$. Right: 3D plot of the solid angle of $\mathrm{P}(3,5-\mathrm{di} \mathrm{BuPh})_{2} \mathrm{Ph}$. 


\section{References}

(S1)Sarria Toro, J. M.; den Hartog, T.; Chen, P. Cyclopropanation of styrenes and stilbenes using lithiomethyl trimethylammonium triflate as methylene donor. Chem. Commun. 2014, 50, 10608-10610.

(S2) Künzi, S. A.; Sarria Toro, J. M.; den Hartog, T.; Chen, P. Nickel-Catalyzed Cyclopropanation with NMe ${ }_{4} \mathrm{OTf}$ and $n$ BuLi. Angew. Chem. Int. Ed. 2015, 54, 10670-10674.

(S3) Friedrich, E. C.; Domek, J. M.; Pong, R. Y. Cyclopropanations of Alkenes Using Dibromomethane. J. Org. Chem. 1985, 50, 4640-4642.

(S4) Den Hartog, T.; Sarria Toro, J. M.; Chen, P. A Palladium-Catalyzed Methylenation of Olefins Using Halomethylboronate Reagents. Org. Lett. 2014, 16, 1100-1103.

(S5) Tchawou, A. S. W.; Raducan, M.; Chen, P. Mechanism-Based Design and Optimization of a Catalytic Electrophilic Cyclopropanation without Diazomethane. Organometallics 2017, 36, 180-191.

(S6) a) Pörschke, K.-R.; Jonas, K.; Wilke, G.; Benn, R.; Mynott, R.; Goddard, R.; Krüger, C. Zur Lewis-Acidität von Nickel(0), I. MethyllithiumKomplexe von Nickel(0). Chem. Ber. 1985, 118, 275-297. b) Pörschke, K.-R.; Wilke, G.; Mynott, R. Zur Lewis-Acidität von Nickel(0), II. Methylentriorganylphosphoran-Komplexe von Nickel(0). Chem. Ber. 1985, 118, 298-312. c) Pörschke, K.-R. Zur Lewis-Acidität von Nickel(0), VI. Dimethylmethylenoxosulfuran-Komplexe von Nickel(0). Chem. Ber. 1987, 120, 425-427.

(S7) Values for the equilibrium constant $\mathrm{K}$ are taken from: Tolman, C. A. Olefin Complexes of Nickel(0). III. Formation Constants of (Olefin)bis(tri-o-tolyl phosphite)nickel Complexes. J. Am. Chem. Soc. 1974, 96, 2780-2789.

(S8) a) Cai, G.; Fu, Y.; Li, Y.; Wan, X.; Shi, Z. Indirect ortho Functionalization of Substituted Toluenes through ortho Olefination of $N, N$,Dimethylbenzylamines Tuned by the Acidity of Reaction Conditions. J. Am. Chem. Soc. 2007, 129, 7666-7673. b) Liang, R.; Li, S.; Wang, R.; Lu, L.; Li, F. N-Methylation of Amines with Methanol Catalyzed by a Cp*Ir Complex Bearing a Functional 2,2'-Bibenzimidazole Ligand. Org. Lett. 2017, 19, 5790-5793.

(S9) (a) Heydenreich, F.; Mollbach, A.; Wilke, G.; Dreeskamp, H.; Hoffmann, E. G.; Schroth, G.; Seevogel, K.; Stempfle, W. Stevensanaloge, durch Nickelkomplexe katalysierte Umlagerung von Triarylphosphoryliden und Darstellung sowie Strukturbestimmung von PhosphorylidNickel-Tricarbonylkomplexen. Isr. J. Chem. 1972, 10, 293-319. (b) Herbert, D. E., Lara, N. C.; Agapie, T. Arene C-H Amination at Nickel in Terphenyl-Diphosphine Complexes with Labile Metal-Arene Interactions. Chem. Eur. J. 2013, 19, 16453-16460.

(S10) Frisch, M. J.; Trucks, G. W.; Schlegel, H. B.; Scuseria, G. E.; Robb, M. A. ; Cheeseman, J. R.; Scalmani, G.; Barone, V.; Petersson, G. A.; Nakatsuji, H.; Li, X.; Caricato, M.; Marenich, A.; Bloino, J.; Janesko, B. G.; Gomperts, R.; Mennucci, B.; Hratchian, H. P.; Ortiz, J. V.; Izmaylov, A. F.; Sonnenberg, J. L.; Williams-Young, D.; Ding, F.; Lipparini, F.; Egidi, F.; Goings, J.; Peng, B.; Petrone, A.; Henderson, T.; Ranasinghe, D.; Zakrzewski, V. G.; Gao, J.; Rega, N.; Zheng, G.; Liang, W.; Hada, M.; Ehara, M.; Toyota, K.; Fukuda, R.; Hasegawa, J.; Ishida, M.; Nakajima, T.; Honda, Y.; Kitao, O.; Nakai, H.; Vreven, T.; Throssell, K.; Montgomery, Jr., J. A.; Peralta, J. E.; Ogliaro, F.; Bearpark, M.; Heyd, J. J.; Brothers, E.; Kudin, K. N.; Staroverov, V. N.; Keith, T.; Kobayashi, R.; Normand, J.; Raghavachari, K.; Rendell, A.; Burant, J. C.; Iyengar, S. S.; Tomasi, J.; Cossi, M.; Millam, J. M.; Klene, M.; Adamo, C.; Cammi, R.; Ochterski, J. W.; Martin, R. L.; Morokuma, K.; Farkas, O.; Foresman, J. B; Fox, D. J. Gaussian 09, Revision D.01; Gaussian, Inc.: Wallingford, CT, 2016.

(S11) Anisimov, V.; Paneth, P. ISOEFF98. A Program for Studies of Isotope Effects Using Hessian Modifications. J. Mathem. Chem. 1999, 26, 75-86.

(S12) see ref. S6a and lluc, V. M.; Hillhouse, G. L. Three-Coordinate Nickel Carbene Complexes and Their One-Electron Oxidation Products. J. Am. Chem. Soc. 2014, 136, 6479-6488.

(S13) (a) Bilbrey, J. A.; Kazez, A. H.; Locklin, J.; Allen, W. D. Exact Ligand Cone Angle. J. Comput. Chem. 2013, 34, 1189-1197. (b) Bilbrey, J. A.; Kazez, A. H.; Locklin, J.; Allen, W. D. Exact Ligand Solid Angles. J. Chem. Theory Comput. 2013, 9, 5734-5744.

(S14) Falivene, L.; Credendino, R.; Poater, A.; Petta, A.; Serra, L.; Oliva, R.; Scarano, V.; Cavallo, L. SambVca 2. A Web Tool for Analyzing Catalytic Pockets with Topographic Steric Maps. Organometallics 2016, 35, 2286-2293. 